- $d$ o

S

$x_{1} x^{\prime}$

y M M $x y$

(xy angeras or rog

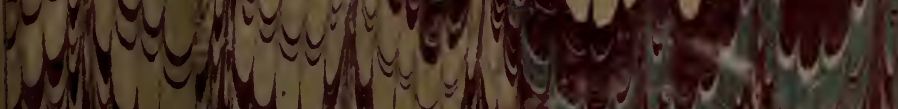
M $x$ a 1 e

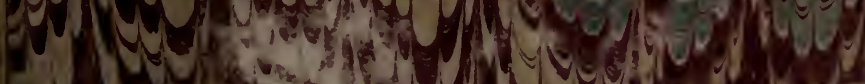
M

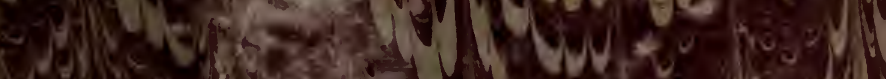
W.

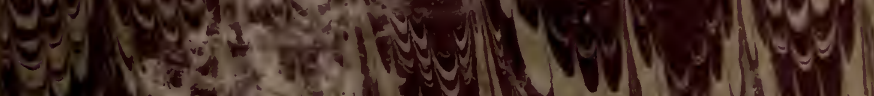

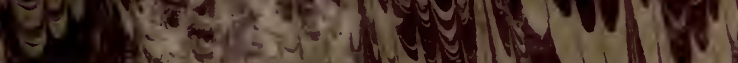

(1)

U. $y=(x-2)-(N)$ - $y^{2}$.

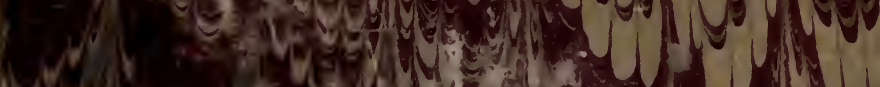

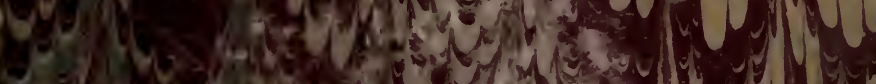
5 . o $y$.

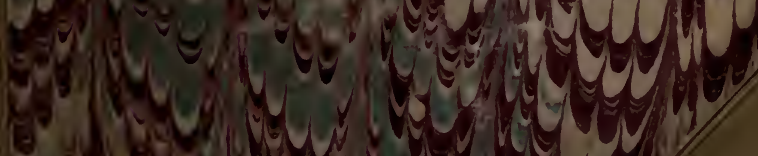
- ver me re

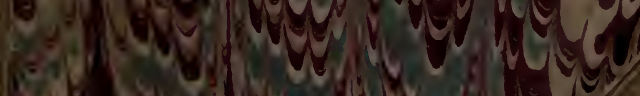



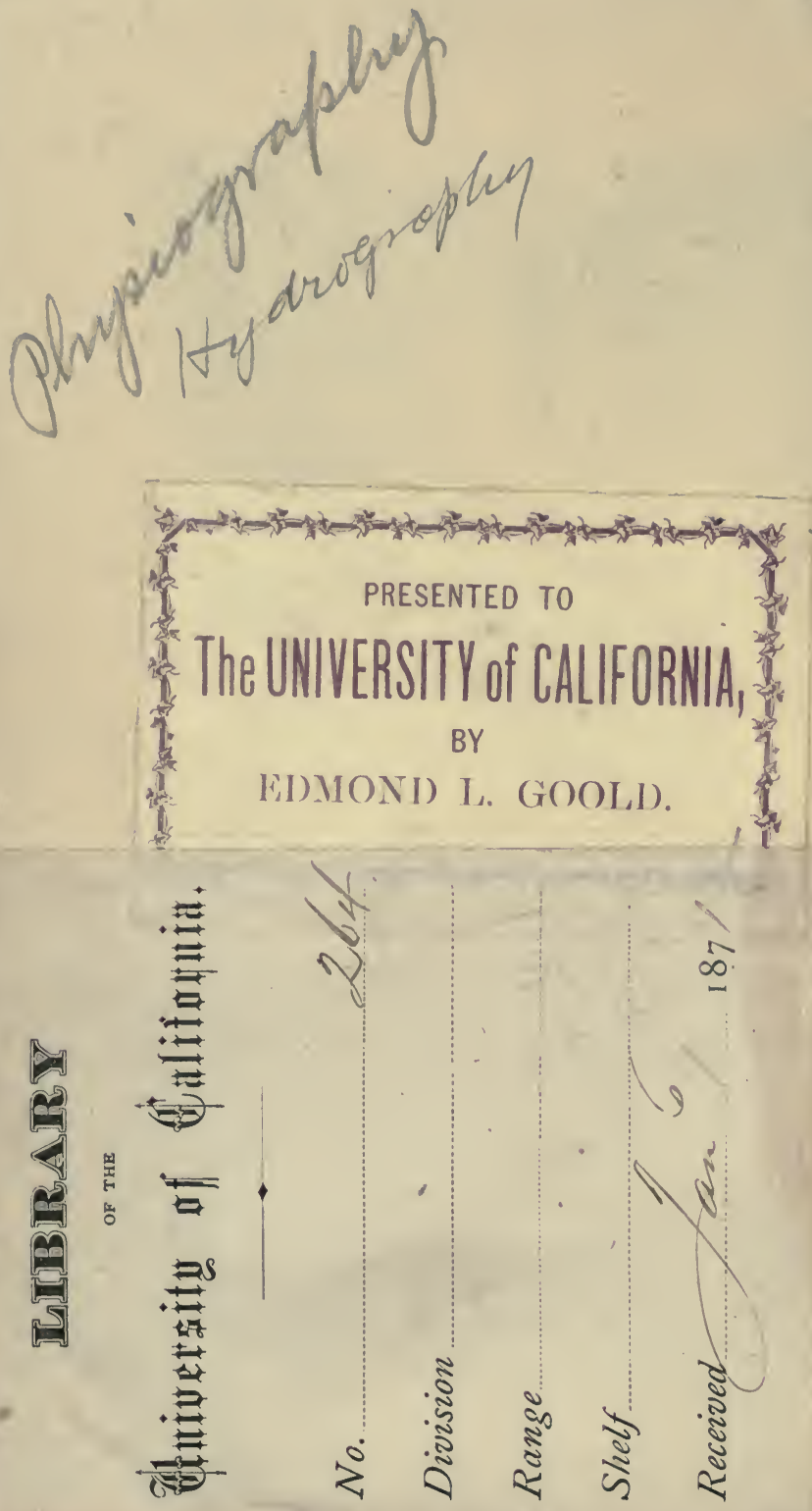
Digitized by the Internet Archive in 2008 with funding from Microsoft Corporation 


T H E

\section{BOTTOM OF THE SEA.}




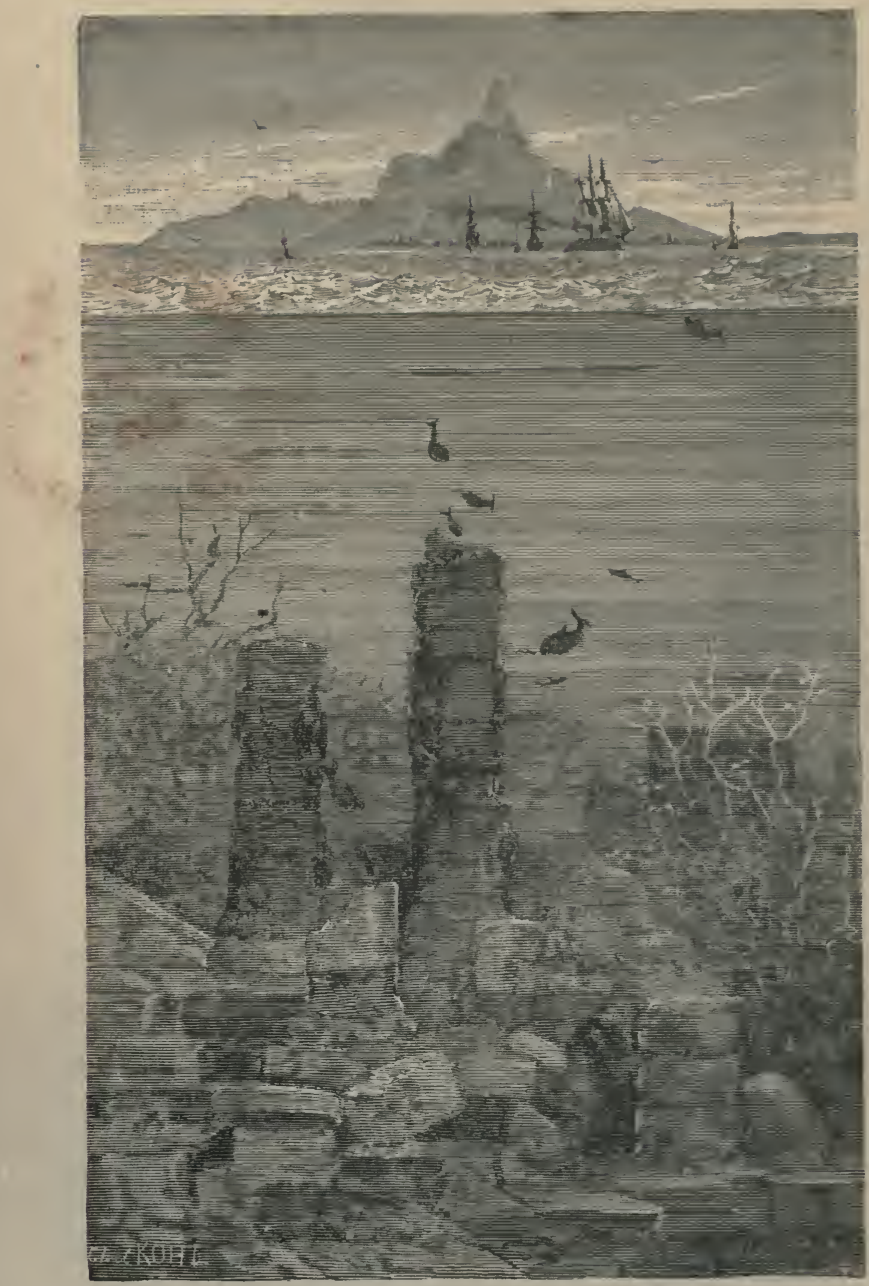

Ruins of the Temple of Hercules at Cibralrar. 


\section{T H E}

\section{BOTTOM OF THE SEA.}

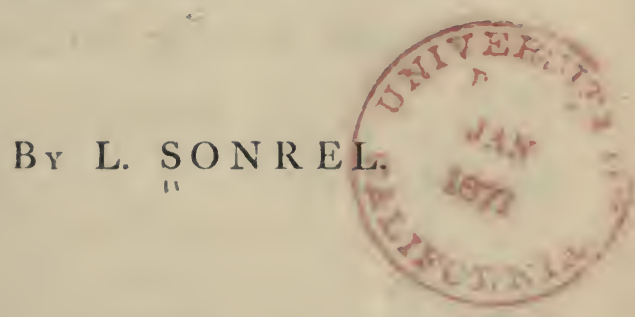

TRANSLATED AND EDITED BY

\section{E L I H U R I C H,}

rKANSLATOR OF CAZIN'S POPULAR TREATISE ON "THE PHENOMENA ANL

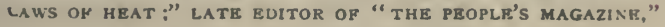
ETC., ETC.

NEW YORK:

CHARLES SCRIBNER AND CO.

$$
\text { I } 870 \text {. }
$$




\section{âllustrated ifibrary of attonders.}

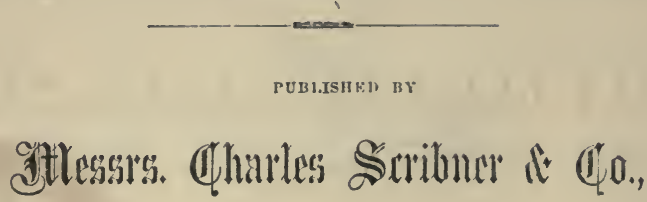

654 BROADWAY, NEWV YORK.

Each oile volume $12 \mathrm{mo}$.

I'rice per volume, $\$ 1.50$.

Titles of Books.

io. of Illustrations

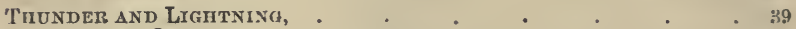

WONDEIS OF OPTICS, . . . . . . . . . . .

WONDERS OF HEAT, . . . . . . . . . . . 9 9

INTELLIGENCE OF ANIMAL, . . . . . . . 54

GREAT HUNTS, . . . . . . . . 22

EgYPT 3,300 Years Ago, . . . . . . . 40

Wonders of Pomíli, . . . . . . . . . . 22

The Nun, BY A. Gulllemin, . . . . . . . 58

SUBlime IN NATURE, . $\quad . \quad$. . . . . . 50

Wonders of Glass Making, . . . . . . . . 63

WONDERS OF ITAIIAN ART, . . . . . . . . . . 28

WONDERS OF TIE HUMAN BODY, . . . . . 45

WONDERS OF ARCHITECTURE, . . . . 5 :

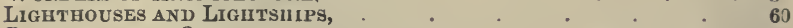

BOTTON OF THE OCEAN, . . . . . . . 65

* Wonders of Bodily Strengti axd skill.,

* Wonderful Balloon Ascents,

Acoustics.

* Wonders of the Heavens, . . . . . . . . . . 48

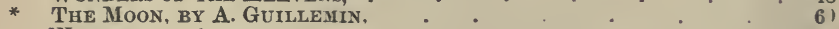

* WoNDEIS OF NCULPTURE, . . . . . . . . . . . 61

* Wonders of Engraving, * . . . . . . . . . . 3.

* Wonders of Vegetation, . . . . . . . . . . 45

* Wonders of THE INVISIBLE WORLd, . . . . . . . . . . . . . .

* Celebrated Escapes.

* Water. . . . . . . . . . . . . 77

* Hydradlics. . . . . . . . . . . 40

* Electricity,

* Subterranean World,

* In Press for early Publication.

The above works sent to any addres3, post pail, upon receipt of the pirice bs ${ }^{2} w$ publishers. 


\section{TRANSLATOR'S PREFACE.}

Thus little book supplies a general and instructive outline of a certain number of interesting facts connected with the sea. It bears the same relation to the strictly scientific treatment of the subject as a popular lecture on art to instruction in the studio, a ramble through a museum to a lecture on science; or a short pleasure-sail on the coast, with here and there an opening glimpse of the scenery, and a pleasant chat on the wonders of the deep, to an accurate survey and a formal report on the same subjects. Occasionally, it may be hoped, the reader will find something more in the following chapters on "The Bottom of the Sea," than these remarks would lead him to suspect; but its pretensions are not such as would justify the kind of eriticism which a scientific treatise like that of Professor 'Tyndall's book on Heat, and many works of less scientific importance, are rightly supposed to challenge.

Our knowledge of the sea is not, indeed, so exact as to justify the same high pretensions to accuracy, 
even in a strictly scientific elucidation, of which many other investigations admit; and yet, as Franklin observed in his time, what persevering efforts have been made to master the secrets of the abyss, and what dangers have been encounterer in the struggle of man with its gigantic forces! Michelet commences his well-known book on the subject by remarking that the first impression which man receives from the Ocean is one of dread; but if this observation be just, that dread of the vast and unknown has in all ages been converted into a source of inspiration, until men of genius have achieved their greatest triumphs where they feared the most. Some of these achievements are remarked upon in the following pages. But the complete record of similar conquests would fill a volume, for it is always on the shores of the sea, and by means of the sea, that men have established their communities, and spread their civilisation over the earth. The sea, not dreaded but loved, and used as a mighty agency, is truly the "Vita Nuova of Nations."

While touching slightly on this topic, and avoiding the dryness of scientific details, this book will be found to give a general idea of the configuration of the sea-bottom, of the action of the sea upon its shores, and of some of the more impressive wonders of the deep. The reader, hitherto uninitiated intc 


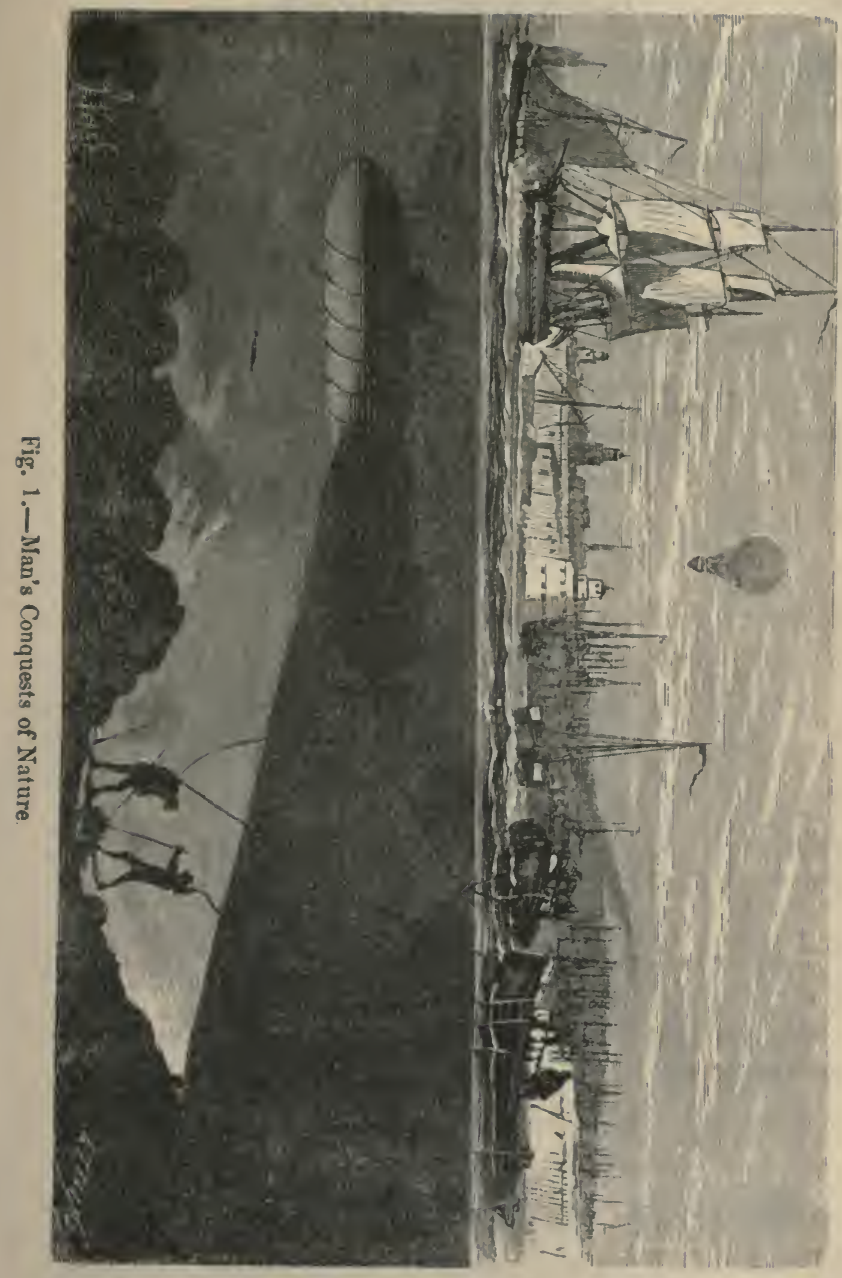



this branch of study, will find, in conclusion, that he has learned somewhat of the great law of perpetual motion aud change in what he may have previously deemer the immoveable crust of the earth. He will have learned to regard the mystery of that movement with a measure of the same awe that is inspired by a study of the distant nebulæ; and he will have felt how essential it is, in studies of this nature, to disembarrass his mind of ideas borrowed from limited views of the measurements of time and space:

God worketh slowly; and a thousand years

He takes to lift His hand off ....

V'́swell Hil.,

January, 1870. 



\section{CONTENTS.}

SUBMARINE OROGRAPHY.

1. The plummet-Brooke's decp-sea sounding apparatus . 1

2. Construction of charts and sections of the ocean-bottomBut little as yet known of this subject-Maury, the founder of submarine orographic science . . . 8

3. Analogy between the configuration of continents, and that of the bottom of the sea-Equatorial section of the earth 18

4. Northern Atlantic Ocean-Chart of Maury . . . 27

5. The Mediterranean and the Black Seas-Chart of Böttger 31

6. The Baltic-The North Sea-The Straits of Dover-The English Channel-The Bay of Biscay . . . 37

THE WATER OF THE OCEAN.

1. Composition of sea-water-Biot's apparatus . . . 42

2. Variations in the saltness of sea-water . . . . 47

3. Variations observed in the gases contained in sea-water . 52

4. Solid bodies in the sea-Phosphorescenco . . . 55

5. Colour of sea-water-To what extent influenced by matters held in suspension, by the bottorn of the sea, and by the agitation of the water $\quad . \quad+\quad . \quad . \quad 63$

6. Measure of temperature at the bottom of the sea . . 68

7. Diminished temperature of the sea in proportion to the depth-Irregularities introduced in this law by the influence of submarine currents - Temperature at the bottom of the ocean constant and uniform-Principral causes of submarine currents 
8. Cause of waves-Their height-Thickness of the mass of water in motion - Ground-swells - "Raz de Marée"-. Waves of translation-Measure of a wave of translation, and of its speed, in the Pacific Ocean-Tides-Résumé

\section{DEPOSITS IN COURSE OF FORMATION AT THE BOTTOMS OF SEAS.}

1. Universality of the process of sedimentation-General view of the mechanism of this phenomenon . . . .

2. Action of waves upon the coasts-Destruction of rockbound shores by the sea-Pierced rocks-Silting-up of shallow waters by marine alluvium . . . .

3. Deposits in mid-ocean, and deposits on the coasts-Importance to geologists of coast-deposits as data for fixing the limits of ancient seas-Deposits of the French seas

4. Transport and deposit of rocks by floating ice .

5. Water-springs in the earth-Funnels or wells of the Jura -'The Aveü of the South of France-Katavotron-Sinkholes-Geysers - Submarine springs-Origin of onlitic formations

\section{SUBMARINE LIFE.}

1. Exuberance of life in the depths of the ocean-Tableau of the tropical seas-Life in the seas of the temperate and the frozen zones-Natural illumination of the oceanic abysses $\cdot \dot{0} \cdot \dot{0} \cdot \dot{0}$

2. Migration of marine animals-Nests at the bottom of the sea-Fisheries : • • • • •

3. Terrible conflicts of marine monsters-Massacre of the weak by the strong

4. Animated forests-Animal stones .

5. Sponges

6. Polypi-Their general structure-Reproduction of polypiVegetative life of polypi - The polypier-Two great classes of polypi distinguished by the form of the polypier-The Tubipora nusica . 
7. Hydra, type of the hydrozoa or hydra polyps-Extraor. dinary properties of the hydra discovered by TrembleyMarine hydrozoa . . . . . . .

8. Actinir-Sen-anemones-Sea-nettles . . . 184

9. Coral-Miraculous virtue attributed to coral by ancient tradition-Coral stone-Coral plant-Marsigli discovers the flowers of the coril-Observations of M. LacazeDuthiers . . . . . . . .

10. Coral chiefly found in the Mediterranean Sea-Various species of coral-The coral fishery-Antipathes, commonly called black coral . . . . . .

11. Gorgons of the old writers-Their animal nature discovered by Peyssonnel, Trembley, and Bernard de Jussieu-The fan-gorgon-Its cosmopolitan character

12. The more active submarine constructors-Astroides-Caryophillia-Madrepora plantıginca-Dendrophyllia-Oceulina, or white cural-Meandrina-Fungia-PoritesMilleporæ • • • • • • •

13. r alley-slaves of the sea-The giants and pigmies of ereatiou-The suckers-Legends of monsters-Singing fishes 207

14. Alga-The untrodden forests and pritics of the ocennAnimal life more abundant than vegetable life-Seaplants less widely distributed than marine animalsInfluence of linht-Collection of seaweed on the coasts -Assistance aftorded by the tide

\section{MAN AND HIS WORK AT THE BOTTOM OF THE SEA.}

1. The empire of the seas denied to man-Numerous attempts at submarine exploration-Disturbance of present social conditions which would ensue from the possibility of travelling beneath the surface of the water-The sea the best tie between nations

2. Explorition of the bottom of the sea-Diving apparatusInvention of MIM. Rouquayrol and Denayrouze-SubInarine electric illumination-Salvage of objects sunk in the sea-A chest of gold recuverel under pcculiar circumstances in thes port of Marseilles . . . . 243

3. Gowan's salvage of Russian vessels in Scbastopol Hurbour $25 j$ 
4. Ships repaired without leaving the water, and even while under sail

5. Sensations of the diver-Depth to which it is possible to descend . . . . . . . . 261

6. Extreme difficulty of working below water-Submarine foundations-Stone worked when in position . . 266

7. Diving-be!ls-Stationary compressed-air apparatus . . 270

8. Payerne's submarine hydrostat . . . . . . 274

9. Villeroy's submarine boat . . . . . . . 278

10. Employment of torpedoes in clearing channels and the entrances to ports . . . . . . 280

11. English mines beneath the ocean . . . . . 284

CHANGES IN PROGRESS AT THE BOTTOMS OF SEAS.THEIR UNIVERSALITY.

1. Extent of the movements of the terrestrial crust-Nature incessantly at work-The gradual cooling of the earth a cause of its present form, owing to the crumpling and breaking of its crust . . . . . . . 286

2. The shore-Its apparent fixity-Traces of the presence of the ocean almost universal

3. Progressive enlargement of the Straits of Gibraltar during the historic period-Columns of the ancient Temple of Hercules submerged - Descriptions left by Avienus, Pliny, and Pomponius-Mellaria, Carteia, and Belon submerged-Other examples of cities and islands covered by the waters, and of mountains violently separated from continents

4. The quantity of water which covers the earth is sensibly constant-An elevation in one point is balanced by a corresponding subsidence in another-Aristotle's opinion about the Greek traditions of the Deluge-The earth will become dryer and colder

SUDDEN MOVEMENTS OF THE SUBMARINE SOIL.

1. Earthquakes modify the bed of the ocean-Submarine volcannes 
2. Greek Archipelago-Delos and Rlıoles upheaved from the bottom of the sea-Successive additions to the Archipelago of Santorin . . . . . . .

3. The Azores-Appearance and disappearance of islan ls subsequent to earthquakes-The ephemeral island Sabrina . 315

4. Submarine volcano in the middle of the Atlantic

5. Submurine eruptions neur liamtschatka-Iceland-Ignited sea ; appearance of an island near lieikianess-Rise of a fiery island from the ocean, near the Aleutian Isles .

6. The bottom of the sea feels the counterblow of terrestrial volcanic phenomena . . . . . . 32:

7 Products of submarine volcanoes-How they differ from the pro.lucts of subaërial volcanoes . . . . 324

8. Bottom of the sea brought to light in consequence of the eruption of submarine volcanoes

\section{GIIADUAL CHANGES OF THE BOTTOM OF THE SEA.}

1. How the gradual change of the sea-bottom can be demonstrated-Modifications which the map of Europe would suffer by a gradual subsidence of thirty feet in a centuryParis submerged-Europe as it would be were the level of the sea raised 500 fect-Toulouse and Vienua as seaports

2. Aucient liuits of the Black Sea-Drying-up of the Russian steppes . . . * . .

3. Movements of the earth in the nothern hisphere-Subsidence in the north of Europe and of America-Eleration of the polar regions-Sinking of the coast of Sweden . Bull

4. Kilevation of Spitzbergen-Sinking of the western coast, and elevation of the eustern coast of Greenland-Gradual submersion of the forests of Labrador and of Nova Seotia - Roman constructious engulfed in the Low Countrits - Origin of the Zuyder Zeo-Failure of the Dutch seadams-The. vulley of the Somme and the coasts of Normandy follow the movement of subsidence of the Low Cuuntrie's

5. Two extensive z'nes of subsidence in the southern hemisphere-They wre separated by a zone of elevatiou-Tle Fiji Islands have been sinking duri:ır 300,000 years . 
ACTION OF RIVERS AND CURRENTS ON THE BOTTOM OF THE SEA.

1. Choking of ports with sand-Deltas, and the action of the tide upon them-The formation of deltas may be either favoured or retarded by marine currents according to circumstances-Deltas formed in shallow seas-Rapid growth of the delta of the Po due to the clearing of the south side of the Alps, and to the damming-in of the shores of the river

2. Egypt, according to Herodotus, a present from the Nile

3. Description of the delta of the Mississippi-A village at anchor-Ships lost in the sand and mud of the river . 360

4. Rapid growth of the deltas of the Po and of the Mississippi -Delta of the Nile enlarged by seven miles during the historic period-The Rhone - $\cdot$.

5. Littoral accumulations-Coast-line-Marine lagoons and pools-Lagoons moved inland by the effects of the dunes in Gascony-Villages buried beneath the dunes noar St. Pol-de-Léon in Brittany, and also in GasconyBordeaux menaced

6. Floating icebergs-Polar winters ..$\quad$. $\quad .37 r^{\circ}$

INFLUENCE OF LIFE ON VARIATIONS IN THE BED OF THE OCEAN.

1. Formation of coral reefs; limit to their growth-Conditions favourable to their development .

2. Life and inanimate nature-Coral insects die in the calm 380 reefs of the Pacific Ocean-Coast reefs-Broken reefsBarrier reefs of Australia-How the coral reef becomes an island . . . . . . . . .

3. Slowness of the growth of coral reefs-Florida Keys-Destruction of coral islands during a tempest in January 1865-Regions in which coral reefs are found

4. Algæ-Submarine forests and prairies-Floating seaweed of the Sargossa seas-Extension of the coasts by the Rhizophora Mangle 


\section{LIST OF ILLUSTRATIONS.}

PAGE.

Ruins of the 'Temple of Hercules at Gibizltur

Frontispiece

1. Man's conquesrs of Nature . . . . . . vii

2. Brooke's deep-sea sounding apparatus . . . . 4

3. Striking the sea-bottom - . $\quad$. 5

4. Measuring the depth of the sea by means of a bomb . 7

5. Vertical section of the Atlantic from Yucatan (const of Mexico) to Senegal . . . . . . . 10

6. Section of the Atlautic Ocean from l'aris to Newfoundlund 23

7. Equatorial sention of the iarth . . . . . 25

s. Chart of the depths of the Atlantic Ocenn - . . 29

9. Chat of the respective depths of the Mediterrancan, the Adriatic, and the Black Seas . . . . . 33

10. Depths of the Adriatic . . . . . . . 36

11. Profile of the ocean-floor from the southernmost point of Norway, viâ the Straits of Dover, to the 10th degree of west longitude and the 47 th degree of north latitude . 39

12. Vertical section of the Straits of Duver . . . . 40

13. Phospliorescent sea at Simon's Town, Cape of Gund Hope 57

14. Incidence of the rays of light on a calm sea . . . 66

15. Incidence of the mys of light on the waves of the sea $\quad 67$

16. Rising of the sen at Acupulen . . . . . 79

17. Waves breaking against a rock-bound coast - . 90

18. Rocks worn through by the waves . . . . . 93

19. Section of the sea and the sea-bottom in the track of ice-

bergs between fireeniand aud Newfunnlland . . 100 
20. Cause of submarine springs

21. Dabs and soles

22. Poulpe, or cuttle-fish

23. The hippocampus .

24. Herrings attucked by tunny-fisls

25. Fight between a swordfish and a whale .

26. Fight between a sailor and a shark

27. Turbots

28. Fishing for sponges on the coast of Syria

29. Coral with polypi nore or less expanded .

30. Branch of coral with polypi indrawn

31. Organ-pipe coral .

32. Sea-pen (Pennatula spinosa) .

. 173

33. Veretillam cynomorium

34. Spiculıo of coral .

35. Portion of the fan-gorgon, magnified

.175

. 183

.183

.185

36. Dendrophyllia ramea .

. 192

37. Caryophillia cyathus

. 196

38. Astrea punctifera

39. Madrepora plantaginea .

197

.198

. 199

40. Dendrophyllia (half the natural size) . . . . 200

41. Meandrina cerebriformis . . . . . 203

42. Millepora alcicornis (one-fourth of the natural size). 204

43. Fungia agariciformis . . . . . . . 206

44. Gneiss bored by the Pholades dactylus . . . 209

45. Malayan divers fishing for holothuria . . . . 237

46. Divers dressed in the apparatus invented by MM. Rouquayrol and Denayrouze . . . . . . . 245

47. Divers finding a box of gold in the port of Marseilles . 253

48. Salvage of Russian ships sunk at Sebastopol . . . 257

49. Caulking a ship while under sail . . . . . 260

50. Sinking blocks of artificial stone at Cherbourg $\quad . \quad .268$

51. Vertical section of hreakwater at Cherbourg $\quad$. 269

52. Div ng-hell . . . . . . . . . . 271 
53. Fixed apparntus, supplierl with enmpr ssed nir . . 272

54. Payerne's submarine hydrrstat . . . . . 276

55. Villeroy's submarine boat . . . . . . . 279

56. Removing an ol struction by means of it torpedo - $28 \%$

57. Section of a tin mine in Cornwall . . . . . 285

58. Vertical section of the Straits of fibrsitar . . . 300

59. Irruption of the sea in Zealand . . . . . 303

60. Eruption of a submarine voleano . . . . . . 309

61. Submarine erupt on at the Azores . . . . . . 316

62. Rise of a new island near Ounimack . . . . 3211

63. Eruption of 'I'omboro in 1821 . . . . . . . 323

61. Paris covered by the sea . . . . . . . . . . . . . . 335

65. A village buried under sand dunes . . . . . 374

66. Flonting glaciers . • . . . . . . . 377

67. Telegraphic cable at the boitom of the occar . . . 35: 



\section{THE BOTTOM OF TIIE SEA.}

SUBMARINE OROGRAPHY.

1. The Plummet-Brooke's Deep-sea Sounding Apparatus.

Is these days of great achievernent, when a voyage round the world has become a holiday trip, the youngest boy who is capable of construing Horaces may wonder that a time ever existed when it was thought to be an act of impious daring to cross the Ocean. Nevertheless, it may be worth a moment's reflection to realise the actual position of a ship which has spread sail for some distant port, and left familiar coasts far behind. What shall wo call a vessel under these circumstances? A house floating in mid-ocean, on a shoreless sea, with nothing visible around but the heavens, overarching everywhere the monotonous waste of waters. The ship suils on, with the drifting clouds above, and thes 
currents of ocean below. $\mathrm{By}$ what miracle shall the sailor be able to keep on the track to his destined port? By what means shall he ascertain the position he occupies on the vast extent of ocean? The science of astronomy comes to his help, furnishing him with the most simple and exact processes, by which he nay discover at any moment the route he is following, and the distance which yet separates him from his haven. It is by her uid that he is able to pass safely through dangers almost numberless, to avoid iron-bound shores and reefs, against which he would blindly hurl himself to destruction if the stars did not light his uncertain way.

But it sometimes happens that the observance of the heavenly bodies fails the mariner at the very moment when he is most in need of their services. Let us recall, for example, the numerous dangers, even when the sea is quite calm, in which the ship is involved which involmutarily approaches a coast hidden from view by a thick curtain of fog. In this and analogous cases, the seaman resorts to other means for help than those furnished by astronomy. Among the means most universally employed is the plummet. It may be that the good ship is slowly drifting on to a bank of sand or gravel which would be its destruction. The lead is thrown, and the sea 
sounded. In the approaches to some roasts or harbours where dangerous rocks ahound, the pluinmet is indispensa'le as a means of discovering the depth and character of the bottom. Is it mud, or sand, or gravel, or rock? Will it be advisable to cast anchor, or to find a more favourable situation? The plummet will answer these questions.

In its simplest form this little instrument consists of a cylinder of lead, suspended by a cord attached to one of its extremities, while the other is tallowed in order that some portion of the soil at the bottom of the sea may adhere to it. It is simply dropped into the water, and allowed to fall suddenly to the bottom. The imperfection and uncertainty of such an instrument are obvious. If the sea be calm and of slight depth, it may prove equal to its work, and report correctly. But how often is the lead pulled up without anything adhering to it! The sea, in fact, is seldom or never at rest, and at all times there are currents below the surface, which may carry away in a bight hundreds of yards of the line, without indicating that the lead has reached the bottom.

Various attempts have been made to inprove the plummet. The olject has been to make quite sure that it shall bring up to the surface a sample of the soil at the bottom of the sea, and to diminish the 
effect of currents, so that no error may be occasioned by the length of line carried away out of the perpendientar. 'The most ingenions of these improved

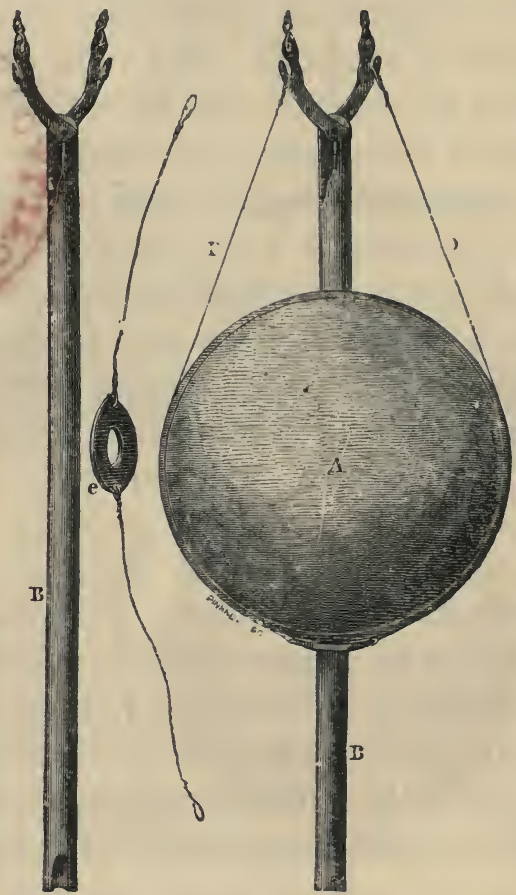

Fïg. 2.-linouke’s Deep-sea sounding Apparatus.

contrivances is that invented by Passed Midshipman J. M. Brooke, of the United States Navy, who was at the time associated with the celebrated Maury. 
This clever contrivance, since well known as Brooke's "Deep-sen Sounding Apparatus," is represented in the annexel engravings (figs. $2 \& 3$ ). AA is a caurou-
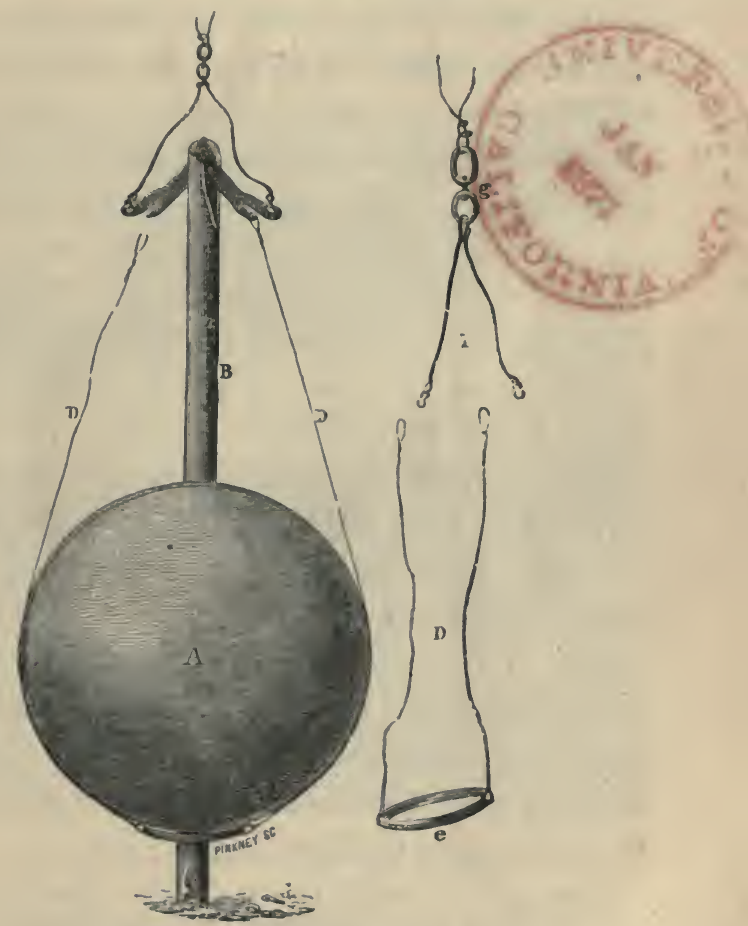

rig. 3.-Striking the Sea-hrottom.

ball, perforated, so that the rod or 'ylinder, BB, may be passed throngh it. Fig. 2 shows the apparatus rearly for being lowered into the sea. The rannon-ball is 
supported a certain distance up the rod, on which it slides freely, by means of the sling $\mathrm{DD}$, the ends of which are looped on to the moveable ears at the top of the rod. To these also the line is attached by which the apparatus is lowered into the ocean. Th, weight of the shot, being sufficient to resist a current carries the line down perpendienlarly; and when the protruding end of the rod strikes the bottom (fig. 3) the line slackens, the moveable ends drop, and th. loops of the sling are disengaged. The shot thes slides down the rod, and the latter, no longer en ('umbered with the weight $A$, can be drawn up wit! ease. It will be seen that a sort of cup is formed a the lower end of the rod, and this is "armed" witl soap or tallow, so that a specimen of the submarin soil may adhere to it: or the barrel of a commor quill is attached to the rod, which is said to answe better. By either contrivance specimens of the sea bottom have been brought up from a depth of nearl! four miles. Every time this apparatus is used thi shot and sling are of course lost, the rod alone being recovered when the line is pulled in.

Attempts to sound the sea before the invention of this method have produced results which are now regarded as being of little or no value. The honour of having made the first attempt belongs to Peter the Great, who constructed an apparatus 
with hooks, especially for the Caspian. Others, guided by theory, have devised petards which were to be exploded, or bells which were to be rung, a certain number of feet beluw the surface of the ocean; and it was hoped that an echo would be heard

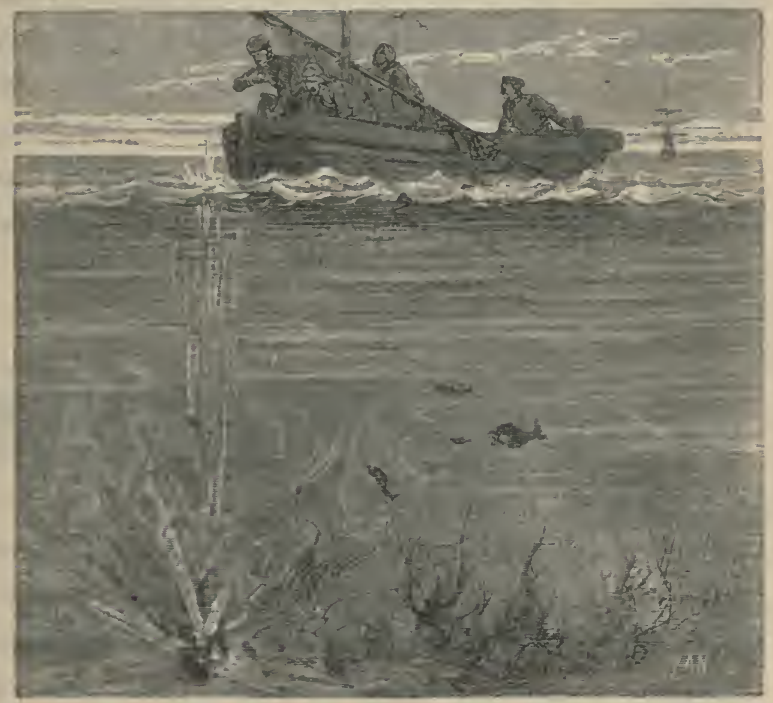

Fig. 4.-Measuring the Depth of the Sea by means of a Bomb.

from the bottom, the distance of which could of course be calculated. Experiments of this lind were made when the winds were hushed and all was still; but echo was silent. M. de Tessan suggested the more likely method of letting a bomb fall into the 
sea which would explode when it struck the botton. The noise of the report would reach the surface, and the time that had elapsed from the moment the lomb was dropped into the water would afford the means of calculating the vertical distance it had fallen. It is well known that water is a good transmitter of sound. Dr. Colladon caused a r.lock to strike under the water of the Lake of Geneva, and it was heard in the first experiment four leagues off, and in the second at more than twice that distance. However, no apparatus has been contrived which solves the problem so thoroughly as the invention of Brooke.

2. Construction of Charts and Sections of the Ocean Bottom-But little as yet known of this subject-Maury, the Founder of Submarine Orographic Science.

Let us imagine the commander of a vessel sailing across the ocean to be capable of taking soundings incessantly from the first to the last moment of his voyage, his apparatus being so contrived that the line would shorten or lengthen with such exactness, according to the varying depth, that the lead always just touched the bottom. His olservations, in such a case, would bear a close resemblance to those which would be made by a boatman crossing a river in the same way. 'The plummet would at first sink to a certain 
depth, then it would rise, then sink lower again; and so go on rising and fulling at various intervals, until the ship arrived at some island or continent, when the lead would, of course, be once more level with the surface. If we imagine, further, that the commander was careful to $\mathrm{r}$ : cord his observations from moment to moment, and, finally, to trace on a sheet of paper the section formed by the constantly varying length of the plummet line, we should see at a glance the exact configuration of the sea-bottom throughout the ship's course from one coast to the other.

Fig. 5 is a vertical section of the Atlantic, in a line from Mexirn, across Yucatan, Cuba, San Domingo, and the Cape de Verds, to Senegambia, on the African coast; and it may be regarded as the result of such a voyage as we have imagined. The horizontal line represents the level of the sea. 'The irregular line which cuts it in many points follows the undulations of the sea-bottom. Where it rises above the horizontal line there is land-that is to say, the solid crust of the earth is higher than the waters. Where its curve falls below the horizontal line, the land is submarine, or under the water. Thus, supposing that we take our departure from the Mexican coast, the plummet descends at first nearly 2000 feet, and returns to the surface on the coast of Yucatan. After doubling this peninsula, 
there is again an abrupt descent of about 3300 feet; and from thence to Cuba the ralley is only interrupted by a chain of submarine hills of little importance. Rounding Cuba, we find ourselves floating above a perpendicular ravine, from 7000 to $\$ 000$ feet deep, betw en that island and IIayti. Between

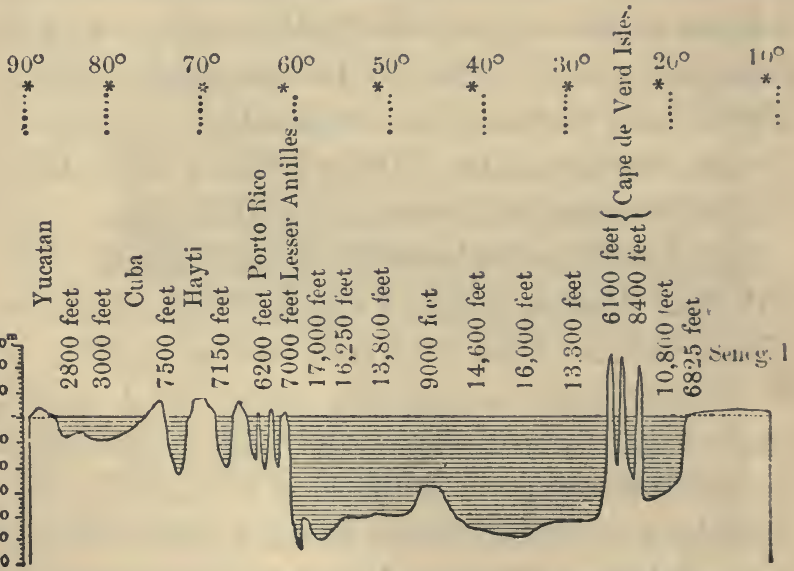

[The scule on tire left $h \cdot n d$ of the diagram is in métres; tiuc depths are given in equivalents of fect. $\rfloor$

Fig 5.-Vertical Section of the Atlantic from Yucatan (coast of Mexico) to Senlegal.

Hayti and Porto Rico, and between the latter and the Windward Isles, the average repth is something less than 7000 feet. Beyond the Lesser Antilles there is nothing abore the waves until we reach the Cape de Verd Islands. When we first spread sail for that point, the plummet falls suddenly to a depih 
of 16,500 feet or more, and rises as surdenly to little more than 13,000 feet. Again, it descends suddenly to 16,000 feet; and then continu's to mark a deptl, varying by sudden ehanges, say from 16,000 to 10,000 fet, until near the Cape de Verd Islands, when the depth, even clo-e inshore, is about 14,700 fert. These pinnacled isles rise to the height of 10,000 feet above the suriace of the sea. Deep gulfs separate the one from the other; and a still deeper trench or canal, with almost perpendicular sides, brings the navigator to the African coast.

We have mentioned the uncertainty of the results obtained by the plummet in ordinary eircumstances; and from the description we have given of this imperfect instrument, it will be obvious that it affords no means for continuous or unbroken observation. It is necessary to make a fresh cast of the lead each time we want to sound the deep. We can only obtain, therefore, a series of points separated by intervals, which must be rendered as short as possible, in order that they may yield an approximately exact representation of the sea-bottom.

In surveying any portion of land, with a view to its exact delineation, we can generally move freely over the surface itself that we are studying. The operations of geo' esy give, with the ntmost accuracy, the positions and the heights of as many 
points as we desire. Suppose, however, that the conditions of our existence were su.h as to maintain as constintly at the height of 16,000 feet above the sea-level? In that (ase, our survey of the land would be attended with the same degree of difficulty as our attempts to delineate the floor of the ocean. 'The highest mountains only would lift their summits into our atmosphere, and those alone we should be able to explore by the observation of actual contact. The plummet, or some analogous instrument, would have to be used for ascertaining the configuration of the less elevated regions. This is precisely our case in regard to the depths of the ocean. 'The regularity of its surface enables us to make use of it as a common point of departure from which to measure the relative heights of different parts of the terrestrial surfice. If sufficient water existed to cover all the land, our globe would everywhere present the regular surface of a sphere, or nearly so. Although this is not the case, yet the great oceans, and all the seas communicating with them, have the 'same level.

The pressure of the air is pretty constant on every point of the ocean-surface, and it is found to diminish in a certain ratio as we ascend in the atmosphere. It must be remembered that the bottom of the atmospheric ocean rests on the surface of the watery veran. If we suppose the whole mass of water to 
consist of a certain number of strata, it is obvious that the lowest of these must bear the weight of all above it, and is therefore more compressed than the next higher, and so on till we reach the surface. So with the atmosphere. Its entire weight presses on the lowest stratum which touches the sea, and that weight of pressure in the torrid and temperate zones is marked by the barometer at 30 inches. If we take the barometer 87 feet above the level of the sea, it will mark the diminished pressure by 29.9 , showing that it is one-tenth less. 'To show a diminution of another tenth it would be necessary to go through a second space of more than 87 feet, because the pressure of the whole atmosphere is less by the height already attained. Thus, we shall find it necessary to rise higher and higher for every successive tenth, until we reach a point when the pressure altngether ceases and is marked by 0 . This would be at the top of the atmosphere.

The reader will now understand how it is that a barometer serves to indicate the height of any part of the earth's surface; indeed, it is the only possible means at our command in many cases for ascertaining height. A process analogous to this would be employed with advantage to measure the depths of the sea. Suppose an iustrument to be sunk in the water. 'The depth of water through which it had fallen 
adding its pressure to that of the superincumbent air, and water being estimated at 1300 times the weight of air, it is plain that calculations which have been made relative to the atmosphere would, $\grave{a}$ fortiori, seem to be possible also relative to the ocean. An instrument so constructed as to indicate the pressure to which it had been subjected in the water would serve to complete or correct the results given by the sounding apparatus. Discordant indications would possibly afford evidence as to the direction and force of submarine currents.

If we add to the imperfection of the processes themselves the difficulties of an accidental character which attend their application, we shall find but little reason for wonder that submarine orography is so little advanced. To make deep-sea soundings, a ship must be provided with a considerable amount of matériel of no use for any other purpose. A single operation during a voyage must employ several persons, and it could only be made in fair weather. In general, therefore, merchant-ships cannot be proviled with instruments and with hands to make deep-sea soundings; they would require cables or lines some four miles in length, and their crews would seldom be strong enough to deai with such heavy tackle. 'T'hen, the time spent in such operations would occasion incalculable loss to merchants and owners; and if the 
cable parted, that expense would be added to the rest, and thus the lost apparatus could seldom be replaced. Evidently, experiments of this kind can only be made by Gorernments, or by commercial companies interested in their results. For example, the laying of submarine telegraph cables has made it necessary in recent times to sound the ocean in various tracks. Almost every day sees some addition made to our knowledge in this way, and there ean be no doubt that the multiplication of submarine telegraph lines will tend very greatly to hasten the time when we shall have an accurate idea of the form of the earth, and of the lesser accidents which affect its surface.

Before the general form of the earth was ascertained, the depths of the ocean were the subject of the most extravagant suppositions. The writings of geographers abound in such expressions as that of " a bottomless and shoreless sea," to designate the Atlantic Ocean. The abandonment of such absurdities is a necessary consequence of the facts known in the present day concerning the form and physical constitution of our planet. But other speculations, not less calculated to fill the imagination with an idea of grandeur, have taken their place. If the mass of water which covers about three-fourths of the solid crust of the globe is, after all, limited in quantity, what is the depth of the basins which contain it? 
The terrestrial shell is known to be irregularly broken, and its fragments, so to speak, piled on one another in gigantic masses of picturesque confusionhere heaved up into the air, there sunk from depth to depth, with the waters of ocean gathered in their deepest gulfs. Plainly, if we add to the measurement of these depths beneath the sea that of the heights above, we shall obtain some useful data, and be enabled to form an approximate estimate of the stupendous forces in the interior of the globe which have produced such irregularities on its surface.

Before Maury made his appeal to the marine of all nations, something was known of the sea-bottom in the vicinity of coasts, and in the most frequented tracts; but very little was apprehended of what lay under blue water. He called upon his brother sailors to commence a systematic observation of the winds and of meteoric phenomena, to note the marine currents, and to sound the sea as they traversed it, if possible, every hundre l leagues. His call was heard. and heartily responded to. In a few years the North Atlantic, ploughed by the ships of all nations, had been sounded in so many points, that Maury was able, by combining the results obtained, to trace the configuration of the bottom of that ocean, and construct a chart analogous to a geographical tracing designed 
to indicate the surface of a country in relief. The curves are so drawn and stippled as to show distinctly when the water is less than 6000 feet deep, when it is less than 12,000 feet deep, when it is less than 18,000 feet, and when its depth lies between that and 24,000 feet. The conclusion is that the average depth of blue water is not more than three or four miles, and that no reliable soundings have been made in water over five miles deep. This map (a reduced copy of which is given opposite p. 28) gives an idea, though an imperfect one, of the configuration of the floor of the North Atlantic Ocean.

The Mediterranean, the Black Sea, the Baltic, and the seaboards of France and the British Isles, are much better known. These seas are shallow compared with the ocean, and the European marine has too great an interest in their study to neglect them.

On the other hand, in the immense spaces left in the southern hemisphere by the continents and islands of Oceania the lead has rarely been thrown. 'The deepsea basins which separate Asia and Africa from Australia and America have been but slightly explored, chiefly because the navigator there sails fearlessly before the wind, and dreads no rock or shoal which would make him desirous of knowing the depth of water on which he floats. Some observa- 
tions have been made by the scientific voyages of observation sent out at the expense of States; but except these we know of none that are available.

The southern part of the Atlantic Ocean is equally a blank; and to make a sum of the whole matter, the greater part of the wcrld beneath the sea is indifferently known. If we add to this fact, that the greater part of continents is desert or savage, traversed occasionally by a few hardy adventurers, we shall begin to see how vast are the lacunæ still remaining in our study of the globe, and what an ample harvest of discovery may yet be reaped by the conscientious observers of nature.

3. Amalogy between the Configuration of Continents, and that of the Bottom of the Sea-Equatorial Section of the Earth.

Although the scientific results which we have already mentioned are incomplete, they are sufficient to prove that the greatest depth of the sea does not exceed about five miles; thus, that it is about equal to the height of the loftiest mountains. This depth has been plummed in all the great oceans, and occasionally deeper soundings have been reported. The results, however, in the latter case have been obtained under circumstances which do not command our confidence. Such are the cases in which it would be eminently satisfactory to employ an instrument to 
indicate the depth by pressure, as suggested in the foregoing section.

The submarine soil in its configurations bears a close resemblance to the subaërial surface. The geographical accidents, so to speak, are the same. There are plains, valleys, ravines, hills, escarpments, deserts of sand, immense deposits of mud, rolled stones, picturesque rocks, and even water-springs and volcanoes.

But while the bones of the earth beneath the waters, or the framework of the picture, so closely resembles that of the soil above, the picture itself presents a very different aspect to the observer. In the first place, there is but scant light a little distance below the surface; then, the vegetation is of a totally different character: the various algæ float their long and brilliantly-coloured ribbons in the most graceful curves and modulations, or display their elegant tracery in fine and clearly-cut relief, like our mountain-trees. Animals, strange to our eyes, move slowly in an element which may be called gross when compared with our atmosphere. Springs of fresh water, instead of running upon the soil, are dispersed in vapour; volcanic eruptions assume a peculiar character. Yet, with all these differences, the basin of the sea, in the eyes of the geometer, is in all essential respects similar to its shores. 
Let us suppose the sea to be suddenly withdrawn from its basin, in order that we may the more clearly apprehend the conformation of the terrestrial crust as a whole, and thus see at a glance the unequal heights and depths which appear to us so considerable, but which, in reality, are very small when compared with the vast bulk of the planet: Let us, in short, suppose the earth to be reduced to the same physical condition as the moon, without an atmosphere and without water:* the eye would be arrested by vast ramparts formed of the earth's upheaved strata, and piled to a total height of some ten or eleven milesthe most gigantic of these picturesque eminences corresponding to the Old World, and having its culminating-point in the Himalayas. All around that vast rocky barrier would be seen a deep furrow separating it from the double gibbosity formed by the two Americas; and taking our stand on the southern extremity of the latter continent, we should descry in the distance the summits of Australia and the neighbouring isles, and the ramparts of the great Austral continent, almost entirely buried under snow and ice.

As the continents have their highest summits, so the oceans have their deepest gulfs, and these are often

* Speaking from present appearances; for, in fact, this point is not yet placed absolutely beyond doubt.-Tr. 
near neighbours to each other. The Himalayan peaks are not far from the deepest part of the ILdian Ocean; the Rocky Mountains have for their near neighbour the deep gulf of the Northern Pacific; the Alleghanies are contiguous to the lowest depths of the North Atlantic; and the towering bulk of Mont Blane may be said to rise out of the deepest part of the wester Mediterranean basin. This remark is of general application, and we may add, that if on any roast the highest point of the upheaved surface almost equals the depth of the depression, that of the opposite coast will be as far removed from it; as if the doublings and upliftings to which the actual configuration of the earth's crust is due were unsymmetrical, and had produced on the one coast a gentle declivity, on the other a steep hill.

On the subaërial part of the earth there are vast plateaux or table-lands, and elevations of considerable altitude. Submarine plateaux are in like manner of frequent occurrence; they separate two basins, the rocky edges of which are not sufficiently high to appear above the waters. In the Northern Atlantic Ocean, for example, a vast plateau stretches from Iceland to the Azores, and thence, southward and westward, to the Antilles or West Indies. 'The Azores correspond to volcanic peaks, rising from that chain of submarine mountains. Another plateau extenis 
to the north, the east, and a little to the south of Newfoundland, terminating abruptly about the latitude of New York in a steep shore, along the escarprent of which flows the celebrated Gulf Stream. Near it, the orographic chart shows the centre of a basin where the sea is about five miles deep, compared with less than a third of that depth on the plateau. The now familiar Telegraphic Plateau is the latest discovery of this kind. It is a remarkidule steppe, extending from Cape Clear in Ireland to Cape Race in Newfoundland, and upon it the mystic chain which unites the intelligence of the Old and the New World reposes in perfect security.

Sumetimes from the submarine plateau there spring numerous mountain-peaks, which lift their heads above the ocean, and rise to a considerable height in the atmosphere. Thus, an archipelago or cluster of islands consists of the culminating-points of mountainchains, the bases of which are planted on submerged plains. If the Americas were covered with water to the depth of a mile, more or less, we should find in their places groups of islands corresponding to the Rocky Mountains, the Andes, the Brazilian Mountains, and to some peaks of the Alleghanies and Antilles. The plummet would indicate the existence beneath the waters of great valleys separated by hills, by plateaux, or by mountains, for the most part with easy declivities; 
but more abrupt near the present shores of the continent, especially on the western side, which overlooks the great ocean.

The bed of the sea cannot, with strict accuracy, be compared to the bed of a river. A section of the Mississippi, at Plaquemines for example, resembles a gutter. Neither does a lake of small extent present the means of a satisfactory comparison, however deep it may be. If we join the two opposite shores of a lake by a straight line, that line will be above the bottom of the lake, and will thus appear as a portion of the surface. This is not true of a sea, if it be of any considerable size. The earth is rounded in form, the free surface of the ocean is almost perfectly spherical; and it is from that surface, as a starting-point, that the depth of the sea must be estimated. Drive a rectilinear tunnel through the earth from Paris to Newfoundland, as sketched in the annexed diagram,

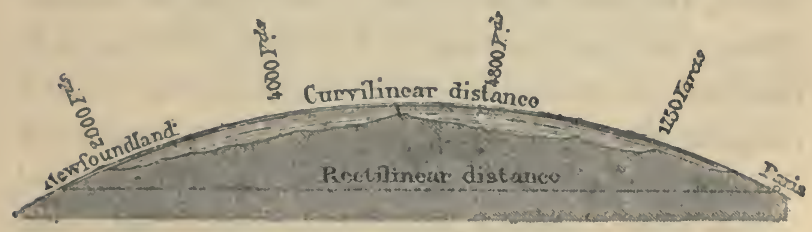

Fig. 6.-Section of the Atluntic Ocean from P'aris to Newfoundland. and it will be found that this tunnel nowhere encomnters the ocean. It will, in fact, pass far beneath it 
Its entrance in Paris will neither be vertical nor horizontal. It will at once pass at a considerable depth under the English Channel and the ocean, notwithstanding the comparatively great depth of the latter. and will reach the surface at Newfoundland obliquely as it had quitted Paris The same observation applies to all the great seas. The form of the earth being spherical, the bottom of the ocean, so far from being a cavity, is in its general outline convex.

In order to give the reader an exact idea of the relative thickness of the solid crust of the earth, of its liquid covering, and of its gaseous atmosphere, we cannot do better than draw a section of the equator (fig. 7). In the centre, marked by the diagonal shading, is incandescent fire, of the character of which we can only form a conception from the productions of volcanic eruptions. A solid crust of comparatively slight thickness envelopes the fluid kernel, and rests upon it like a raft upon the waves. When that internal sea of fire is agitated, its palpitations are revealed to us by startling results-in a word, by the breaking-up of that fragile crust upon which repose all our hopes.

This solid covering is enveloped by a double atmosphere. The lower (or aqueous) portion is not adapted to our mode of existence; we can but float upon its surface. It is divided or broken up by the 
elevation of the earth into the higher or gaseous portion, which is alone appropriate to our nature.

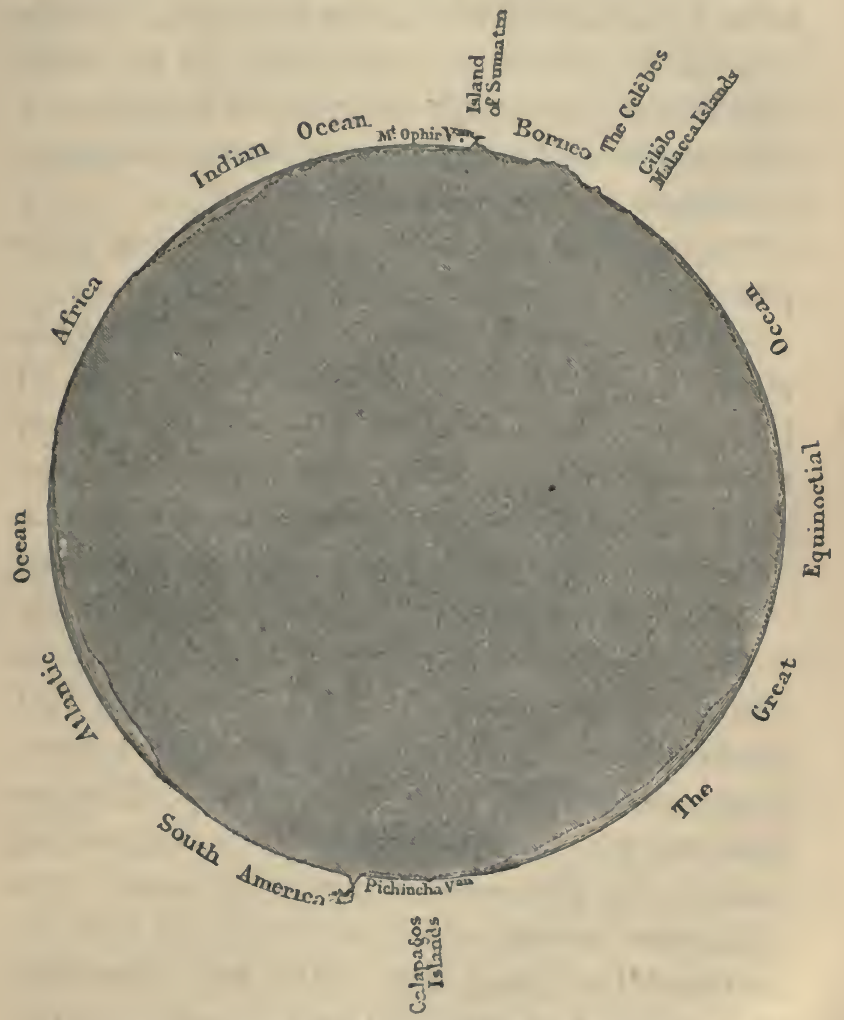

[The secule of dept'ss is fifty times greater than thut of lengths.]

F.g. 7.-Equato: ial section of the Earth.

In all prubability the thickness of the earth's 
crust is very far from being uniform. Its maximum cannot exceed, even if it reaches, sixty miles, or less than the sixtieth part of the earth's radius. In some places it is certainly very much less. In the neighbourhood of volcanoes, for example, it is so thin that. combustible matters are ejected through the fissures in which these mountains abound.

The greatest depth of the liquid envelope is probably less than six miles, and the gaseous atmosphere, so far as it is respirable, can hardly be said to reach five miles in height. It is in this limited zone, of ten or twelve miles' thickness, that all the phenomena of life take place. How small is this space compared with the great mass of the globe; and, to follow out the contrast, what an atom is man compared with the immensity of the universe!

In the section (fig. 7) the bed of the great Equinoctial Ocean, and that of the Indian Ocean, is marked by a dotted line, the data being insufficient to determine their depths with precision. This section cuts the northern part of South America, and touches the Pichincha volcano. It asses by the Galapagos Islands, which are separated from the continent by a deep arm of the sea. Traversing the middle of the Pacific Ocean, it cuts the archipelago of the Scarborough Isles; and, farther on, the Moluccas, the island of Borneo; Sumatra, with one 
of its volcanoes; Mount Ophir, directly opposite Pichincha-then the Indian Ocean, the immense plateau of Africa, the isle of St. 'Thomas, and the Atlantic. In making this circuit, we are chiefly impressed by the fact that the external surface of the earth's crust is almost exactly represented by a circle. It is not without difficulty that we represent only a slightly undulating line, the inequalities being exaggerated in order that they may be at all perceptible.

4. Northern Atlantic Ocean-Chart of Maury.

The Atlantic Ocean takes the form of a great canal, stretching directly from north to south, and trending to the east in its northern part. With Maury's Chart before us we shall find it comparatively easy to form an idea of the configuration of this ocean-bed.

The curves which indicate its varying level are drawn at such a distance from each other as to mark a thousand fathoms' difference in the relative depths. 'Thus all the points situated between the shores and the first curve vary in depth from 0 to 1000 fathoms, or 6000 feet; all the points between the first curve and the second angment in depth from 1000 to 2000 fathoms; those between the second and third from 2000 to 3000 fathoms; and those between the third 
and fourth from 3000 to 4000 fathoms. Any greater depth is indicated by the blanks. On referring $t$, the chart (fig. 8), it will be seen that a depth exceeding 4000 fathoms is thus marked between Newfoundland and the Bermuda Islands, in the track of the Gulf Stream. The plummet there descends to a depth of about 5000 fathoms, or nearly 30,000 feet. Westward of the Canary Islands is another deep point, the indication of the plummet being about '24,300 feet.

A marked region of this ocean-bed, having a depth which varies from about 3000 to 4000 fathoms, extends from the south of Newfoundland, rounds the Bermudas, and follows very nearly the direction of the American coast to the extreme latitude of Florida. It then winds south-east, keeping a certain distance from the Antilles, and terminating near the northeastern extremity of that archipelago.

A second remarkable trough, separated trom the last-mentioned by a submarine chain of mountains, extends like a long gutter from the north-west to the south-east, even beyond the equator. It is nearer to the Brazilian than to the African coast.

Throughout these regions, which are the deepest in the Atlantic Ocean, the bottom exhibits great irregularity. The gulf deepens rapidly from the coast of America and the Antilles, but slopes gently from Europe and Africa. We observe, in fact, that the 
curres of the chart approach very near to each other on the west, and are farthest from each other on the east of the depression. Another noticeable feature is the immense plateau ranging almost parallel with the European and African coast, and dividing what may be called the shelving side of the ocean-gulf into two parts, for which reason it has been named by Maury the "Middle Ground." It commences at Iceland, passes the Azores, and extends southward to the latitude of the Canary Islands; then trends towards the Bermudas, and bulges southward to a point east of the Antilles. The depth of the sea at the southern termination of this plateau is marked in the chart by a curve, which indicates less than 2000 fathoms, or from 11,000 to 12,000 feet. This locality is identical with a part of the Grassy Sea. Between this middle ground and the coast of Europe a long valley extends north and south, and, at the Cape de Verd Islands, joins the depression which is bounded by Africa. America, and the plateau or middle-ground just described.

The depth of this valley is almost everywhere a little under 3000 fathoms, the exception being another spot, previously alluded to, west of the Canary Islands. In the northern end, westward from the British Isles, and even across the Middle Ground to Newfoundland, the depth is so uniform, that when soundings were 
made for the purpose of laying a telegraphic cable between the Old World and the New, all this part of the ocean-bottom seemed as if it were purposely designed to form the bed of that wonderful conductor of thought. Hence the name of "Telegraphic Plateau" was given to it.

For a considerable distance around the Azores the depth is less than 1000 fathoms. About halfway between the Azores and Newfoundland, there is also a circumscribed region of comparatively slight depth -being marked in Maury's Chart as less than 2000 fathoms. In the whole of this route-that is to say, from Spain to the Azores, and from the Azores to Newfoundland-the depth nowhere exceeds 3000 fathoms. It has therefore appeared to presenta suitable course for a telegraphic cable. The French line is laid midway between this plateau and the English cable of 1866.

Along the coasts of Brazil and Guiana the sea becomes rapidly shallower; and as the great equatorial current which carries the waters from east to west is of vast breadth, we need not feel.surprised to observe that it increases in swiftness as it approaches the coasts which confine its bed. There is then a descent or lower depth of the sea-bottom extending eastward from the Isthmus of Panama to St. Domingo, as if the rush of the current had washed out a gulf. This 
is succeeded by the comparatively shallow space of the Gulf of Mexico, and the sea in the neighbourhood of the Greater Antilles and the United States.

A great extent of shallow sea is also to be observed extending from Nova Scotia to the east of the Great Bank of Newfoundland, and to the coast of Labrador. It is by this ronte, as all know, that the polar ice and icebergs descend towards the Gulf Stream, the warm current of which causes them to melt, and deposit in the bed of the sea the debris of the land from which they had drifted away.

\section{The Mediterranean and the Blark Seas-Chart of Bütiger.}

The Mediterranean and the Black Seas are of no great depth. The plummet seldom reaches 12,000 feet, and not more than half that depth in the greater part of their extent. The waters of the Mediterranean, however, cover many great valleys. The deepest is surrounded by the shores of 'Tripoli, Greece, and Italy. It is separated by a narrow chain of mountains from another great valley, which occupies the space bounded by the Grecian Archipelago, Asia Minor and the coasts of Syria and Egypt.

Beginning at the Straits of Gibraltar, we find the submarine soil highest near the coasts of Spain and Morocco. At the western end of the strait, the depth 
does not exceed 1000 or 1200 feet. As we advance castward the depth augments rapidly, till it reaches nearly 12,000 feet south-east of Malaga. Soon, however, the soil rises again. North of Melilla (a port on the coast of Morocco) it is about 1200 feet from the level of the sea, and forms a submarine mountainchain, which bounds on the east a sort of little basin confined between the Sierra Nevada and the Marocco mountains, which are reunited under the sea in the Straits of Gibraltar.

Continuing eastward, the explorer would descend into another valley almost as deep as that mentioned above, and communicating with that great depression by a neck of the chain which stretches under the waters from Oran to the Cape of Gades. Having surmounted this obstacle, we bend our steps northeast, and find ourselves in a great depression, which is narrow at first, but gradually spreading out becomes a great plain stretching to the Balearic Isles and the coasts of Sardinia and Algeria. We leave this great depression or basin by climbing a very steep ascent to the north-west. We then find ourselves upon an extended plateau, from which rise numerous mountainpeaks. The principal of these form the Balearic Isles. The plateau is scarcely interrupted by Carthagena and Valencia, by the Balearic Isles, and by Corsica. It narrows, however, between these islands. 


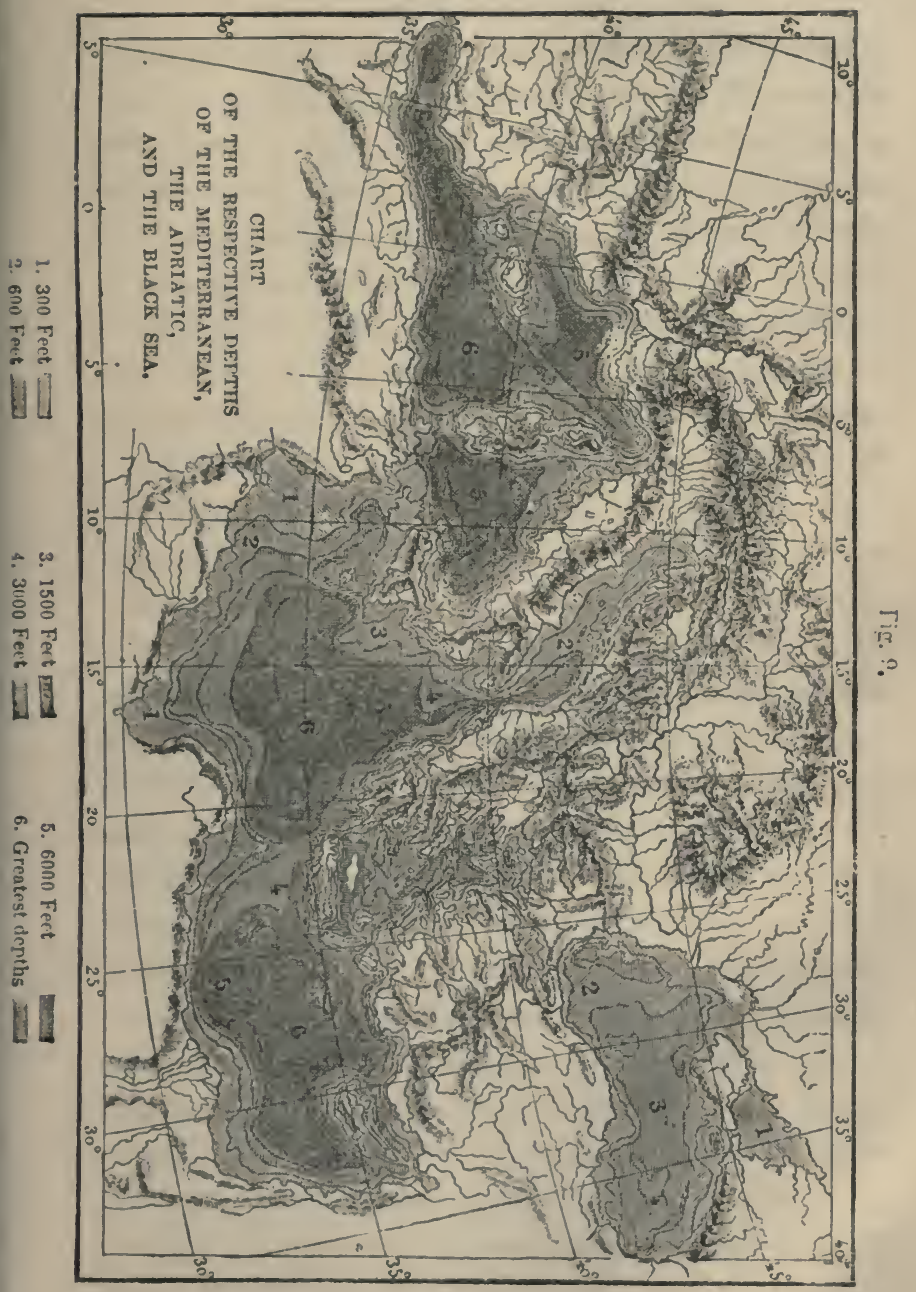



and we discover to the north another irregular cavity occupying the space comprised between Majorca and the coast of Spain, and the Gulfs of Lyons and Genoa. The depth of the sea there does not exceed 6000 feet; and from this bottom there rises an isolated peak at the entrance of the Gulf of Lyons.

To ascend from the Algerian depression eastward, it would be necessary to avoid the escarpments around Sardinia, and draw towards 'Tunis, in order to find an easier declivity. All around Sardinia and Corsica the depth of the sea is slight; the basin formed by the 'Tyrrhenian Sea has nothing to boast of but two straight and elongated ravines-the one extending from west to east, rounding the Lipari Islands; the other from north-west to south-east, rumning parallel to the Neapolitan coasts.

The Bank Aventure and the Rocks of Skerki, near Tunis and Sicily, form an undulating plateau, over which we pass to the eastern basin of the Mediterranean. A steep desceut leads from Malta, one of the culminating-points of the plateau, to the bottom of the depression which has for its boundaries Italy and Greece, Asiatic Turkey and Africa. The greatest depth is near Malta, where the plummet descends more than 14,000 feet, or alout $2 \frac{1}{2}$ miles. No other spot in the Mediterranean is so deep as this.

The mountains of Greece and Candia are prolonged 
beneath the waters, and they divide into two nearly equal parts the great cavity we are now considering. The western part presents some steep slopes, but generally the bottom rises very gradually, till we come to the shallow waters of the coast of Africa on the one hand, and to those of the Adriatic on the other.

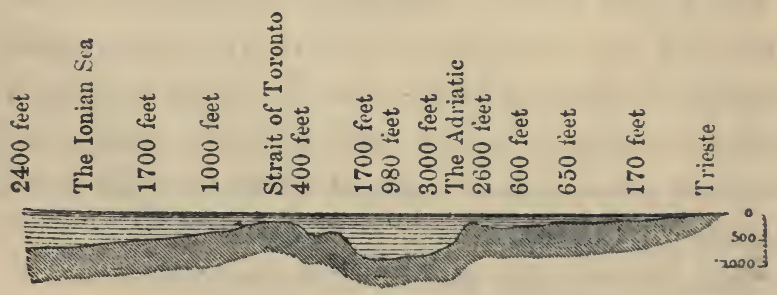

[Scale of depths a hundied times that of the length.]

Fig. 10.-Depths of the Adriatic.

In this sea, if we except a little basin about 4000 feet deep, the plummet rarely if ever descends more than 600 feet. The eastern half, or Græco-Egyptian basin, extends to the southern part of the Archipelago, as far as the coasts of Greece. The islands of Candia, Caxo, Scarpanto, Rhodes, and Cyprus are planted on its borders. The alluvial deposits of the Nile tend to raise the level southward, as indicated by the map. The lines, which mark a depth not exceeding 300 feet, form a spacious area in front of the Delta, and are succeeded by the curves of 600 feet, then by those of 1500 feet, and so on to the greatest depth of 
the basin, about 10,000 feet. The course of the marine currents near the mouths of the Nile is from west to east. The action of these currents, it is hardly necessary to say, tends to carry the alluvial matter eastward; hence the deep part of the sea is farther from the coast eastward from the Nile than westward.

If we ascend from this basin to the north-west, we shall find ourselves among the rocky gorges dominated by Candia and Scarpanto. These irregular and broken elevations form a great volcanic region, the principal peaks of which form the islands of the Greek Archipelago.

The defiles of the Dardanelles, the valley covered by the Sea of Marmora, and the ravine commanded by Constantinople and Seutari, open to the plain upon which debouch the greatest rivers of Europe. The Black Sea is of little depth. It is surrounded on its southern shores by the heights of the Cancasus, the Armenian mountains, and the Balkan. Northward the Russian steppes extend under the sea, which their débris, washed down by the great rivers, tend to fill up.

6. The Baltic-The North Sea-The Straits of Dover-The English Channel-The Bay of Biscuy.

The Baltic, like the Black Sea, is of little depth. We shall see by-and-by that its bed is the seat of very remarkable phenomena. Its northern part is 
slowly but steadily rising, insomuch that the Gulf of Bothnia diminishes in extent and depth at a certain constant rate. At the same time, the southern part of this ocean-bed is sinking, and the sea is gradually taking possession of the lower plains of Mecklenburg and Pomerania.

The Skager Rack leads from the Baltic into the North Sea, which is likewise of slight depth. Excepting a long narrow trough which follows the direction of the coast of Norway, the bed of the North Sea may be described as an undulating plain, never more than 600 feet deep. Some of the greater banks almost reach the level of the waters; others are not more than a hundred feet beneath the surface. In this sea various kinds of fish are abundantly nourished by marine worms; numerous sites covered with algæ provide them with an agreeable retreat; and the water, constantly beaten by the winds, is plenteously supplied with air for the respiration of its innumerable hosts.

The shores of the British Isles are very abrupt, but the sea is of no great depth until we pass beyond the west of Ireland and the Hebrides. At the distance of about twenty leagues from Valencia we find a depth of 600 feet, which increases westward, until we arrive at the Telegraphic Plateau already doscribed. 
The whole extent of France and the English Channel, of the British Isles and the North Sea, forms one great plateau, which is terminated on the west and on the north by a steep declivity. 'The following section (fig. 11) will give an idea of what we mean. Tho straight horizontal line represents the level of the

\section{Thie Channel.}
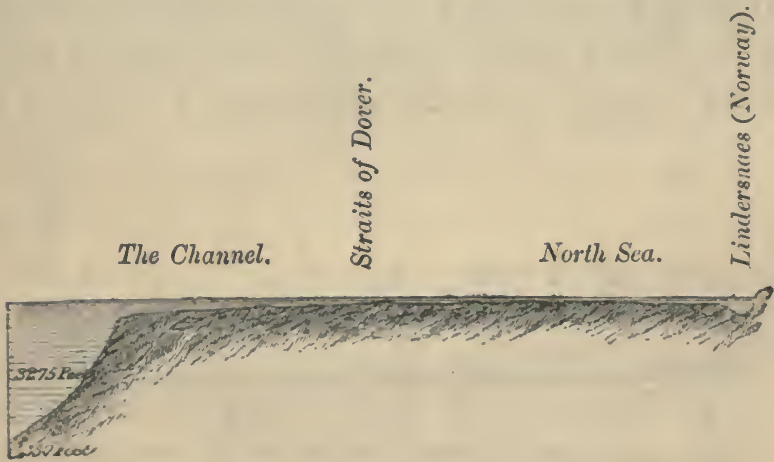

Fig. 11.-Profile of the Ocean Floor from the southernmost point of Norway, via the Straits of Dover, to the 10 th degree of west lougitude and the 47 tir degree of north latitude.

sea. The irregular line beneath it represents the bottom of the sea, which resembles a vast plateau or block of table-land. Near the coast of Norway we find the deep trough, or ravine, already mentioned. To the left, the soil slopes off very gradually (interrupted by a ridge, or bank, about the middle of the Straits of Dover); but it deepens considerably in the Chanvel, and then suddenly sinks away, and presents 
a declivity which may be compared to a rampurt à la Vauban. We may remark here that, contrary to the general opinion, the aspect of the coast often suggests a false idea of the sea-bottom. When a precipitous mountain descends sheer into the water, we are apt to fancy the sea inust be very deep at that spot; whereas, if we try the plummet, it will most likely be found shallow. Here, again, a sandbank suggests a low flat shore beyond it, devoid of
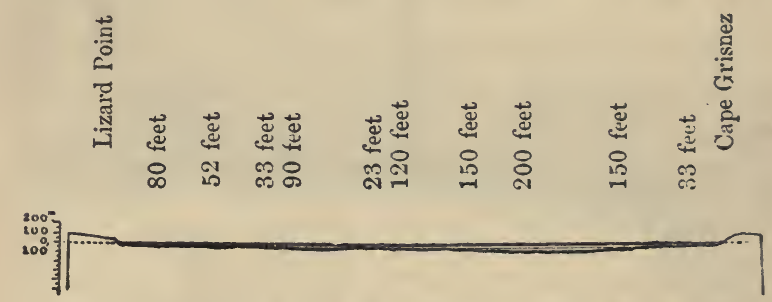

[The scale on the left hand of the diagram is in metres, lut the depiths are given in equivalents of fect.]

Fig. 12.- Vertical Section of the Straits of Dover.

rocks; we sail on and drop the lead, but cannot touch bottom. Many examples of these deceptive appearances must have struck the reader during our rapid survey of the ocean-floor.

Notwithstanding its steep shores the English Channel is of slight depth. Notwithstanding the cliffs which confront each other on the opposite coasts of England and France, there is so little water in the Straits of Dover, that if the level of 
the sea were reduced by sixty yards the two countries would be united by a natural causeway; nay, if the water were only drawn off to the extent of eight yards in depth, an island would be left in the middle of the narrow passage. Unhappily for the enemies of England, the contrary of this is more likely to occur, as the tendency of the soil in this part of Europe is to sink, as will be seen further on. 
THE WATER OF THE OCEAN.

1. Composition of Sea-water-Biot's Apparatus.

SEAS are the products of atmospheric vapour, condensed into fresh-water. But the earth, with wbish the water came into contact, contains varions soluble matters. These were dissolved by the water, and its purity was irrevocably lost.

The vapour which is lifted from the seas by the action of the atmospheric currents may be said to rise in a pure state; in other words, it is fresh water that is raised. But, again, it falls in the form of rain or snow upon the soil, over which it passes slowly to its destination, and thus becomes charged anew with salts which it conveys into the sea. Every time evaporation takes place, the vapour returns in the form of water laden with fresh matter from the surface of the earth. This alternate migration of vapour and water must tend to augment continually the saltness of the sea, and if there were no countervailing cause, its saltness would increase to the extreme point of saturation. 
The fact is, however, that countless myriads of animals extract from the waters of the ocean enough solid matter to build continents of. 'The foraminiferæ, the polypi, and the molluses hence derive the calcareous coverings which form their shells or skins. An estimate may be formed of the stupendous nature of the agency of these little creatures, by considering the vast extent of the beds of calcareous rock which form part of the earth's crust, and which are composed of the débris of creatures so small that upwards of fiftyeight thousand of them have been counted in a cubic inch of chalk. No doubt other marine animals extract other salts from the ocean, and we must add to their action that of the marine vegetation. Setting these considerations aside for the present, the actual composition of sea-water is found to be as follows :-

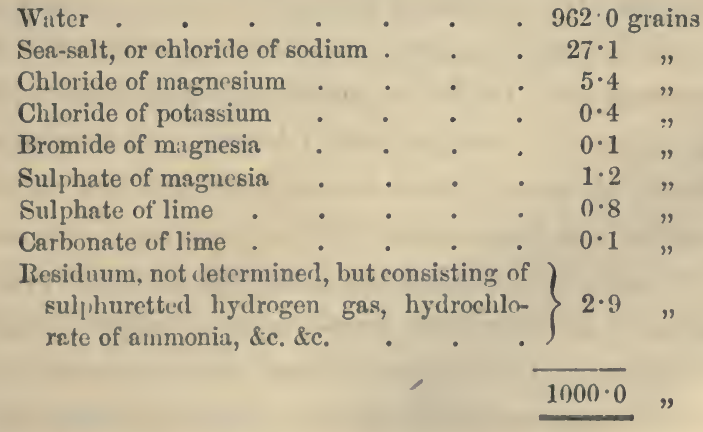

Sea-water, being thus composed, is considerably 
heavier than fresh-water of equal volume. Thus, a litre of fresh-water (nearly $1 \frac{3}{4}$ pint) weighs less than a kilogramme (exactly $0^{k} \cdot 998$ ) at the temperature of $68^{\circ}$ Fahrenheit ; the same volume of fresh-water under the same conditions would weigh $\mathbf{1}^{\mathrm{k} \cdot 027}$. But the weight of sea-water, like its composition, is far from being constant; it varies according to times and places, and even according to the depth from which it is taken. Southern sea-water is heavier than that of the northern hemisphere in the proportion of 1.0272 to 1.0262 of specific gravity, owing to the greater quantity of salt it contains. Off Cape Horn its specific gravity is 1.028, the heaviest known. The upper current of the Gulf Stream is lighter than the current below, because it is less saturated with salt; but these facts will be further elucidated by-and-by.

As the air, at whatever height we take a sample, is found to be of the same composition, an interesting question arises whether or not the sea partakes of this property? Are the gases which enter into its composition always in the same proportions? These questions are not easy to solve, because the enormous pressure exercised by a column of water many thousands of yards in depth causes extraordinary difficulties in the construction of the necessary apparatus. It must be remembered that it is essential to obtain the water at the required depth, and bring 
it to the surface with all that it contains in hermetically-sealed vessels. It is not possible to employ empty vessels, such as are used for investigations into the character of the atmosphere, contrived to open at the required depths. The water would either break the vessels or filter through them. On their approaching the surface, any gases that had been subject to the enormous powers of compression of the superincumbent water, would dilate to an extent which no vessel hermetically sealed could be expected to resist. Biot has, to some extent, overcome these difficulties in the following manner.

He takes for his vessel a hollow cylinder of glass, closed at one end by a solid plate of metal, so as to resemble a pail. Like a pail also it has a handle, with a cord attached, by which it is let down into the sea. This pail being open to the surrounding water, descends to any required depth without injury from the pressure of the water; and whenever the operator pleases he pulls a second cord, attached to the bottom of the pail by means of an inverted handle, and this causes the vessel to tip over. By the same cord he draws it to the surface. It must now be observed that the metal bottom of the pail is double; oue of its parts being fixed, the other moveable like a piston, and capable of descending in the cylinder by its own weight when the vessel is 
reversed. In the fixed bottom there is a small hole, furnished with a valve, which opens from the exterior to the interior, so that the water passes through and fills the space between the descending piston and the fixed bottom. This being done, the valve is closed by the action of a spring, and the water contained in the pail is isolated.

If this water contained any quantity of compressed air, nothing would be able to resist its expansive power when it was drawn to the surface, and the pressure of the exterior water ceased to act. It would then burst the apparatus and escape. As a safeguard against this violence, a free issue is prepared, sufficient to serve for any possible expansion of the air in the water. In the fixed bottom there is a passage communicating with a bladder, which is empty and folded up when the apparatus is let down into the sea, but which receives whatever gas or air the water in the pail may disengage as it ascends, and thus returns to the surface more or less inflated. The operator then closes the stopcocks with which the passage of communication between the pail and the bladder is fitted; and having separated the latter, he proceeds to measure and analyse the air contained in it. Having done this, he can study at his leisure the water enclosed in the pail, and whatever matter it holds in solution. 
2. Variations in the Saltness of Sea-water.

Water is so much the more heavy as it is more salt. It is not surprising, therefore, that the saltness of the sea should increase with its depth. That increase is not indefinite, because water at a certain temperature can only hold in solution a given quantity of mineral matters.

We must at once confess to our ignorance of the quantity of salts held in solution in the profound lepths of the Ocean. With the apparatus of Biot we can, it is true, obtain water from great depths. Still, it is not possible to operate at distances of 20,000 or 30,000 feet from the surface; or, if possible, the business is at once too costly and too difficult to be often attempted.

Rain and evaporation cause the saltness of the superficial waters of the sea to vary considerably. Evaporation increases, rain diminishes it. The effects due to these causes are, generally speaking, not very apparent; but they are very observable when one of them predominates. If it rains frequently in certain regions, the saltness of the surface of the sea is slight in comparison with that of places where the clearness of the atmosphere favours evaporation. It is less at the equator than near the tropics. It is greatest at the 21st parallel of north latitude, and 
the 16th of south latitude, in the Atlantic Ocean. Above these latitudes the saltness diminishes continually to the polar regions.

On the other hand, we must not forget that there exists near the equator a zone (the Equatorial Calm - Belt), where the precipitation of the vapour of water, in the form of rain, is almost incessant. To the north and south the trade-winds sweep the surface of the sea, and the atmosphere is clear, or only shadowed by clouds floating towards the region of rains. We also find, on approaching the poles, two zones of variable winds, where frequent tempests disturb the air, and cause abundant condensations. The relation of evaporation and rain to the saltness of the sea is thus made evident.

In the polar regions the saltness of the sea is modified by another cause not less active than the above-namely, the melting of the ice, accumulated like two vast cowls over the extremities of the earth. Every year, during the summer of each hemisphere, torrents of fresh-water are poured out towards the temperate regions. These torrents gradually mingle with the salt-water of the ocean, upon which they first flow along as a river on its bed; and as a consequence of this, and the other active causes to which we have alluded, the saltness of the sea grows less at the surface in proportion as we approach the poles. 
The water which the ocean loses by evaporation is returned to it in full measure by rains and rivers. It is not so, however, in the case of certain interior seas, completely isolated from the ocean, or only communicating with it by means of a narrow channel. The winds which blow upon such a sea may be despoiled of their humidity by their passage across great continents, and the rivers themselves may not bring a sufficient tribute to supply the loss caused by a powerful evaporation; or it may happen that the quantity of water returned by rains and rivers is exactly equal to that which is lost by evaporation; or, finally, the supply may exceed the loss. In either case, the result, as regards the saltness of the sea, is obvious. In the first case its water will be salter than that of the ocean; in the second, it will be about the same; in the third, less.

If the interior sea communicates with the ocean, there will generally be a current in the channel which unites them. This current will float ships into the interior sea if that sea lo:es more water than it receives; but it will bear them towards the ocean if it receives more water than it loses. The Mediterranean and the Red Sea both receive the waters of the ocean. The Black Sea and the Baltic. are, so to speak, too rich; they contribute their excess of water to the neighbouring seas. 
When the interior sea is the bottom of a basin without issue, either the supply of water by means of rains and rivers must equal in volume that which is lost by evaporation, or the sea must gxadually dry up. The Caspian and the Dead Seas are both examples in point. The first is surrounded by calt steppes, where it is easy to discover traces of the recent existence of the waters. Its level is above 100 feet below that of the Black Sea, and it is constantly decreasing in extent, and is very salt. The Deal Sea is at present about 1400 feet below the level of the Red Sea; yet travellers have recognised between the two seas the dried-up bed of a river, which, through causes not yet ascertained, has ceased to unite them. Since that epoch, the Dead Sea has not received sufficient water from the Jordan to supply the loss ocasioned by evaporation ; its level has consequently sunk and its saltness has proportionately increased, until an equilibrium has been established between the supply and loss.

There are many salt lakes, both in the Old World and the New, which owe their saltness entirely to the rivers which flow into them. The delivery of water is increased, and the lakes overflow ; it is diminished, the lake retires, and its saltness increases. When the supply of water is quite insufficient to compensate for evaporation, the lake dries up, and in its place is seen a valley covered with a bed of salt. 
The composition of sen-water varies most in the neighbourhood of the coasts. It is only at a considerable distance from its embouchure that the water of a river mixes with that of the ocean, and the one is often distinguished from the other by a well-defined line. This phenomenon is most striking at the embouchure of the Mississippi. The "Father of Waters" rolls into the sea laden with yellow mud, which forms a shifting promontory in the midst of the dark waters of the Mexican Gulf.

"Suddenly," says a recent traveller,* "it seemed to me that the colour of the water had changed: the deep blue had become yellow, and the distinction between them was marked by a line as straight as if drawn with a cord, extending from east to west. Northward, a darkish coast-line, half concealed by mist, indicated the direction of the land: we were floating on the waters of the Mississippi. Soon the speed of the ship was slackened, she was scarcely able to make way; all at once she stopped, her keel was fast in the mul."

Another cause sometimes tends to diminish the saltness of the superficial waters near the coasts. Rain which falls upon the steep or sloping shores at once finds its way into the sea. In this case the waves and currents combine to mingle the fresh

* M. Elisée Reclus : Fragment d'un Voyage à la Nouvelle-Orleuns 
and the salt water together, and the accidental anomaly is soon lost to observation.

Fresh-water is contributed even by the bottom of the sea itself. It is true the phenomenon of submarine springs is of rare occurrence, yet some remarkable instances are known, and many others may have escaped notice. In some places, generally near the shore, the sea may be seen to bubble, and yet no gas is disengaged. The movement is occasionally so pronounced that the surface of the sea swells as with a wave; and if, in such a case, we test the water, it will be found to be less salt than usual. If the sample be taken from near the bottom, it will prove to be nearly fresh; indeed, if the source be abundant, it will be found to be quite fresh. The effect of these springs, however, is not traceable to any considerable distance, and as they are always near the shore, we can only regard them, in connection with our subject, as objects of curiosity.

3. Variations observed in the Gases contained in Sea-water.

Sea-water not only contains salts, but gases. Air penetrates into the sea, as water penetrates into the atmosphere, in the state of vapour. Thus a kind of exchange or reciprocity of action is established, and in both cases a sort of refinement or purification is effected 
Water converted into vapour is disturdened of its salts; air contained in water becomes richer in oxygen. This gas plays a most important part in oceanic phenomena. Without it no living thing could exist in the sea. Except for it, even those beautiful algæ, whose long and brilliantly-coloured ribbons are floated in undulating curves by the marine currents, would no longer charm the eye. The whole race of polypi would cease to construct their stony habitations, which are so much admired by the lovers of nature.

The deeper we penetrate into the ocean the more abundant are the gases. The increase of carbonic acid gas with the increasing depth is especially remarkable; and hence the gaseous mixture found in the deeper parts of the sea is less suitable for respiration than that which is nearer the surface. It is further to be observed that the renewal of gases in deep water is effected with much less facility; and this may be regarded as one of the causes which tend to prevent the existence of organised beings at a great depth. As aërial plants and animals are confined to the lower strata of tho atmosphere, so marine plants and animals are condemned to remain near the surface of the waters, comparatively speaking. Thus, the living beings which flourish on our globe are confined to a very limited 
stratum of air and water, and they reach their maximum development where the two atmospheres meet.*

When a volcanic eruption takes place in the sea, the composition of the gases contained in the water is necessarily changed in the neighbourhood of the volcano by the subterranean emanations. Some seas, like the Caspian, are literally poisoned by volcanic products, and this to such a degree that it is hardly possible to live near them. A bird cannot hover above their waters without the risk of perishing from their deadly influence. $t$ In the great oceans the gases produced by volcanic eruptions are reduced to insignificant proportions by the action of the marine currents.

* Notwitlistanding the general truth there is in this statement, urganised ereatures have recently been discovered in much greater depths than had been anticipated.-TR.

$\dagger$ This was for a long time the popular notion encerning the Dead Sea. The fact is now known to be otherwise. Mrr. Tristram, in that ehapter of his interesting journal where he describes "the Dead Sea shore," mentions haring seen a fine brown-necked raven, which flew quite across the lake, and a kingfisher actualiy sitting on a deul bough in the water. Many gulls were also fishing in their eustomary manner; small flocks of pochard dueks skimmed the surface, and close along tho shore were duulins, redshanks, and wagtails, and one specimen of the desert wheatear. At the same time, he says, "it is quite certain that no form of either vertebrate ur molluscous life can exist for rnore than a very short time in the sea. itself, and that all that enter it are almost immediately poisoned alu galted down." - $\mathrm{T} r$. 
4. Solid Bodies in the Sca-Phosphorescence.

The sea holds in suspension a great variety of solid matters. In the first rank are fish, which float in the liquid element as birds in the air, whilst the other living ereatures of the ocean are under the necessity of finding a point of support on the submarine soil. The number of creatures floating in the water is enormous. Many species of them congregate in shoals, which have sometimes been known to cover hundreds of square leagues of surface, and extend several hundreds of feet in thickness or depth. It is not, however, to the natural history of animals that our attention is now called. Our subject is the sea-bottom, and it is only so far as any creature lives on the submarine soil, or leaves its spoils there, that we owe it any special regard. One passing observation may be made. It seems certain that such immense shoals of living beings must vitiate the aqueous atmosphere in which they float, just as any other similar congregation of men or animals would affect the surface of the earth and the air they breathe. Their débris must undoubtedly be reckoned among the agents by which the basin of the sea is more or less modified.

The spawn of fish existing in such numbers forms enormous banks, and it is to this cause that the 
phosphorescence of the sea is sometimes due. M. de Tessan has observed a phenomenon of this kind at Simon's Town, Cape of Good Hope :-

"On the 10th of April, in the evening, the sea, in the roadstead of Simon's 'Town, presented an extraordinary phosphorescence of the most vivid character. At whatever points the phosphorescence was greatest, the water was coloured on the surface as red as blood, and it contained such an immense quantity of little globules that it had the consistency of a syrup. A bucket of water taken up at one of these points, and filtered through a piece of linen, left on the filter a mass of globules greater in volume than the water that had passed through: in other words, the globules constituted more than half of the whole quantity of sea-water taken up in the bucket. Viewed through a magnifying-glass, these globules presented the appearance of little transparent and inflated bladders, having on their surface a black point, surrounded with equally black radiating striæ. They had a very perceptible odour of the sea, and most probably they were the spawn of fish. Thus isolated from the water, they were highly phosphorescent; the least agitation, the least contact made them throw out a vivid greenish light, whilst the water that had been filtered away from them had completely lost the property of becoming phos- 


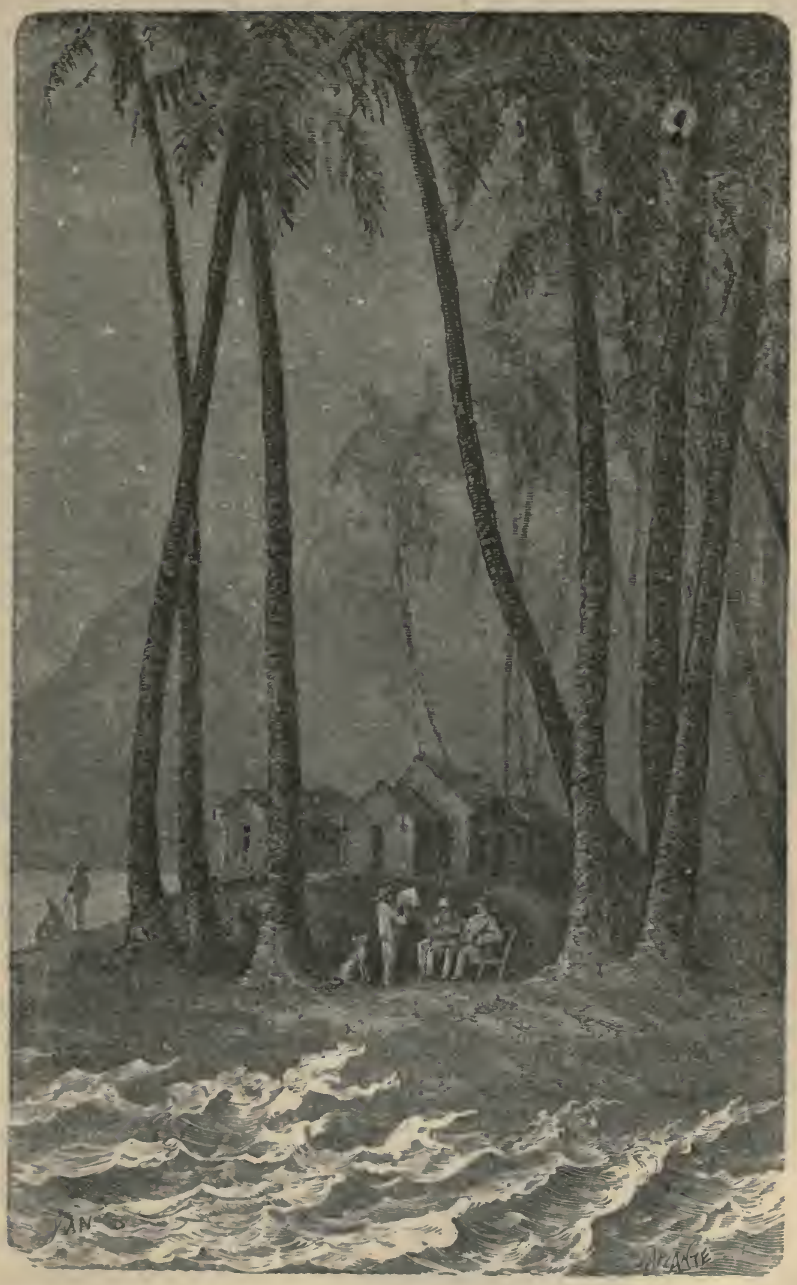

Fig. 13. - Phosphorescent Sea at Simon's Town, Cape of Good Hope. 

phorescent by agitation. Pressed in the hand, the mass of globules made a slight crackling, like that of snow pressed between the fingers After remaining about twelre hours in a vessel it smelt like stinking fish, and was no longer phosphorescent, in which respect it differed from other organic matters which become phosphorescent when they putrefy. Such was the matter which, as the waves in which it floated washed the shore, broke out in vivid flashes like lightning. This comparison was surgested to me by the clearness with which it lighted up the chamber that I and my companions occupied in the house of Mr. Bull, though it was situated more than fifty yards distant from the breakers: I even attempted to write by the light, but the flashes were of too short duration. The greatest part of this matter was eventually thrown up on the coast, where it putrefied, and spread far and wide a stinking odour."

IMolluscs, of very small size, swimming in large numbers on the surface of the sea, communicate to it an artificial colouring. This appearance might be attributed to any cause whatsoever-for example, to mud, or any mineral matters held in solution. But, independently of the microscope, which reveals the structure of these beings, and of the appearances presented when the substance is burnt, and the smell 
as of burnt horn which it diffuses, there is nu difficulty in determining the animal or vegetable nature of such colouring-matter, when it forms banks of considerable extent, far from any coast, and in deep sea-bottoms. The following examples, from M. de Tessan's account of the physical facts obserred during the voyage of the Venus, will give un idea of these phenomena:-

"Latitude $21^{\circ} 50^{\prime} \mathrm{N}$.; longitude $19^{\circ} 48^{\prime} \mathrm{W}$.-We had sounded a depth of about 1600 feet, when it was observed that the colour of the sea suddenly changed. It had become a dirty yellowish-green. We took a fresh sounding, and marked more than 3000 feet without reaching the bottom. The water brought to the surface contained nothing remarkable but a number of very small transparent molluscs, not more than the four-hundredth part of an inch in length, and with yellow stomachs. It was, perhaps, to the existence of large numbers of these little animals in the deeper water, that the accidental colouring was due. However, as the locality in question was only about 50 leagues eastward from Cape Blanco, on the coast of Africa, the change might be due to a river debouching somewhere thereabouts. The coloured band was not above two leagues in extent."

The Venus fell in with another yellowish- 
coloured band in the Southern Atlantic Ocean. Again, in the Pacitic Ocean, going from Valparaiso to Callao, the port of Lima, the sea assumed a deep olive-green colour, owing to a thin mud or slime which it held in suspension :-

“ Latitude $13^{\circ} 50^{\prime} \mathrm{S}$. ; longitude $76^{\circ} 51^{\prime} \mathrm{W}$.-During the watch, we had remarked an extraordinary colour in the water of the sea; the tint had changed to a deep olive-green. On the 22nd of May, the plummet found bottom at less than 700 feet, and made us aware of the fact that the mud was of the same colour, but of a clearer tint. The commander, M. Dupetit-Thouars, by means of dredging, brought up a considerable quantity of the same mud, of which some samples were retained. The substance is almost impalpable, and has no odour in its natural state; but when calcined, it diffuses a strong odour, like that of burnt animal matter, and leaves a considerable quantity of a whitish-grey ash. Even the surface-water contained this matter in suspension, for the ship's hull at the water-mark was covered with a thin layer of it. It was evidently to this matter that the sea was indebted for its deep olive-green colouring, the permanence of which in these latitudes, notwithstanding the strength of the current, which carries the waters northward, is a curious fact. Are we to suppose that the tropical heat penetrating 
the immense volume of polar water* gives birth to these microscopic animalculæ?"

In the same latitudes, with a bottom of more than 5000 feet, the sea presented the same tint, and yielded the same animalculæ. It would appear as if the great Peruvian current, just alluded to, was filled with them. The same phenomenon was observed as the frigate approached New Zealand, where it arrived in the month of October.

In the polar regions, seamen often ubserve green bands of considerable extent, and extremely well defined. They are found to enclose myriads of medusæ. These animals have a yellowish tint, which combines with the blue of the sea to produce a green colour.

Enormous masses of microscopic animals floating on the surface of the sea near Cape Palmas, were traversed by Tuckey, whose ship.seemed to swim in milk. Other navigators have observed zones of a red colour, like carmine, in the Great Ocean. The cause of this phenomenon is analogous to those already related. It is owing to an immense number of animalculæ, or of microscopic algæ, floating near the surface.

Besides these minute bodies, sea-water holds in

* The great occan-current flowing from the antarctic pole towards the equat'r, and known as the whaling-ground of the southicm suas.-See Maury's 9th Plate.-'T'r. 
suspension many regetable species, animals of various strange forms and every size, and a great mass of indescribable debris washed away from the coasts. Too often also the troubled waters toss to and fro the broken remains of ships destroyed by the tempests which in certain regions are of frequent occurrence.

5. Colour of Sea-water-To what extent influenced by matters held in suspension, by the Bottom of the Sea, and by the agitation of the Water.

What is the colour of sea-water? Captain Scoresby likens the general aspect of glacial seas to the blue of the deep ocean. The finest indigo, or celestial blue, represents, according to M. Costoz, the colour of the Mediterranean. The Atlantic has displayed to the eyes of Captain Tuckey a tint so rich, that he has tried to satisity his sense of poetical justice by calling it a living azure. Taking a hint from these various expressions, we are disposed to think the sea has the same colour as fresh water running from a bed of snow or a glacier. When the quantity is small, such water indeed appears to be colourless; but when a great volume of it is seen, it assumes a beautiful blue colour.

The Ocean always presents this reflected blue, more or less deep in tint-that is to say, more or less mingled with white light-if the causes already 
enumerated do not modify it in various ways, and if the bottom of the sea itself does not further complicate the phenomenon by superimposing upon the colour of the water its own reflected hue.

If the bottom be of a more intense colour than the sea, its reflected hue will not be much affected. Thus, while a yellowish sand will change the tint of the blue water to green, a very bright yellow will make the water itself appear of that tint, because the lesser intensity of the blue does not affect the yellow sufficiently to make a green. Tuckey observed, at Loango, that the sea was of the colour of blood; the bottom was very red. In other places, where the bottom might be of a similar but less lively colour, the sea would not appear red, but orange, or even yellow.

The influence of the bottom on the tint of the sea would appear to be limited to those cases in which the depth is very slight. In fact, the water of the sea absorbs so rapidly the rays of light, that in no great degree of thickness it becomes opaque. There are, indeed, instances which seem to imply the contrary. Among other observations, the following, made by M. de Tessan near Cape Agulhas, on the southern coast of Africa, seems to show, that even in the case of great depths the bottom may have a sensible influence on the colour of the water :- " The 
sea," he says, "has very sensibly changed in colour since our arrival upon the bank of Cape Agulhas this morning. As we are sailing in the direction of the current, which bears us rapidly along, this variation of tint cannot be ascribed to the colouring of the water itself. We are compelled to conclude that it is the effect of the colour of the sea-bottom, tha yellowish tint of which, traversing the water, and mingling with its normal blue, produces the greenish hue that we have observed." As the depth is between 600 and 700 feet at this point, the solar light reflected from the bottom hal traversed about 1300 feet of water without being extinguished; since, on being reflected back to the surface, it was still so intense as to influence the colour of the water.

The contradiction between this fact and the theory, is only in appearance. Let two surfaces-the one bright, but small in extent; the other less bright, but of much larger size-be viewed through an imperfectly diaphanous body. Then let them be removed to a distance simultaneously, and it will be found that for a considerable time after the small bright surface has disappeared, the larger and duller will be visible. It is easy to perceive that the colouring of the sea, as witnessed at Cape Agulhas, is a phenomenon of the same kind. The bank is a surface of very considerable extent, feebly illuminated, 
and is seen from a great distance, by its reflected light, through an imperfectly diaphanous medium.

'To appreciate correctly the colour of the sea-bottom, we must be on our guard against a very common illusion. Why should a white sand change the colour of the water, or affect it otherwise than with a slight tint of white? 'To answer this question, we must re-

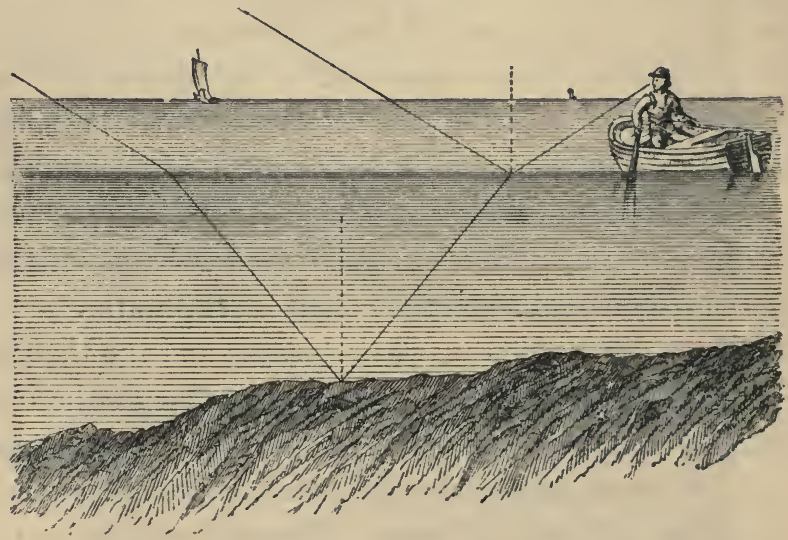

Fig. 14.-Incidence of the Rays of Light on a Calm Sea.

member that sand is white when it is taken out of the water and dried. If we throw upon it rays of red, or green, or any other coloured light, the sand will appear of that colour. Water seen by reflection appears blue; seen by transparency, it appears green. As the sand at the bottom of the sea receives a green 
light, it eannot appear white, and the greenish tint which it presents mingles with that of the water. In a word, it is necessary in all cases to remember that the bottom of the sea receires a green light, and not the white light which falls upon the surface.

When the surface of the sea loses its uniformity the foregoing remarks cease to be applicable. Un-

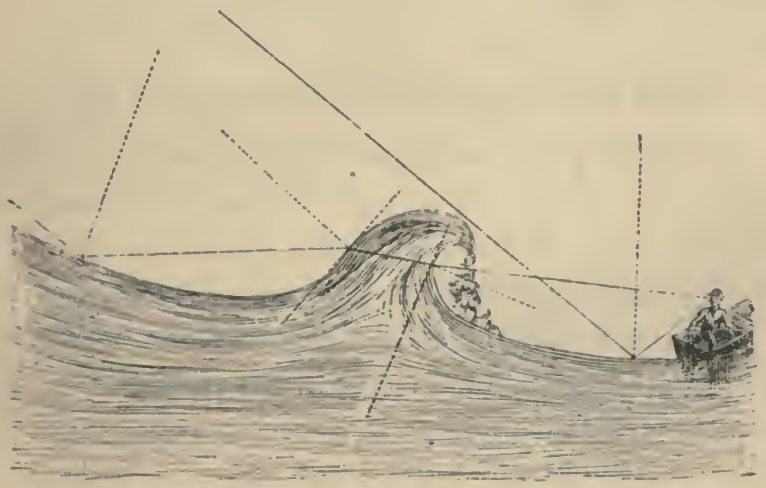

Fig. 15.-Incidence of the Rays of Light on the Waves of the Sea.

dulations or waves cause light which has traversed the water to reach the eye of the observer at the same time as the light reflected from it. The former is that which falls on the anterior part of a wave, and. being reflected, traverses the superior part of the wave following before reaching the eye. This transinitted light is green. If it dominates the reflected light, 
which is blue, the wave will appear greenish-yellow. Further, it is obvious that the different orientations of the wave relative to the position of the sun must contribute, as much as its changes of form, to vary the play of light. This optic property of the waves enables us to recognise afar off a change in the winl, as it produces a different tint in the changing surface of the sea.

6. Measure of Temperature at the Bottom of the Sea.

The attempt to ascertain the temperature at the bottom of the sea at any given time is surrounded with as many difficulties as the procuring of water from certain depths. The thermometer is subjected not merely to the influence of temperature, but to the pressure of the water by which it. is environed. Of slight importance when the depth is inconsiderable, this pressure becomes enormous when the descent is measured by thousauds of yards.

M. Despretz has proposed to leave the thermometer open, in such a manner that the pressure would be sustained both by the interior and the exterior of the tube. It is generally preferred to enclose the instrument in some very solid envelope, and close it hermetically. This envelope, formed of iron or copper, is a good conductor of heat. 'I'he thermometer 
which it protects will, therefore, soon indicate an equilibrium of temperature between itself and the surrounding water.

The temperature of the deeper waters is not the same as that of the superficial mass. It is therefore necessary to employ iustruments, so constructed as to keep a record of the extreme temperatures through which they are passed. To effect this, Péron enclosed the instrument in a tube made of a substance that was a bad conductor of heat. This apparatus, being immersed for a sufficiently long time, at length acquired the temperature of the water that surroundel it, and being quickly withdrawn, there was no time for the heat to escape before the indication was read off.

Bunten has attained the same end, by inventing what he calls the "Thermometer Plunger." The instrument is put into a tube closed by a valve, which opens from the exterior to the interior; thus allowing the water of the sea to enter, but preventing it from returning when the apparatus is withdrawn. The thermometer, therefore, is brought to the surface surrounded with sea-water; but it is easy to see that we cannot be sure of the depth from which the water is . taken, as in the case of Péron's instrument. Finally, the thermometer is not protected from the pressure of the water. Bunten's Plunger, therefore, is not available for deep thermometric soundings. 
Perhaps the best methou discovered up to the present time consists in enclosing one of Walferdin's metastatic thermometers in a strong box of wroughtiron or copper, noting on the return of the instrument the lowest temperature that it has marked. Sometimes, however, the box will be found crushed.

7. Diminished Temperature of the Sea in proportion to the Dupth -Irregularities introduced in this law by the influence of Submarine Currents-Temperature at the Bottom of the Occan constant and uniform-Principal causes of Subm:trine Currents.

The temperature of the atmosphere diminishes in the degree that we ascend above the level of the sea ; that of the sea generally diminishes in the degree that we descend below its surface. It varies but little from day to night, and even from season to season. At no great depth it ceases to vary at all.

The surface is hottest at the equator; it is frozen at the poles. Between these extreme latitudes there is a succession of diminishing temperatures, but they are far from decreasing in regular gradation from the equator to the poles. The water is influenced by marine currents, which have the effect of masking the otherwise regular law of decrease.

The law which varies the temperature according to the depth is also complicated by accidental causes. Often marine currents flow one above another-the 
one being cold, the other hot; their directions also cross each other in a thousand ways. There may thus be many successive beds or strata of currents, their density in each case being the greater in proportion to the depth from the surface at which they are situated. As a proof that such different currents really exist, it may suffice to mention the suddenness with which the thermometer varies after passing through a certain depth of water, and then continues constant while the plummet descends through a lower bed.

Thermometric soundings have marked a temperature of $41^{\circ} \mathrm{Fahr}$. in the latitude of $43^{\circ}$ and $37^{\circ}$ under the equator, at the same depth, of somewhat less than 6,000 feet. 'This agrees with the direction of the submarine currents, coming respectively from the poles and from the equator. In the torrid zone between $33^{\circ}$ and $34^{\circ}$ Fahr. have been indicated at a depth of 12,000 feet, whilst the temperature at the surface was about $80^{\circ} \mathrm{Fahr}$. This result will be thought less surprising if we bear in mind that while fresh-water attains its maximum density at $39^{\circ} 5^{\prime} \mathbf{r}^{\prime} u \mathrm{~L}_{L} \mathbf{x}$., average sea-water does not arrive at its degree of maximum density until it passes its freezing-point $\left(27^{\circ} 2^{\prime}\right)$ and reaches the temperature of $25^{\circ} 6^{\prime}$.

As seu-water is not easily penetrated by the rays of the sun, it keeps pretty nearly at the temperature of the locality where it has been detained for any 
length of time. Thus the play of the polar waters makes itself known to the mariner by a fall in the temperature of the sea, and the equatorial currents carry with them into the arctic zones a warm and grateful reminiscence of the sunny climes from which they have descended.

In general, the density of a current is in inverse propurtion to its degree of heat, and accordingly, overlying currents show a decreasing temperature according to their depth. But in the polar seas this is not so. The temperature there increases with the depth, within certain limits, and thus assists in fusing the lower part of the ice. To account for this anomaly, snow and ice are bad conductors of heat. Farmers and gardeners are well acquainted with the fact that a covering of snow keeps the earth warm in winter. The effect of ice in the arctic regions is similar. It has been proved by thermometric observations that, at a surface temperature of $52^{\circ}$ below zero (Fahr.), the water under a bed of ice thirty-two feet thick remained relatively hot, its temperature not having descended below $28^{\circ} 4^{\prime} \mathrm{Fahr}$.

Thus sea-water is hottest near the surface in the neighbourhood of the equator, while in the arctic regions it is hottest at a certain depth, and coldest in its upper stratum. The temperature of the sea-bottom is, however, uniform over all the world, and differ: 
little from $32^{\circ}$ Fahr., or five degrees above its freezingpoint.

In the case of landlocked seas there is not this great difference between the temperature of the surface and of the lower strata. The Mediterranean, for example, receives the surface-waters of the ocean throngh the Straits of Gibraltar, whilst its deeper waters flow outwards.* Consequently, it is the heated water of the ocean which penetrates into this interior sea; and the action of the sun being upon a closed basin, so to speak, and by far more constant than upon the ocean, which is traversed by the polar waters rushing in a mighty torrent to sun themselves in the torrid zone, the bottom of the Mediterranean cannot possibly be so cold as the bottom of the ocean itself. 'The lied Sea presents the same phenomena, in this respect, as the Mediterranean. 'The currents of Babelmandeb are analagous to those of Gibraltar. The Red Sea is one of the hottest expanses of water on the globe. Life pulsates in every corner and recess of it, and

* A very curious incident first suggested the existence of a submarine current in the Straits of Gibraltur. A corsair brig sunk in sight of Ceuta, and disappeared. At this point the current runs very strun and, of course, from west to east. What then was the surprise of everybody to see the brig reappear somo time afterwards many leagnes westward of the point whore she had sunk! It is plain that the resscl must have been drifted to that puint by a submarine current runuing in the contrary direction to the current on h.essuriaro 
there the polypi erect their most gigantic ramparts of stone.

If we were to sink a well on the shore to the depth of 12,000 feet, the temperature at its bottom would be about $300^{\circ} \mathrm{Fahr}$. Yet we have just seen that the temperature at the bottom of the sea is nearly constant at $32^{\circ}$. This fact is sufficient to prove that the water of the ocean exercises an immense influence on the distribution of temperature over the surface of the earth.

The Ocean is in turn affected by heat, even to its lowest abysses. Inequalities of temperature and of saltness give birth to currents both on its surface and in its depths. The former, however, are more generally due to the action of the constant winds. By-and-by we shall have to consider the action exercised by currents upon their bed.

8. Cause of Waves-Therr Height-Thickness of the Mass of Water in motion-Ground-swells-"Ruz de MIurée"-Waves of Translation-Measure of a Wave of Trumslation, and of its Specd, in the Pacific Ocean-Tides-Résumé.

When winds have not the constancy of the Trades, they force the surface of the sea into heaps, and plough it in furrows more or less deep: in a word, they cause waves. This movement of the water does not extend to any considerable depth. 
The highest wave observed by M. de Tessan, during the voyage of the Venus, measured about 24 feet from its crest to the bottom of its cavity. The greatest height admitted by Humboldt, and at a distanco from any coast, is 37 feet. As to the mass of water set in motion, observations were made by M. Siau, in St. Paul's Bay, Isle of Bourbon, which seem to show that it does not exceed a thickness of 600 feet. But the height of the wave is supposed to furnish a clue to the depth of the agitation it causes. Weber concluded, from his eelebrated experiments, that every wave propagates its motion to a depth of about 350 times its own height. If so, a wave only 6 feet in height would stir the North Sea to its lowest abysses, while a wave 30 feet high would make itself felt to a depth of 10,000 feet. However this may be, we know that the movement becomes very feeble even at a slight. depth, and it must soon become altogether insensible, even if it continues to extend itself, because Weber himself has demonstrated that it decreases in geometrical proportion according to the depth.

So long as a wave extends its motion downwards in a deep place, it produces no effect on the soil. Let it, however, wash against a bank or a shore, and it begins to play a part well worthy of observation. Sometimes, in combination with lccal currents, it produces very curious phenomena. For example, 
near Callao, the port of Lima, a considerable dike of rolled stones parallel to the shore has been thrown up. Its height in some parts is nearly 20 feet. On the landward side it is steepest, and on the other descends towards the sea with a gentle slope; the rolled stones of which it is composed are spherical or oval in shape. To account for its existence, there is, at some distance off, between Callao and Moro-Solar, a cliff, which measures some 140 feet in height. Its base is incessantly battered and eaten away by the waves, and the débris is carried away northward by the current. In this remarkable instance the current transports the materials of which the dike is constructed, and the waves build them up.

Where a marine current passes over a level bottom and comes to a gentle slope, its speed is a little accelerated by reason of the confinement of its bed; but this increased speed is lost again when the obstacle has been passed. The case is different if the bottom of the sea, instead of becoming gradually higher, rises abruptly. A wave is then produced, which propagates itself under the water, and causes what is known as a ground-swell. This wave augments as it approaches the shore, and, advancing rapidly, breaks in a mass of foam which escapes from beneath the liquid bulk. If the shore be steep, it hurls itself against it, and throws an immense head of foam 
to a great height. There is a rock in the Marianne Isles known as "Lot's Wife," which stands 350 feet above its base, yet the foam is thrown to its summit.

Mr. Scott Russell has testified from experience, that an abrupt rise in the bottom of the sea (under the circumstances alluded to above) causes an elevation of the water over that particular spot. The rise of the water is as abrupt as that of the sea-bottom, and a ship passing over it experiences a shock so violent as to induce the belief that it has struck on a rock. This fact is familiar to observers accustomed to cross the sea, and there can be no mistake as to the occasional violence of the shock, when we recall that a whaler was dismasted by this cause on the coast of Chili, in 1837.

Sometimes, particularly in the neighbourhood of the Antilles, a tumultuous movement of the sea is produced near the coast, whilst everywhere else within the field of immediate observation there is a perfect calm. 'This phenomenon is always connected either' with a volcanic eruption, or an earthquake, or the passage of a cyclone at some distance. An experience related by Dr. Rooke as having occurred to him at the Sandwich Islands is a striking example of the Raz de Marée (Race of the Tide) caused by an earthquake and a volcanic eruption. His account of the phenomenon is substantially as follows:- 
On the 7 th of November, 1837, during fine weather, and in the absence of any perceptible shock of earthquake, the sea was all at once moved in an extraordinary manner. First, it retired so great a distance from the shore as to leave the reef which surrounds the island (Maui) dry. The inhabitants, fearing no harm, collected on the reef to gather up the fish which the sea had left on retiring, and were merrily engaged in this occupation when, after some moments of repose, the sea suddenly returned with extreme rapidity, and, advancing like a wall, engulfed every living being. The phenomenon was not everywhere accompanied by events so tragic. Even at Honolulu, where Dr. Rooke himself observed it, the movement of the sea was not nearly so considerable: nevertheless, all the time that it lasted the mean level of the sea was everywhere about five feet lower than ordinary. The conclusion is that the island itself was lifted, bodily, five feet above the position it habitually occupied, and to which it returned.

While the sea, and as we suppose the land, were thus strangely moved, the volcano of Mauna-Kea, in the island of Maui, gave manifest signs of increased activity. At this very time also the inhabitants of Acapulco, situated to the east under the same parallel, were kept in perpetual fear by undulating movements of the earth, which came from the direction of the west. 


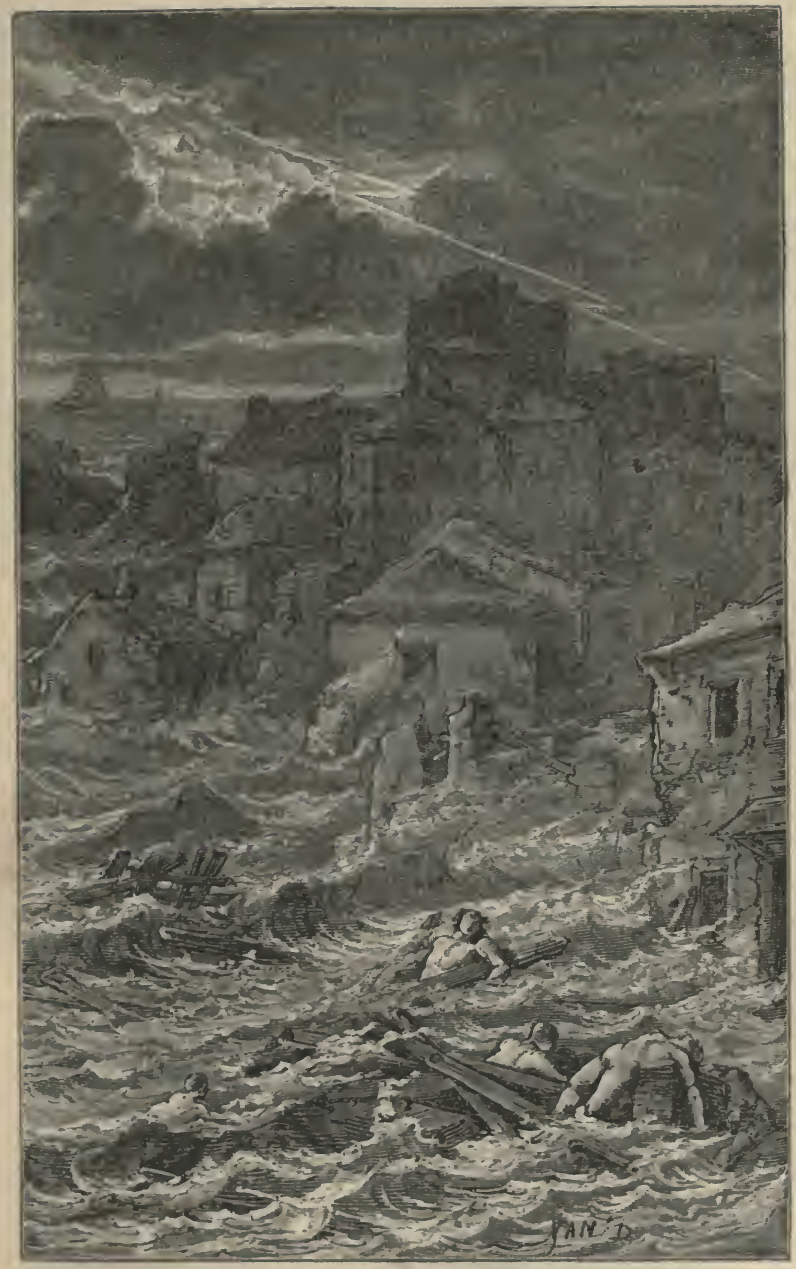

Fig. 16. - Rising of the Sea at Acapulco. 

Earthquakes are always accompanied, on the coasts, by movements of the sea more or less considerable, and it is this part of the phenomenon which has eaused the greatest disasters. To the movement of the sea, again, is added a temporary or permanent change of its level.

During the earthquake of 1820 the level of the sea at Acapulco remained during two hours at about 30 feet below the points of the coast which corresponded with its ordinary level. A part of the roadstead was lelt dry. After two hours the sea returned, and rose from four to five yards above its ordinary level-that is to say, from 40 to 45 feet above the point to which it had receded: it then oscillated about its ordinary position, and finally resumed its old relative level. There can be no doubt that the soil of Acapulco was itself raised during this two hours to the height mentioned, and afterwards settled down again as described. The effect of the razde marée was terrible. The sea, resuming possession of its bed, advanced upon the land like a wall with extreme rapidity; and then, overleaping its ancient limits by the impetus of its return, overthrew whatever opposed its progress, and destroyed a part of the eity.

Similar movements of the sea accompanied the earthquake which destroyed 'I'alcaguana, on the coast 
of Chili; only in this case the soil remained elevated sorne five or six feet above its former position. After the earthquake which destroyed Old Callao, on the contrary, the soil was found to be permanently lowered some four or five feet. The effect of the raz de marée was similar to the preceding.

It is obvious that earthquakes which extend under the ocean must stir the waters to their most profound depths. They give rise to a phenomenon which has been named by Mr. Scott Russell the "Wave of Translation." He has demonstrated that the movement of the water is as great at the bottom of the sea as at its surface-a fact that has been verified by the transport of objects that were lying at the bottom. Further, the wave advances by forming a swelling on the surface without breaking like other waves, and its speed of propagation is proportional to the square root of the depth. If its course be obstructed by an abrupt elevation of the sea-bottom, its effects will be exaggerated and complicated with those of the ground-swell. As it reaches the shore it produces the raz de marée.

Lisbon was destroyed on the 1st of November, 1755 , by the most violent and most extended earthquake on record. The shock was felt on the same day over the North Atlantic Ocean; between Spain, the Antilles, and Newfoundland; in Canada · in Great 
Britain; on the coasts of Sireden and the shores of the Baltic; in Germany, Switzerland, Italy; and in the North of Africa. It was accompanied by a huge wave of translation, that swept the coasts of Spain, and attained, at Cadiz, a height of 60 feet. It inun-. dated the ports of Madeira. A vast bulk of water rushed violently into the marketplace of a city in Ireland (Kinsale). The sea rose and fell at Tangier; and, though the soil was not deranged, an extraordinary morement was perceptible in England, both in the waters of the interior and on the seacoasts.

On the 23rd of December, 1854, at a quarter before 10 in the morning, the Russian frigate Dianu felt several shocks at the entrance of the Bay of Simoda, in Japan. At 10 o'clock a huge wave overwhelmed the city. A second wave immediately followed the first, and when it retired every house was found to be thrown down. The frigate, after striking several times, foundered on the shore. Some hours later, at a distance of nearly 5,000 miles, waves of an unusual height broke upon the shores of California. During the intermediate time the same phenomenon had been observed in the islands of the Pacific: thus, in a few hours, the waves had traversed the Great Ocean. By comparing the various observations, it was ascertained that the breadth of each wave was about 250 miles, and its velocity about 440 
miles an hour. The mean depth of the ocean between Japan and California is from 12,000 to 13,000 feet.

Again, as the tides are movements produced in the great mass of the waters, they are likely to cause certain effects on the bottorns of seas which it would be useful to ascertain. But that action takes place near the surface, and is difficult to distinguish from the effects of the waves.

All the causes of the agitation of the sea are exterior to it. However far their influence extends, we may yet conceive that a limit exists beyond which it ceases to produce itself. The "waves of translation" alone heave up the ocean from its lowest depths; but this phenomenon only takes place in connection with earthquakes, and is, happily, of rare and but momentary occurrence.

Marine currents extend to a great depth; they sweep through the ocean one above another, and it has been proved, by the soundings made during the lust few years, that their effects extend, we may almost say, to the lowest deeps. It has been ascertained that in certain regions they are sensible at irum 10,000 to 12,000 feet from the surface. It is certain, however, that their course is less violent in proportion to their depth; and in the deepest recesses of the ocean, if any movement could be supposed to 
exist, it would be insensible. There is a region, of which we cannot define the limits, which enjoys a perfect calm, and if any displacement occurs it is that which results from slow and imperceptible molecular motion. The temperature of that region is very nearly the same over all parts of the globe, and its :altness is considerable. There also reigns the most profound obscurity ; and life, ronstrained in its levelopment by the absence of light, the insufficient supply of oxygen, and the great quantity of carbonic acid contained in the water, ceases at last altogether, probably as it does in the aërial atmosphere at a height exceeding 26,000 feet. 'The study of that calm and perhaps lifeless region is not, however, uninteresting. By means of soundings we are able to ascertain, in some measure, what is passing there; and if we avail ourselves of these facts, aided by the science of the geologist, it will not be difficult to infer from them some curious details concerning the history of the globe. 


\section{DEPOSITS IN COURSE OF FORMATION AT THE BOTTOMS OF SEAS.}

1. Universality of the process of Sedimentation-General view of the Mechanism of this Phenomenon.

From the solid rock to the smallest particle of slime, from the monstrous whale to the microscropic infusoriæ, from the algæ and the polypus to the towering denizen of the forest and the bird which hovers high above it in the air, the Geogenic Basin (a term which will be presently explained) absorbs all. The work of sedimentation is universal.

In order the better to comprehend this phenomenon we will follow it through some of its various phases. The rock which forms the culminatingpoint of the highest mountains flies into splinters when subjected, as in winter, to sudden changes of temperature; or, if not, it yields slowly to the constant action of atmospheric agencies, and, broken up by continually increasing fissures, rolls its débris into the bed of a torrent. The troubled water breaks furiously against the obstruction, and grinds. 
the fragments to pieces one against another. On reaching the plains, these broken and partiallyrounded pieces are washed into the comparatively quiet eurrent of a river, and in course of time, by the constant motion of the water and the attrition eaused by it, assume the character of pebbles. Tho river slowly carries the pebbles towards the sea, and all the time their size is diminishing. Instead of pebbles they become gravel; the particles of gravel, still diminishing in size, become sand; and the sand -more especially if the river be of any considerable width-tends to choke its bed. The remedial action of the river is to carry the sand, and the broken earth washed from its banks, down to the sea, where it deposits them, at a distance more or less great from its embouchure, according to the weight or tenuity of the particles and the strength of the current. Finally, the smaller stones are thrown upon the shore, the sancls are deposited farther off in the sea, and the light mud is carried away and slowly deposited at a still greater distance. The muddy water of the Amazon is distinguishable at sea nearly a hundred miles from the emboucliure of the river.

The rocks of the seashore also yield their tribute to the bottom of the sea, and assist very materially to fill up the deeper abysses, the slow and continual 
rising of which must seriously modify the aspect of our globe. Stormed without ceasing by the waves, the most iron-bound coast must gradually give way, but with results which vary according to the nature and formation of the coast-line.

The heavier débris is naturally disposed to continue its descent till it reaches the greatest depths. The action of gravitation is, in this respect, favoured by the action of the currents. We have explained in a previous chapter that the crust of the globe is, so to speak, ploughed up in furrows, the sides of which combine to form basins or cavities which are separated from each other by ridges of rock more or less sharply set. In geographical science these furrows are, one and all, regarded as the basins of rivers. The waters flowing in them naturally tend to the lower parts, and in those lower parts they combine to form perhaps a single current. This current flows down to a still lower level-that of the sea. Nor even here does the conformation lose its character of a furrow or basin. We follow it under the sea until we have descended so deep that we seem to have reached a central point from which it is impossible to advance in any direction without reascending. Using this lowest point as a centre, we draw a line around it at a greater or less distance, and that line indicates the circumference of what we have 
called a geogenic basin, to distinguish it from a geographic basin.

Thus, the basins of the Rhone, the Ebro, the Arno, the Tiber, and several other rivers, all combine to form one vast geogenic basin. The 'lyrrhenian Sea is one of the divisions of this great basin, the Gulf of Lyons is another, that of Genva a third.

2. Action of Waves upon the Coasts-Destruction of Ruck-bound Shores by the Sea-Pierced Rocks-Silting-up of Shallow Waters by Marine Alluvium.

In the case of a steep shore the erosive action of the sea is considerable. It beats against the rocky barrier with all its force. The base of the cliff, incessantly attacked by the waves, is of course eaten away with a rapidity proportioned to the ease with which the matter of the rock can be disintegrated. The upper part of the cliff, though not subjected to the direct action of the waves, falls forward, and occasionally forms deep rocky caverns such as we see at Bonifacio. At length the superincumbent and tottering mass falls into the sea. If the depth be great, or the current strong, the accumuluted debris is swept away, and the action of the waves against the broken cliff is continued with undiminished intensity. In this manuer entire promontories have been destroyed; even within the historio period, the 
Straits of Gibraltar have been enlarged by this process. If, on the other hand, the depth be slight at the base of the cliff, the force of the waves is broken by the opposing rampart of fallen stones, the shore is preserved from destruction, and it is only at some

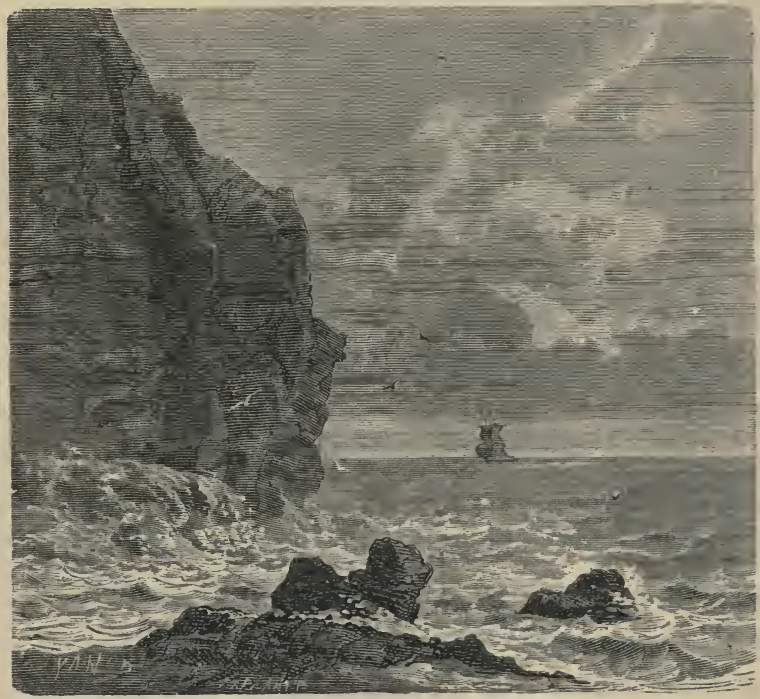

Fig. 17-Waves breaking against a Rock-bound Coast.

distance from the self-formed talus that the rolled stones are, in the course of ages, carried away by the currents of the ocean.

The foot of the cliff marks the level of the sea. If this level be changed from any cause, the cliff will 
be formed anew in accordance with it. In seas of little extent, such as the Mediterranean or Caspian, and at those points of the ocean where the tidal elevation is but small, the cliff will consist of but one simple escarpment. When, however, the difference between the level of high and low water is considerable, as in the English Channel and other narrow pissages, there will be found a second cliff corresponding with the level of low-water.

Many marine caverus have been formed by the erosive action of the sea upon massive beds of basalt. This rock is the product of ancient volcanic eruptions, the volcanic matter having separated itself into prismatic columns in the process of cooling. The sea, by its reiterated assaults through a long lapse of time, causes the lower beds of basalt, which are the most exposed to the fury of the waves, to yield first. Thus are formed caves, or sometimes extended galleries and halls, of which the Cave of Fingal is a beautiful example.

The erosive action of waves is slower when the rock is in horizontal beds. In such cases the water rolls over the inclined surface until its course is arrested, and in its return it breaks the force of the next approaching wave.

A striking effect of the erosive action of the sea is shown in the phenomenon, so frequently met with, of 
pierced rocks. Sometimes they are found isolated in mid-ocean; sometimes they are united to the land, or ouly separated by narrow, and perhaps tortuous, channels. Let us hear what M. de Tessan has to say, in the work already quoted, of the manner in which waves act upon such rocks:-

“Lat. $25^{\circ} 0.9^{\prime} \mathrm{N}$.; long. $120^{\circ} 76^{\prime} \mathrm{W}$.-We have passed very near the Alijos Rocks, which are still marked as doubtful in some charts. The highest of them rises about 150 feet above the sea. It is pierced through in the direction from south-east to north-west. This phenomenon of pierced rocks occurs most often when the rocks are composed of superimposed beds, of no great thickness, and not well compacted one with another. It is to be explained by the action of the billows; in fact, their most destructive effect is produced upon the perpendicular face of the rock, about the middle of its elevation, and in the direction in which the waves strike against it. The rock of course has a tendency to crumble away at that point more than elsewhere, and if its composition be such that it cannot resist the incessant shock of the waves, an excavation necessarily results. The hollow, once formed, becomes itself the cause of an increased destructive effect on the action of the waves. Gliding along the sides of the excavation, they strike with re- 


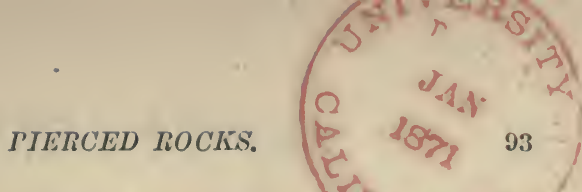

doubled speed upon its bottom, where the former débris of the rock, dashed about with immense force, helps also to break up the rock and make fresh debris. In this way the depth of the excavation increases, its sides are enlarged, and at last daylight

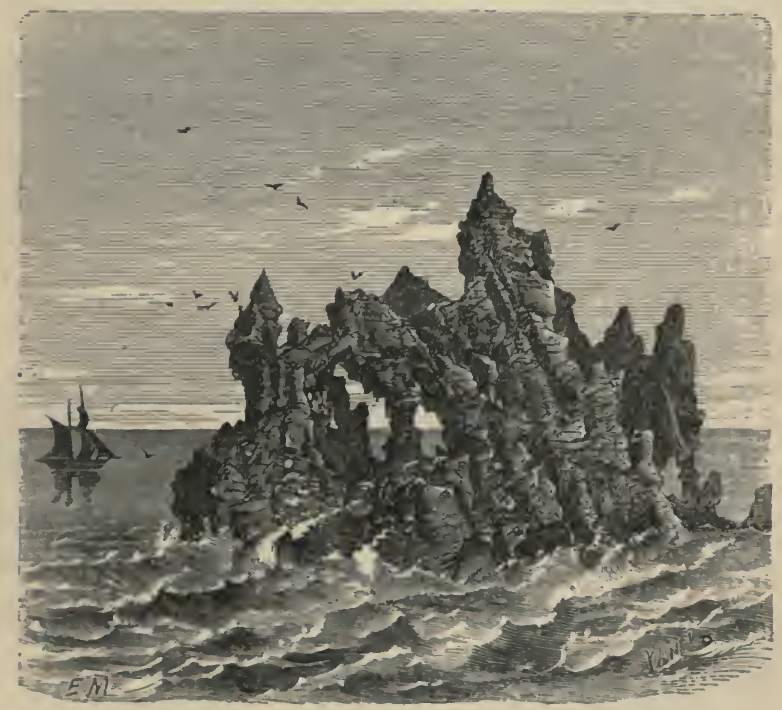

Fig. 18. - Rocks worn through by the Waves.

is let in from the other side. To produce this result, however, the rock must not be too thick, because there is obviously a limit in the depth of the excaration at which the wave loses its force." 
If the sea struggles victoriously against the land when the latter opposes to it some formidable obstacle, its efforts fail, its force, so to speak, expires when there is no such resistance. It batters down the rock-bound shore with resistless force; it flows harmlessly over low and sandy flats. Further, the débris of the stubborn rock serves to strengthen the shifting sands, and to renew the dunes which the winds scatter in light clouds of dust. The tidal wave spreads out over the level shore, until it has lost all its speed, and when it retires it leaves behind it on the sands all the materials which it had pushed before it as it came in from the sea.

3. Deposits in Mid-ocean, and Deposits on the Coasts-Importance to Geologists of Cuast Deposits as data for fixing the limits of Ancient Seas-Deposits of the French Seas.

It is only from a large number of skilful soundings that we have been able to ascertain the character of submarine deposits. Soundings at great depths generally indicate the presence of the débris of rocks in a state of minute subdivision. To take a single example: at a point seventy leagues south of the Aleutian Isles, and at a depth of 9000 feet, we detect the presence of fine sand and mud.

The deeper parts of the ocean occur at too great a distance from the coasts for the larger and heavier 
Eubstances to be carried down into those profound gulfs by the marine currents. If the remains of animals and plants fall directly from the surface into such depths, they preserve their forms, however delicate, because the calm which reigns in these still, mysterious regions allows them to rest undisturbed for an indefinite period in the spot they first touch. Thus the accumulation of materials is a slow and gentle process. They repose quietly in horizontal and homogeneous beds, and, as a consequence, produce compact and finely-grained rocks.

On the coasts, and in those parts of the sea which are of slight depth, we generally find stones and bodies too large to be carried away by the currents. The materials thus accumulated are subjected to the continual action of the water. They lose their angles, and become rounded or oval in form. They are incessantly worn away and incessantly renewed. The result is that coast deposits have neither the same regularity nor the same consistency as those of the deeper seas. They do not exhibit, like the latter, a compact structure, nor do the substances which conpose them display sharp angles and well-preserved forms.

The action of the waves extends to an inconsidergble depth from the surface, especially in all ordinary times when there is no extreme agitation. The 
littoral deposits are, therefore, of comparatively slight amount when regarded as to their quantity merely, but theoretically they are of the greatest inuportance. An exact knowledge of their character often enables the physicist to determine the oscillations of the sea, how it has retired from the land or encroached upon it, and consequently to what extent the terrestrial crust has been affected. The following details are borrowed from a work presented to the French Institute, some two years ago, by M. Delesse, and which may be described as a complete study of the deposits which are being formed in our time upon the coasts of France, and of the relations they bear to currents and marine animals, but more particularly to the nature of the rocks which form the shore.

This littoral deposit presents a mineralogic crmposition of considerable variety at a level corresponding to that of high-tide, because it includes the débris of the neighbouring cliffs. At the level of low tide, on the shores of the Ocean, it is much more uniform, and even exhibits a constant character to a great extent. Where we find this to be the case, we may be sure that, whatever be the character of the rocks which concur to form the deposit, the sea is not slow to destroy them. The minerals we discover are those which offer considerable resistance to 
the action of the sea, owing to their hardness or tho unalterable nature of their composition.

The most common of all minerals in the littoral deposit of France, at the level of low-tide, is transparent quartz. It is distributed in such profusion that the deposit is sometimes almost entirely composed of it. This is to be accounted for by its extreme hardness and its abundance in the cliffs.

The clays are found in the deposit at the bottom of gulfs and retired creeks; they are carried away in the form of mud, and settle down when the sea is calm and deep. In some cases where beds of clay or schist abound on a coast (as at Honfleur), the proportion of clay contained in the littoral deposit is very great.

Carbonate of lime or chalk is found in very variable proportions, and is derived from calcareous rocks and the remains of molluscs. In the Mediterranean it is most abundant when the cliffs are composed of calcareous rock, as at Nice and Marseilles. Its fragments are always well-rounded. On the shores of the Ocean, the littoral deposit of lime is small, because the movement caused by the tides dissolves and disposes of it very rapidly even when it is strong or compact. An instance of this may be observed between Havre and Dunkirk, or, better still, at the foot of the Lower Pyrenees. It may even happen 
that the deposit formed on a chalky shore does not contain a trace of calcareous débris. On the Atlantic coasts of France the carbonate of lime found in the littoral deposit comes almost entirely from the shells of molluses of the existing period. It is composed of angular or slightly-rounded fragments, and it resists destruction much better than the most compact limestone. On the other hand, we may see a coast without limestone, like that of Brittany, present nevertheless a rich littoral deposit of carbonate of lime, exclusively derived from the débris of shells.

As we proceed to a distance from the shore, the depth of the water increases, and the marine deposit changes its physical and chemical properties. 'Thus, the proportion of carbonate of lime grows larger, and its particles at the same time diminish in size. On the whole, these researches demonstrate that the littoral deposit varies in its character with the hydrographic basin to which it appertains, and with the coasts, above and below the water, upon which it is formed; in the Ocean, on the contrary, it remains pretty constantly the same over a vast extent of suriace.*

* Delesse: Recherches sur le dépôt littoral de la France (Comptess Rendus de l'Institut de France, Number for January 2S, 1867, pp. 165 et seq.) 
4. Transport and Deposit of Rocks by Floating Ice.

When fragments of rock are transported by the water, it carries the smaller and lighter sand to a greater distance than the heavier, this again to a greater distance than stones or pebbles, and these latter, of course, much farther than great blocks of stone. These materials of the earth's crust find also a powerful and majestic means of transport in floating ice; but it carries its load without discrimination, and deposits fragments of all sizes and of every description that may chance to be imbedded in its mass. During winter we see our rivers covered with a sheet of ice: the spring returns, the frozen surface is melted, and masses of ice float seaward in disordered heaps. This phenomenon constitutes an annual break-up. Where the water touches the shore stones and earth become imbedded in its solidified mass. If the river be completely frozen in its whole depth (which happens sometimes in northern countries), its bed as well as its shores will load the ice with debris, which is thus transported to a distance.

This phenomenon, which we witness once a year, is produced on a grand scale in the polar seas. On those inhospitable shores the rivers of ice; called glaciers, glide down from mountain heights into the sea, and carry on their surface, as well as in their 
interior, massive fragments of rock, gravel, and dirt. Sometimes a mass is detached from the glacier, and, floating away into the open sea, is impelled by the marine currents and the winds towards the equator. On the passage, the shock of one such mass striking against another, the action of the waves, and the melting of the surface of the ice, destroy the mass,

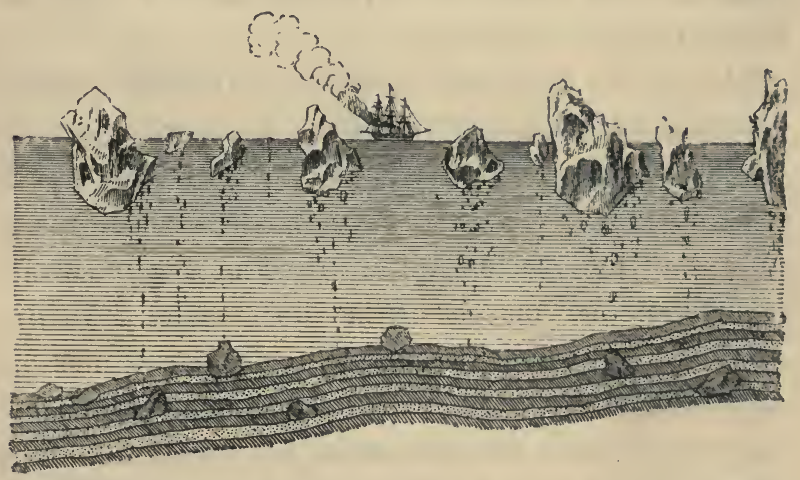

Fig. 19. - Section of the Sea and the Sea-bottom in the Track of Jcehergs between Greenland and Newfoundland.

and the débris which it carries drops from time to time to the bottom of the water. In this manner, icebergs perform their part in the work of sedimentation

The deposits formed by icebergs attain in course of time to a great thickness The Bank of Newfoundland appears to have been formed in this way. 
Every year the cold currents flowing from Baffin's Bay (which in strictness should be called a sea) visit Newfoundland with their imposing freight of icefields and frozen mountains. On approaching that island they enccunter the Gulf Stream, and the frozen masses gradually disappear, being eaten away by the waters, the heat of which undermines them. The earth and fragments of rock which they carry fall to the bottom of the sea.

Every year the warmer current of the Gulf Stream arrests these masses of ice at the same point of their track, and eauses them to break up and disappear. A simple current of water opposes to them an impassable barrier. The debris accumulates year after year in the neighbourhood of Newfoundland without ever entering into the Mexican current. What ages must it have required for this submarine deposit to have filled up an abyss to a height of from 20,000 to 30,000 feet!

Thus the influence of the polar ice-fields is so great as to modify, in course of time, the form of the earth's surface. This too occurs over a large extent of the globe, seeing that the ice in the northern hemisphere actually attains to the 40th degree of latitude, and in the southern hemssphere to the 30 th degree. 
5. Water-springs in the Earth-Funnels or Wells of the JuraThe Aveui of the South of France-Katavotron-SinkholesGeysers-Submarine Springs-Origin of Oolitic Formations.

$\mathrm{W}^{\gamma}$ ater spread on the earth penetrates to a certain distance below the surface. It sinks through sandy places, cultivated lands of all kinds, and even through the hardest rocks. Fissures are produced in the latter by the influence of temperature, and by these little channels the water descends into the interior of the earth's crust. Limestones favour a cavernous structure, and conceal gulfs or pits which are known by different names in different countries. These are the Funnels or Wells of the Jura, the Sinkholes of America, the Katavotron of Greece, and the Aveü of the South of France. Such gulfs may sometimes be found in the course of rivers. In a word, by whatever means of absorption, the water finds its way into the terrestrial crust, and that to a very considerable extent. After an interval, more or less prolonged, it returns to the surface. Springs, fountains, artesian-wells, geysers, are thus originated. Geysers are intermittent springs of boiling water, observed for the first time in Iceland, where the phenomenon is attended by remarkable circumstances.*

The return of the water to the surface takes place

* See "Iceland: its Scenes and Sagas," by S. Baring-Gould. 
under the sea no less than on continents, as proved by numerous observations of submarine springs of fresh-water. Many such have been remarked on the Mediterranean littoral. According to M. de Villeneuve-Flayose, those which we find between Perpig-. nan and Spezzia, at a distance more or less great from

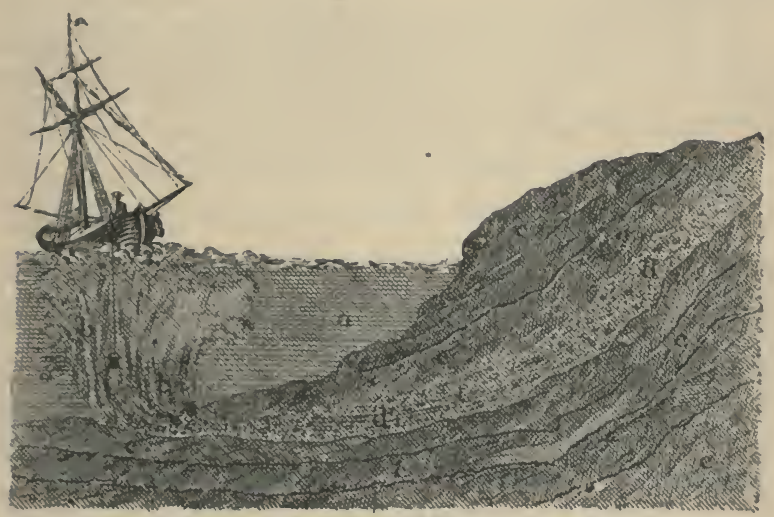

Fig. 20. - Cause of Submarine Springs: (aa) Sea Water; $(b b)$ Fresh Water; $(c c)$ Impermenble Stratil, $(d d)$ a Permeable Stratum in which the Fresh Water flows.

the shore, deliver some 50 cubic métres every second, which is about one-third of the quantity of water delivered by the Seine in the same time.

In the Gulf of Spezzia, at the distance of 60 or 70 yards from the shore, we see a kind of swelling in the sea it extends over a space about 80 fect 
in diameter, and is something less than six inches in height. When the sea is calm it is easy to see vertical jets of water springing from the bottom. This water is found to be fresh, and it comes from a submarine spring. Its superior lightness causes it to reach the surface of the sea before the salt-water has time to affect it.

At some distance from the embouchure of the Galaso, in the Gulf of 'Tarentum, there springs from the bottom of the sea a jet of fresh-water so powerful that it can be procured without mixture with the saltwater. A similar jet exists in the famous salt-pool. of Thau, near Cette (on the Mediterranean coast of France); here the fresh-water rises so rapidly that it produces waves.

What may be called a true subterranean river debouches under the sea near Ragusa. 'There are sweetwater springs in the ports of Cattaro and Aulona, near the embouchure of the Acheron, in the midst of the sea; over a space of 40 feet in diameter fresh-water is thrown up abundantly with great force. 'This is probably the same spring of which Pausanias speaks.

A stream of fresh-water springs from the bottom of the sea near Tortosa, on the coast of Syria. Its force is so great that the sweet water can be taken without mixture with the salt. Pliny speaks of a similar phenomenon near Arcadus. 
The Gulf of Argos supplies an example of a very abundant source of fresh-water named Anavolco, and situatel between Kiveri and Astros. Ancient writers affirm, though this may be a little uncertain, that it has been in activity some 1700 years. Colonel Leake, a traveller remarkable for his minute observa. tion, informs us that the column of fresh-water appears to be not less than 50 feet in diameter. When the atmosphere was calm he observed that the water rose with such force from the bottom of the sea as to swell the surface, and argitate it in concentric circles to a distance of some hundreds of feet. $\mathrm{He}$ attributed this to the embouchure of a subterranean river at the bottom of the sea.

This phenomenon may, in a certain measure, be compared with that of artesian-wells, now so familiar to us. The water firds its way into the earth by filtration through certain permeable strata. These are so enclosed by beds of clay, or other matters not permeable, that they form conduits which accidentally terminate beneath the sea. The fresh-water running in these natural conduits is lighter than salt-water. If it exists in sufficient quantity to prevent its being mixed completely with the latter, it rises to the surface on the same principle that oil floats on the surface of ordinary water.

It is not surprising, therefore, that we shonld find 
in all seas submarine springs of fresh-water. Humboldt observed one, two or three leagues southward from Cuba, rising with such force that the smaller craft could not approach without risk. Ships supply themselves with this water, and find it sweeter than water taken from other places of greater depth.

Water that has been in the earth holds in solution a certain amount of salts, proportioned to the time it has been detained underground, and to the depth and consequently increased temperature it may have attained. On returning to the surface, whether it be on the land or beneath the sea, it makes some slight deposit of the salt it holds in solution. Of course the quantity is not greater than is usually to be tound in what is called fresh-water, yet the deposit, accumulated:through a long period of time, assists in the work of sedimentation, and thus modifies the bottom of the sea. To express by one word the character in common of all the deposits thus formed, they may be called "Geyserian." This appellation has been given to them by M. Alexandre Vézian, from the phenomenon which may be considered typical.

Springs charged with stony matter, that is to say, petrifying springs, are the cause of deposits after their kind, but differing considerably according as the water in which they rise is calm or troubled. In the first case, the deposit is made tranquilly, and the 
result is a compact and bomogeneous rock. When, however, the water thus charged rises from a slight depth, or at a point where it is subjected to the influence of marine currents, the matters already deposited are so tossed about that they present all their surfaces to the petrifying action. The incrustation thus caused deposits itself all around them in concentric layers; and their final combination, or massing together, causes them to resemble a heap of little eggs. The aggregation of all these oolitic particles by the incrusting matter does not completely deprive the deposit so formed of its primitive character, and it is accordingly named oolite (or stone formed of eggs). The structure of this kind of rock has been called by geologists, Oolitic.

The submarine deposits resulting from Geyserian action are of much less importance than those which are due to mechanical sedimentation. The physical forces play only a special part in their production. The life of the globe is the cause of numerous modifications in the aspect of the submarine soil, and in the nature of the deposits which accumulate at the bottom of the Ocean. Independently of the remains of terrestrial animals and plants which are borne into the sea, and swept through its deptlis by marine currents, or rolled by the waves, innumerable creatures live in the sea itself, and enrich it with 
their spoils. A rapid study of these beings is indispensable to whomsoever would form an accurate idea of the submerged portion of the earth's crust, and of the phenomena which are produced on that wonderin] stage of animate and inanimate existence. 
SUBMARINE LIFE.

1 lixuberamee of Life in the Deptlis of the Ocean-Tableau of the 'Trupical Seas-Life in the Seas of the Temperate and tho Frozen Zunes-Natural Illumination of the Oceanic Abyssos.

Shall we say the play of life is pleasing to the Deity? Everywhere we see, or we sensate, that great and incomprehensible manifestation of His omnipctence. Myriads of animals and plants people the earth and the air with forms of grace and beanty; but in no part does the creative power reveal itself with more of grandeur and magnificence than in the abysses of Ocean. There, in fact, may be discovered the principles of all life. In the inspired account of the creation we are told that " in the beginning" the Spirit of God " moved upon the face of the waters." The surface of the sea is less varied than that of the dry land; but look deep into its bosom, and no region of the earth could give so vivid an idea of the exuberance of life. Forms the most unexpected, a fecundity the most marvellous, challenge our admiration at every step we take through these wonderful regions. Here, to all appearance, is a plant, a miniature tree growing upon a rock; its branches ars 
verdureless, but, "trange to say, flowers of the must brilliant colours spring from their extremities. The petals have the po:ver of motion, and by this motion they cause a mii:iature current to flow unceasingly towards them. T'nhappy are the animalculre who may be drawn into this perpetually renewed stream, for it flows into the mouths of the zoantharia, or animal-flower to which they serve for food!

See!-there are two eyes sparkling in the sandy bottom. A living form, which escaped our observation before, detaches itself, as if a leaf rose, undulating in the water, after having stirred up around it a cloud of sand or other earthy particles. That living form is a turbot or a sole. At the least hint of danger it will retreat to the bottom, and, disposing itself flat upon the sand or mud, become almost invisible. This ruse is the only meauz of defence possessed by these creatures, and almost any other fish is bold enough to make them its prey. It is worth noting that one side of the body is white, the other (on which the eyes are placed) is greenish-brown, resembling the bottom of the sea.

And that bundle of serpents in violent agitation at the entrance of an ocean-cavern! How they twine and writhe as they seize upon the living prey which an evil destiny draws into their neiglibourhood! Suddenly they launch themselves precipitately out 


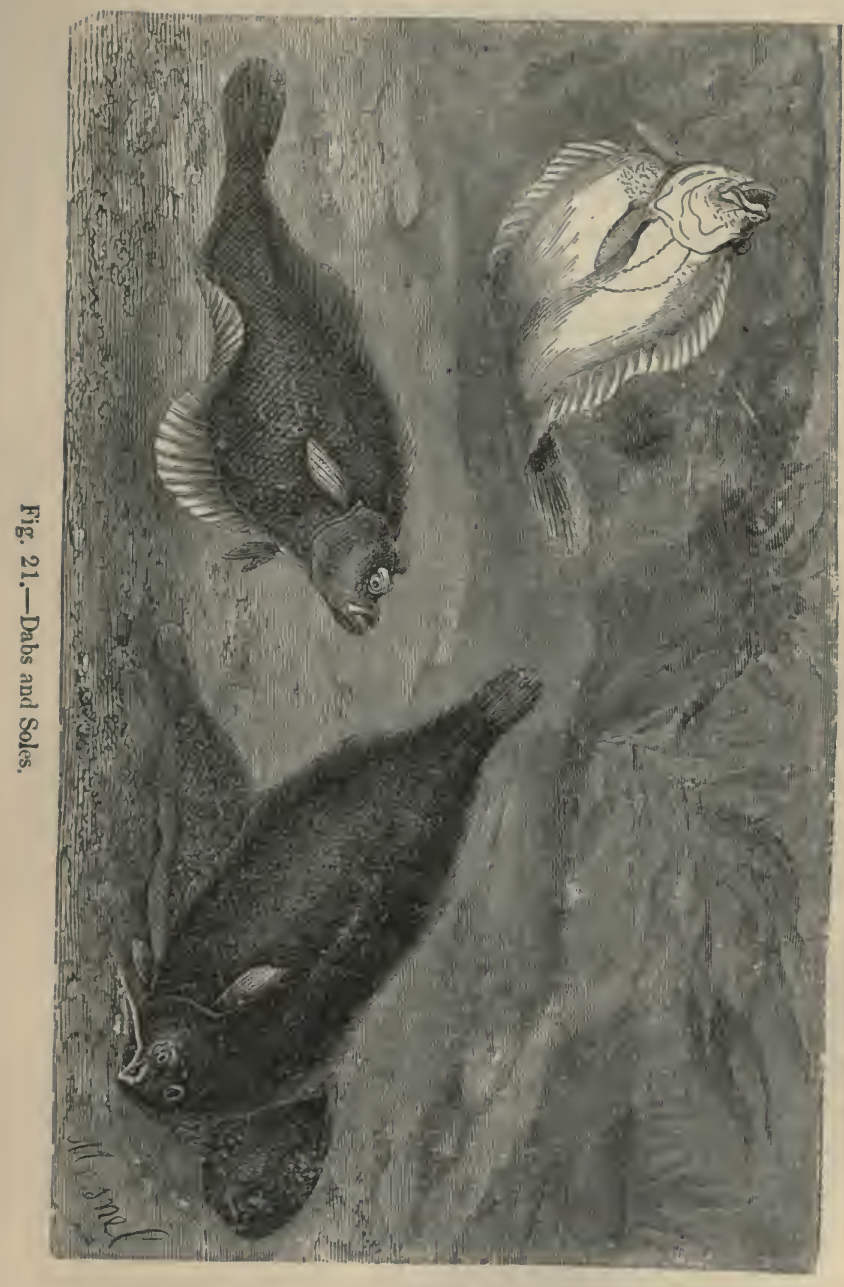



of their larksome retreat; a body of some kind, armed with a sharp beak, has clutched hold of the creature; two enormous eyes light the march of a more hideous monster than imagination ever depicted. But a gigantic form advances rapidly against it. A terrible struggle seems imminent. No! the monster with the long arns vomits a black poison; the water to a great distance around it is filled with a dense fog; the enemy retires, and the poulpe continues to hunt his prey in a domain which few animals dare approach.

The ungainly bulk of the various kinds of whales; the elegant forms of the argonuuta; the crab in his coat-of-mail; the sea-urchin, which one would with difficulty recognise for an animal if it were not for the singular movement of his spines and his locomotive suckers; the innumerable swarms of fish which everywhere furrow the ocean, thicker than birds and insects wing the air; the immense shoals of melusa transported by the marine currents like clouds of locusts on the wings of the wind-all these hosts of the sea, after all, occupy but a limited region in its immense extent.

As soon as we descend a little below the surface, what interesting species and elegant forms conceal themselves, so to speak, in organisms of the simplest character, because adapted to the uniform existence 
which they all lead! What richness may be found in that relative poverty!- -what profusion of life in those abysses to which we have not even access!

The inhabitants of the greatest depths, .k ke those of the greatest heights, are the most uniformly distributed. Many of them are genuine citizens of the world; others, inhabiting the low bottoms, are separated from the rest of the world by the deep waters as by an impassable barrier. It is near the common surface, in regions swept by the winds, and subject to every variety of temperature, that animals exhibit those diversities of character which fit them either for the torrid zone, or the frozen regions which surround the poles. A current of warm water is as effective in keeping the distinct faunæ apart as a rampart of flames. The Gulf Stream nourishes beings to which the neighbouring waters would prove fatal ; while, on the other hand, its own genial boundaries are impassable to species accustomed to the cold northern seas.

That roving giant, the whale, hunts in cold waters, and we never encounter him except he is in pursuit of $a$ shoal of herrings or other small fish, of which he devours whole nations at once. Throwing his vast bulk upon the serried ranks of his feeble enemy, he fills his maw with legions of victims, and keeps them rrowded together in that antechamber of death, to devour them leisurely one by one-his contracted 


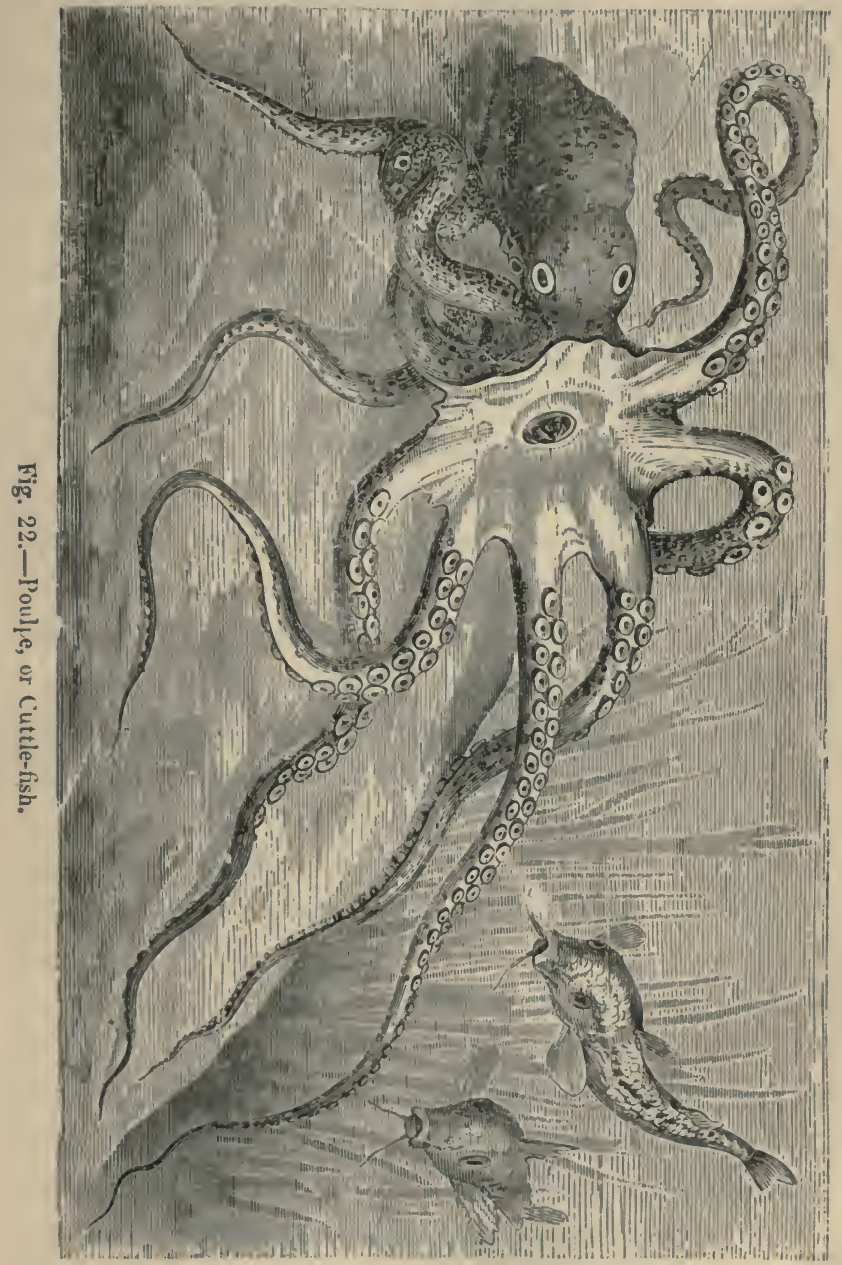



swallow setting a limit to his enormous appetite. The cachalot (spermaceti whale) finds himself at home in warm regions, and there disputes the empire of the sea with the terrible shark. The phoca or sea-cow, the porpoise, and the narwhal leave free to the dolphin the equatorial belt of waters, and fix their cantonments in colder regions. Olten they furnish unhoped-for resources to the adventurous wanderer in latitudes covered with frost and suow.

There is an immense difference in the aspects respectively of warm and cold seas. The actors are not the same. The landscape itself presents totally different characters. Numerous plants contribute their graceful presence to adorn the hills and valleys, but (as we observe on land), they are not the same which grace the heights with their long flexible ribbons, swept by the currents, and which constitute the sea-green meadows in the calm deeps of the ocean. The richest vegetation is found in the temperate zones. There flourish immense forests, even more mysterious than the sacred woods of olden time. Fish, molluses, crabs, are the happy denizens of these shady retreats. But who can flatter himself that he is familiar with these haunts? Do they not rather seem for ever closed against the intrusion of man? Who can presume to fathom the mystery of these immense tracts, denser with foliage than the virgin 
forests of the New World? And what of the joys and griefs, the struggles and massacres, of which, if the faint conceptions of our imagination can be trusted, these vast wildernesses may be the scene?

If you desire an illustration, see there, among the rank herbage and flags at the embouchure of that great river, an animal which measures anything under eighteen feet from the head to the extremity of the tail. His form recalls that of a pentagonal column or a log of wood. He is squatting there, silent, immoveable. His tremendous jaws have an almost benignant expression, and all around float barbillons, looking like little worms. What a prey for any little fish that may be swimming in the neighbourhood! But these worms are under the guard of a great monster. The little fish advances in haste to seize them. The benign jaws separate, and in a moment he is swallowed. Perchance he makes a silent vow that he will never again hunt this kind of prey; but if he has been this time the sport of an illusion, has he not often given chase to worms as supple and as frisky?

The worm floats in the water, or hollows out for itself some abode in the fine sand, far from all agitation. It nourishes itself with the infinitely little, but sometimes it attaches itself to great animals, at whose expense it lives, as we see in the case of terrestrial creatures. Certain species attain a consider- 
able length. Everywhere they encounter voracious enemies. Pursued into the pools, tracked in the sands, these creatures escape annihilation only by their extreme fecundity.

It would seem as if Nature-in the greater number of beings that people the ocean-had sought to compensate them by an incredible fecundity for the causes of destruction by which they are surrounded. Some fish of large size have only two or three young, like the majority of terrestrial animals; but what shall we say of the fertility of the herring, the mackerel, the cod, the sturgeon, and other inhabitants of the seas? It has been calculated that if a herring could multiply during twenty years without losing any of its spawn or fry, its offspring would form a mass ten times greater than the globe. Obviously, the smaller creatures which are destined to serve as food to these enormous hosts must be more prolific still!

As we advance towards the equator, regetation becomes less abundant and less varied. The waters are too much heated to be agreeable to the greater number of the algx, and if in any part of the equatorial seas the submarine vegetation attains the scale of grandeur, it is still wanting in the delicacy and elegance which characterise the vegetation of the temperate zones. 
Nor are the frozen regions of the earth more agreeable to the alga than those which are ton highly heated. They disappear long before we cease to find traces of animal life. Flowers preserve their brilliance under the snow, which protects them from the too intense cold; but the polar ice does not seem to perform a similar kind office for marine plants. Life is extinguished at the poles by sheer numbness, and these plants are among the first of living things to resent that effect. Rocks, sand, and mud are here only accidents of the submarine landscape. Here we no longer find the charming rural retreats (if the expression be allowable) of the hippocampi, those quaint hybrids of the creation: here are none of those republics of stone built up through age succeeding age by armies of insect workmen. Nature seems to have reached the end of her resources. The beings condemned to these gloony solitudes are not the creatures of a single element, but pass their lives alternately in the air and in the water. They are like a link between the aërial and the submarine worlds. The sea, covered with thick masses of ice, supplies them with but little nourishment in winter. During this season, therefore, they hunt such land animals as chance may throw in their way; they even prey upon one another, and we know how 
dangerous their neighbourhool is to the sailor who is compelled to winter in these inhospitable regions.

'Thus, heat on the one hand, anil cold on the other, arrest the extension of life beneath the ocean.

It is not necessary to descend far lelow the sur-

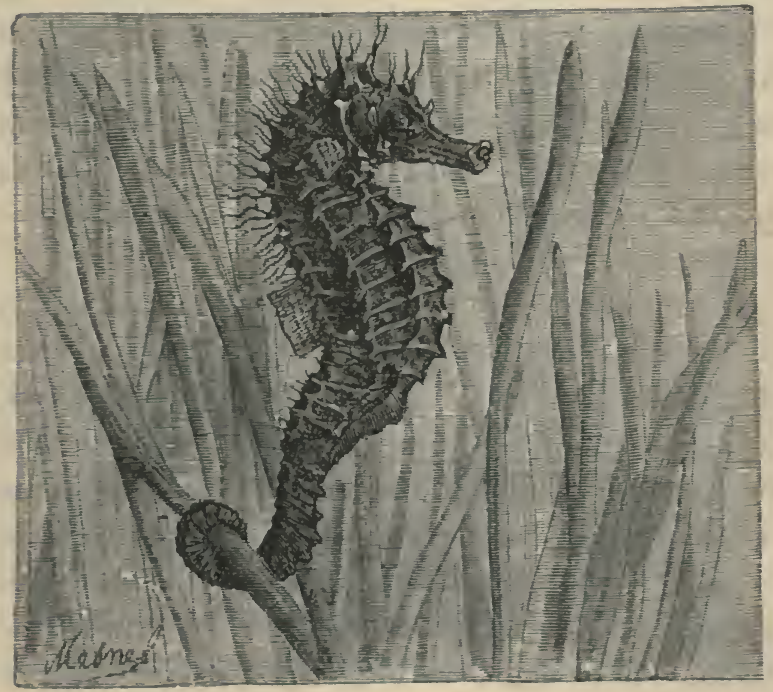

Fin. 23.-The Hiprocampus.

face of the sea to find the limits of that vital zone which seems to us at first so inmensely extended. At slight depths cvery undulation of the surface acts as a disturbing cause, and obscures vision by rapid alternations of light and shade. Soo: the 
silence and the darkness are not more than momintarily troubled by the sinking of a cable, or the l:roken remains of a wrecked vessel. Before arriving at these profound depths there are regions to which the light of day but rarely and with difficulty penetrates, and which yet are inhabited by legions of living beings.' From what star unknown to us do they borrow their light? Or does their special nature permit them to substitute for sight a sense more delicate still? No! these animals see clearly, and one of their functions is to find light for themselves-they are phosphorescent.

Frédol observes: "We are now aware that the infusoriæ are not the only animals which cause the phosphorescence of the sea. This beautiful phenomenon is determined also by the medusæ, the asterias, the molluscs, the nereids, and by some crustaceans and fishes. These animals engender light as the gymuotus engenders electricity. They eren multiply and develope the effects of the phenomenon. The light which they produce rapidly changes from a greenish to a reddish tinge. At certain moments, the darkness is lighted as by radiant points running into starry feathers or fringes of light. So vast is the number of these phosphorescent animals, that they appear at a distance like metallic masses heated to whiteness, or like 
bouquets of fire formed of myriads of glittering points; or, again, they may be compared to festoons of coloured lamps such as are used in public illuminations-or, yet again, to burning meteors, elongated or globular. Mingling and grouping, approaching and separating, ascending and descending, these wonderful wreaths of light describe a thousand capricious curves; and if they fade away or seem to be extinguisherl, it is only to be rekindled the next moment, and to pursue again the same fantastic course."

It is in the waters of the warmer latitudes that the starfishes display all their brilliance. The finest illumination on the occasion of a public fête can scarcely give an idea of this submarine spectacle. Has the reader seen on a fine summer evening the flashing splendour of the myriads of fireflies which sport away their brief existence in the valleys of Italy or of Corsica, and which for their immense numbers inay be justly compared to the sparks issuing from a conflagration? Has he remarked in the blossoming herbage how the pretty little glowworm spreads around it a brilliant red or green light? Imagine, then, glowworms and fireflies mingled togrether in all forms and colours, and in such immense numbers as to extend over many hundreds of square leagues; add to this that every nook of the vast region which they illuminate has its own proper light-that what 
seems to us brown, lustreless, and uniformly dull when we observe it by the light of day, acquires in the abysses of the Ocean those rich tints and phosphorescent gleams with which the Arab story-tellers have glorified their dreams of fairyland-and you will have a faint idea of the wonderful spectacle presented by the Ocean to the diver who dares to brave the innumerable dangers of a submarine excursion!

2. Migration of Marine Animals-Nests at the Bottom of the SeaFisheries.

In all ages man has derived instruction from the observation of nature. The sea above all has sharpened his intelligence, and therefore we are not surprised to be told that the nautilus or argonaut, one of the oldest-known of marine animals, has the "redit of having taught him navigation. The species which inhabits the Mediterranean (Argonauta Argo) must in former days have been more widely diffused than at present. It is now found only in the better sheltered latitudes-the Archipelago, the Adriatic, and the Straits of Messina. On a beautifully fine day, when the air is serene and the sea tranquil, the elegant shell of the argonaut may be seen floating on the water, which it navigates by means of a locomotive tube, and by spreading to the wind two 
of its limbs furnished with fine silver-coloured membranes-the other limbs being extended, like oars, on either side of the shell. Gazing on this elegrant and living vessel, its delicate shining membranes looking like little wings, it is easy to understand how Aristotle and Pliny saw in the nautilus one of the marvels of the sea, and pictured it as a representative in miniature of the art of navigation.

'The argonant is found in many seas, but is not, properly speaking, a traveller. The least billow, the approach of the slightest peril, causes the timid creature to draw in his arms, upon which, in consequence of refilling his shell with water, he sinks into the calm and safe deptlis of the sea. His re. treat is so cleverly managed that it is extremely difficult to take him captive. The officers of the Vaillant, desiring to obtain some of these beautiful objects, sent a boat's crew, during a voyage to the Cape of Good Hope, to capture one or more specim^ns; but scarcely had the men moved their hands tuwards them, than the too clairvoyant animals suddenly filled their shells, and, sinking to the bottum, left the sailors gazing at each other in disappointed admiration.

Attention has always been attracted by the forms of fishes, and from them, in fact, we appear to have borrowed the idea for the forms of ships. 'Thes 
incredible agility of the dolphin, which travels in :I company so numerous, and gambols so joyously in the track of the sailor, together with the sudden appearance and disappearance of immense shoals of fish at certain seasons, and the analogous migration of birds, naturally suggested that fish make long journeys, and that certain species accomplish these journeys periodically. The curious circumstances of these periodic expeditions did not, however, become known until the surface of the Ocean had been subdued by the nations of the West; until the fisheries of Newfoundland, of the coasts of Norway, of England, and of Brittany had called the attention of the learned to the facts, a few instances of which were alone known to the ancients.

The tunny is among the number of fish that were known to be travellers before the modern epoch. It is found in the Mediterranean moving in a triangular phalanx; one point forming the advance, as if to cleave the waves more easily, while the base is often of great extent. It is also abundant in the German Ocean, on the coast of Guinea, in the region of the Antilles, in the waters of Brazil, and in those of Chili and China. The warmer waters are resorted to by the tunny for breeding. Immense numbers pass the winter in the eastern part of the Mediterranean, where they deposit their eggs at depths o? 
about a hundred feet more or less, avoiding with great care the shoal-water. Troops of them leave the east in the month of May, and are then to be found in abundance on the coasts of Sicily and of Southern Italy. In the autumn they return to the 'Tyrrhenian Sea.

Pliny relates that the fleet of Alexander encountered such irrmense numbers of tunny-fish that they could not make their way through the living mass, nor could any noise or commotion they could raise avail to disperse them. They were compelled at last to range themselves in order of battle, as if to break through an enemy's line.

The dolphin, the salmon, and the sturgeon also travel in companies of their own species, but not in great numbers. They even mount the larger rivers, and forget, for a time, the salt-waters in which they had so many enemies to encounter. But of all fish-travellers, for the distance traversed and other points of interest, commend us to the inliabitants of the colder parts of the temperate zone.

The herring occupies the first rank in those classes of animals of which man has sufficient knowledge to convert them to his profit. It abounds in the northern seas, and it has even been thought that immense shoals of herrings live during a great part of the year under the polar ice, where they are safe from the 
attacks of their numerous enemies.* However that may be, some naturalists think-and, as it appears to us, with good reason-that durirg the spawning season the herring simply quits the level bottom of the Ocean to deposit its eggs in the waters which afford the protection of rocks or of abrupt eminences against the force of the marine currents.

Herrings do not obey simply the rule of caprice in making their migrations. They appear to select the coasts towards which they are travelling. As all the paths of the sea may not be convenient for the passage of a great host, though small detachments may make their way without difficulty, the armies of herrings do not follow indifferently any ronte. They traverse the regions where the staple of their nourishment most abounds. Having visited a coast they will return there freely the following year. But suddenly, without any apparent reason, they may disappear for a time, or perhaps for ever. The arrival of the mackerel is sometimes the cause of their departure. Being of larger size than the herring, as well as better armed, the latter flies as at sight of an enemy too formidable to be encountered.

* The best authorities no longer countenance this theory. The following paragraphs, in which the fact of the migration of herrings is impli 1 , are also open to dispute. The reader is ruferred to the spucial works of Bertram and Mitchell.-Tr. 


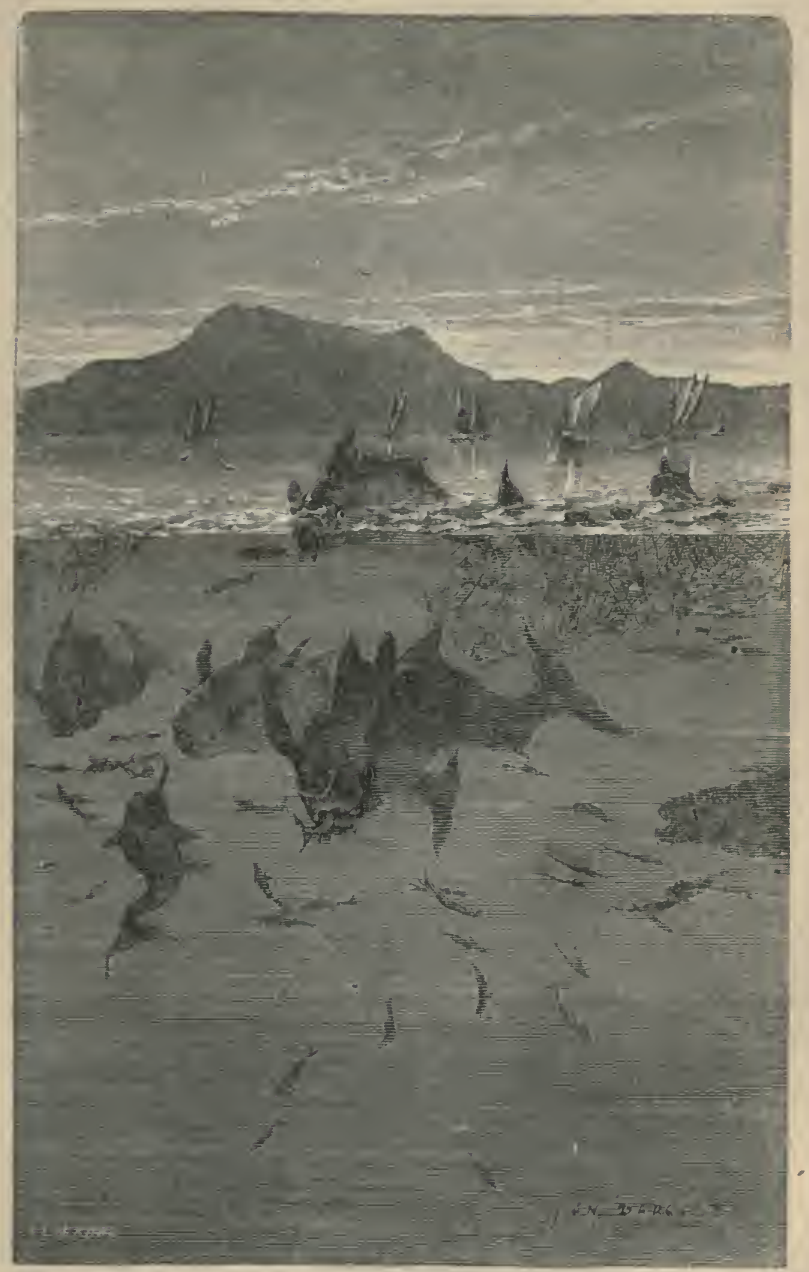

Fig. 24.-Herrings attacked ly Tunny-fish. 

Nearly all fishes are to be more or less dreaded by herrings. They fly like troops incessantly harassed by guerilla bands excited to the pursuit. The cod, the tunny, and the shark emulate each other in the destruction of these swarming multitudes, whose propagation would be too rapid if they did not serve as nutriment to the other inhabitants of the seas.

During many ages the coasts of Norway were the favourite resort of herrings. Thousands of vessels were devoted to the fishery. About the year 1600 they migrated towards the German coast, and their fishery enriched the Hanseatic cities. It is about a hundred years since immense shoals of them visited St. George's Channel. We are equally ignorant of the cause of their arrival and that of their departure. At the present time, mackerel are very abundant on the coast of Norway. May this fact account for the abrupt departure of the herrings? Or is it that the herrings have not found, as in St. George's Channel, a sufficiency of nourishment? However this may be, the celebrated Franklin put to a profitable application the memory of the herring, and its love for its native place. Of two neighbouring rivers, the one was visited by a great number of these fish, whilst none appeared in the other. Franklin caused the nets covered with spawn to be taken from the one and placed in the other. The herrings 
did not fail, in the following year, to make their pilgrimage to the river which had given them birth, and afterwards both rivers were equally well frequented.

The following facts will give an idea of the immense armies of herrings which invade our seas. The single city of Glasgow, in Scotland, exports annually more than twenty thousand pounds' worth in value. In 1773 the fishery in a single firth upon the Scottish coast employed every night one thousand six hundred and fifty boats, and the weight of the fish they captured was twenty thousand tons. On one occasion, upon the westein coast of the Isle of Skye, their number was so great that it was impossible to dispose of them in the usual way. After all the smacks had been filled, and the whole neighbourhood was sufficiently provided, the farmers used the remainder for manure. For a long time the shoal continued to visit the same coast, and appeared in the Sound of Sleat in such immense numbers, that they quite filled Loch Hourn from one extremity to the other, though it is more than half a league in depth. The tide left so many behind it, that the shore was covered to a depth which varied from three or four inches to eighteen inches, and at low-water they were visible as far as the eye could reach.

Herring-shoals are not only very thick, but the fish 
are closely packed in them, and in their advance they sometimes drive all other fish before them. 'The shoal of which we have just spoken had thus driven before it flounders, skates, and other large fish, which perished on the shore among the first ranks of the herrings. The mere pressure of the mass forces those in the front ranks to advance, whaterer obstacle presents itself. This fact is utilised in the fishery. Very long nets, to one side of which are fixed plummets of lead, and to the other buoys, are let down vertically into the sfa. The meshes are large enough to admit the head of the fish, but not to let the entire body pass through. If the herring were to try to withdraw, the openings of his gills would catch in the net and make escape impossible. 'The net is generally let down at night, because the herrings are then more abundant.

The cod, that other nomad of the sea, is found in armies at the meeting of the cold and warm waters upon the Bank of Newfoundland. An immense quantity of small worms are found in that locality, of which the cod makes his favourite food. Year by year these barbarian hordes renew their invasionevery year they are arrested in their course by the Gulf Stream; and after being decimated by the fislsers, their great enemies, the broken remainder of the band retire into the polar seas to recruit their 
strength. The fecundity of the cod is incredibly great. The celebrated microscopist, Leuwenhoeck, counted in a single individual as many as nine millions of eggs. Their multiplication being so rapid, it is easy to repair in a single season the losses of an army.

Sharks and other great fishes destroy the cod by thousands; man-a more terrible enemy still, perhaps-makes a shambles of his feeding-ground. What a blessing it was to these creatures when our race was confined to the limits of the ancient world! What a happy tranquillity did they not enjoy, before the illustrious Cabots dared to face the fogs and frozen waters of Newfoundland and Canada!

The cod-fishery is by fur more dangerous and more tedious than that of the herring. The net cannot be employed with the same facility, although it is still used upon the coasts of Norway. A line is generally substituted for it. 'To the line is fixed a hook, with a bait which the cod is not slow to seize hold of. His weight renders the operation of pulling in most laborious. To form an idea of the amount of work done by a fisherman in a single day, it is enough to state that a strong man may capture as many as four hundred of these fish, weighing, on the average, from fifteen to twenty pounds earh; some individuals, however, measuring, nearly five feet in circumference, and 
from six to seven feet in length, and weighing as much us eighty pounds. Each vessel employed in the fisherv sends, on an average, thirty thousand cod to Europe, and we know how large is the number of vessels engaged in the trarle.

Many other fish furrow the vast extent of ocean on every hand, swim in innumerable legions along the coast, or hide themselves in the deeps, where the calm promises them greater security. The mackerel is of all the most cosmopolitan. 'This popular farourite visits every year the coasts of Norway; it abounds in the markets of Germany and of England during the summer (the season at which it swarms in the North Sea and the Baltic); it is found in equal plenty on the coasts of Iceland, of Ireland, and of Spain in the Mediterranean. It is fished by the inhabitants of the Cauary Isles, in the neighbourhood of nearly all the American islands, and even at Japan and Surinam. It disappears every year at a certain time, retiring far from the surface to return again in the spring. The mackerel, we may observe, in conclusion, is a great feeder; it is so voracious that it will not hesitate to attack animals larger than itself; the shoals of small fish which keep in general near the coast are, however, its great resource.

Small fish which travel in shoals or immense herds ure next to defenceless. If the centre of the mass is 
comparatively safe from the greater number of their enemies, the sides are exposed; and the accumulation of such immense masses of living beings must of course attract the attention of rays, sharks, and other tigers of the sea. Some species of small size, such as the anchovy and sardine, are great travellers. They dwell in the Atlantic Ocean and the Mediterranean Sea. The anchovy also is found in the seas of Asia and America. It passes from the Atlantic into the Mediterranean during the months of May, June, and July, and directs its course towards the Archipelago and the Syrian coast. The most considerable fishery is in the Tuscan waters, where large numbers are captured from April to the end of July.

The anchovy is taken during the night, when there is no moon, by means of a boat called by the fishermen a fastier, upon the deck of which a fire is made. Another boat carries a net called a rissole, which is more than two hundred feet long by about thirty feet in breadth. When the fastier is surrounded by a sufficient number of anchovies, the sailor in charge gives a signal to his companions, who throw the net into the sea, and extend it in such a manner as to surround the fish that have been attracted by the light. Suddenly the fire on the fastier is extinguished, the terrified anchovies fly in all directions, and are of course captured in the meshes 
of the net. 'This method of fishing is practised at a distance of one or two leagues from the coast. At the period of spawning a different plan is adopted. The fish then approach the shore to deposit their eggs upon the shallow sands, and are caught in great seines or drawnets in the ordinary way.

The sardine fishery is managed like that of the anchovies, only the meshes of the net are a little more open. The sardine is found in its highest perfection on the coasts of Brittany.

Herrings, mackerel, and col prefer to deposit their spawn in rocky localities; anchovies luve better the shallow sandy bottoms. 'Thus the character of the sea-bottom influences the inhabitants of the deep in their peregrinations. Some examples of this fact are generally known. The following is one of the most remarkable.

The Spaniards for a long time enjoyed the monopoly of the tunny trade: seven immense establishments of this fishery existed on the shores neighbouring the Straits of Gibraltar; and there passed annually through the Pillars of Hercules more than four hundred thousand of this fish. 'This source of wealth was lost in a single day, owing to the earthquake which overtlirew Lisbon. The Spanish coasts were rocky, and furnished an agreeable resort to the oceanic travellers. On the day of the 
earthquake great quantities of sand and pebbles were torn from the coasts of Africa, and thrown upon those of Europe. 'The latter were thus converted into shallows and sandbanks. The tunny-fish, having to extend their journeys to the coasts of Tetuan and Salé, acquired more liberty. It required nets extravagantly long to capture them, and, in fine, the fishery was transferred to the Sardinian and Italian coasts.

It would be very difficult to account for the preference shown by the tunny for a rocky coast. It is possible, however, that the facilities it affords for shelter is the chief reason. Great and imposing as the tunny looks, he is so timid that he makes scarcely an effort to escape from the net after a first attempt has failed, and thus gives very little trouble to the fishermen.

The nets used for the tunny fishery in the Mediterranean are like enormous sacks, which in Italy are called tonnárè. It is at the commencement of April that the fishermen begin to construct the fortress into which they expect the tunny to enter; immense nets are fixed to the bottom, by means of anchors, and weights so heavy that the most violent tempest will not dislodge them. The tunny loves, as we have said, the rocky coasts, or passages between the isles. It is in such places that the fishers establish their 
tonnarè the passage throughout is carefully close I by nets, between which only a small opening is left, which we may call the exterior gate of the submarine fortalice. That gate which leads into the first apartment, called the halle, is made on the side of the channel by which the tunny arrives every year. When a troop of these animals has entered into the halle, the fishers close the exterior gate of the tonnára; they then terrify the tunnies by throwing gravel at them, or by scarecrows made of sheepskin-or they even pursue them until they are induced to pass through a second gate, into the "antechamber ;" this second gate being then closed, the first is opened again to admit a fresh party into the halle. When a sufficiently large number of these animals are assembled in the antechamber, similar tricks are resorted to to drive them into the chamber of death, where the fishermen kill them with lances. Sometimes despair renders them furious; they fling themselves out of the water, and break their necks or bruise their heads against the rocks and boats.

We have reason to be astonished at the facility with which the tunny is fished, when we recall to mind its great size. It is generally from two to three or more feet long, but occasionally is considerably bigger. It is often found of the size of a man, and has been taken from six-feet-six to eight feet 
long, upon the coast of Brazil. Some naturalists relate instances in which tunnies still longer have been captured, and which were otherwise remarkable for their unusual dimensions.

In many other cases, and sometimes to capture a prey less precious, man is himself forced to descend to. the bottom of the sea. It is thus that he fishes the sponge, the pearl, the trepang, and the coral. We will devote a special chapter to these adventurous and barbarous expeditions. At present we continue our observations from the shores, or, at least, we will just now explore such parts only of the bottom as we call sound by means of a boat.

Here is a quantity of spawn floating on the surface. This spawn is composed of a number of eggs, united by a transparent jelly. It serves as pasture to fish of every kind; but that which is not devoured will become little fish, and be called to higher destinies, if the sticklebacks, greediest of all the small fry, do not destroy it, or if the swell of the sea does nut throw it upon the coast, where it will corrupt and spread around a phosphorescent glow.

At the bottom, the cod, the herring, the mackerel, the tunny, and other fish have deposited their spawn in the crannies of the rocks, under the stones, in all places well defended against the agitation of the waters. Notwithstanding these precautions, how 
many generations of them are not devoured before they are hatched, by hungry rovers, and often by the fish themselves, who had secreted their offspring with such care! Life is preserved in the sea by the incredible fecundity of marine animals, a fecundity of which we have now seen a few examples.

Some inhabitants of the seas, however, appear to take the most jealous precautions to protect their descendants from the attacks of a too implacable enemy. Some, like the marine worm, the solen, hide themselves entirely in the sand; others content themselves with secreting their eggs; others, again, actually construct nests in the algæ, the leaves of which they interlace for the purpose.

The stickleback, in particular, so much to be dreaded for the fry of other fish, takes the greatest care of its own eggs. Living usually in the submarine forests, it is of the most savage character. In the spawning season, it weaves its nest most artistically, and there deposits its eggs. Unhappy is the fish which approaches that sanctuary: whatever be its size, it will have to defend itself from the furious attack of the stickleback-it will have to bear stroke redoubled upon stroke of its prickles. Its bites will sometimes rend the skin. M. Arderon relates that he once preserved a stickleback in a great jar of water, where it devoured in five hours 
fourteen small fry about an inch long, and it seemed to be very comfortable after its sumptuous repast. It would not suffer any other fish in the same vessel, and attacked any that might be put in, even though they were ten times its own size. One day M. Arderon put a small fish in; the stickleback immediately gave it chase, bit a morsel out of its tail, and if it had not been taken from the vessel, it would most certainly have killed it.

3. Terrible Conflicts of Marine Monsters-Massacre of the Weak by the Strong.

Life is sustained by death; we are constant witnesses to the truth of this adage. It would seem as if a given quantity of life had been conferred on the globe, and that it neither augments nor diminishes, but that it is incessantly transformed and renewedin a word, that all death reproduces an equivalent quantity of life.*

Although it is true that man has sustained the most deadly struggles against monsters since the earliest ages, the memory of which is perpetuated in legends and fables, he has in later times extended

* Quantity cannot be predieated of life. M. Sonrel occasionally philosophises in this vein, and we have generally allowed him to have his own way. If the reader cares for another opinion, ours is that this is not the language a plilosopher ought to use.-Tr. 
verv considerably the circle of his adventurous expeditions. $\Lambda \mathrm{s}$ the marvellous has given place to more exact ideas concerning the theatre of his exploits and the nature of his enemies he has felt his audacity increase day by day. $\mathrm{He}$ has driven his keels through every inch of the sea's surface, and he has sought to bring the powers of the Ocean under the same subjection as those of the earth. He has offered deadly combat to the whale, and pursued him even into the solitudes of the frozen regions, where some species have taken refuge to escape his blows. He derives from nearly all its species a great profit by melting down their grease and their liver to extract an oil. 'The thick skin of the greater number of whales is converted to numerous uses; the fins of the balæna, the spermaceti lodged in the head of the cachalot, the ambergris which forms in the intestines of that animal when he is ill, are among the articles of commerce furnished by the whale species.

It is to the pursuit of these treasures that we are indebted, in a great degree, for our exact knowledge of the habits of these marine monsters. Between some of them there prevails a sufficiently good understanding, but others appear to live in continual warfure; each being ready, at an instant's notice, to precipitate itself upon the other when they meet. Such appears to be the ease with the balapna, ar 
whalebone whale, and the swordfish, though sume say the latter is always the aggressor. Sailors report that the balæna, whose vast mass imposes on nearly all the inhabitants of the seas, and who, under his thick cuirass of blubber, may brave with impunity their attacks, seems to be troubled in an extraordinary manner when he perceives the swordfish at a distance. According to the same statements, the swordfish makes a rush at the whale, which dives to the bottom to avoid him. His enemy, keeping close in pursuit, compels him to remount to the surface. The whale has no other means of defence but his tail; with a single blow he might annihilate his enemy, if he could only get at him, but the swordsman is quite as alert as his antagonist is strong, and easily eludes his efforts; he springs into the air and comes down upon the whale, not to pierce him with his sword, but to give him still more dangerous wounds with the serrated edge of that terrible arm. M. de Tessan witnessed an interesting combat of this kind in mid-ocean : the entry in his diary is as follows :“Lat. $23^{\circ} 1 t^{\prime}$ N., Long. $108^{\circ} 49^{\prime}$ W. ; 16th Dec., 1837.-I have had a good view, although at a considerable distance, of a fight between a whale and a swordfish. The latter leaped into the air, to the beight of ten or twelve feet, made a half-turn, and came down is the water upon the head of the whale. 


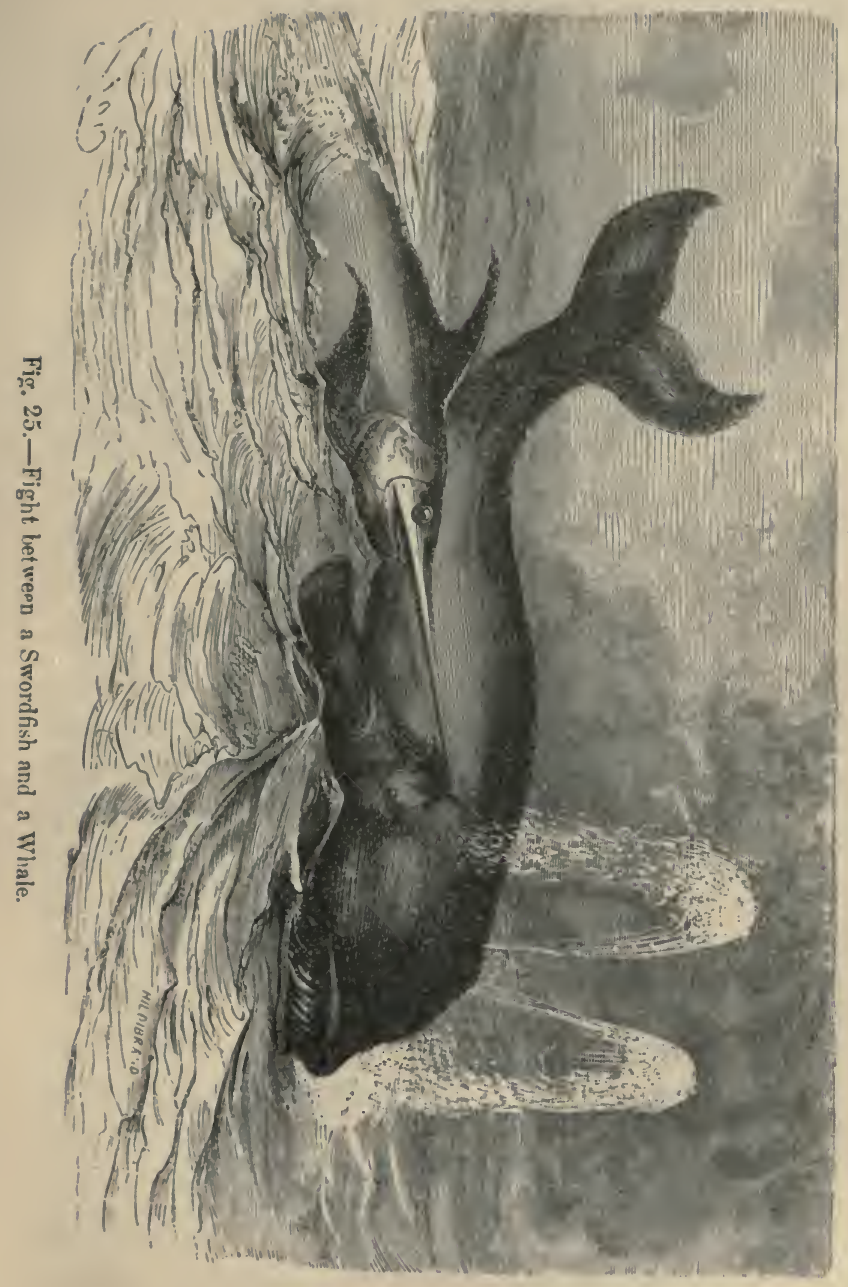



His blows were repeuted again and again; and the whale, at each fresh attack, struck the water violently with his tail, and often appeare. above the surface to bluw. The combat lasted a long time, and was always confined to the same spot-which proves that the whale did not attempt to fly from his enemy. Suddenly, after a moment of repose, the whale itself sprang from the water, to a height of about three yards, and, coming down with a crash, caused the water to spring up with great force. After this tremendous effort the struggle appeared to cease, at least I saw nothing more of it."

The balæena, or whalebone whale, is the least voracions of the cetacea. He is much less so than the eachalot or spermaceti, which, although of less bulk, may nevertheless be reckoned among the giants of creation. The spermaceti has a large throat, and is able to swallow at a mouthful a large quantity of fish. Some eurious statements are made, to this effect, to which it is difficult to yield implicit faith. although they are vouched for by naturalists. "A spermaceti whale, having beeen wounded," says Grantz, "vomited a shark sixteen feet long; and there were found in his stomach the bones of a fish more than six feet long. Probably," adds the same author, "the fish that swallowed Jonah was of this species." 
What a monster this must have been, which could relieve the ocean, at a single mouthful, of one of its most dreaded inhabitants!

The voracity and power of the shark itself are terrible almost beyond credence. It is formidable even to the great cetacea; it will follow, without intermission, vessels sailing in the torrid zone, and devour whatever they let fall into the sea. Should any portion of the equipment or baggage fall overboard; it instantly becomes the prey of this monster. Its jaws, furnished with a hundred and thirty strong and pointed teeth, are powerful enough to chop a man in two at one blow. The only check imposed on its voracity by nature is due to the pusition of its mouth. Instead of being at the extremity of its body, it is placed on the lower surface, at some distance from the snout, so that to seize its prey the shark is obliged tn incline itself on one side. While it is making this movement its intended victim often escapes.

When it has once tasterl human flesh, the shark is certain to continue its visits to the places where he expects to find it. For this reason the pearl-fisheries are the theatre of dreadful struggles, in which the coolness and intelligence if man happily triumph sometimes over this tiger of the seas. Every diver, when he descends, is armed with a sharp knife. 
When a shark attempts to charge upon lim, the object of the diver is to stab him with his knife in the belly. The negroes of America do not fear to measure their strength and skill against him. The instant they perceive their enemy they dive to a great

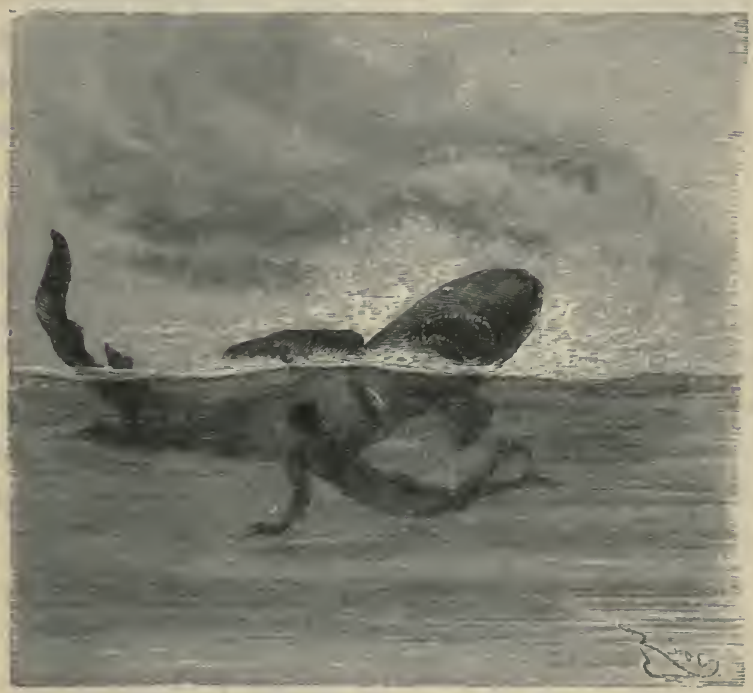

Fig. 26.-Fight between a Sailor and a Shark.

depth; then, rising as suddenly, they stab the shark in the belly before he has time to take up his offensive position.

But it is not necessary to seck in the annals of negroes or Asiatics for acts of courage and of hand-to- 
hand struggles (if one may use the expression) between heroic men and their terrible adversary. An English merchant-ressel having arrived at Barbadoes, many of the sailors threw themselves into the sea to take a bath. An enormous shark advanced towards them; every one endeavoured to reach the ship's boat sent to their aid. At the instant when he was about to escape from the water, one of these poor fellows was bitten in two by the monster. The friend of this unfortunate man was lashed into fury, and, seeing that the shark was looking about in the bloody water for the remains of his victim, the brave young fellow sprang into the sea, resolved to perish as his friend had done, or make the monster pay for his audacity with his life. In a moment the shark made a dash at the intrepid sailor, and now he was close upon him. Already he had turned himself over on his side, and opened his immense jaws.

With his left hand the sailor gripped hold of the shark under his pectoral fin, and with his right hand, in which he held a sharp poniard, he struck him blow redoubled upon blow. It was in vain the shark endeavoured to disembarrass hin:self of his enemy; the sea was dyed with his blood, and yet the sailor's arm never seemed to tire of repeating the blows. The men in the boats belonging to the rarious ships moored in the road awaited with anguish the end of 


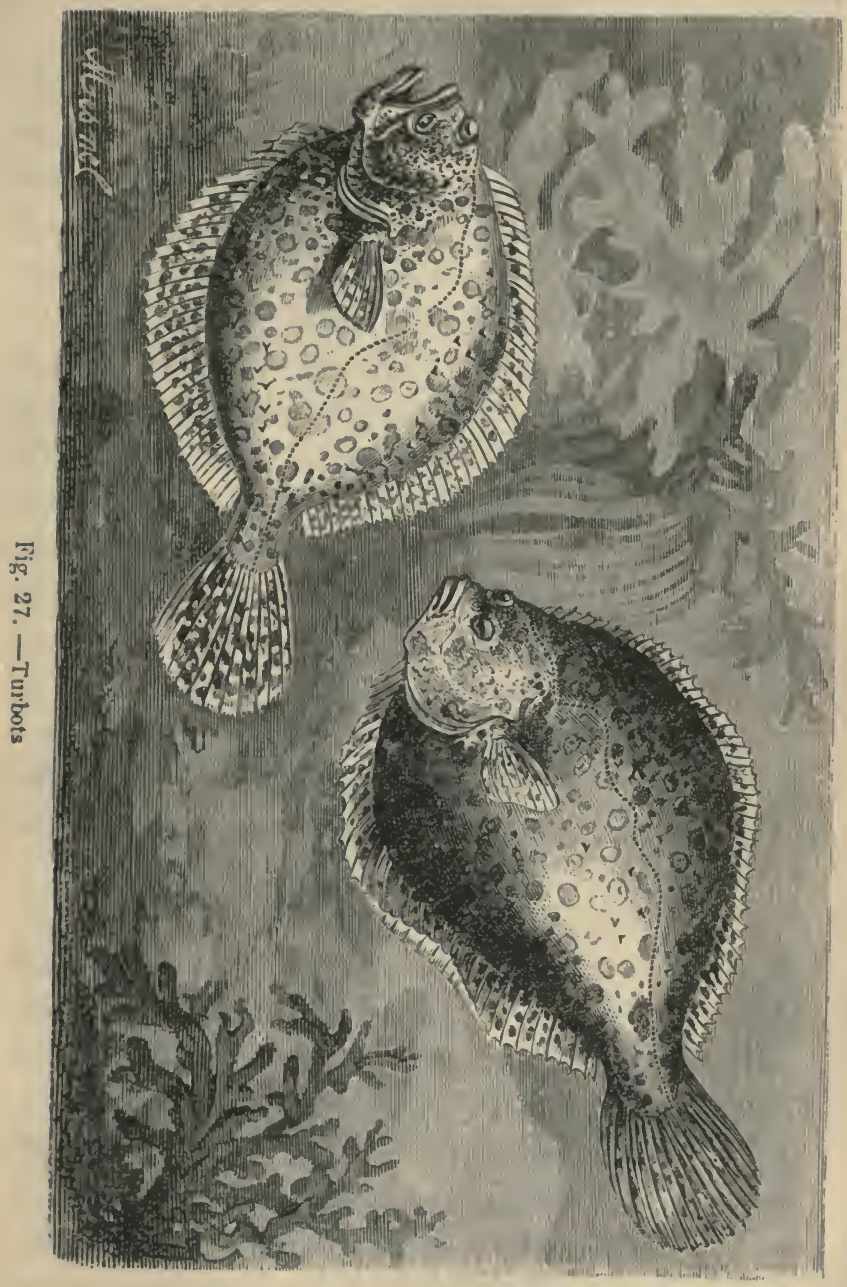



the terrible conflict. At length they could breathe freely. Human heroism and skill had triumphed; the man was seen pushing the carcase of the monster towards the shore, where he tore out his entrails, and took from them the mangled remains of his friend.

Nearly all the other inhabitants of the sea are voracious; but their small dimensions, and their feebleness relative to their means of attack, render them less terrible to man, and mask their massacres and depredations of all kinds. It needs the eye of the naturalist and the sailor to observe those lesser details of oceanic life which do not affect us directly, nor strike our imaginations like the more frightful rarages of the great marine monsters.

The turbot and the sole, those deformed outcasts of society, as some might think, are nevertheless your true cosmopolites. They are equally at home in sandy and rocky places, but their flesh acquires a preferable taste in the latter. They are fished upon the coasts of Europe, at the Cape of Good Hope, in the Indian Ocean, and even in the Chinese seas. Everywhere they are the prey of numerous enemies, yet let us not be too prodigal of our pity for them. What they need is strength alone, not voracity. The bait used in their fishery are morsels of herrings, little lampreys, worms, limpets, and mussels. They will only eat, however, either living or freshly-killed 
flesh; they will not bite at a urorsel of herring that has been more than twelve hours dead. Look at this specimen of the delicate inoffensive gourmet! How, with a body so thin and supple, with a mouth devoid of teeth, or any hard substance which might supply their place, could he dream of becoming an assailant? Nevertheless, that animated leaf swallows the shells along with their inhabitants!

At every step in the sea we have to note the destruction of the feeble by the strong, the little by the great. Let us not forget that life alone is capable of sustaining life; it is in general the stronger that is charged with the duty of avenging the fate of the feebler. The tunny ruthlessly destroys the herring, but the pleasures of the chase are embittered by his inevitable encounter with the shark; and often when he is in the very midst of a delicious meal of herring, he is himself victimised by the tyrant of the seas.

The entire life of marine animals seems to be passed in a study or a struggle how one shall eat the other. The problem has to be settled by continual ruses, attacks and precipitous flights, battles and deaths, without a spectator to compassionate the sorrows of the vanquished. 'There is no outcry, no useless talk over these tragedies. One meets another, attacks him, devours him-that is all!

This ferocious cruelty, this coldblooded and 
implacable ferocity, we do not find in the crab. It seems that this gallant chevalier, covered with a thick cuirass, has his fits of anger, his joys after a triumph, and is very sensible to the dishonour of defeat. The most deadly combats will take place between crabs With their great claws they seize on the hind-legs of their adversaries, and the latter find it no easy matter to withdraw their limbs safe and sound. Where is the brigand that would take pleasure in tearing his adversary limb from limb? Instances of such cruelty have occurred, but they are happily rare. Procrustes does not often find imitators. That which disgusts us is the nonchalance with which crabs indulge themselves in this luxury, often carrying off with them, as a trophy, a foot or a leg of their enemy. They are so irascible, that, if we were to put one of his own legs between a crab's claws, he would attack it withont perceiving that he was himself the aggressor, and would continue to pinch and tear himself for a long time after he discorered the fact.

It is not always against his own species that the crab directs his attacks. With his great pincers and his armour-like shell, which render him almost in vulnerable, he is the doughty enemy of all the small marine animals.

But, as with the knights of old, that rery armour is sometimes the cause of danger to him. The growth 
of the shell by no means keeps pace with the growth of the crab. There are times when you will see him painfully squeezed up in an unyielding garment too small for his body. Day after day the bondage grows more intolerable; the creature's limbs are paralysed, his whole life is an agony; at length the crisis arrives, and, with an extraordinary effort, he suddenly breaks ont of his prison and gains his liberty. Many die in making this painful effort; old crabs have had the benefit of the experience two or three times repeated. In the case of the domestic crab, which inhabits the craggy coasts of Europe and t! ’e West Indies, the change takes place between Christmas and Easter. Until the new shell acquires its destined hardness, the sole covering of the liberated crab is a skin-like soddened parchment; in this unprotected condition it retires into the clefts of the rocks, or buries itself under the sand, where it remains in a state of absolute immobility. But all these ruses are of little avail ; its enemies pursue it with an avidity all the greater that the crab is known to be less capable of resistance, and it is with difficulty that it escapes their vengeance.

The lobster changes its shell like the crab. Some days before the period of renewal the animal seems stupefied; he settles down in a state of torpidity, and the first sign of returning activity is when he throws 
himself upon his back, and battles with his pincers one against the other. Then a shudder runs through his limbs and his whole body; they throb and dilate, the joints of the armour open along the belly, those of the claws come apart-the moment of the creature's deliverance is at hand. But when thus freed from his shell, the lobster is so feeble that he remains altogether without motion, and in this state becomes the easy prey of cod and other ravenous fishes. His own species, however, are in general his most dangerous neighbours. They have the meanness to devour the smallest and feeblest of their kind, even preferring them to the little worms hidden in the sand, or to the spawn of fish.

'The greater part of a lobster's life is passed in a retreat which he selects between two rocks. This lurking-place is scarcely larger than the animal himself, and from thence he springs with agility upon his prey. The instant any danger menaces him he flies rapidly towards his den, springing from the ground tail-foremost, and sometimes clearing more than thirty feet at a single bound.

This armour-plated brigand, so ready to pounce on his defenceless prey, is so far from being a hero, that certain species, whose coat-of-mail is partly defective, are glad to take refuge in the deserted shell of a brother crustacean. This is the case with the 
hermit or soldier-crab. His armour, defensive and offensive, consists of two great claws, as large as a man's thumb, and so powerful that they are capable of making very deep wounds. This ugly fellow may' often be seen on the rolled pebbles of a beach, dragging his old house behind him. Presently he stops before an empty crabshell, he examines it under all its aspects, and, after withdrawing his tail from his old abode, he tries to enter backwards, as his wont, into the new house. Probably he does not find it to his taste, in which case he tucks himself into his former habitation, and marches off again in search of a more convenient apartment.' He looks at one shell after another, until he finds an abode to his liking; he then huddles himself into it, though it may be sufficiently capacious to contain not only his body but his great claws. It occasionally happens that two of these animals select the same shell for their lodging. When this happens, they fight with their claws till the weaker is obliged to give way. The virtor then takes possession of his conquest, and for some time marches boastfully up and down before his discomfited rival.

Among the smallest of these crustaceans, there is one (the Bernhardus, or hermit-crab) which has a penchant for the shells of the small molluscs. It is only partly armed, having a helmet and a breast- 
plate, while the rest of its body is covered with a soft skin. 'The hermit dues not trouble itself to look for an empty shell, or to drive the owner of a shell out of his home; he wisely eats him. The Coquilla univalva-helix-shaped, liked our garden snail-is easy to transport. Having devoured the inhabitant, and comfortably ensconced himself in one of these shells, some imprudent neighbour of the supposed molluse approaches to make a meal of him,- - the crab's head pops out, and the would-be eater is eaten.

Let us return to the high seas. There we find the ray, a flat fish, with two different coloured surfaces. The skin of some species is so rough that it is employed, like that of the sea-cow, to polish ivory and various woods. A powerful jaw, in some instances a tail set with spines, are for the ray formidable weapons. In fact, all these monsters are apparently furnished with means of defence, and breathe defiance to their victims even from a distance. Sometimes their striking colours, or the phosphorescent aureole which surrounds them, awakes the attention of the feeble, and gives them time to prepare for the attack.

In the torpedo and the gymnotus there is nothing outward to suggest how terribly they are armed. The one formed like the raiadx, the other like an eel or snake, they carry weapons more to be dreaded than 
those of any animals of their species. Any fish that approaches them is killed, as with a stroke of lightning, and devoured without a struggle. Touch them, and a shock is given like that of an electric charge; yet certain anthors assure us that the negroes handle the torpedo without danger.

The electrical power of the gymnotus was unknown in Europe until 1671, when the astronomer Richer, who was sent on a mission to Cayenne by the French Academy of Sciences, observed and made known the remarkable power of this fish. "I was much astonished," says Richer, "to see a fish resembling an eel, some three or four feet in length, deprive of all motion for a quarter of an hour the arm and shoulder of one who touched it with his finger or with a stick. I was not only an eyewitness of this effect, but I have myself felt it on touching one of these fishes, still living, though wounded by the hook with which the Indians had drawn it from the water."

The savans of Paris were at that time a sceptical people. Richer's account made so little impression on them, that for seventy years no naturalist troubled himself to inquire into it. 'This indifference lasted to the time of Condamine, who spoke, in his "Voyages en Amérique," of a fish which produced the effects described by Richer. The phenomenon now excited attention. Dr. Ingram published some views about 
it in 1750 , and attributed the effects to electricity. The Dutch physician and philosopher, Gravesende, recognised the galvanic nature of the shocks given by this animal. "The effect produced by this fish," he wrote in 1755, "is the same as that caused by the Leyden jar, only with this difference, that no spark is observed, however strong the shock may be; for if the fish is a large one, those who touch it are struck down, and feel the shock through their whole body."

The gymnotus does not seem to make any use of his weapon except in self-defence. He feeds on small fishes and worms, of which great numbers are found in the waters of South America and the Indian seas. The torpedo is more cosmopolitan; it is notoriously frequent in the seas of Europe. These two monsters, depositories of thunder, appear to share between them the universe of waters. Like the ray, the turbot, and the sole, the torpedo prefers for his portion the sandy flats and shallows; the gymnotus hides among the rocks, in clear waters, and in the neighbourhood of rivers, which he often ascends.

\section{Animated Forests-Animal Stones.}

The bottom of the sea is an enchanted country; the animals, its inlabitants, are self-luminous; they 
thunder upon their enemies from a distance; they harden themselves into stone.

We read that Daphne was transformed into a laurel. The narrators of this fable have not depicted for us the sufferings of that unfortunate maiden, her languor, the growing numbness of her limbs, her feet. dried up and spreading into long roots, her arms shaping into branches covered with a polished bark. But this dream is realised in the Ocean every moment. There is no region with a farourable climate and an agreeable site, where animals are not found living in colonies, and working, by their petrifaction, at the construction of rocks and reefs of an immense extent.

Heat favours their development. No part of the world presents them in the same marvellous variety as the Great Ocean and the Indian seas : "If we direct our gaze into the liquid crystal of the Indian Ocean. we shall there see realised the most wonderful dreams and fairy-tales of our childhood. Fantastic bushes bearing living flowers, the massive structure of the meandrina and astrea contrasting with the branchy tufts of the explanaria, which blossom in the form of cups, with the madriporidæ, of elegant structure and ever-varying ramifications. Everywhere throughout this region the eye is charmed with the brilliancy of colour: delicate shades of sea-green alternating with 
browns and yellows, rich purple tints passing from the most vivid red to the deepest blue; nullipores, yellow or pink, delicately touched as the peach, covering decaying plants with a fresh development of life, and themselves enveloped with a black tissue of retipores resembling the most delicate carvings in ivory. Near by wave the yellow and lilac fans of the gorgona, worked liked jewelry in filigree. Strewn over the sandy bottom are thousands of sea-stars and sea-urchins of the most curious forms and varied colours. The flustra, the eschara attached to branches of coral-like mosses and lichens, and the patellidæ striped with yellow and purple, look like great cochineal insects on the ground. Then the sea-anemones, looking like immense cactus-flowers, brilliant with the most glaring colours, adorn the clefts of the rocks with their waving crowns, or spread out their blooms, till the sea-bottom resembles a border of many-coloured ranunculuses. Around the coral-bushes play the hummingbirds of the ocean -brilliant little fishes, now sparkling with metallic red or blue, now with a golden green, or with the soft hue of silver. All this marvellous manifestation of life is displayed in the midst of the most rapid alternations of light and shade, changing with every breath, with every undulation that ripples the surface of the sea. When daylight declines, the shadows 
of night spread in the deep waters, the exquisite garden which they cover is lighted up with new splendours. 'The medusæ and the microscopic crustaceans shine in the darkness like fairy-stars. The pennatula, which during the day is of a reddish cinnabar colour, floats in a phosphorescent light; every corner of the seabottom sends out its ray of colour; objects that look brown and dull in the universal radiation of daylight, now shine with the most charming green, yellow, and red light; and to complete the marvels of this enchanted night-scene, the large silver disc of the moon of the sea (Orthagoriscus mola, commonly called the. moon-fish), moves softly through the whirling vortices of little stars. The most luxuriant vegetation of the tropics fails to develope so much wealth of form, and lags far behind the magnificent gardens of the ocean, composed almost entirely of animals, for variety and brilliance of colour. That marine fauna is not less remarkable for its extraordinary development than the abundant vegetation of the bed of the sea in the temperate zones. All that is beautiful, marvellous, or extraordinary in the great classes of fish, of echinodermata, of medusæ, of polypi, and of shell-covered molluses bred in the warm and limpid waters of the tropical ocean, repose there on the white sands, attach themselves to the rough rocks, or (should the place they covet be already occupied) fasten like 
parasites on other existences as wonderful as themselves, or float on the surface and in the depths in the midst of a vegetation relatively rare."*

\section{Sponges.}

For a long time the zoophytes were taken for indurated marine plants. Their animal nature, and their likeness to animals under forms and aspects so grotesquely various, were not thoronghly recognised until our own times; the name they still retain recalls their apparent analogy to vegetables.

The characters of animality which they present endure but for an insignificant period of their existence. At first they move freely in the water, some solid body arrests them in their course, the young animal whose body is sometimes-in the sponges, for example-surrounded with vibratile ciliæ, attaches itself to the obstruction, where it soon loses all power of movement, and commences a series of strange metamorphoses. The body, at first gelatinous, breaks into holes, which change by extension into winding canals, traversing the mass in all directions. In these winding channels the water circulates, and vrungs to the animal whatever substance may be

* Schleiden, La Plunte el sa Vie. 
necessary to its development. The creature has lost its mobility, and become to all appearance an inert mass. It resembles a most irregular and ill-formed regetable; the holes begin to bristle with horny filaments entangled one in the other, and constituting a kind of solid carpentry. By-and-by other siliceous or calcareous filaments mingle with the first, and fill up the cavities which had been left among them. The forms of these are most varied according to the species to which they belong, and often spiculæ very different in their aspect are combined in the same individual. They are generally so small that their nature is only discovered by means of the microscope. With its aid some are seen to be shaped like harpoons, some like stakes with pointed ends, some like stars or crystal knots of the most curious forms.

The various species of sponge are distinguished by their tissue being more or less close, more or less crooked. Sometimes their mass is surrounded in nearly every part with a siliceous or calcareous envelope. The coasts of Europe furnish some sponges of this kind, but the most remarkable come from the sea of the Antilles and from that of Japan. Sometimes the siliceous spiculæ fill the tissues so completely that the sponge serves as a polishing material. The use, however, to which the sponge is generally destined is suggested by the facility with which it takes up 


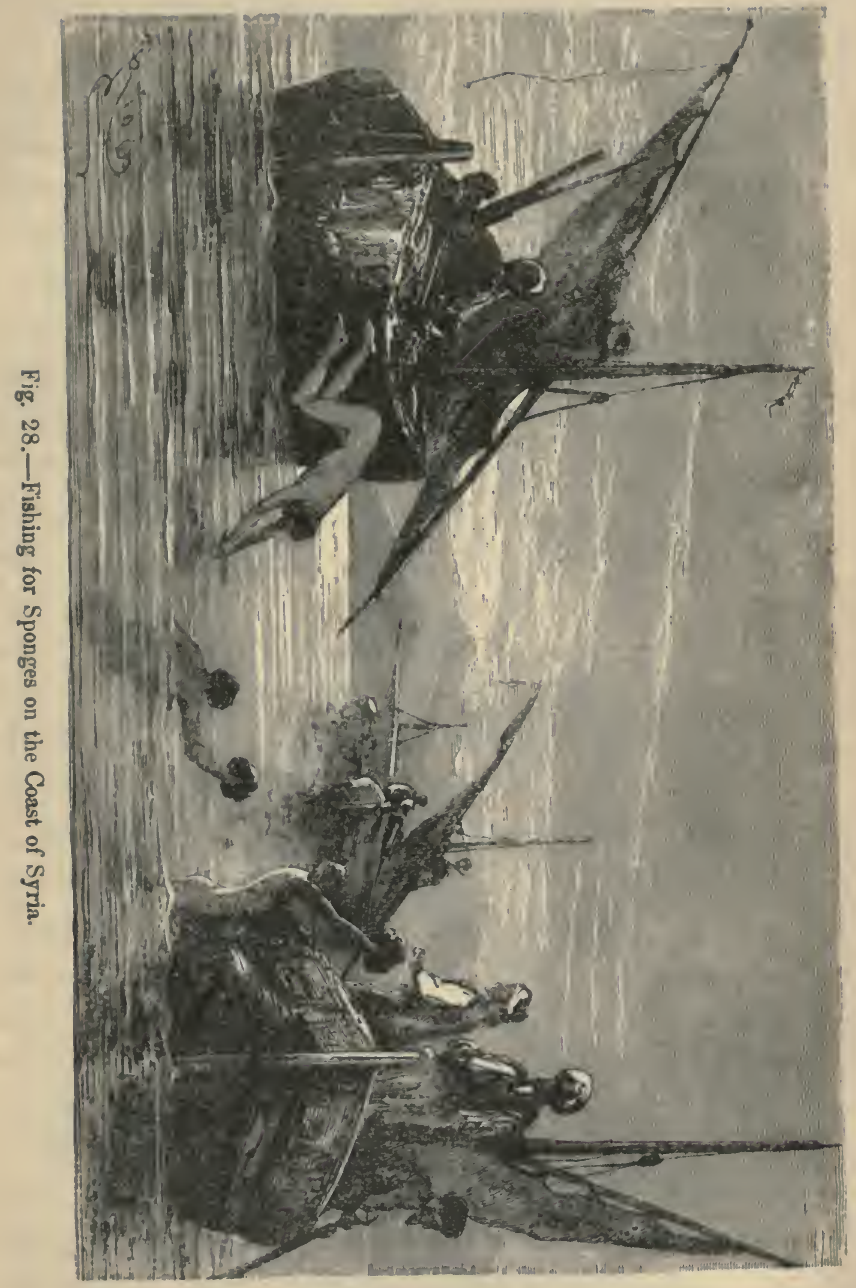


water. Most of the species are unfit for that pur. pose; they are very numerous, and appear to inhabit indifferently every sea, being more abundant, however, near the equator.

'The Red Sea, the coasts of Syria, the seas of America, the Middle Atlantic, and the Southern Seas, are rich in sponges capable of serving for domestic purposes.

Sponges are torn from the rucks to which they are attached by divers, who pursue their trade more particularly in the seas of Asia. Should we not feel astonished by the low price at which they can be sold, when we reflect that every sponge collected in the submarine forest has been gathered at the risk ot death to one of these unfortunate men, to whom li i: is nothing but one long agony?

At certain periods of the year certain ovoid or - spherical corpuscles are developed in the spongy mass, and thence pass into the channels with which the sponge is pierced. Carried out into the sea by the currents of water which circulate in these channels, they propagate the sponge in the manner described above.

When the spongy mass, for any reason whatever, decays or breaks up, the spiculæ are scattered upon the bottom. In some seas, such as the Indian Ocean, the sea of coral, the specimens of the bottom, taken 
from the depth of about four miles, are principally formed of these spiculæ; they accumulate in thick and far-extended beds, the importance of which in course of time, relative to the surface-form of the globe, must be very considerable.

6. Polypi-Their general structure-Reproduction of PolypiVegetative life of Polypi-The Polypier-Two great classes of Polypi distinguished by the form of the Polypier-The Tubipora musica.

Most of the polypi live in colonies, and find a point of support on the rocks. IVe say live, but more strictly speaking they vegetate, their movements being extremely limited. Their bodies become encrusted with calcareous matter, and life gradually withdraws from the petrifying animal. Eggs abandoned to the sea at various periods of the year, or buds developed on the polypus, are two methods equally common by which they are propagated.

The body of the polypus is soft; its form is that of a hollow cylinder; at one of its extremities an opening serves for the introduction of aliment into the body of the animal, and for the expulsion of matters which have not served for its nutrition. This single opening of the body is surrounded with fleshy appendices or tentacles, more or less numerous; the digestive apparatus, however, is not always marked 
by this simplicity of structure. It is often formed of a double pocket, the one completely enveloping the other. The animal in this ease might be we!l enough described as a sack, closed at one of its extremities, and with its superior or opened part folded back upon the bottom.

The tentaculie are always hollow, and all the cavities communicate one with another. Leaf-like formations, or foldings of the envelope of the body close the internal cavity; the walls of that cavity reunite at the base of the animal. They contract or they dilate at its pleasure, in order to give free passage to the aliment prepared for nourishment in that first chamber. Matters unfit for nutrition are at the same time ejected, by the only door which has given them entrance. Between the wall of this stomach, and the exterior envelope of the animal's body, a sort of double bottom, imperfectly partitioned off, collects the aliments that have been suitably prepared, and it is there that the eggs of the animal are lodged.

The spaces left between the foldings of the skin in that second pouch are prolonged into the tentaculæ, which the animal can withdraw into itself at will, or spread out like the blossom of a flower. Fig. 29 shows the polypus in its various degrees of expansion. The entire polypus is enveloped in a great number of 
species, with a tough sheath from which it projects itself at will. Fig. 30 represents a number of sucil polypi indrawn-that is to say, with the body of the polypus retracted and hidden under the protecting envelope which surrounds its base.

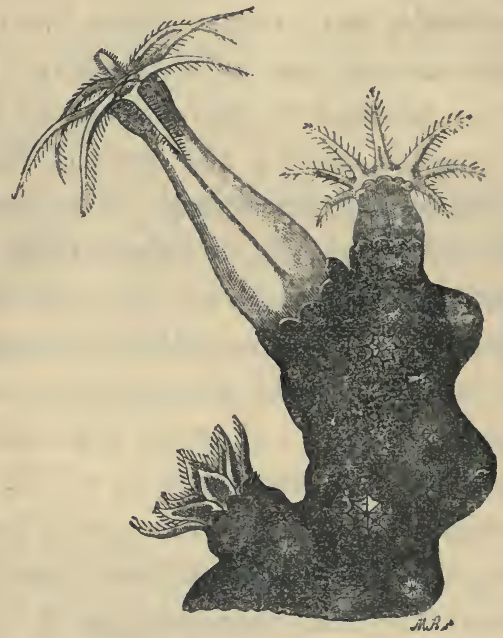

Fig. 29.-Coral with Polypi more or less expanded.

The polypi, whose digestive apparatus is formed of a single pouch, are called hydras or sertularias; those whose digestive apparatus is formed of a double pouch, are corallines, or polypi proper.

The inferior extremity of the polypus is the prolongation of that envelope, but more hardened, in 
which, as we have seen, the animal has power to shut itself up. It is the point of adherence to the foreign body, to which the polypus fixes itself.

Polypi reproduce themselves in two different ways - by eggs and by buds. The eggs, or larvæ, are lodged on the walls of the only eavity which encloses the body of the animal. At certain periods of the year, they leave the body and float in the water, as we have seen is the case with the sponges also, until they meet with a place upon which they can root themselves.

We have already observed that the sponge, during a greater part

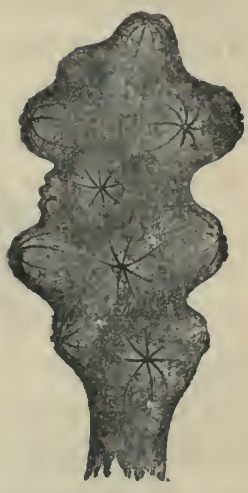

Fig. 30.-Branch of Coral with Polypi indrawa. of its existence, lives a vegetative life. So, when a polypus is once fixed upon a solid body, its base extends. If other animals of the same species join it to form a colony, or if it produce buds, the mass gradually increases. Each polypus secretes a matter which, on hardening, becomes horny or stony, and constitutes the polypier, or polypus tree. 'The nature and form which the polypier gives to the colony serves to characterise the different kinds of animals of this class.

An inspecticn of the polypier construeted by 
polypi, suggests their division into two great classes, a division which has been already indicated by the essential difference we have pointed out in the digestive apparatus of the different species. 'The hydras grow from the exterior-that is to say, they surround themselves with a horny or stony envelope, whilst they have no interior calcareous basis or polypier. 'The corallines present a character altogether the opposite. They have an internal polypierthat is to say, the hardest parts of the polypus tree are in the interior, and the living bed in the midst of which are the polypi is superficial.

One particular kind of polypus, originally from the Indian Ocean, produces a very remarkable polypier. It is formed of tubes in regular juxtaposition with each other, and joined by transverse partitions runing from one to the other (fig. 31). It is for this reason called the Tubipora musica, or organ-pipe coral. The tubes are placed next to each other, like those of a mouth-organ. In the engraving it is represented half the natural size.

The organ-pipe coral is of a beautiful red colour. The first naturalist who observed it in the Indian Ocean took it for a colony of great marine worms, and it is only in recent times that its true nature has been fully understood.

This polypus is not an ordinary hydra, notwith- 
standing the tubular form assumed by the hardenerl envelopes. The polypi in the tubipora are, in fact, completely independent of one another. When fresh inhabitants are added to the colony, they grow by placing themselves parallel to their predecessors, to whom they are attached by transverse partitions.

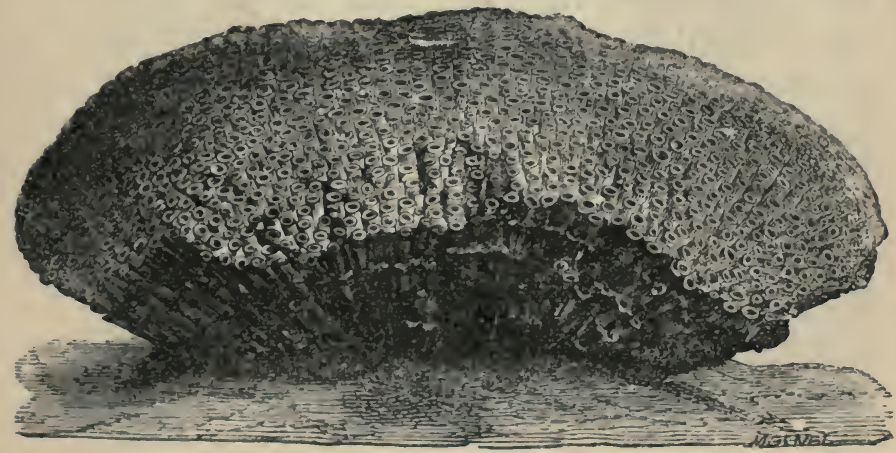

Fig. 31,-Organ-pipe Coral.

Each polypus lives and grows in its own tube, and holds no relations with the others, except that of good neighbourhood, when it leaves its abode to spread its snares for the little marine animals. It is not so with the true hydras. In them the hardened envelope resembles a continuous canal, uniting all the polypi one with another. At whatever point of the common trunk a bud is produced, the calcareous matter envelopes it, and establishes its immediate relationship with the rest of the colony. 
7. Hydra, type of the Hydrozon or Hydra Polyps-Extraordinary properties of the Hydra discovered by Trembley-Mariue Hydrozoa.

The hydrozoa owe their name to a special type, the hydra, which inhabits fresh waters. The celebrated naturalist Trembley, tutor to the sons of Count Bentinck in Holland, was the first to recognise their nature, in 1740. The remarkable properties which he discovered among these little beings struck the learned of the eighteenth century with astonishment. The flesh-eating habits and the spontaneous movements which he had remarked among the hydræ led him to believe they were animals, while their appearance resembled that of aquatic plants.

Trembley made the following decisive experiment. Plants have the property of reproducing themselves by cuttings-that is to say, a branch of the plant being cut off, and planted under suitable conditions, roots develope themselves at the cut extremity, and the branch becomes a plant similar to its parent. As no known animals possessed this singular faculty, it was to be presumed that the hydra would not reproduce itself by cuttings. What then was the astonishment of Trembley when he observed, some days after the mutilation of a polyp, each morsel transformed into a complete body. 
having the same characters as the creature of which it had lately formed a part!

Evidently science had become enriched by the discovery of a new fact. Her classification had proved defective, inasmuch as an attribute considered as peculiar to plants had been proved by this experiment to belong to creatures of which the animal nature was incontestable. Hence, notwithstanding the difficulty of communication among the learned in those days compared with the present time, this new experience was speedily rumoured throughout Europe. Every naturalist repeated the experiment for himself: at first, upon polypi which Trembley sent in his letters, after having had them properly dried; afterwards upon specimens which they found for themselves in stagnant waters. Reaumur was one of the first. "I declare," said he, "when I saw for the first time two polyps gradually form themselves from one that I had cut into two pieces, I could hardly believe my eyes; and the truth is, I am not yet accustomed to the belief, although I have repeated the experiment a hundred times over." Soon afterwards, Reaumur began to observe the same phenomenon in various species of worms, and that which had seemed incredible was soon recognised as being but another of the common phenomena of nature. 
This is but one example of the fate common to great discoveries. At first, people are astonished by them, and receive them incredulously ; afterwards, as facts accumulate, it seems as if each experimenter had either made the discovery for himself, or very nearly approached it. If the reader has followed, even in a general sort of way, the scientific movement, he will be able to recall in illustration of this fact the new ideas introduced into meteorology by the learned physician, M. Marie Davy; how doubtfully his first communications upon the general cause of storms was received, how people hesitated in the very presence of the facts by which the exactness of his observations was verified, and how the merit due to the first observer has finaliy been acknowledged.

Let us return to Trembley's hydra. Its body is soft, and consists of one long pouch with a single opening. The pouch is surrounded with tentacles, which in the species we are describing are six in number. On the walls of the membranous sac which constitutes the animal, the buds or eggs develope themselves. The latter, having arrived at a certain size, leave their first home and float freely in the water. The buds can either separate themselves from the mother hydra, or remain fixed to her; in the latter case the same foot or stalk bears two hydras, the one of which is, so to speak, grafted upon the other. 
Hydras are found in grassy waters, lakes, pools, and canals. The best mean cf procuring them is to take haphazard, from the water supposed to contain them, any aquatic plants, leaves of trees that have fallen into the water, or bits of wood which have accumulated there, and to these the hydras will be found attached. They transport themselves from one point to another by swimming or crawling.

Trembley has made a special study of three species of hydra. He has named them the long-armed polypus, green polypus, and brown or grey polypus (Hydra Grisea). 'Their bodies, which are very contractile, are variously formed. The tentacula are often immoveable. The ordinary species, including their arms, may reach five-eighths of an inch in length, but other species attain larger dimensions.

Ancient writers mention, under the name of hydra, a mythologic animal with seven heads, each of which was reproduced as fast as it was cut off. 'Trembley's hydra, more accomplished than this fabulous animal, formed two perfect creatures when divided. Nor is this all. What does the reader, when made acquainted with the fact for the first time, think of an animal able to turn itself inside-out like a glove without ceasing to live? Trembley tells us that his hydra undergoes this operation without being in the 
least degree incommoded. "I have seen," he says, in his fourth memoir, "a polypus turned inside-nut, which has eaten a little worm two days after the operation. Others have not recovered their appetite so quickly; they have been four or five days, more $o^{*}$ less, without wanting to eat. After that time they ate as well as other polyps which had retained their proper insides. I have kept a polyp that had been turred inside-out more than two years. His progeny had become very numeruus. Once, when I had successfully turned a few polyps, I was impressed to repeat the experiment in the presence of good observers, that I might be able to cite other evidence than my own in proof of this strange fact. I succeeded so well that others attenipted to follow my example. Monsieur Allamand, whom I begged to try, succeeded as well as myself. He las turned many polyps, and some that he experimented upon have remained inside-ont and continued to live. He has even done more than this : he has turned polypi again which had been turned some time before, and this although they liad eaten after the first experiment. $\mathrm{He}$ even found that they ate as well atter the second operation. Finally, he turned some a third time, but they died atter a few days, without having recovered their appetites. Whether their decease was owing to the operation or not cannot very well be decided." 
The hydra feeds on the larve of insects. Though less formirlable than its mythologic namesake, its natural properties are, to say the least, quite as remarkable. What can be more insignificant to all appearance than a creature so small that its threadlike body cannot very well be studied without the aid of a magnifying-glass or a microscope! But what more curious in reality! And how greatly has the discoverer been rewarled for his devotion to science by the ever-increasing importance of the facts he has made known! It is thus that Nature rewarls the labourers who devote their lives to the contemplation of her marvellous works.

Hydras proper inhabit the fresh waters; sea-wreaths or sertulariæ, which have an analogous structure, are well known to those observers of nature who pursue their studies on the shores of the ocean. The buds, which in the case of the hydras proper generally detach themselves from the mother-stalk, remain fixed to it in the case of the sertularian polypi. 'The result is that a horny polypier is formed exteriorly, not interiorly, the polypi being enclused in the orifices of the horny envelope. The latter also assumes the most varied forms. It often fixes itself at the bottom of the sea, but also often rests there without rooting itself. The polypier of the hydra proper adheres to the soil by its base. In its 
perfection it may be compared to a tree. Marine plants are generally attached to it, and at its extremities are stalks analogous to those of flowers.

One entire farnily of polyps is remarkable for its attachment to a common stalk, which is capable of supporting the colony without fixing itself to the bottom of the sea. The foot buries itself in the mud or sand, or, better still, the polypier floats in the water. This is the family of pennatulæ, of which we will mention only three examples-the pennatula, the virgularia, and the veretillum.

The virgularia has a rough resemblance to a pen. The polypier is in the form of a cylinder split lengthwise. The principal stem does not itself bear any polypi, but they are attached, like blossoms, to the short lateral branches which proseed from the stem at equal distances from the top of the polypier almost to its other extremity.

The Pennatula spinosa (fig. 32) is destitute of polyps over the greater part of its surface. They are arranged to the right and left of a large stem, upon fan-like branches. The foot, which serves to fix the polypier in the sand, is shaped like the hilt of a sword.

In the Veretillum cynomorium (fig. 33) the polypi are arranged with great regularity over the greater part of the polypier. They are inserted directly in 
the fleshy matter which fills the interior of the common stalk. A cylindrical prolongation of the stalk serves, as in the Pennatula spinosa, for the instantaneous
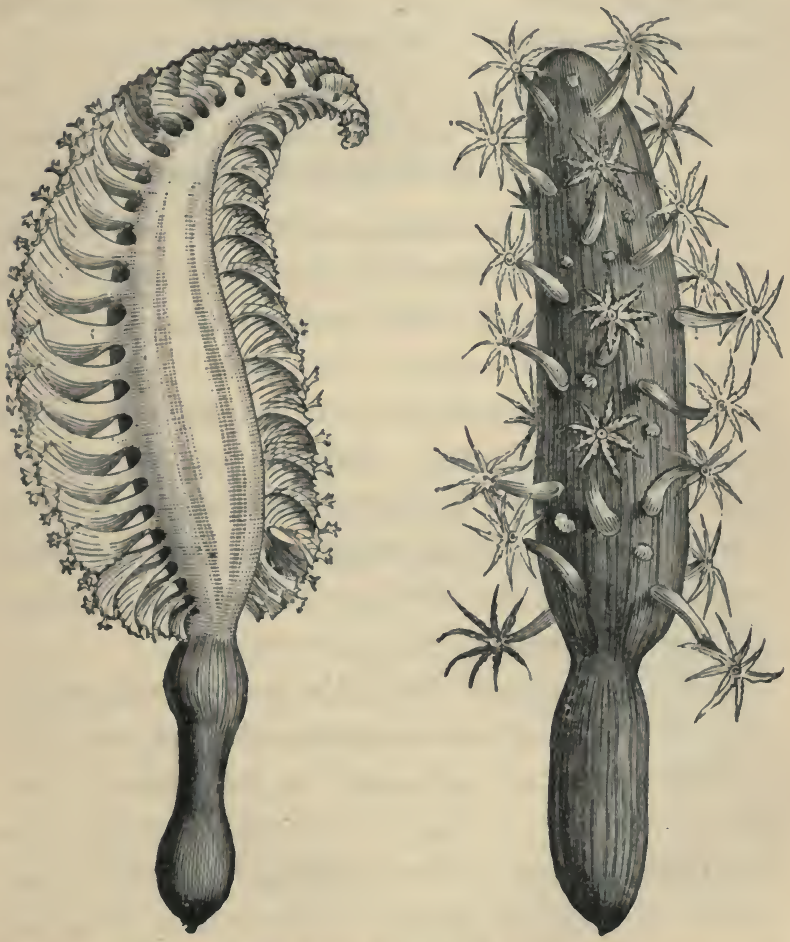

Fig. 32.-Sea-pen (Pennatula spinosa). Fig. 33.-Veretillum Cynomorium. mplantation of the entire colony in the place chosen for its residence. 
'I'he pennatulæ rank with animals which are generally phosphorescent-that is to say, which emit light in the night. They abound most near the shores of European seas. Cuvier gave them the namo of "swimming polypi" (Polypes nageurs).

\section{Actiniæ-Sea-Anemones-Sea-Nettles.}

'The actinx, or sea-anemones, though independent creatures, attach themselves firmly (and for a considerable length of time without changing their locality) to the rocks. Adhesion is effected by means of a large and fleshy base, which secretes a glutinous matter, and it depends entirely on the will of the animal. It moves from one situation to another when it pleases, using its tentaculæ as feet, or gliding along at the bottom of the sea by a movement which can scarcely be perceived.

The actiniæ appear under the most varied aspects, owing to the innumerable modifications of which the tentaculæ are susceptible, and to the diversfied characters of the foot itself. We may compare one of these creatures to a flower plunged in water, with petals so soft and flexible that they yield to its slightest movements. At one moment they may be seen gathered together to agitate the water, as a neans of renewing its freshness before the mouth 
which they protect; at another they contract and disappear before some threatened danger, or they stretch themselves out to seize their almost invisible prey.

'The exterior surface of the actinaria is thickly set with oblong lance-shaped prominences, terminating in a stylet, rigid and sometimes barbed, to which is probably due the burning sensation produced by their contact. It is from that sensation that this species of polyps has derived the name of sea-nettles. They have been called anemones, from their resemblance to that beautiful flower, and actinia (starlike) from the rays or tentacles which surround the mouth.

The coralline polyps are all, like the actinaria, armed with spiculæ, of which the forms are most varied, according to the species. Fig. 34 shows the general character of these spiculæ. The body of the actinia, almost cylindrical when extended, is contractile. It becomes globular, or almost spherical, when the animal is folded back upon itself. Its tentacles are then contracted, and almost completely covered by the tough envelope of the

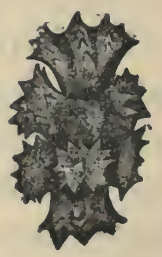

Fig. 3 t. Spicula of Coral. body. When extended they serve to arrest by simple contact the little marine animals which touch them.

The actinia do not reside in great depths. They 
are generally found attached to rocks in the neighbourhood of coasts. They are almost all useless, but one species is eaten in Provence and at Nice. It is very soft and of a greenish colour, with brown stains on the body. The extremities of its tentaculæ, often very long, are frequently of a pinkish hue.

These animals, unlike coralline polyps, are nearly always found separate from other inclividuals of their species. While other polypi are for the most part bound to their native place, the actinaria are free to choose their abode, and change it at pleasure.

9. Coral-Miraculous virtue attributed to Coral by ancient tradition-Coral Stone-Coral Plant-Marsigli discovers the Flowers of the Coral-Observations of M. Lacaze-Duthiers.

One of the most interesting of the fixed polypi is, without doubt, the coral. Naturalists of ancient times regarded it as a stone, or as the solid axis of a marine plant. Dioscorides thought it to be a marine shrub which hardened on being taken out of the sea and exposed to the air. He even thought it petrified if touched while it was alive in the water. In 1585, the Chevalier J. B. de Nicolai, previous to fishing coral on the coasts of Tunis, persuaded a fisherman to dive for the purpose of ascertaining whether the coral, in situ, was hard or soft. Contrary to the. 
opinion of ancient times, this man reported that it was hard. Nicolai, resolved to be sure of the fact, dived himself, and ascertained the truth of the man's statement.

In 1671, an Italian naturalist decided that as coral had neither flowers nor leaves, nor seeds nor fruits, it ought to be classed with stones. 'This idea seemed all the more strange, considering that after the time of Nicolai, a Lyonnese gentleman, named Poitier, had observed, in 1613, the presence of a milky juice in fresh coral, and had demonstrated that it was only necessary to remove a kind of crust to give it the polish and the red colour.

Marsigli, in 1706, announced to the Academy of Sciences that he had discovered small white bodies, like flowers, on the surface of the coral. So long as he left the branch of coral in sea-water, the flowers remained expanded; but they instantly rlosed when the coral was taken from the water, reappearing as instantly when it was replaced. Without investigating whether these might be animals or not, Marsigli concluded that the coral was a plant.

'I'he merit of having discovered the true nature of coral belongs exclusively to a Frenchman, Jean André de Peyssonnel, a physician and botanist, whose observations were made on the coasts of Provence and Barbary, at the instance of the Academy of Sciences. 
The Museum of Natural History at Paris possesses the unprinted manuscripts which contain the results of his studies of the nature of coral, and of many zoophytes. He demonstrates that the coral branch is an aggregation of animalcules, and he compares them to the sea-nettles, whose name was already known. "I have had," he says, "the pleasure of seeing removed the claws or feet of that nettle, and having put the vessel of water, in which the coral was placed, over a fire, all the animalcules expanded. I stirred the fire and caused the water to hoil, when the creatures came out of the coral precisely as when one cooks any kind of shellfish."*

This discovery was opposed to so many prejudices that it was badly received for some time. Reaumur, whose name was then all-powerful in science, expressed ironically his dissent, without having in the least attempted to test the researches of Peyssonnel, and this probably prevented the publication of a manuscript which would be well worthy of being rescued from oblivion.

Numerous other labours in this field of research, among which those of M. Lacaze-Duthiers may be mentioned as not the least remarkable, have made us pretty well acquainted with the nature of coral. It results from the interior hardening of a polypier,

* Traite du Corcail. 
or colony of polyps. The supposed crust is simply the newest part, and as it has not acquired the consistency of the interior mass, it is not capable of being utilised commercially. The polypi are lodged in the little cavities or hollows of that crust, which they secrete, an I which serves them for support.

10. Coral chiefly found in the Mediterranean Ser-Various species of Coral-The Coral Fishery-Antipathes, commonly called Black Coral.

'The coral of which we are here to speak is that beautiful production of the seas with which ladies are familiar among their elegant articles of bijouterie, not, the masses which form coral reefs in the Pacific; Ocean. It is found in the Meliterranean chiefly, but also in the Rer Sea. Its chief habitats are in the neighbourhood of Marseilles, on the coasts of Corsica, Sardinia, Sicily, the Balearic Isles, and near T'unis and La Calle. 'The last-mentioned locality has for a long time supplied the greater part of the coral of commerce. It is fixed to the rocks by an enlargement of its hase. 'The fishers state that its dimensions grow less in proportion as the depth at which it is found increases. It is generally fished in comparatively shallow waters, ranging from ten to fifty 
yards, and is never taken at greater depths than from 200 to 350 yards.

'The colour of coral is generally a beautiful red, but it is found of every intermediate tint between red and white. That fished on the coasts of France owes its celebrity to the richness of its colours. The different kinds are known to commerce under the various names of "blood coral," first, second, and third, \&c., according to the shade. White coral is but little esteemed, if we except that kind known as "cornelian-white."

The coral fishery is chiefly in the hands of the Maltese, but it is also pursued by the Italians and the French. An idea of the manner in which it is practised on the coasts of Sicily will not be uninteresting to the reader. The little fleet engaged in the fishery consists of small barks, attended by boats which are manned by three or four men, who take up various positions over the coral bank. 'The tackle used is a kind of drag with arms, worked by means of a capstan. Each branch or arm of the drag has a kind of netted sack at the end of it, into which the coral falls as it is broken off. Beneath the centre of the cross formed by the arms, a heavy stone is swung; and the whole apparatus is dragged along the rocky bottom by the forward motion of the vessel and the lifting motion of the capstan operated 
at the same time. When the drag is pulled on deck, the available coral is selected from the mass and (leansed for sale. The occupation is a very laborious one, more especially as it is pursued under the burning sun of the Mediterranean.

Black coral, so called, is the stalk of a polypier of another species, called the antipathes. The polyps are very small, and have six tentaculæ; in the middle of them is the only opening of the creature's body, the internal texture of which is analogous to that which we have already described as common to polypi in general. It derives a certain commercial value from the fact that, in drying, the centre and hardened part of the stulk completely sheds the cortical envelope and the polypi attached to it.

11. Gorgons of the old writers-Their animal nature discovered by Peyssonnel, Trembley, and Bernard de Jussieu-The Fan Gorgon-Its cosmopolitan character.

The gorgous, su named by Pliny, were originally taken, like other polypiers, for marine plants. Even yet, we are not thoroughly acquainted with their manner of life. By means of the microscope, the naturalists of the last two centuries have been able to demonstrate the existence of these polyps, which nau been legardeu as lluwer's. Peyssumled, irembley, 
-and, above all, Bernard de Jussieu and Guettard, liare demonstrated their animal nature. The polypier is tlexible, in consequence of not

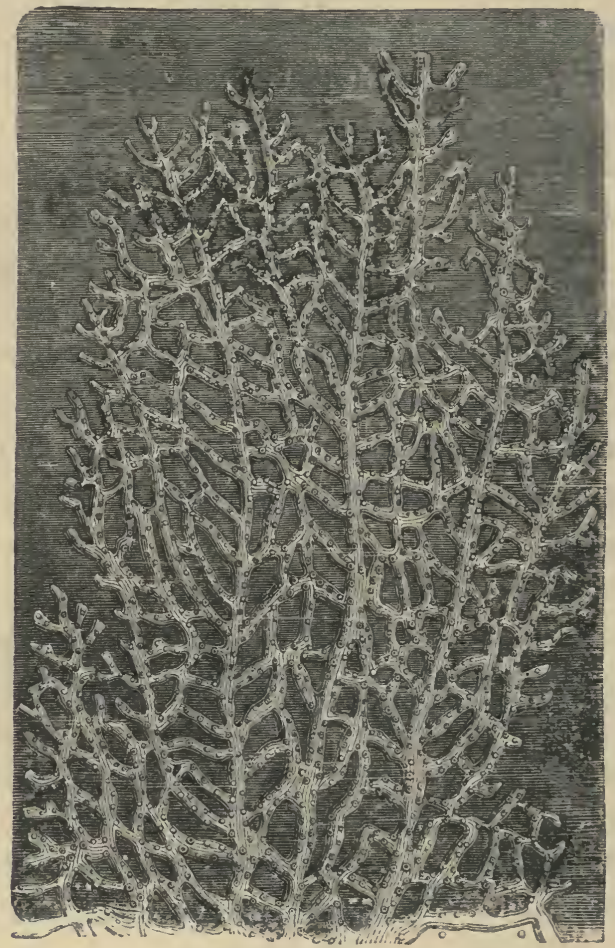

Fig. 35.-Portion of the Fan Gurgon, magnified.

being entirelv stony. utilised in the arts.
It has, therefore, not been It has, however, been . 
employed in the construction of small objects requiring a substance at once hard and elastic.

Gorgons live, like other marine polyps, at the bottom of the sea, or upon marine bodies to which they attach themselves. As is the case with the coral and the antipathidæ, a great number of individuals live upon the same polypier. The body is retractile. Generally, it is small; and, for many species, a marnifying-glass is necessary to distinguish clearly the animal from the living fleshy crust which surrounds the polypier.

The portion of the fan-rorgon represented in fig. 35 , shows the polypi in the form of sinall round tubercles with a hollow in their centre. The polypi are still more apparent in the whorled gorgon (Gorgonia verticellata). This species has been so named because the polyps are grouped at different points of the stalk, and form at cach of those points a whorl of animals all round the branch.*

'The gorgonidæ display the most beantiful colours in the sia, but tleir hues fade soon after they have been taken from the water, and retain only the pale shadows of white, black, red, green, violet or yellow, s.ich as we see in the collections.

* The worl tert:cellated is (mployed by botanists to designate the grouping of leaves which grow at the same heigl.t upon a branc., around which they $f \mathrm{rm}$ us sort of crowit. - Tr. 
The polypier of the gorgonidx is very variously formed in the different species. Sometimes the branches are almost straight, as in the whorled gorgon; sometimes they cross and interlace in a thousand ways, and give to the polypier the aspect of network, more or less close.

The fan-gorgon is a remarkable example of this. The enlarged extremity of its principal stem, denuded of its living crust, is attached to the rock. From this stem spring many hard and naked branches, which, intersecting one with another, pass into a network in which the polypi live.

In size the gorgonidæ range between two very distant limits. The smallest that has been studied may be less than an inch in height; others reach many feet. Some fragments have been seen by the writer, which show that the entire individual was of still more considerable dimensions.

These animals live at a great depth, and inhabit every sea. The fan-gorgon is more generally distributed than any other. They most abound in the warmer waters, as is the case with other species of polyps. 
12. The more active submarine constructors - Astroides - Caryophillia-Madrepora Plantacinea-Dendrophyllia-Oeculinil, or White Coral-Mean Jrina-Fungia-Porites-Milleporæ.

The purely calcareous polypiers have their principal seat in tropical regions. These are the species which exereise the most marked influence upon the varied surface of the sea-buttom, and which have distinguished themselves as the constructors of reefs and islands. The principal types of this cluss of polypiers are the caryophillia, the meandrina, the fungia, and the pentacrini. For a long time these species were confounded together under the gentrul name of madrepores, and it is only during late years that their polypi have been recognised.

These polypi bear a very close resemblance to those of actinia and corals; but the foldings whirh we have remarked in the digestive eavity are not connected, as is the case in the latter. They generally occur at the base, so as to constitute a central axis surrounded with raliating cells, which are only quite separated from each other at the lower part of the animal. Their similarity to the actinix, already described, is apparent at first sight. In proportion as the polypier grows, its lower part becomes calcareous, and reproduces in stone the soft structure that had ber n formed by the living animal. The 
divisious of the fissures or cells harden gradually, owing to the deposit of calcareous matter in the interior of their tissue. It forms little trunsverse plates, which close the bottum of the cells, bounded by the radiating divisions. When the polyp dies, we discover at the bottom of the place which it occupied a stuny polypier, divided by plates which converge towards an axis, and terminate at the upper extremity by forming a little starry cup (fir. 36 ).
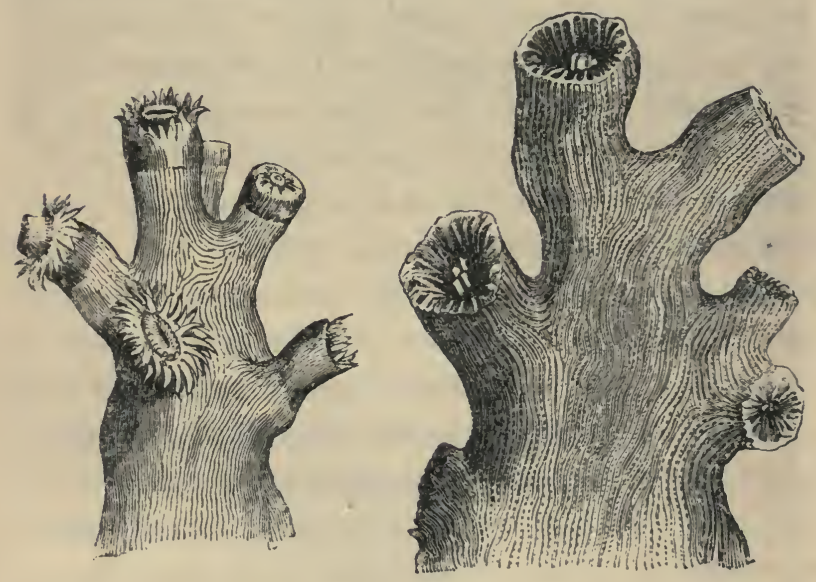

Fi. 36. - Dendrophyllia Ramea.

3. Natural size, with polyps.

2. Magnified, with the polyps dead.

'The difference between the varions polypi of this gromp consists especially in their mo.ie of reprc- 
duction, and in the consequent form of the polypier which they produce. When the individuals are isolated, or not closely grouped (fig. 37), the polypier attains no great dimeusions. The caryophillia presents this character, and examples of them are to be found even in European seas.

In other varieties the buds do not separate the'm-

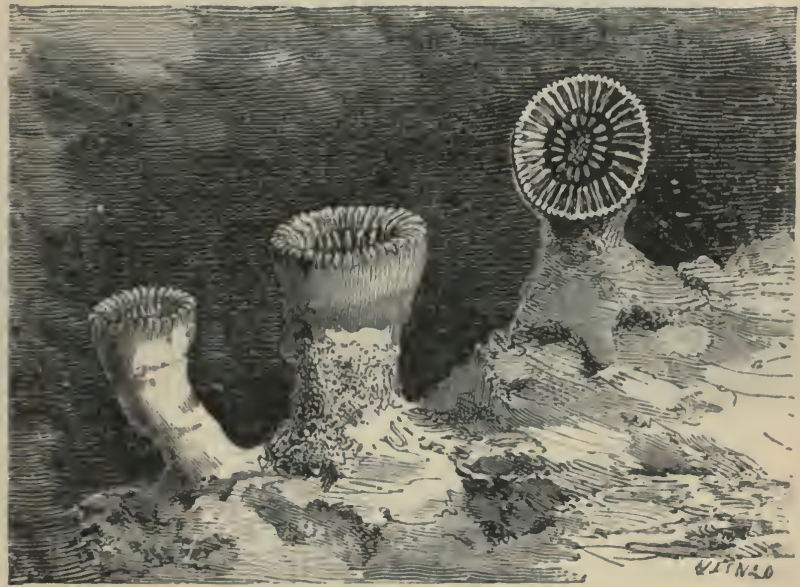

Fig. 37.-Caryophillia Cratisus.

selves from the original stem, but remain an integral part of it as they grow in number and size (fig. $\Sigma 8$ ). They develope side by side, and are joinel one to another by a compact tissue, which is thus formed into thirk masses. The polypier is esper ially charac- 
terised by the continuity of each column lown to the base. The species of astrea are numerous, more particularly in the neighbourhood of the equator.

When the buds in the process of development do not remain parallel with the mother-branch, the

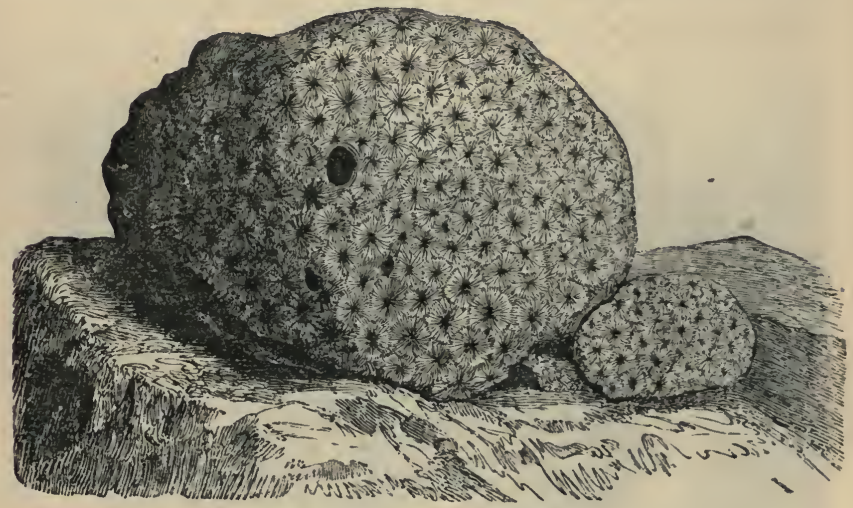

Fig. 38.-Astrea Punctifera.

polypier takes the form of a tree, more or less distinctly. In this case, the name it bears recalls the veretable form to which it approximates. The Madrepora plantaginea (fig. 39) is formed by the agrgregation of small polypi joined together by masses more or less conical in form. To every polypus there is a corresponding little depression, surrounded with a slight eminence. In general appearance the polypier with its polyps resembles a spike of plantain. 
$\Lambda$ deeper separation still of the polypi, as well as a greater amount of divergence one from another, brings us back to the arborescent forms assumel by the coral.

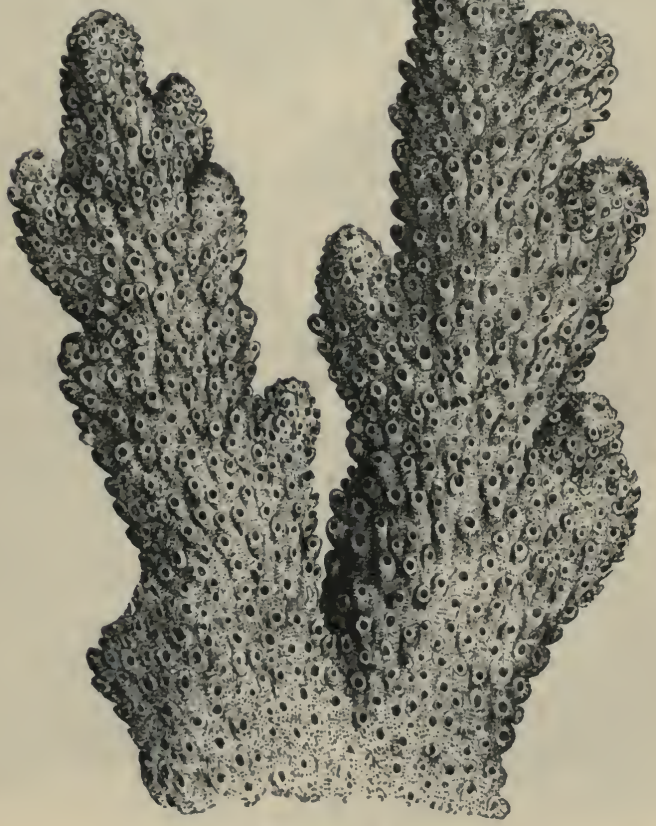

Fig. 39._Madrepora Pliutaginea.

The dendrophyllia, represented half the natural size (fig. 40), has a massive trunk, by which it 
seems to grow out of the rock as a tree out of the ground, and from which the branches procced in all possible directions. At the extremities of the

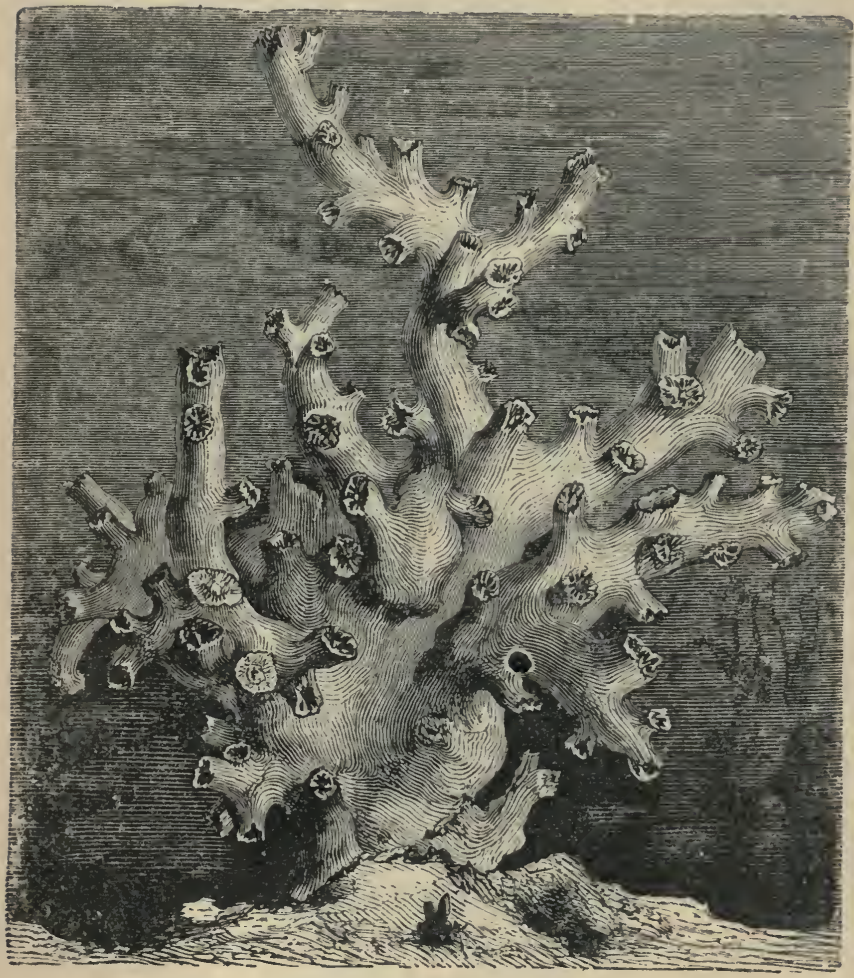

Fig. 40.-Dendrophyllia (half the natural size).

branches are the cuplike hollows in which the polypi live. 
A kindred species, the occulina, is remarkable for the excessive subdivision of its branches, as well as for their arrangement. The polypi are found both on the surface of the stems, and at their extremities, and every one of them gires birth to a new branch-the whole constituting a very elegant treelike formation. The type of the species is the Occulina virginea, sometimes called white coral. It is common in the Mediterranean, and is also found in the neighbourhood of the equator.

No such symmetry as we have observed in the coralline polypiers is to be found in the meandrina, or brain coral, of which there are some fine specimens in the British Museum. The polyps of this species have no tentacles around their mouths, but short lateral ones. They are huddled together in the shallow sinuosities which furrow the surface of the polypier; but sometimes they disappear altogether, as in a species found in the Red Sea. All that can be discovered in the furrows is a row of mouths. The sinuosities vary according to the species. Their numerous folds wind among one another like a maze, reminding one of the famous Cretan labyrinth; hence the name given to this species (meandrina, meandering). They are generally globular, or nearly so, in form, and are found of various sizes on isolated rocks. They are abundant 
in the Rerl Sea, ${ }^{*}$ but are still more frequent in the equatorial seas, where their size and their general aspect have suggested the name by which they are sometimes called by sailors-Neptune's Brain. A specimen in the British Museum is four feet in circumference. Their great size is accounted for by the manner of their formation. "As one fleshy mass expires," observes Dr. Mantell, "another appears and gradually expands, pouring out its calcareous secretion on the parent mass of coral : thus successive generations go on accumulating vast beds of stony matter, and lay the foundation for coral reels and islanàs." As remarked in Lyell's "Principles of Geology," "We may compare the operations of the zoophytes in the ocean to the effects produced on a smaller scale on land by the plants which generate peat; in which the upper part of the sphagnum vegetates, while the lowt $\mathrm{r}$ is entering into a mineral mass, in which the traces of organisation remain when life has entirely ceased. In corals, in like manner, the more durable materials of the generation that has passed away serve as the foundation on which their progeny are continuing

* "The whole bed of this extensive basin of water is absolutely a forest of submarine plants and corals. Here are sponges, madrepores, corals, fungiæ, and other polyparia, with fuci, :1gæ, and all the variety of marine vegetation, covering every pirt of the bottom, and presenting the appearance of a submarine garden of the most exquisite verdure."-Mantell. 
to spread successive accumulations of calcareous matter."

'I'he porites, or poritidie, belong to the same gruup,

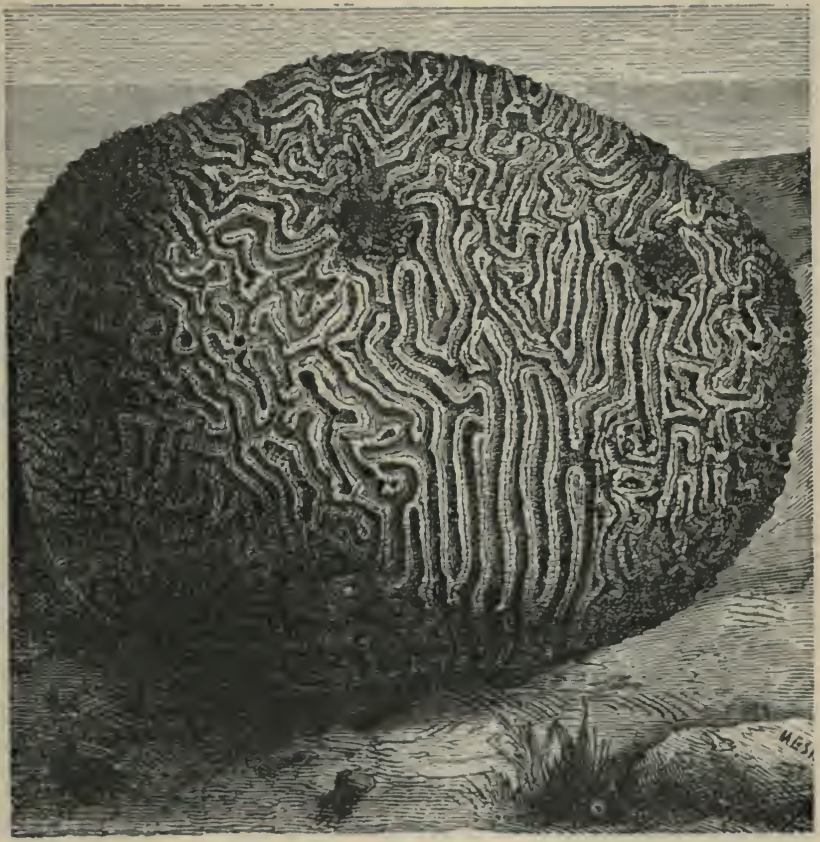

Fig. 41.-Meandrinit Cerebritormis.

and aro among the number of polypiers which often attain very large dimensions. Their substance is ealcareons. Their surface is riddled with pores, or rather little shallow cups, in which the living polyps 
are found. Most frequently the polypier is set with polyps from its foot to its summit, although those at

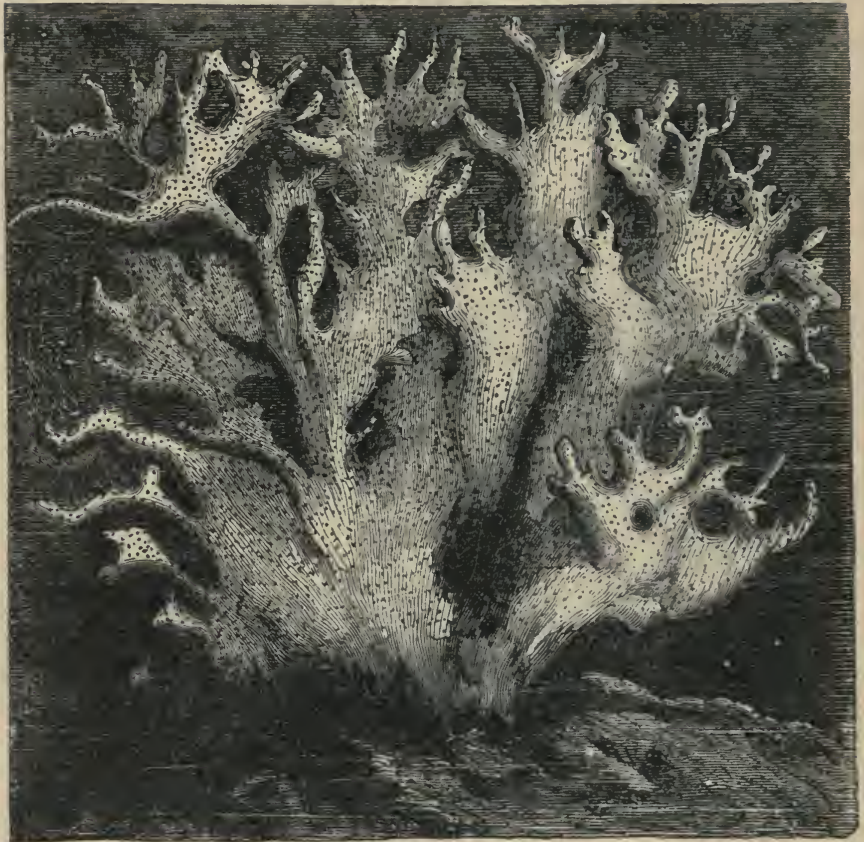

Fig. 42.-Millepora Alcicornis (one-fourth of the natural size).

the base may no longer be living. Each of these little animals is marked by the characteristics which we have noticel more than once. The number of 
tentarles differs in the various species, and is often very considerable.

When the polyps are removed from the stem, the little hollows with their imperfeet divisions become visible all over the polypier. The latter assumes the most varied forms, according to the manuer in which the poly ps are reproduced. Sometimes they are most complex and elegant, as in the case of the Millepora. alcicomis (fig. 42).

These animals differ from the astroides proper in the arrangement of their polypi, and from the corallines in the absence of the fleshy incrustation around the polypier. The polypier is wholly culcareous. Its development is owing to the hardening of the transverse divisions of the polypi and of their external covering. Their growth is irregular, and it leaves no trace of the animals themselves except the irregular pores. 'They are found in the seas of the North and of America.

The variety of entirely calcareous polypiers is very numerous. One in particular we must not overlookthe jungia, so ealled from its resemblance to the vegetable fungi. 'The animal of this species is gelatinous or membranous, somewhat oval in form, and much flattened. The engraving (fig. 43) represents a mouth in the centre of a large disc, the interior of which is made solid by a calcareous deposit, while the solid core is 
covered with plates or lamellæ, radiating from the centre towards the circumference. Protruding from the disc are a great number of tentaculie, which the animal

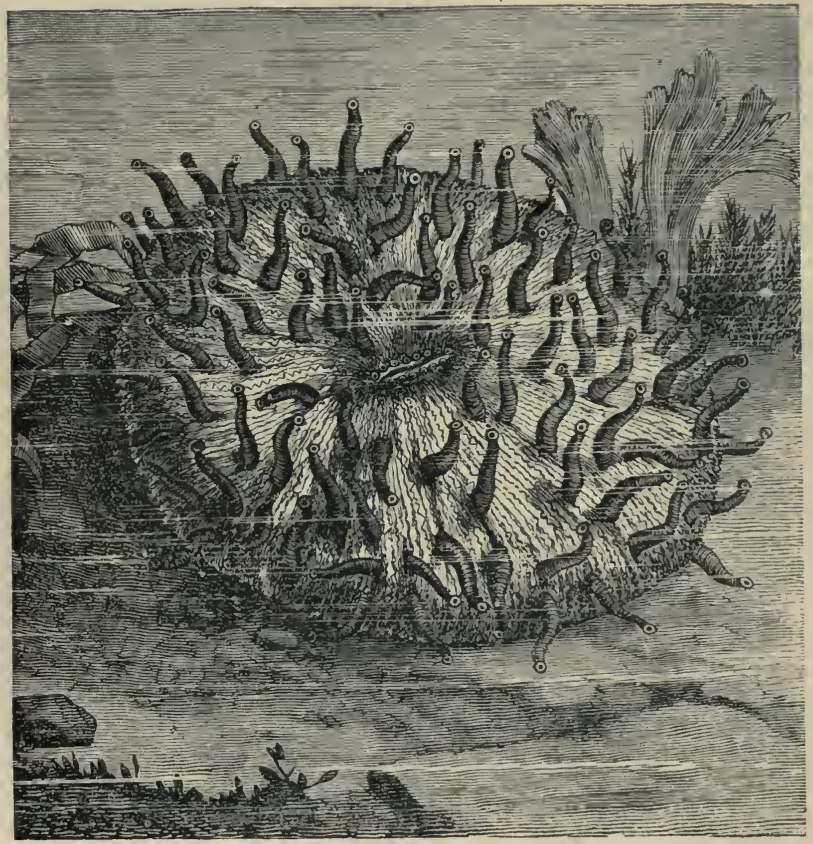

- Fig. 43.-Fungia Agaricitormis.

contracts or extends at will from between the sharp, thin plates of the polypier. At the end of each tentacle a sucker is represented; it is used by the animal to capture its prey, 
13. Gimley-slaves of the Sea-The Giants and Pigmies of Creation -The Suckers-Legends of Monsters-Singing Fishes.

'The greatest activity prevails beneath the surface of the sea. Were it possible to lift the veil, scenes the most varied and unexpected would meet our gaze. Creatures which inhabit the deep would be seen incessantly labouring to renew or adorn the earth. Some are engaged in the work of destruction, some in building up. The one class supplies the other with the materials which it fashions into forms of beanty.

Among those we have called destroyers, the pholas, though it plays an obscure part, is very remarkable. It does not browse on the animal flowers of the polypier. It does not play the part of a tiger in the sea, and devour armies of fish. It simply eats its way into the hardest stones, as the xylophagi burrow in wood. Even the hardness of gneiss is not proof against its patient determination.

At first sight we should be disposed to say that no weapon, no tool, aids this indefatigable labourer. 'The shell has two valves of the ordinary character, turning on a cartilaginous hinge. The body has two openings. Its substance is capable of being elongated so as to form a tube traversed by two channels-one of which serves for the absorption of water, the other to eject it as from a syringe, Tine soft rounded lo:y 
of the animal seems to be furnished with no organ by which uven the softest substance could be pierced. It has two teeth, but they are so deeply seated that it is impossible they could ever operate upon the walls of the retreat which the creature bores out for itself. Our attention is directed to the anterior part of the shell, which appears to be set with hard points, so arranged on the surfaces extending from the hinge, forward, as to form a kind of file. At this end, a short foot or tongue is protruded, by which the animal holds on to the rock, while at the same time it partly turns itself, and thus by the firiction of the serrated shell rasps away the chalk or rock. The work commences from the beginning of the creature's life. It first makes a slight hollow in the stone, in which it ensconces itself. In that position the water of the sei brings it sufficient food. Little by little, as the animal grows, it enlarges the shell in which it lives, and at the same time buries itself more deeply in the stune. Their advance is made almost horizontally at first; but having reached a certain depth, they suddenly change their direction, and bore out their reticat perpendicularly. It is at once theit Jwelling and their tomb, and in form resembles a common tobacco-pipe-the stalk debouching in the sea, and the bowl containing the animal.

In the regions frequented by pholades, the rocks 
are thus pierced in every direction. We even see enormous stones bored quite through, from side to side, by these destroyers. It was for a long time be-

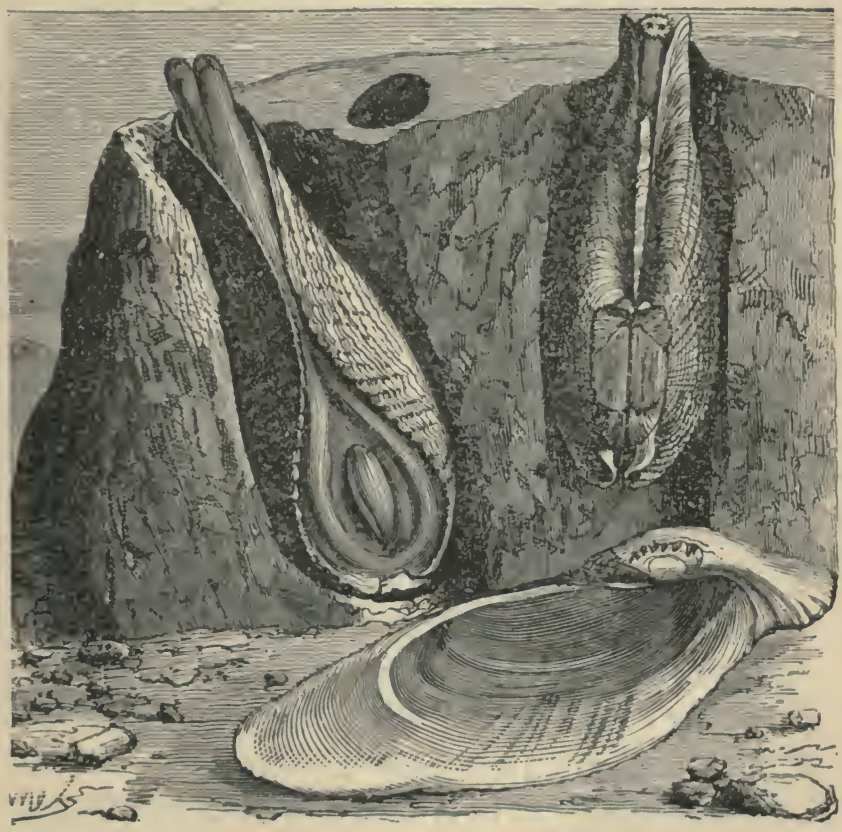

Fig. 44.-Gneiss bored by the Pholades Dactylus.

lieved that they effected their lodgment while the roak was in a soft state, and that it afterwards grew hard around them, and enclosed them as in a living tomb, owing to the petrifying virtne of the water. 
This opinion was abandoned when it was observed that the columns of the ancient temple of Serapis, at Pozzuolis, which had been submerged for many years in consequence of an earthquake, and again restored to the light of day, had been pierced all over by pholades.

Shut up in a prison from which they can never make their escape, these galley-slaves of the sea continue their work of destruction to the end of their lives, and they have only themselves to blame for their perpetual seclusion from society. Without the least care for the morrow, they go on boring their way through the rock, enlarging themselves and their stony habitation as they advance farther from the sea. The open end of this singular gallery is the gate by which the sea washes in all that these animals need for their nourishment, and for which the pholas repays the ocean in a perpetual tribute of dust. Every wave carries something into the mine, and brings something away-another and very striking example of the universal work of sedimentation.

Rocks too hard to be breached by the waves themselves, are thus eaten away and scattered on the floor of the ocean by the pholades. For others are the transparent waters, the romantic ocean ravines, or the extended plains of sand and mud. The oyster the solen, and the razor-fish linger in agreeable situa- 
tions, and enjoy abundance of water privilege. The pholades, like other molluses, exist in numerous colonies, but all the members of this great family obey the word of command. Their mission is to go for ever forwaril, extending or enlarging their mine, and leaving off work only when they die. Thus employed, their whole lives would be passed in darkness, if nature had not provided every one of these little miners with a lamp. The pholades are phosphorescent.

This fict was remarked by Pliny, but the cause of the phenomenon remained long unknown. Reaumur observed that if he washed his hands after touching a pholas, the water became phosphorescent; and at the end of a certain time the phosphorescent matter fell to the bottom of the vessel. We now know that the phosphorescence is die to a liquid continually secreted ly the body of the animal.

In contrast with these pioneers of the ocean, of these slaves who precede and assist him in the destruction of continents, there is a creature whose fate it is te float incessantly in the water, at the mercy of the most ('apricious winds and currents. We have already seen (in the chapter on the Colour of the Ocean) that the water holds in suspension a mass of microscopic beings. It is to the existence of these creatures that is due the yellowish milky, red. or olive-green tint 
so frequently observed. Freyssinet and Turrel observed, near the shores of Luzon, an extent of some sixty millions of square yards coloured a bright scarlet. This tint was owing to the presence of an organisation so small that forty millions of individuals occupied the space of a square millimetre.* As the discoloration extended to a considerable depth, it would be impossible to form even an approximate. irlea of the number of living beings which caused it.

Some of these microscopic creatures never develope to anything beyond a little cell surrounded with vibratory ciliæ, unequally distributed over the surface, and serving the creature either as rowers or as an organ for continually renewing the water which surrounds it by creating a current. Their mode of reproduction is extremely simple, and, at the same time, admits of their propagation with almost frightful rapidity. Abont the middle of the creature the body contracts like the division between the two parts of an insect, and the contraction increases until it separates into two. Each part goes through the same process as its parent, continually dividing into new creatures, until in about twenty generations a single infusoria may have engendered more than a million. One generation succeeds another very quickly. If, then, a variety of causes did not conspire

* A millimetre is $\cdot 03937$ ths of an inch. 
to check their increase, the infusoria would long since hava filled the world.

When the body of the animal is soft without any calcareous addition, we find no traces at the bottom of the sea of their short existence. But many species are furnished with a sort of shell, the débris of which constitutes the greater part of the sand formerl on the ocean-bottom.

The foraminiferæ contribute largely in conjunction with the infusuria to the levelling-up of the submarine valleys. Their microscopic remains - not very long known to be so, indeed-oceur in such enormous masses that no part of the earth's crust is of greater interest to the geologist.

If we compare with the whale, the shark, and other giants of the creation, the modest infusoria, the foraminiferæ, and the Noctiluca miliaris, of which we find as many as 25,000 individuals in thirty cubic centi metres of water, we shall be disposed to attach very little, if any, importance to the infinitely little. The giant attracts our eyes by his mass and his force, while we often strive in vain to see the pigmies of creation, as we should look in vain for an atom of dust blown by the wind. The giant, however, will pass avay, leaving but few traces of his existence. Here and there a bone or a tooth, perhaps a footprint, informs us of the fact that a monster once 
existed whose remains have long been the sport of the waves. The pigmies, feeble when taken singly, are powerful in their multitude. There are great animals in the ocean, but the armies of the infinitely little count by millions. The giants of the deep make their presence felt while they live; the pigmies of creation are the true world-makers.

'The first specimens of infusoriæ were taken from the bottom of the sea by the apparatus of Brooke, when the submarine plateau upon which reposes the telegraphic cable between Newfoundland and Irelan 1 was under investigation. The appearance presented to the eye was argillaceous, but the celebrated Professor Bailey, of West Point, having studied the specimens with the aid of microscopes, recognised numerous calcareous shells in a state of perfect preservation.

The average depth of the telegraphic plateau is something under 10,000 feet. That depth, though considerable, and exceeding the supposed thickness of the submarine vital zone, is far from marking the limits of the empire of the foraminiferæ. Where they cannot live, their spoil, so light, is carried by the ocean-currents, and deposited in obedience to the ordinary physical laws. Specimens obtained by sounlings made between North America and Asia have demonstrated the presence of their calcareous shells at depths exreeding 6000 yards. 
If we reflect that the sand of the seas is often almost entirely composed of these little shells, so variously and elegantly formed; if we remember that they have been accumulated by the action of marine currents in regions where their force is relaxed, that their débris meets with conditions favourable to their preservation in the calm deeps of ocean, who will not marvel at the enormous influence they exercise upon the distribution of the waters upon the surface of the globe? Yet we may state, on the authority of M. Alcide d'Orbigny, that many of these creatures do not exceed one-half or one-sixth of a millimetre in dimensions. The same authority states that he has found 30,000 individuals in half an ounce of fine sand brought from the Antilles, or thirty millions in a kilogramme. Another learned naturalist, Plancus, has ceunted about 200,000 in a pound of sand from the Adriatic.

The creative power is more wonderfully manifested in these small beings than in the great. The complicated organs and the harmonious richness of the most powerful mechanical appliances impress us in the giants of creation. Our astonishmient is greater still, perhaps, in face of the pigmies. The sea, in fact, is full of surprises. We imagine all that is mysterious beneath its waters. The furious tempests which disturb its surface and lash the air seem to 
assigu a limit to the habitable world. "The sea and all that therein is" appears surrounded with a poetic and miraculous aureole, which is the birth at once of fear and of superstition.

Before our ancestors had dared to launch ont upon the boundless ocean, the Mediterranean and its shores were the abode of the marvellous. As man extended the bounds of his empire, the region of wonder and superstition also gradually enlarged itself. Old records show that the Spirit of the Storms demander its victims of the first navigators who doubled the dreaded Cape of Good Hope; monsters the most hideous or grotesque were supposed to haunt the coasts of Norway; and the bottomless Maelstrom had its genii like the rocks of Scylla and Charybdis.

Popular tradition pointed to the existence of islands situated far away to the westward. The report went that, after the conquest of Spain by the Arabs, a certain number of Christians put to sea, and found refuge in the legendary islands, where they built seven cities. At the time of Columbus this supposed country bore the reputed name of Sette Citade, and was called by geographers Antilia, which name appears on the maps down to the end of the fifteenth century-together with that of another great island, situate in the latitude of Newfoundland, and called 
the Isle of Sutan. According to Arab traditions, a great hand rose every night from the sea, near the latter island, and, seizing the inlabitants, plunged them into a dark abyss. Myths of the highest antiquity refer to the Atlantic Ocean as the abode of the blest and the kingdom of the dead, and traces of these legends are preserved even to the present day in Scotland and Ireland.

On a certain occasion a fishing-boat, in the northeru seas, was engaged in the fishing of bishop-fish and monk-fish. The kraken, a monster of many square leagues in size, rose from the bottom of the sea; the vessel, receiving a shock as if it had struck on a rock, was sunk with all its erew and equipage.

Another form of monster, dreaded by the fearful and superstitious, had immense suckers and arms; a luge mouth in the midst of his tentaculæe swallowed all that he could seize; his arms were supposed to be liundreds of feet in length, and so powerful that they could enfold and crush ships of considerable size. The gigantic poulpe, or devil-fish, and the seaserpent, have been the subjects of the most marvellous stories, which in our day have been reduced to their just value. These terrible monsters generally resolve into immense cordons, or vast fields of algæ, interlaced one with another, and waving hither and thither at the mercy of every breath of wind which 
stirs the waves, or with the feeblest motion of the ocean-currents.

'The giant poulpe has yet to be discovered. We find, indeed, on rocky coasts, in the rugged fissures and caverns of the ocean, the well-known devilfish, hideous enough truly, resembling a sack with serpent-like arms surrounding a horrible mouth. With these arms the poulpe seizes. his prey in a far from agreeable embrace, and suckș him, as a spider does a fly, before swallowing him, so as to enjoy at his ease the juicy flesh of his struggling victim. 'These horrible creatures will sometimes attack man, though, generally speaking, they avoid him. In all the recorded instances, however, the danger and the horror have been exaggerated. An adventurer bold enough to thrust his arm into one of these glutinous sacks may turn it inside-out like a glove, and, contrary to what we have observed in the fresh-water hydra, the marine monster will not survive the operation. In one other respect it is very inferior to the hydra of mythology, for its arms are very far from possessing the power of recoil after a wound; if they are separated from the trunk, the collapse is instantaneous.

The calmars appear to reach much larger dimensions than the poulpes: they are sufficiently formidable to be dreaded by the savages who traverse, in 
their light cunoes, the waters which they frequent. 'These animals will seize with their arms a light boat and overthrow it if the tentaculæ are not cut away with a hatchet. The French corvette Alecton encountered a gigantic calmar in the waters of Teneriffe. The animal was secured by means of a harpoon and a rope, but the head with its tentacles dropped into the sea while it was being drawn on board, owing to the rope cutting through the soft flesh of the creature.

Marvels have been recorded even of the teeth, the skin, and the spines of certain species of fish. 'The hooked spines of the ray have almost invariably inspired terror. According to Allian and Pliny, the wounds made by the sting of the ray are incurable. 'The former relates that a thief who was making off with one of these fish was wounded by its spines, and died immediately. In our day fishermen have no fear of it at all. The Japanese consider that the best possible remedy for the bite of serpents is to rub the place with the spine of this species of ray. Many of the Japanese carry it about with them for the purpose, but, strictly speaking, to possess this virtue it must have been eut from the living fish and applied fresh to the wound.

The negroes believe that the sting of the ray is venomous, but they have no more reason for this 
idea than the Japanese have for their notion that it serves as an antidote to the bite of serpents.

Side by side with the legends, often of terrible import, to which the sea and its inhabitants have given birtl, we meet with others of a ludicrous character. Such is the belief, which prevails in the North of Europe, that the Anatifera concha engender's the barnacle-goose. The barnacle, as all the world knows, attaches itself to rocks, the shells of oysters, and other testacea-to any solid body floating in the water, especially to the hulls of ships, and to submarine telegraphic cables.

The protecting envelope of this animal is composed of five distinct parts. Through two opposite openings the ante : $_{2}$ or tentacles pass out; they are very supple, and covered with filaments; from another part protrudes the foot, which is analogous, in its external aspect, to the branch of a polypier. By this the creature fixes itself to solid bodies. In the midst of the tentacles is a kind of trunk, in which is a thin tongue, rolled into a spiral form, and of a deep colour. The trunk or trumpet-like process is transparent, and formed of a series of rings, diminishing in diameter from the base to the other extremity. The tentacles serve as a kind of net for seizing prey.

When the barnacle is taken from the water, it 
quickly dries up, and to such a degree that, after some days, it is very difficult to find among the shells the remains of the shrivelled animal. This has probably given rise to the belief in the marine origin of the wild duck. The canard rising from the water has broken its shell, and left nothing but its débris on the shore. Experience and reasoning are powerless in face of this prejudice. If the rustics of the North cannot say they have seen the canard leave the shell, the only reason is, they would answer, that it is hatched during the night.

Fabulous legends of this kind have lidden the true facts in a surrounding of incredible circumstances, owing to the strong inclination for the marvellous which has characterised young nations and oriental races. The sea was, in olden times, peopled by sirens who played a great part in navigation. Unlucky was it for the voyager who had too great a liking for art and beauty! Charmed by the perfidions but sweet songs of the siren, he became the sport of fantastic illusions; he saw imaginary coasts, and was wrecked on invisible rocks. The siren is a fabulous being. But harmonious sounds float over the ocean, though perhaps they are only those made by the sobbing of the waves, by the suash of the water against the ship's sides, or against the bulk of some great fish. 
Without reflection, it might appear that no other sounds than such as these contribute to the oreanic concert. Fish do not seem to possess any vocal organ, and if their throats were better adapted for the emission of sound, it is doubtful if we could hear their songs. Let us remember that sound results from the vibration of some elastic, gaseous, liquid, or solid body-that sound travels more rapidly in water than in air. Considering that the celebrated physicist Cagniard-Latour has constructed a little apparatus, by the aid of which sounds are produced at will, in the air or in the water, and which for that reason he calls the siren, we need not be astonished to learn that many fish emit sounds, and that in some instances these sounds assume the character of true singing.

Without speaking particularly of the coincoin, whose grunting sas peen compared to the cry of a wild goose; of the vieille, which ntters a plaintive cry when it is seized; or of the tunny, which wails like an infant when taken from the water-let us listen for a moment to an account of a discovery not many years ago in America. The narrator, Mons. O. de Thoron, was walking one day on the shore of a bay situated to the north of the province of Esmeraldas, in South America. All at once, when the sun was setting, he heard with astonishment an 
indefinable sound, very sonorous and long sustained: In that country, where the insect race is often very troublesome, he thought at first that the sound proceeded from insects of unusual dimensions. Failing to discover anything of the kind in the air, or on the sea, he questioned a man who was rowing by, and was informed that the sound proceeded from a fish, called by some the siren by others the musician. M. de Thoron, desirous that no other sound should interrupt his enjoyment of this phenomenon, requested the boatman to rest on his oars. All around a multitude of sounds rose from the sea, forming the most singular concert it is possible to imagine; the undertone of a church organ heard at a consiclerable distance might be said to resemble it. The concert commenced at sunset, and continued all through the night. The presence of auditors, M. de Thoron observes, did not seem in the least to intimidate this new species of choristers.

'They build, they feast, they make love, they steal; they live in captivity, in freedom, or are enslaved in the ocean. As Frédol says, "There is joy in its waves, there is happiness on its shores, there is a pervading bliss throughout all !" Animal life displayed in the most opposed forms, the most grotesque organisations, appears in greater beauty than on the withered earth. 'I'ribes of living creatures rejoice incessantly 
in the most marvellous variations of light and shade, in the most fairylike illuminations, changing and reversing at every instant. They almost talk, they murmur their complaints, they sing, they get up concerts of which we can form but a feeble idea. What then is wanting to the completeness of life in the Ocean?-Only MaN.

14. Algæ-The untrodden Forests and Prairies of the. OceanAnimal Life more abundant than Vegetable Life-Sea Plants less widely distributed than Marine Animals-Influence of Light-Collection of Seaweed on the Coasts-Assistance afforded by the Tide.

Marine vegetable life is very far from equalling in richness the animal life of the Ocean. The marine flora is limited almost entirely to one class of plantsnamely, the algæ tribe. These plants assume the most strange and grotesque forms imaginable. The number of species seems almost unlimited. The learned Linnæus counted only fifty, but at the present time at least 2000 are known.

As we have remarked in an earlier chapter, the marine flora is developed to the greatest extent in the temperate zones. Its extent and variety may be appreciated from the fact, that in English waters, 105 genera and 370 species of algæ may be counted. The richness and variety of this class of plants diminish gradnally as we recede from the temperate 
zones towards the equator or the poles. " It is, moreover, remarkable that the law under which the animal kingdom, which more readily adapts itself to surrounding circumstances, becomes more extensively developed than the vegetable kingilom, applies to the ocean as well as to the land. Thus the polar seas abound in whales, seals, fish, and aquatic birds, and are populated by an infinite multitude of inferior animals, when all vegetation has disappeared from this region of ice and cold. This law is also found w apply as we descend deeper into the ocean, for in so doing we discover that vegetable life disappears much sooner than animal life: indeed, in abysses where hardly a ray of light can penetrate, soundings still demonstrate the presence of living infusorix."

We know what life does, although we know not what she is. 'There is no region of natural phenomena to which this remark applies more forcibly than to the ocean. We there see animals blooming; so to speak, in the most brilliant and varied colours, like flowers, and flowers almost without colour.

On the other hand, the animals lose their power of motion, and become more allied to the alga themselves. Modern investigations show that, during the first part of their existence, vegetable cells have the motions characteristic of animal life, so that the alge might almost be cousidered as varieties of 
polypier, linking together the two kingdoms of nature. But the algæ do not petrify like the polyp, to whose labours we owe the existence of the coral reefs of the Pacific; they remain soft and flexible, at the same time establishing immense colonies of their kind.

What striking objects, what prodigies, do we find in each step of our submarine investigations! Is it matter of astonishment that in the presence of these marvels man's mind should have invented that fairy mythology, the memory of which has been partly perpetuated by the legends of the middle ages?

Marine plants are sometimes microscopical. 'Their floating millions sometimes colour the sea; among others, the Red Sea owes its name to such circumstances. At certain seasons of the year, this sea swarms with filamentous confervæ of a beautiful purple colour. The beautiful tint which has from a remote period given thissea the name of Eryth ræan, is due to the infinite numbers of the marine confervæ. In other cases marine plants attain gigantic dimensions. The Wellingtonia gigantea is no dwarf in size, but what comparison can there be between it and the Varec porte-poire of Terra del Fuego, which grows to a height of 1000 feet!

Marine plants have no need of earth. They grow 
anywhere, as their nourishment is not obtained from the soil; but from the sea itself. For the same reason they hare no root; indeed, the species which float have not even the semblance of roots, while those which remain stationary are attached by a species of sucker more or less lobed or divided. The earth goes for nothing in their development, because their origin is always exterior. 'Their whole growth is in the water, which supplies all they need, and to which all ultimately return. Land regetation would not find sufficient subsistence in the atmosphere; it requires a suil, and trunk, and branches. The alga is supporterl by the water on which it feeds; it is held down by the rock or earth to which it is attached; if it becomes detached, instead of falling like a tree, it rises and floats on the surface of the water.

As terrestrial plants yield a resting-place for the eggs of birds and insects, so do seaweeds for marine animals ; but, instead of supporting them, it prevents them from rising to the surface, and also shelters thein from the voracity of the monsters of the deep.

As the insect tribes establish their republies in the trees of our forests, so the sponges attach themselves to the light algae, and the polypi take them for their fragile base. Even the sea-worm, like the terrestrial scrpent, winds its encircling length around the stens, the better to seize its prey. 
How strange a tree would look which, torn up by the tempest, should rise through the atmosphere and float above the clouds! Such phenomena occur continually in the ocean. The marine currents detach plants of all kinds from the bottom of the ocean. They collect in parts of the ocean where the currents are weaker. There they form immense floating islands, which sometimes hinder the progiress of ships.

Light is as necessary for marine plants as for terrestrial ones, and this prevents them from living at a great depth; still they grow many hundred feet below the surface, where light penetrates but feebly. Shells are distinctly visible in certain parts of the Arctic Ocean at a depth of 460 feet; at a depth of 940 feet the light is still of sufficient intensity to permit the objcets to be seen dimly. The bottom of the sea is equally visible at the same depth in the Antilles, but the objects are not distinct. Absolute darkness prevails at a depth of 1000 feet. 'The: rays of the moon penetrate only to a depth of about 40 feet.

It is, therefore, within a limit of 1000 feet in depth, or about one-tenth of the average depth of the seas, that marine plants vegetate, forming a belt around our continents and islands, or crowning the summits of submerged mountains.

Has light any influence on the colour of vegetarion 
in the sea? Modern botanists have proved, experimentally, that plants are very sensible to the action of light, and it has been found that marine plants are of different colours, according to the depth at which they grow.

They have been divided, according to their prevailing tint, into three main sections: the brown or black (melanospermea), the green (chlorospermea), and the red (rhodospermea). 'The green live only near the surface; they often float, and are found in large quantities in the grassy seas. The red are found at small depths on rocks near the coasts. The brown, which are much more numerous, grow at greater depths. They constitute the greater part of the submarine forests.

Although the algae occupy, relatively, but a small portion of the earth's surface, being distributed in what may be called oceanic belts, their number is immense. Wherever the physical conditions are favourable to their development, they fill the sea with their impenetrable masses. This abundant vegretation is utilised by man, whom the sea itself aids in collecting them. Wind-storms sometimes prorluce terrible effects, but oceanic storms far exceer them in destructive force. If the first overthrow chormous trees or immense edifices, the latter easily tear whole forests of marine plants from their 
feeble hold of the soil or rocks. This madness of the ocean is man's gain. On the various coasts, and especially in the bays of the ocean, he collects the seaweed which is thrown ashore by each tempest, and even by every tide, in quantities which may be called incalculable, and yet the supply seems never to diminish. There are bays in which 30,000 people are sometimes occupied in gathering this spoil.

Seaweed makes very bad fuel, but it is occasionally used for firing. Its most important use is as manure, or as the raw material of soda, which is extracted from its ashes. A still more curious application of it is made by the Dutch, who use seaweed in constructing the dams which preserve their lands from the inroads of the sea: thus the ocean itself furnishes the materials which are to be opposed to it as an obstacle. Alas! we know too well that the courageous efforts of the inhabitants of the country must at last fail, and that the sea will again assert its dominion over the earth and the ephemeral works of man! 
MAN AND HIS WORK AT THE BOT'TOM OF THE SEA.

1. The Empire of the Seas denied to Man-Numerous attempts at Submarine Exploration-I)isturbance of present social conditious which would ensue from the possibility of travelling beneath the surface of the Water-The Sea the best tie between Nations.

AIR is necessary to the life of man ; his organisation forbids a too protracted stay beneath the surface of the water. If he dives he is soon compelled to return to the surface. $\mathrm{He}$ is, therefore, unable to acquire any extensive acquaintance with the submerged part of the earth, for no sooner does the depth exceed a few feet than some special apparatus becomes requisite. The explorations which have been made, however, besides their theoretical importance, have resulted in great commercial gain.

What enormous wealth has been engulfed in the sea since man first dared its dangers, and entrusted his treasures to its fatal grasp! Each year a further tribute is levied by the moving torrent of waters, which yields up, here and there, an insignificant portion of its spoil, but jealously guards the more precious 
treasures in its secret bosom. How could the faintest hope exist that the mighty ships laden with rich merchandise, which have sunk beneath the surface, could ever again be recorered? What man so daring as to attempt their extraction, piece by piece, from the ocean which hides them with such jealous care?

Every such enterprise was for long considered merely chimerical. Even now, any attempt of the kind is, in most cases, impracticable; and in those rare instances where some hope of success may fairly be indulirerl, it is only by great sacrifices, and by the exercise of much ingenuity, that our expectations are adequately realised.

In presence of the vastness of the sea, man is involuntarily impressed with mingled respect and terror. He may sail about on its surface boldly enough, but he penetrates its depths with hesitation. In his pursuit of a marine monster, he harasses it so long as it imprudently remains near the surface of its vast empire. No sooner, however, does the monster feel the power of his enemy, and the danger of remaining within his reach, than he sinks, though only a few yards, down into the abyss of waters, and man's power of pursuit immediately ceases.

If nature had gone so far as to endow man with a large reservoir, where, like the whale and other seamonsters, he could store up a sufficient volume of 
air, and carry it with him to the farthermost depths of the ocean, what service could he extract from so marvellous a provision, if his eyes, constructer so as to give him the power of vision in a limpid and dazzlingly luminous atmosphere, made him conscious only of darkness, and left him a defenceless prey to the voracity of the monsters of the deep?

But man is ambitions to assert his sovereign right over the whole globe; universal nature is his inheritance, and he studies her every phase and all her changing humours with patience. In his thirst for knowledge he fearlessly grapples with, and seldom fails to overcome, whatever obstacle may be thrown in his path. With a sublime audacity he would penetrate and master, in every direction, an empire the limits of which appear to him to be too narrow. $\mathrm{He}$ is not satisfied to run with lightning-speed over the surface of the earth; he would also cleave the air like a bird, and dispute their darkest and dreariest retreats with the inhabitants of the seas. As if couscious of her irresistible attractions, the Ocean allows him occasional glimpses of her treasured charms, and, at the same time, one might almost say that she defies him to deprive her of any portion of them. Corals, sponges, and pearls have to be snatcher from her depths. The magnificent purpl of the ancients-sepia, nother-of-prarl, ambergris- 
are but a few of the valuable substances which are well known to be of oceanic origin.

Ambition and the love of gold are an almost universal motive power. Poverty and fear often supply their place. The first attempts at circumnavigation were made by daring sailors imbued with a desire to make a rapid fortune. Sponges and pearls were long procured exclusively by the labour of slaves. In many parts of the world the old fashion is still followed, insofar that diving is the only means employed to obtain those treasures of the deep. The process is of the most primitive kind. On reaching the scene of his labours, the adventurous diver detaches the sponge from the rocks to which it is fastened; nets are suspended from boats and sunk within reach of the workmen, who fill them with their spoil, and, on a signal being given, the well-laden nets are drawn up by a cord.

Edible oysters inhabit the European and Indian seas; they are very abundant on the French and English coasts. Oyster-fishing is carried on by means of a net furnished with a scraper, which is dragged over the rocks to which the oysters are fixed. The oysters detached from the bottom are accumulaterl in the net, together with any other animals which accompany them.

As Goldsmith relates, the unfortunates condemned 
to the painful and laborious occupation to which we have referred on the coasts of Persia, are either the negroes or the poorest of the inhabitants. Divers not only run the risk of drowning, and of being devoured by sharks, but they are also in danger of being suffocated in consequence of having to hold their breath for a protracted time; and if no worse effects ensue, this condition often results in bloodspitting. 'T'he most robust and healthy young men are chosen for this trade, but they can seldom continue in it for more than five or six years. Their filres stiffen, the pupils of their eyes become red, and they often die of consumption. . . They deposit the pearls, or rather the oysters which contain them, in boats 28 feet long, of which there are often 300 or 400 at sea at one time. Each of these boats has seven or eight stones, which serve it as anchors, and on board are from five to eight men, who dive by turns. They are all naked, 'ut have a net suspended from their necks, into wich they throw the oysters; their hands are gloved, to preserve them from the wounds which they might otherwise get in detaching the shells from the rocks. They descend with the help of a cord, $t$ which is attached a weight of about 50 pounds. They plare their feet in a kind of stirrup; with the left hand they hold the cord, and with the right they close the nostrils, to prevent 
the exit of the air, of which they have taken a deep breath previous to their descent. Having reached the bottom, they commence operations by giving the signal to those who remain in the boat that they may raise the stone, after which they set to work collecting the shells, with which they fill their nets as speedily as possible; they then make another signal, upon which the net is raised, and immediately afterwards they themselves rise to breathe. All the shells are carried to the shore, where they are piled in heaps until the fishing-season, which lasts during November and December, is at an end.

The holothuria, or trepang, much sought after in Asia, is gathered by divers, or harpooned on the bodies to which it attaches itself. The harpoon is fixed to the extremity of a series of long bamboos fitting one within another. Leaning over the bow of his boat, the fisher gazes into the depths of the sea; the most perfect calm is indisponsable, and it is asserted that in such case he can see, at a depth of 100 feet, the animal attached to the rocks or coral banks; the harpoon descends as gently as possible until it reaches the animal, when it strikes it suddenly, and rarely in vain.

In tle greatest number of instances the diver descends as far as his sight will permit him, but this s to a slight depth only Modern apparatus facilitates 


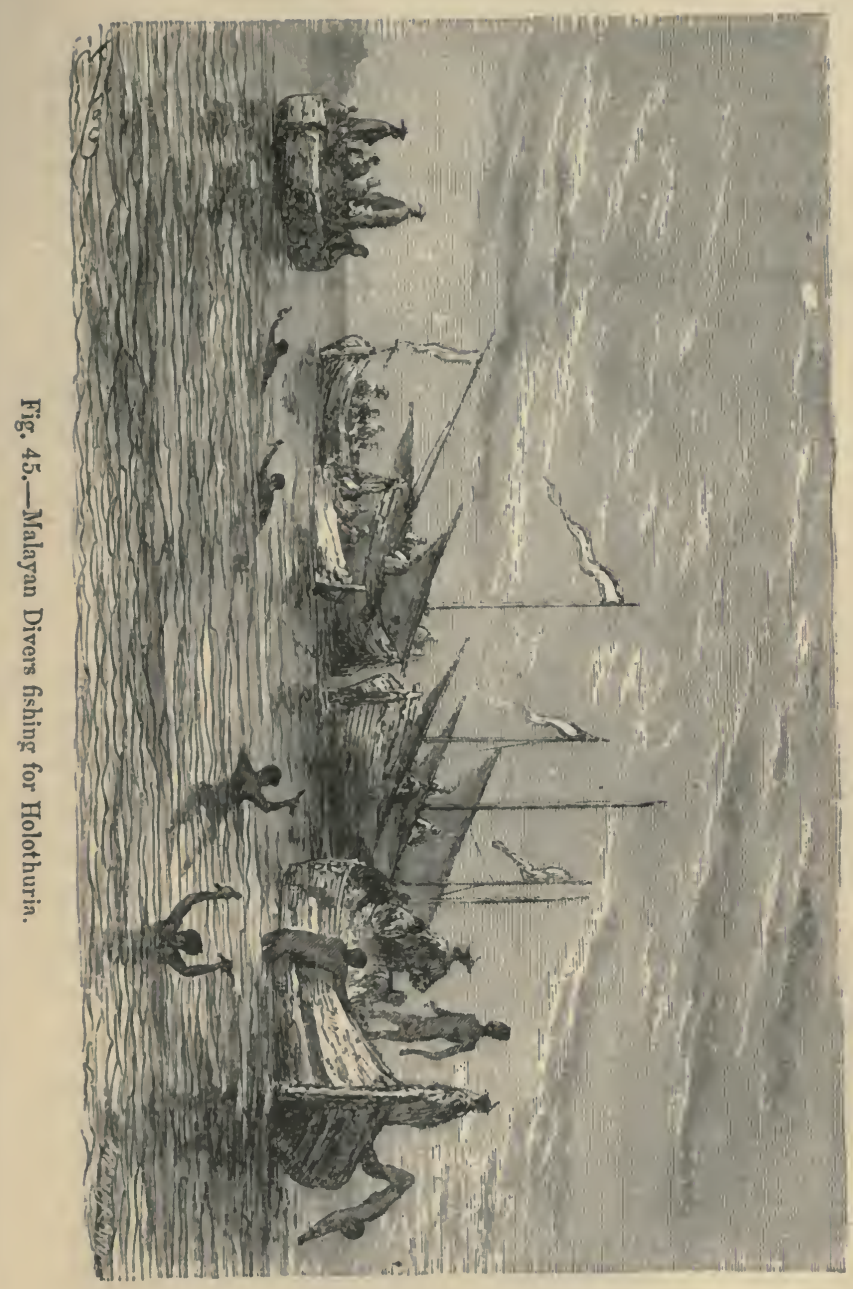



his expeditions, but it has not much extended tneur rarlius. In fact, the pressure supported by tne intrepid explorer augments by one atmosphere when he has reached a depth of 32 feet; it soon becomes so great as to involve conditions in which it wonld be impossible to live. Aspliyxia, ravenous monsters, and darkness, are not therefore the only obstacles which man has to encounter in his submarine explorations. He cannot descend into the immense oceanic valleys as he faces the cold and rarefaction of the air on the high mountains of the terrestrial surface. Beyond the region of the monsters he must enter the realms of darkness, and, should he go further still, encounter sure destruction.

Who can form an idea of the immense changes which would result if men were able to travel free! $y$ under the surface of the waters? Where would be the natural frontiers which politicians so much desiderate? Man darting through the air like a bird; locomotives competing with the eagle in point of speed, and losing themselves in the midst of the clouds; powerful machines plunging beneath the oceanic tempests, and scattering in terrified hosts the multitudinous inhabitants of the sea! Who would dare to entertain for one moment dreams or aspirations of so chimerical a nature? Great minds have nevertheless devoted their labours and thoughts 
to sich objects, and we shall presently see how they nave partially resolved the question in respect to the Ucean. Sailors of a new order may now be shipped for submarine expeditions; the adventurer can already carry with him a provision of air, light, and food; he can sink or rise at will, or maintain himself at any particular depth, like a spirit of the deep; he can suddenly maike his presence felt in the midst of a fleet, or on a hostile coast, before the astounded enemy has time to prepare for defence; he can discharge his powerful batteries and engulf himself in his adopted element, like a true marine monster, while they seek in vain for the cause of the disaster with which they are suddenly smitten.

If a few steps have been made towards the realisation of such marvels, how many more still remain to be accomplished! It will perhaps never be man's lot to tread the hitherto unfathomable abysses of the sea; the hum of civilisation will never disturb the profound peace which the monsters of the deep are themselves bound to respect. At any rate, there must be patient waiting through a long series of ages for this result, and we must leave to our descendants the rare of adding another chapter to the history of the earth. They may perhaps see cultivated lands, forests, and mountains, where the present level of the sea permits only a wild waste of waters; or perhaps they may, 
in digging their roads, canals, and tunnels, study the deposits now in course of actual formation, whilst coral reef's, sponges, and oyster-banks will cover the edifices of which we are now so proud.

Without descending to any great depth, we may see even near the surface and the coast, in the midst of reefs which seem to permit man to penetrate the oceanic waste but to forbid his return, submarine life conspire with the waters to bury out of sight the evidences of the destruction they have wrought. The nations would be rich if the sea did not levy a heavy tribute upon them. But the sea only corrodes and wastes the spoil it seizes; the abundance of oceanic life engulfs it a second time. Molluscs, barnacles, and seaweed very readily attach themselves to bodies plunged into the sea. Ships which make long voyages sometimes become loaded with so enormous a cargo of shells and barnacles, that they resemble floating aquarii, and lose much of their speed. The work of the sea is incessant. Every hour, every minute, adds to the thickness of the covering with which she conceals her thefts; and so long as the methods of search remain as imperfect as they are at present, we must be content if we recover ocasionally such fragments only as this fascinating monster is willing to render up.

We are prevented by a variety of causes from 
exploring by far the larger portion of the earth's crust. Nature has been jealously careful to remove it from our sight, to preserve it from our unappeasable curiosity. Should we not congratulate ourselves on this fact? And does not this water, which hides so many marvels, serve now, and has it not always served, to human need, as one of our most powerful auxiliaries? It is water which most facilitates the relations that are established between the inhabitants of different countries, which invites to exchanges and transactions of all kinds, and is in fact the soul of commerce, of which civilisation is the offspring.

Though flourishing on the coasts, civilisation penetrates but slowly into the interior of continents. By the sea it is speedily transmitted from shore to shore of neighbouring islands, and so on to the remotest. On the continent it sprearls slowly, step by step, and its progress is almost invariably parallel with the course of rivers and streams. Remove the water, and civilisation would disappear; the desert would again reign supreme; one waste of sand would cover everything with a moveable shroud, like the waves of the sea, but even more terrible. How many have paid with their lives for the audacity which impelled them to penetrate the secrets of the desert!

To all who have the courage to confide in her. the 
sea provides a means of transport at once agreeable and conrenient. The sea supports the load, the wind propels it, and man directs it on its journey. From this easy means of transport results a great commercial movement, a circulation of ideas as well as products, which enlarges the field of industrial genius, encourages useful inventions, promotes that affability and those humane feelings which spring from much intercourse, and, in a word, developes relations between one people and another which could not otherwise be established. Further, the discoveries of sailors, the voyages to distant countries, to very different climates with varied productions, the rapidity of exchange, and the wellbeing which results, are the first step towards that universal union which is the end and aim of all civilisation properly understood.

2. Exploration of the Bottom of the Sea-Diring Apparatus-Invention of MMI. Rouquayrol and Denayrouze - Submarine Electric Illumination-Salvage of objects sunk in the Sta-A Chest of Gold recovered under peculiar eircumstances in the: Port of Marscilles.

'The exploration of the bottom of the sea made but little progress in ancient times, or in the middlo ages. During many centuries the few attempts of which we hear are rather of a legendary than 
authentic character. We can scarcely be astonished at this when we picture to ourselves the profound ignorance which prevailed relative to the properties of gases. Aristotle, for example, wishing to demonstrate the weight of atmospheric air, weighed an empty bladder, and the same bladder again when filled with air, and found no difference between the two results. Hardly three centuries ago, the fact of water rising in the tube of a pump was explained by the supposition that Nature abhors a vacuum.

It is hardly a century since the celebrated astronomer Halley, commencing the experiments in submarine exploration which have been continued to our time, descended to a depth of 50 feet in a diving-bell which he had constructed. English engineers utilised this invention until the year 1830 , in building the immense submarine structures with which they have covered the English coasts. At this time another apparatus, more convenient aud at the same time less costly, gradually replaced the diving-bell.

The object of the diving apparatus, to which we are now referring, is to give to each individual workman the utmost possible liberty of movement. An impervious habit, made of cloth and metal, allows him a certain liberty of motion, which he cannot possibly have when enclosed in a bell. A pipe com- 
Inunicating with the interior of his clothing supplies him with the air necessary to respiration. This air is supplied by a lift and force-pump, placed on the bank or in a buat. 'This appariatus is of French origin.

Attempts of a different kind were made, at the end

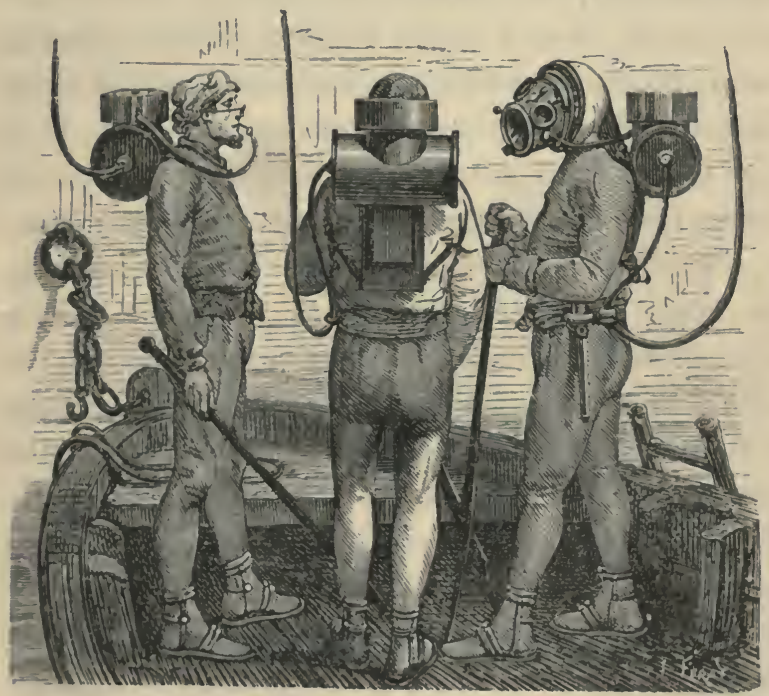

Fig. 46.-Divers dressed in the Apparatus invented by MM. Rouquayrol and Denayrouze.

of the last century, by an inhabitant of Breslau. A diver descended into the water carrying his supply of air in a reservoir, into which large quantities of 
this gas had been compressed. The man cerried this reservoir on his back, and it communicated with his mouth by a tube.

Mhurr also made attempts to improve the apparatus in France, but without superseding the original invention. In England some form of the apparatus was constantly used, and, in 1830, the discovery of caoutchouc gave a great impulse to this industry, and improvements became more feasible, at the same time that they were more necessary than ever. This was the state of affairs when two Frenchmen-M. Rouquayrol, a mining engineer, and M. Denayrouze, a naval lieutenant-solved this difficult problem. Their apparatus suffices for all the exigencies of subaqueous work. Whether the man be naked, or covered with impervious clothing, his respiration depends entirely on the exercise of his own will, anu on the power of his lungs.

This result is obtained by means of an artificial lung or supply-regulator, which consists of a reservoir made of steel or iron, capable of resisting very great pressure, and surmounted by a chamber so constructed as to regulate the afflux of air. The diver carries this apparatus on his back. A respiratory tube issues from this chamber, and is terminated by a mouthpiece composed of a piece of sheet-caoutchouc, which is held between the lips and the teeth of the diver. 
This pipe is furnished with a valve, which permits the expulsion of air, but opposes the entrance of water. The steel reservoir is separated from the air-chamber by a conical valve opening from the air-chamber towards the reservoir in such a manner, as to open only by the influence of an exterior pressure-the pressure of the air in the reservoir tending to close it.

It is obvious that the use of this apparatus renders the regular working of the air-pump unnecessary. The air which it transmits to the diver is stored up in the steel reservoir. From this store the diver can supply his needs without fatigue in the following manner.

The air-chamber is closed by a moveable lid, to which is attached the tail of the conical valve. The diameter of the lid is somewhat less than the interior diameter of the chamber, and it is corered with caoutchoue to render it airtight. It yields to both interior and exterior pressure-the former causing it to rise, the latter to fall.

When exterior pressure is exerted on this lid, the valve is inmediately affected through the intermediary tail or rod; communication between the reservoir and the air-chamber is opened, and a portion of the compressed air flows into the chamber. Should the latter contain an excess of 
air, the pressure of it against the moveable lid keeps the valve closed.

The entire apparatus, when under water, works as follows. By drawing in his breath, the workman removes a certain part of the air from the chamber; exterior pressure is then immediately exerted on the moveable lid, which falls, and through the intermediate rod causes the valve to open. Air issues from the reservoir, and re-establishes the equilibrium between the interior of the air-chamber and the surrounding medium ; the lid rises, and the conical valve, returning to its former position, again intercepts the communication between the reservoir and the air-chamber, until another aspiration brings about a repetition of these phenomena. When the workman respires, the valve, which we have already mentioned as existing in the respiratory tube, permits the air expelled from the lungs to escape into the water.

This apparatus works automatically; whatever be the irregularity in the working of the air-pump, its action is as regular as that of the steam-engine. The workman receives exactly the quantity of air necessary for respiration ; this air reaches him at a pressure equivalent to that to which the rest of his body is submitted, and he is able to breathe without attention or effort.

MM. Rouquayrol and Denayrouze, not content with itaving enabled the workman to breathe independently 
of the action of the pump, have considerably improved the latter apparatus by constructing pumps in such a manner that the leakage deereases, until, as the pressure increases, it can scarcely be appreriate.l.

It is well known that air becomes hot simply by being strongly compressed. The supply of air in the heated state is injurious to the divers. The pumps of which we speak, and in which the air traverses two layers of water before entering the steel reservoir, remedy this inconvenience. Moreover, the air, in passing from the steel reservoir into the air-chamber, from whence the workman is supplied, expands again and becomes still cooler. Another important advantage connected with this apparatus is that the expired air rises in bubbles to the surface. So long as the diver breathes regularly, the intervals which separate the appearance of the bubbles are sensibly equal. If they come more rapidly or more slowly than usual, it is a sign that something abnormal is going on. If they cease altogether, the diver must have ceased breathing, and should be hauled up immediately.

In the old diving-dress the air filled the space betwixt the body of the diver and his impervious clothing, the expired air escaping by a little valve fitted into the helmet. But the excess of air transmitted by the pump also escaped by this valve. Irregularity in working the pump would therefore 
cause irregularity in the escape of the bubbles, and if the pumpers continued their work they might, quite unconscionsly, for a long time continue to send air to a corpse. With the new apparatus, however, the escaping air affords constant evidence of the health of the diver. The moment he requires help, his attendants are on the qui vive, while in the former case they could know nothing of his condition. This advantage in the new apparatus can hardly fail to encourage the most timirl.

Further, he who wears the old apparatus exposes his life much more than he who uses the apparatus of Rouquayrol and Denayrouze. His life, or at least the security and duration of his labours, depend entirely on the strength and substance of his clothing. In the new system the caoutchouc dress serves only to protect the diver from the cold. It requires. therefore, much less solidity than the other, and thus leaves the diver greater freedom of motion.

MM. Kouquayrol and Denayrouze have done everything to bring their incontestably useful apparatus within the reach of all. Experiesced and intelligent divers are no longer requisite-neither is it necessary to employ workmen accustomed by long practice to work the pump in a uniform manner. We have already seen how the diver is enabled to obtain a regular supply of air in spite of any irregularities 
in working the pump. The substitution of a simple mask, in place of the helmet hitherto in use, allows the dress to be closed hermetically with much greater facility, a single bolt effecting this completely.

There are, nevertheless, several precautions necessary. If these are not ohserved, the miners run risks which are, to say the least, disagreeable. The pressure to be supported increases by one atmosphere for every 32 feet of the depth. The workman's body is therefore under a pressure of about four atmospheres when at a depth of 100 feet, whilst at the surface he would be under the pressure of one only. A rapid transference from one pressure to another so different cannot be effected with impunity. But the body will gradually become accustomed to these new physiological conditions, if the man begin by descending a few teet, and increasing the depth day by day. Even with this preliminary training, each descent should be made very slowly. The return should be even more slow; and to avoid all inconvenience, it would be well to allow about one minute for every six or seven feet of rise. If these simple recommendations are not followed, much suffering may be caused-such as singing in the ears, and headache. The workman must be trained gradually, as is the case in all borlily exercises.

The light is very feeble beneath the water, and 
darkness increases with the depth, soon becoming such that the workman has to grope his way aboutmore especially where the bottom is muddy, and in parts where it is impossible to see beyond a depth of twelve or fifteen feet. To remedy this serious inconvenience, attempts have been made to use an oil or spirit-lamp, and even a simple lantern lighted with a candle. A pipe, communicating with a pump, is needed to convey the air necessary for combustion; another, rising to the surface, permits the escape of the products of combustion. Withont referring to the inconvenience which was generally felt in working these lamps and their two pipes, the light was always found insufficient. The dense air transmitted by the pumps gave rise to the singular phenomena to be observed in compressed air-tubes; the wicks carbonised, the light was pale, and lasted hardly a quarter of an hour. These difficulties have been overcome by employing the electric light. A perfectly watertight lamp of iron or brass encloses the regulator of an electric light on Serrin's system. 'The wires which conduct the current enter the lamp by traversing a non-conducting plug of tow. The current is derivea from a pile of fifty elements, and a dazzling light, equivalent to two thousand of Carcel's jets, is obtained. The sides of the lamp resist the pressure exerted by the water, an' the gases, becoming dilated 
by the heat, escape by means of a little valve analogous to that used in the artificial lung.

The regularity of the light thus obtained depends only on the regulator itself, and not at all on the depth; it will maintain its energy for about three hours, and then it is only necessary to ch.mge tle carbon-points.

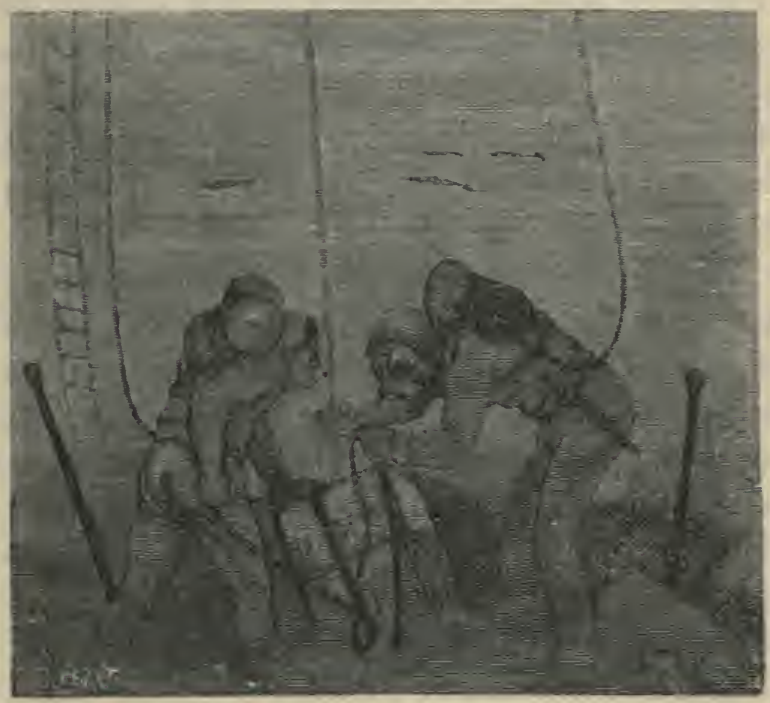

Fig. 47.-Divers finding a Box of Gold in the Port of Marseilles.

Divers are very generally employed to recover things which have fallen into the sea. How many valuable objects have been rescned from the ocean 
by this means, in spite of the mud or sand which harl already commenced to cover them up! 'The diver, with the equipments we have described, makes his investigations in perfect safety and ease; he can see quite as well as in full daylight; he examines every cranny; he overturns the soil stone by stone; he maps out his field of operations, and thus saves himself from a useless repetition of his search. His patient investigations are rarely without some valuable result. In the excellent description of the Rouquayrol-Denayrouze apparatus, we find the following remarkable example of a salvage effected by the help of this apparatus:-

"The packet-boats Ganges and l'Imperatrice came into collision in the outer port of Marseilles. The Imperatrice had one of her wheels broken, and the officers' quarters damaget. One of the cabins con- tained a chest full of gold, which fell into the thick mud which forms the bottom of the port of Marseilles. It was important that this precious package should be recovered the next day. 'The sea. was rough, and the exact spot where the accilent occurred, unknown. The box was not strong, its colour was black. At the supposed spot a plumb of 60 kilogrammes was sunk. This plumb carried two cords divided into meters; two divers dragged them in separate directions, and, taking each the knot corresponding to one meter, 
they described consecutive circles, examining the ground at each step. After seeking three hours, the gold was found and restored to its owner, who had watched the operations with intense anxiety. 'This salvage was effected on February 19, 1867, by M. Barbotin, contractor for submarine work at Marseilles."

3. Gowan's Salvage of Russian Vessels in Sehastopol Haıbour.

An American engineer, named Gowan, has recently effected a much more important salvage, by explorations of the bottom of the sea of greater magnitude than had ever been attempted before. Prince Mentschikoff, closely besieged in Sebastopol by the Anglo-French army, perceiving that the weak point of the fortified town was its roadstead, and that the "nemy's fleet was about to force an entrance, sank a line of ships and frigates in the passage between Forts Catherine and Alexander. A second line of vessels was sunk to fill the gaps created in this submarine barrier by the autumn storms. At last, when the hour for the Russian retreat had arrived, he dis. appointed his conquerors by sinking all that remained of the fleet, with the exception of a few solitary barks, in the bay, the muddy bottom of which was now the bed of at least 100 vessels, representing in value some fourteen millions sterling. 
The ressels thus sunk had been treated in such a manner as to resist as much as possible the deleterious action of the sea; any part likely to be deteriorated, such as the engines and all metallic fittings, being covered with tar or tallow. Peace being concluded, the struggle was commenced between man and the sea. Gowan equipped himself as a diver, visited and examined the half-buried hulks of the ships, and determined that the sea should yield the sunken vessels; some, he was of opinion, might be recovered entire, others piece by piece.

An enormous pump, raising nearly 1000 tons per minute, was used to withdraw the water from the interior of the vessels, the portholes and other openings of which had been previously imperfectly closerl. This powerful machine emptied the hulk of a submerged vessel in a very short space of time. 'The lightening was so sudden, that the vessel rose to the surface before the water had time to re-enter by the various openings left. An enormous chain, 1000 feet in length, each link in which weighed 150 kilogrammes, served as an auxiliary to this pump, or when necessary replaced it entirely. 'I'o conclude, a detachment of divers was occupier in seeking for detached portions of wreck, much of which was already halfburied in mud. 


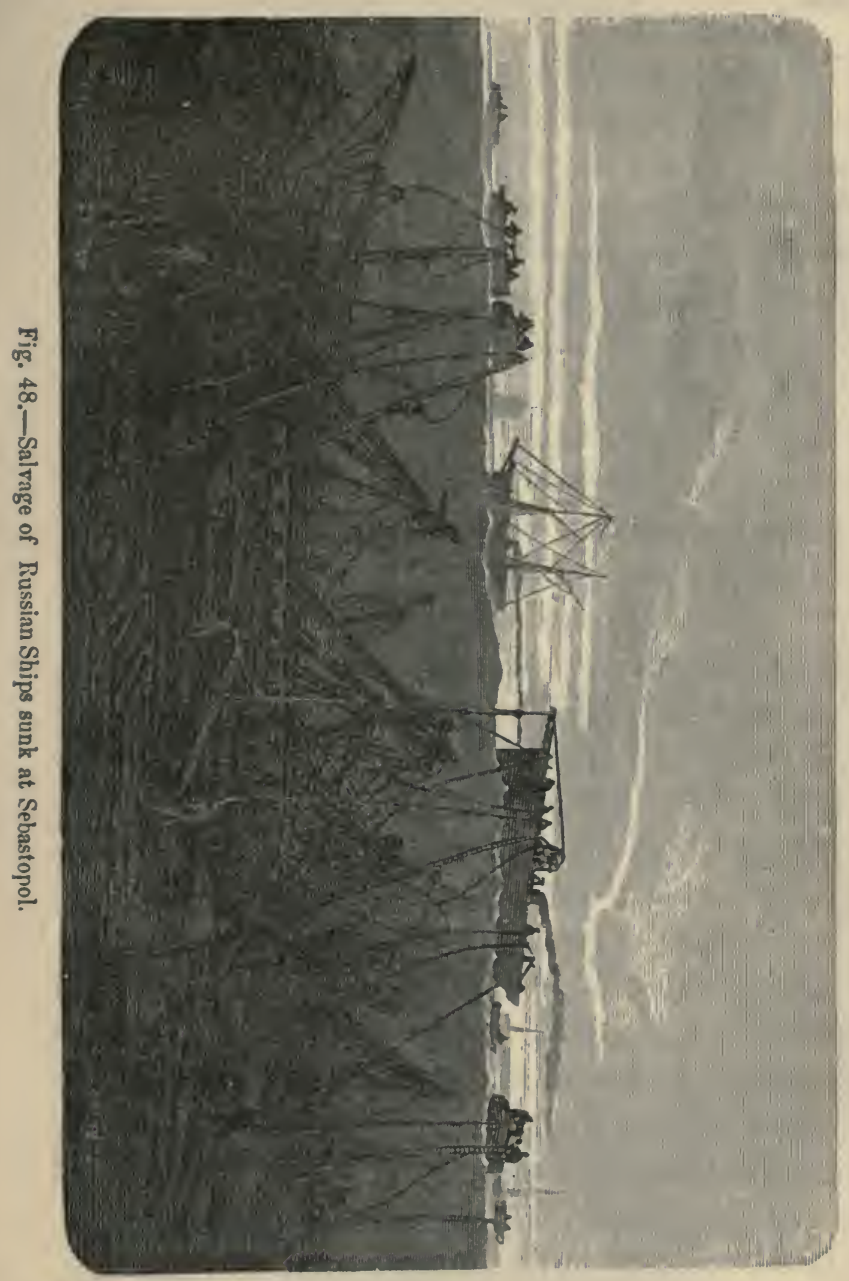



4. Ships repaired withont lenving the Water, and even while under Sail.

We have alrealy mentioned the great utility of the diving apparatus in recovering sunken treasure, and in submarine masonry ; but its utility is much greater to the sailor when it becomes desirable to clean or repair the bottom of his vessel. Every day increasing importance attaches to the parts of the vessel below water-mark. Seagoing steam-vessels, especially, require the frequent employment of submarine workmen. 'The apparatus formerly used, when the life of the man depended simply on the strength ard consistence of his dress, was but little adapted to the rude buffetings of the sea. The improved divingdress which we have just described is far from presenting the same inconveniences.

To clean or repair the bottom of a ship it is no longer necessary, as heretofore, to lay the vessel up in dock, and thus incur great expense, as well as the loss of valuable time. A rope-ladder, with rungs of wood or iron, is passed under the vessel. The ladde: having been stretched tight, the diver descends, and clings to its rungs by means of a triangle, the base of which is iron and the two sides of rope, terminated by an iron hook. This renders the use of his hands annecestary to his support. He may fill his airtight 
clothing with air, and thus be in a manner fioated against the overhanging siles of the ship and sustained witlıout any trouble.

'T'he American monitor Miantonomoh returned from Cronstadt seriously damaged; the sailors of the

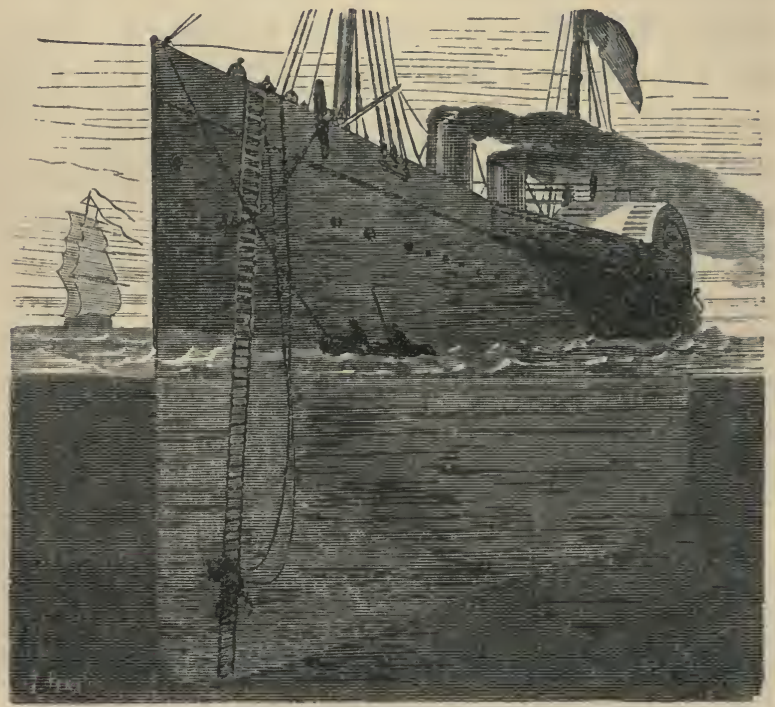

Fig. 49.-Caulking a Ship while uniler Sail.

American frigate Colorado repaired the ressel in Cherbourg Roads, during rongh weather, in the space of five days. Cruising in the Mediterranean, the same vessel received fresh damage in a pipe at the 
stem. The sailors, provided with the improved apparatus, repaired the pipe in seven hours.

It is very important to keep the buttoms of vessels . cleansed while they are on $n$ voyage, especially in hot climates. If the apparatus were employed by passage-boats, a great economy of coal would be effected. In 109 hours of labour beneath the water, the armour-plated ram Tuureau, which had been afloat four months, and the bottom of which was thickly cover er with seaweed, little shells, and muscles, was completely cleanse l; its speed, as ascertained immediately afterwards, was $12 \frac{3}{4}$ linots - a high rate of sailing for a vessel of that class.

5. Sensations of the Diver-Depth to which it is possible descend.

There is a limit beyond which it is very dangerous, not to say impossible, to descend. This limit is at the depth of about 200 feet. The diver at that depth is subjected to the pressure of seven atmosplieres, and any trifling incident might endanger his life. The reader will find a curious example of this in the Annales de Sauvetage Maritime (May, 1866):-

"On February 17, 1865, about 3 o'clock in the afternoon, a steamer on fire was sighted off Ushasit. 
'The vessel was low down in the water; it was dismasted, and had lost its boats ; it sailed under a topsail, gallant, and jib; the other sails hung in shreds from their ropes. Instead of anchoring in Stiff Bay, situated west of the island of Ushant, towards which it appeared to direct its course, this illfated vessel got entangled in the rocks between one of the points of this bay an't the Men-Corn, and very shortly grounded. The sailors were seen to run about the deck as if they were mad. 'The sea was lumpy, wind violent in the extreme; no help could reach them from the land, as neither a rope nor the means of throwing one on toard coul 1 be procured. 'The rising ti le soon floated the vessel, now deprived of her rudder, however, which had been broken on the rocks; and being at the mercy of the winds and currents, she drifted into the Helle channel. It now appeared that she had sprung a leak, as her stern gradually settled down, and an hour afterwards the vessel was wholly engulfed, just as darkness hid her from view. This ship was the Columbia.

"Left Molène on the 31st of August, at half-past 4 in the morning. About 11 o'clock the pilots grappled what they believed to be the Columbia. The Flambeau moored herself by four anchors as nearly us possible at the spot indicated. A sounding taken by the captain gave 180 feet as the depth to the 
deck of the wreck; the lead indicated pit-coal, red lead, and black paint The buttom to the south'ast of the ship was about $200 \mathrm{fe} \cdot \mathrm{t}$; to the northwest about 230 feet. 'The northernmost anchor was at a depth of 250 feet. 'The four anchors were laid down by 1 o'clock. While the men dive we prepare the battery and the lamp, which burns well in the air. The pumps and other apparutus are got in order. At 25 minutes past 3 the diver, Deschamps, has his mask fitted on.

"The following is his own description of the impressions he received in his two descents:-

"First Trial.-He descends step by step, resting at intervals, and receiving and transmitting the signals with regularity. At the filtieth step, water enters by the back valve, which he closes a little; at the sixtieth he closes it entirely; at the hundred-andtwentieth (130 feet) the water enters by his front valve, which he closes a little. He asks for more air. At the hundred-and-sixtieth step (180 feet) he makes a rather longer pause; he shuts his valve still closer; the air issues only by bubbles. He counts 174 steps; the ladder does not reach the ground; he can feel and distinguish the cast-iron weights which serve to stretch the ladder; he hangs by them and rests his feet on the ground-a soft sand, into which he sinks. Just as he stoops to pick 
up something white, like a pebble, he feels himself raised with great rapidity, and his feet strike against each rung in the ladder; he holds the ladder with one hand, but cannot succeed in grasping it with the other. An accident has happened to the pumps. and he has not been in any way conscious of it. At the filtieth step he loses sight of the lamp and wires; they had appeared to him like ordinary thin brass wires. On touching the ground he felt the water enter at his right foot.

"Second Trial.-At the fortieth step, water enters by the back valve; he screws it up a little, and is obliged to close it at the sixtieth. At 160 feet, water enters by the front valve, which he holds nearly closed. At 195 feet, water enters by his leg; he closes the valve and rests on the sand, in which his feet sink. The pressure is general over the whole body, and is exerted on the bladder, which empties itself involuntarily. This effect had also been produced with less intensity when he reached the ground the first time. He detaches one end of his guide-cord; he can distinguish this cord, the weights, his hands, and he advances a few steps. He has great difficulty in withdrawing his feet from the sand, to which he feels rooted. All at once his sight is obscured, his head turns; he returns instinctively to the ladder, and asks to be raised. $\mathrm{He}$ 
begins to ascend as well as his strength will allow; feels himself impeded by his guide-cord, which he cuts; and then rises alone very rapidly, having lost his senses. A violent shock brings him to; he recognises the sides of the ship, against which his musk has struck, and regains his courage. He waves his hand over the surface of the water, and feels himself sinking. His mask having got displaced, the cullar almost chokes him. He feels himself seized by the arms, and grasps a rope which his hand halpened to touch. $\mathrm{H}_{\mathrm{e}}$ again loses consciousness for a moment in the ship's boat, and asks to be raised on deck as soon as his mask shall be unscrewed. He suffers much from the right hand, breathes with difficulty; his extremities are cold, and neck painful. 'I'wice he nearly faints, and ceases to breathe. His sight appears troubled, everything turns round with him, and his gaze has no steadiness.

"We unanimously concluded that the state of the diver and his apparatus proved that neither could work with regularity under a pressure of six atmospheres, and that it would be very imprudent to expose the lives of men by causing them to work under this pressure. The diver wished to repeat the attempt, but neither the captain nor the engineers would permit him to do so. The above experiments show that the diver may breathe, that his organs 
may remain in their normal state, and he may preserve his presence of mind, to a depth of 130 feet; but when he exceeds this depth by 10 or 20 feet, the external pressure causes physiological effects on his organs independent of his will. One hundred and thirty feet is therefore the depth which experiment shows to be the greatest at which any hope can be entertained of performing any prolonged submarine work. . . Within this limit, security to life is perfectly compatible with the conditions involved in an attempt to recover any ship or sunken treasure which will pay the necessary expenses.

$$
\text { (Signed) "Carvallo." }
$$

6. Extreme difficulty of working below Water-Submarine foundations-Stone worked when in position.

It appears from what we have stater above, that, notwithstanding all the efforts of genins, we cannot penetrate the oceanic abysses. Nearly all that we can do must be done on the borders of the vast expanse. Nevertheless, our visits to the sea, thougn limited, have a great theoretical and practical importance, of which we have already cited numerous examples.

The art of diving is almost indispensable in building submarine constructions. What great work can 
a man perform who works in the rark, easting his materials "l nost haphazarl into the lap of an element which de dares not or cannot grapple with? Would his labours be much more valuable if he had to dive and leave the water every instant, throwing only a coup d'oeil over the work which he could not wait to improve or advance?

When, by continuous efforts, and by the use of an immense amount of materials, man shall have built up a foundation in the bed of the sea, he will still find himself continually arrested by the difficulty of making permanent progress at the surface. In calı weather his building goes on apace; he is prourl of it, and regards the sea as a subjugated enemy. But the furious waves of a sudden tempest breaks down his work as if by enchantment, as if it had deter mined to crush man with the greater humiliation for having allowed him sufficient re-pite to make such arduous progress.

The beautiful breakwater at Cherbourg, one of the most gigantic of modern undertakings, had been thrown down many times by the sea before it stood in its invincible strength to form an impassable barrier to the fury of the waves. Such works were formerly built by casting into the sea at the chosen site a vast number of immense boulders, stones, and concrete, piling them up in the irregular pell-mell 
fishion attributed to the giants in the fable when seeking to scale the heavens. These works are now effected with less precipitation and infinitely more studied circumspection; enormous blocks are built one upon another, upon which the sea may exercise its utmost fury in vain. These blocks are?

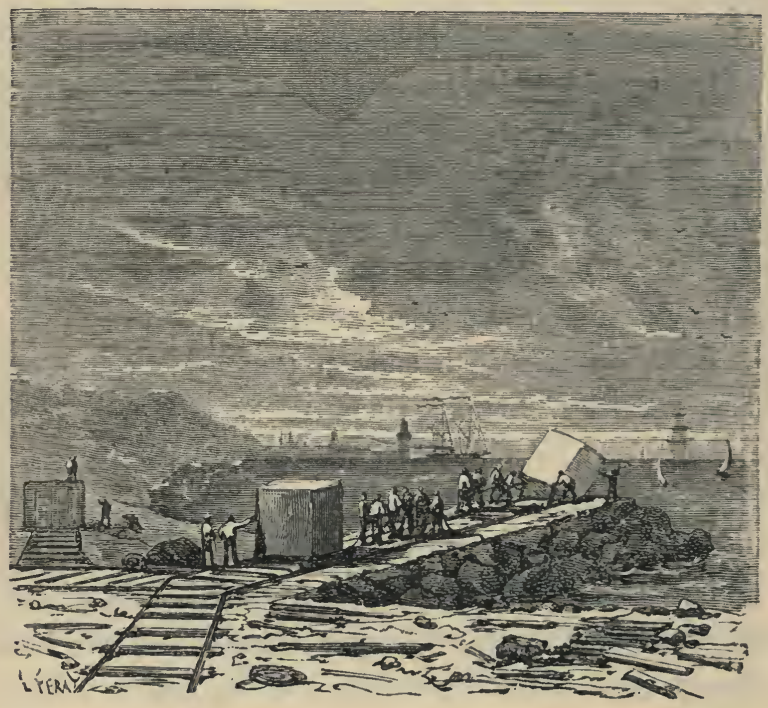

Fig. 50.-Sinkung Blocks of artificial Stone at Cherbourg.

manufactured on the spot, by filling enormous rectangular caissons with a kind of coarse concrete, which hardens by contact with the air, and particularly with water (fig. 50). 
When tne block is sufficiently solidified to bear submersion, the mould is remored and the block is sunk into the sea. But the diver must have first prepared the foundations of this cyclopean wall on a perfect level. Provided with levers and other tools, he raises the block, and places it in the exact position indicated by the engineer. The care demanded by

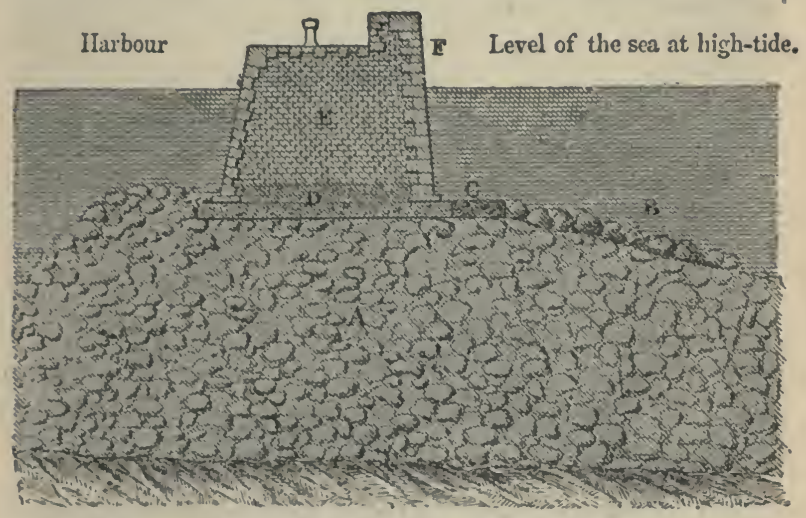

Fig. 51.-Vertical Section of Breakwater at Cherbourg.
A. Rockwork of rough stones.
D. Foundation of artificial stone.
B. Unwrought blocks.
E. Wall laid in hydraulic mortar.
C. Blocks of squared stone.
F. Granite facing.

this process renders it necessary that the divers should be continually descenling and ascending, in order to examine the work on all sides. Furnished with the apparatus we have described, they can, by means of a simple tap, fill or empty their caoutchoue 
clothing of the air it contains, and thus make it answer the purpose of a swimming-bladder. They may manœuvre in the most varied manner when beneath the water by simply turning a tap. The blocks of stone are thus built up with as much regularity as on dry land, and are capable of opposing the greatest possible resistance to the incessant attacks of the waves.

7. Diving Bells-Stationary Compressed-air Apparatns.

Previous to the invention of the apparatus which we have now described at some length, diving-bells were employed in the construction of jetties, fortifications, lighthouses, docks-in a word, in all important submarine work. This invention consists of a large cast-iron bell, communicating, at its upper part, with a force-pump.

Invert a common drinking-glass in a basin of water; the air diminishes in volume as the glass is sunk further in the water; indeed, its bulk may be seen to decrease by the gradual rise of the water in the glass. The air collects in the upper part of the glass, and becomes gradually more compressed-preventing the water, however, from completely filling the vessel. Make a communication between the bottom of the glass and a reservoir of air compressed to the same 
extent as that in the glass, the water still remaining at the same level. Compress this somewhat more, it drives the water from the glais, which it fills. This is precisely what happens in the diving-bell.

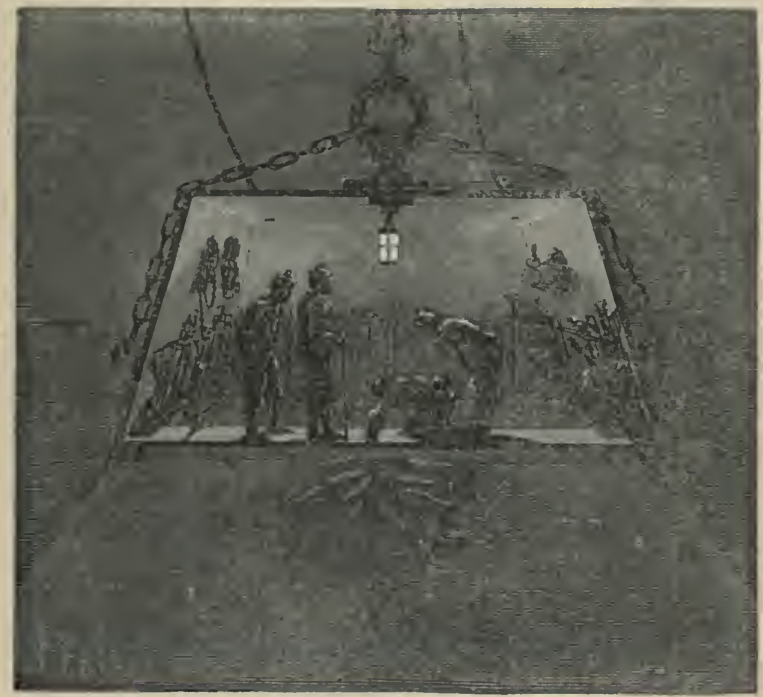

Fig. 52.-Diving Bell.

While the bell descends the workmen are supported on transverse benches. Having reached the bottom, the air from the pump drives out all the water from the. bell, and the men ean then leave their seats and commence work. As they cannot leave the bell, 
the field of their operations is necessarily limitedan inconvenience which is remedied by moving the bell laterally. In fact, this inconvenience is only nominal when, as is often the case, the labour consists in making an excavation in one particular

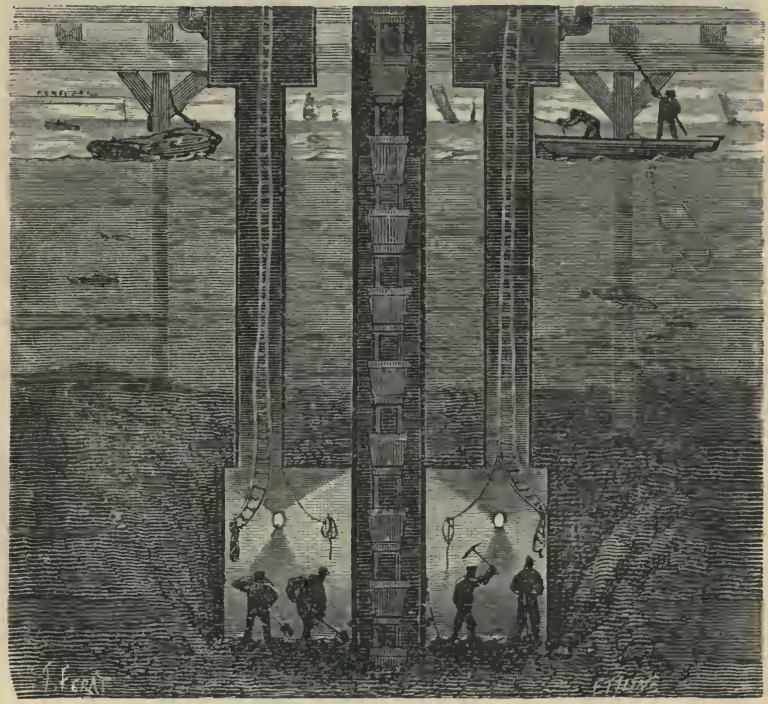

Fig. 53.-Fixed Apparatus, supplied with Compressed Air.

spot. In such cases the diving-bell may be even advantageously replaced by apparatus employing compressed air, and of such a form as the conditions of the work demand. It was by the exercise of 
increnuity in this respect that the magnificent bridge uver the Rhine, near Strasbourg, was so rapidly constructed.

Each of the piers of this bridge rests on a foundation composed of four iron caissons of large size and weight. Each caisson was open at its lower part (fig. 53). The upper part supported three shafts, a middle and two lateral ones. All three rose above the surface of the waters of the Rhine. The middle shaft communicated with the open air, and the water rose in it to the general level of the river. It enclosed a dredging-apparatus worked by a steam-engine. 'I'his dredge, as well as the shaft itself, descended to the bottom of the river. The workmen loaded the compartments of the dredge, which discharged its load into the river.

The two lateral shafts terminated at the upper part of the caisson. The workmen first shut themselves up hermetically in the upper part of the shaft, which they afterwards put in communication with blowing-machines. The compressed air driven by these machines gradually expelle 1 the air from the shaft, and ultimately from the caisson, into which the workmen would now descend and commence their excavations, carrying the débris to the dredges. When the workmen wish to leave, they first mount to the upper part of the lateral shaft; the action of 
the blowing-machine is then gradually lessened, so as to diminish by degrees the pressure of the air they breathe. The water rises at the same time in tho caissons and lateral shafts until it has attained tho level of the river. The dour is then opened and the men leave their prison, which may be regarded as a species of diving-bell, but of a form devisel for a special service.

- 8. Payerne's Submarine Hydrostit

The diving-bell proper has been much improved by M. Payerne. His "Submarine Hydrostat" possesses the immense advantage of being capable, at the will of those enclosed in it, either of floating on the surface, or of sinking or rising, as may be desired. Thirty men may work in it with ease for a number of hours without inconvenience. It is therefore of great service in clearing ports, and in facilitating the execution of other submarine work.

The principle of the machine is very ingenious. Externally, it has the appearance of one large rectangular box, surmounted by another smaller one, completely closed in except at the bottom.

The interior of the hydrostit consists of three principal compartments. 'The lower, or hold, is open 
below, as just stated, and communicates by a large chimney, or shaft, with the upper compartment, or between-decks. Between these is a third compartment, or orlop-deck, which only communicates with the others by means of stopcocks. All round the hold and the orlop-deck runs a gallery, hermetically closed, and connected with the former compartments by stopcocks only. The lower part of the gallery receives the ballast of the machine, whilst the upper is filled with air or water as occasion requires. (Fig. 54.)

Whilst the hydrostat floats, the hold and one portion of the shaft are full of water; the orlop-deck, its gallery, and the between-decks being full of air. A lift and force-pump are found in the latter, where the workmen would now be stationed.

When it is wished to sink the hydrostat, the hatch of the between-decks and the door of the shaft are closed hermetically. The pump is worked in such a manner as to draw water from the exterior, and fill the orlop-deck and its gallery. A pipe furnished with a stopcock allows communication between the upper part of the orlop-deck and the hold. At the same time that the latter is filling with compressed air, the apparatus fills with water, gets heavier, and ultimately sinks. 'The water which was in the hold las, it is true, been expelled; but the contents of 
this compartment are equal to that of the orlop-deck. 'Ihe hold was originally full of water, but now both the orlop-deck and the gallery are full. The workmen now open the door of the shaft and descenrl into the hold, having the bottom of the sea for a

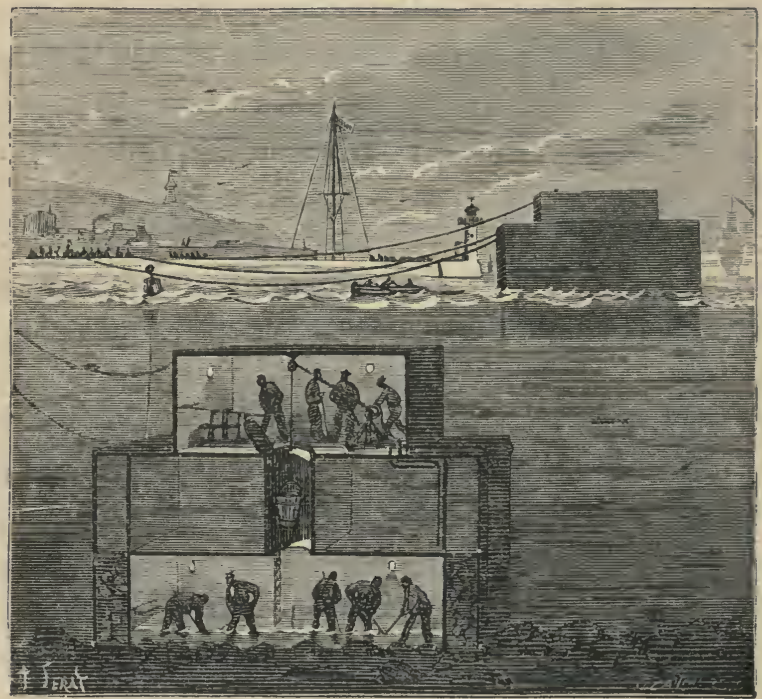

Fig. 54.-Parerne's Submarine Hrilrostat.

floor, and the scene of their labours. One or two remain in the between-decks, there to store away the excavated material, and wor's the pump when neres:arr. 
When they wish to rise again to the surface, the men re-enter the between-decks by the shaft, which they close hermetically. The pump is worked so as to withdraw the air from the hold, and transmit it to the orlop-deck and gallery. The water escapes by the pipe communicating with the exterior. 'The hydrostat becomes lighter as the hold fills with water, and soon floats on the surface as before. The men then open the hatch, and obtain communication with the outer world. The hydrostat is removed from one spot to another by towing.

The hold is square. It measures about 26 feet in the side, by 6 feet 6 inches in depth. The orlop-decli has the same dimensions. The between-decks has the same depth, but measures only 16 feet in the side. The hydrostat is, therefore, nearly 20 feet in height, and its base, which has the bottom of the sea for a floor, covers an area of 625 square feet. We have already stated that an airtight gallery surrounds both the lower storeys. This gallery, like the orlop-deck, is divided into a number of smaller compartments, which can be made to communicate, or kept distinct, by means of stopcocks.

M. Payerne's submarine hydrostat resolves several difficulties at once. By interior arrangements, as wo have seen, it may be made to rise or fall at will, and it will readily float about like a raft. This ingenious 
machine has already been put to the test. The port of Fécamp was choke l up with shingle, which closed it against all vessels beyond a certain tonnage. The hydrostat was employed, and the port cleaned and again opened to commerce. The cases in which it might be employed with advantage are obviously very numerous.

Ports are more generally made by digging vast basins in the neighbourhood of coasts than by seeking to enclose portions of the sea by neans of jetties. The work is more easily and quickly done in the open air, and there is not the probability that the sea will overturn it at any moment. The port enclosed by hills, or the natural port, has the double advantage of giving shelter both against wind and wave. But if the port fill up gradually, if its mouth become obstructed by mud or sand washe 1 up by the sea, the hydrostat may be advantageously employed.

\section{Villeroy's Submarine Boat.}

What ingenuity has been brought to bear on the construction of submarine engines, both for purposes of destruction and investigation! Boats to sail beneath the water, diving-bells and dresses, submarine fireships and torpedoes, are all so many evidences of the activity dereloped in the human mind by the sea. 
M. Villeroy, a French engineer, constructed at Philadelphia, a few years ago, a remarkable machine, intended to swim at any depth beneath the surface of the sea that its conductor might desire. This submarine vessel was shaped like a cylinder, with conical

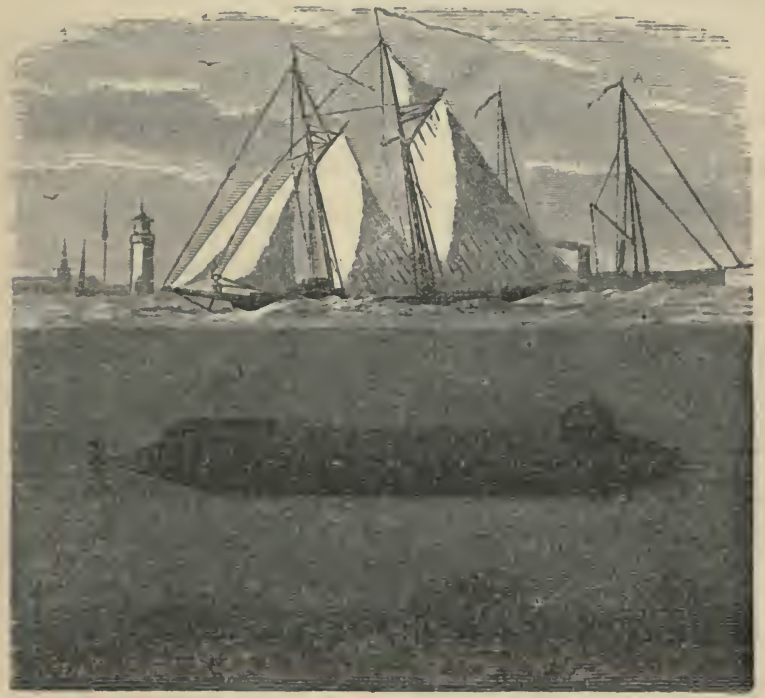

Fig. 55.-Villeroy's Submarine Boat.

ends. It was closed hermetically. It was lighted by a large number of circular windows cut in its iron skin, and closed up with thick glass. A hatchway allowed ingress and egress. Gutta-percha tubes, placed in the interior, communicated with the exterior 
by means of a conduit-tube furnished with a stopcock. By means of a pump the vessel could be filled with water at will. To cause the vessel to sink it was only necessary to allow the water to penetrate these tubes; its ejection caused the ressel to rise. A screw worked at the stern.

Villeroy's structure was 35 feet in length, and 44 inches in diameter. The screw was 3 feet in diameter. By lighting the bottom of the sea by means of an electric light placed in the interior of the vessel, a convenient method of exploration would be obtained, at least in the neighbourhood of the coasts.

This vessel, built during the American war contemporaneously with the production of the monitors, which may be said to have saved the North from the humiliation of defeat, is a worthy companion of the torpedo-that terrible instrument of war, which, in a moment of supposed security, is capable of destroying the most formidable ship of war with even more certainty than a tempest.

10. Employment of Torpedoes in clearing Channels and the Entrances to Ports.

In our age-which may be called an age of progress, since it has witnessed the development of so many 
ideas which illustrate the fraternity of men, and the solidarity of their interests, without which we are little superior to the brutes-how many instruments of destruction have been converted from their original design in the interests of our common humanity, and applied to beneficent purposes! Manby in England, and Delvigne in France, have transformed the cannon into an instrument for the salvation of life, so that the destructive missile is hurled through the air as a messenger of hope to the shipwrecked crew, by carrying the thread on which depends their safety. In the same spirit, Tixier has enıployed the torpedo as an instrument of salvation. The Dunkirk Pilot mentions an operation, the perfect success of which leaves no doubt of the happy results we may expect from the services of this terrible yet docile auxiliary of man.

The schooner Virginie, of St. Malo, sunk at the entrance to that port by the steamboat Zingari, was partly broken up by a torpedo exploded in its hold by M. François 'Tixier, who undertook this operation and brought it to a successful termination. The various phases of the explosion, up to the time which would elapse between igniting the Bickford fuse and the result itself, had been previously indicated with remarkable precision, which the result fully confirmed, and which was attested by numerous 
spectators. The explosion, which caused a tremendous upheaval of the water and pieces of wreck, accompanied with quantities of sand, was received with acclamations by the spectators, as a demoustration that the expectations of the operator had been

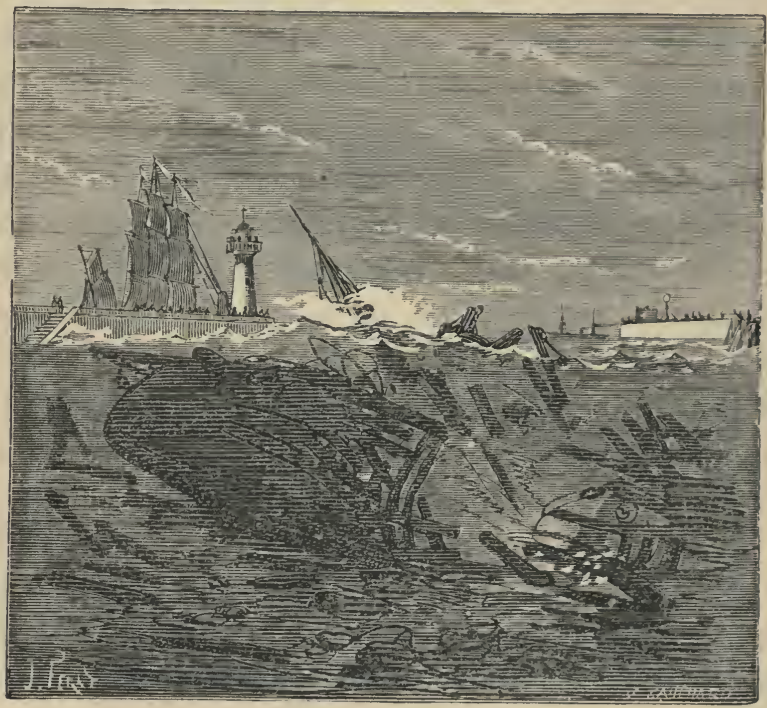

Fig. 56.-Removing an Obstruction by means of a Torpedo.

fulfilled. This experiment proves that we hare, even now, an important addition to our means of removing the débris arising from disasters similar to the above, the number of which has increased greatly of late years. The whole of the wreck may 
thus be removed piecemeal, until the passage shall have bcen completely cleared, and the possible cause of many serious accidents removed.

It is seldom that so powerful an instrument as the torpedo is necessary, but submarine blasting is often resorted to; and, in such cases, a diver comes into requisition. He directs the apparatus, worked either by hand or steam-power, and prepares the ground for the introduction of the destructive agent. When the hole is made he inserts the iron vessel filled with powder or nitro-glycerine. He covers it with cement, and places it in communication with the shore, by means of conducting wires for the electric current, or a fuse which will burn under water. The diver then retires. Either the fuse is lighted, or an electric current is sent through the wires, and the explosion takes place.

At great depths the action of the powder is prodigious. Compressed by a column of water, the gases exert an increased force on the rock (if that be the nature of the obstruction), and tear it in a thousand directions. At the surface there is scarcely any indication of the concussion below, except a slight agitation of the water. Dead fish float about the scene of action, and a hollow sound is heard. If, however, the depth of the water be slight, the explosion causes the projection of a jet into the air, 
and the rock is less affected by it. For this reason, where there is a tide, the operators await the period when it is at its highest before firing the charge. This precaution is more than ever necessary where the rock is broken up, and it is sufficient to take advantage of its natural crevices and employ a charge applied in bottles.

\section{English Mines beneath the Ocean.}

Man's submarine labours are not limited to the surface of the sea-bottom. Nature hides some of her treasures beneath the sea as well as beneath mountains. Coal, iron, tin, and other minerals are often obtained from great depths. A vertical shaft affords communication with the horizontal galleries from which the mineral is extracted. At several points of the English coast the miner does not hesitate to carry his galleries beneath the sea, at the risk of being drowned, if the least fissure permits the ingress of water. But this danger is also encountered in ordinary mines, for the immense bodies of water known to exist in the crust of the earth would be much more than sufficient to destroy, in an instant, the most gigantic subterranean works. The enterprise is not, therefore, so hazardous as might appear at first sight; it presents in other cases about 
the same amount of difficulty. Fire-damp is as dangerous, and its effects are as disastrous in the one case as in the other. Kindled beneath the sea, it soon bursts its rocky barriers; the fire spreads, an explosion destroys the walls of the subterranean channel, entire hills are lifted or overthrown as by a volcanic eruption. It is of little consequence to the

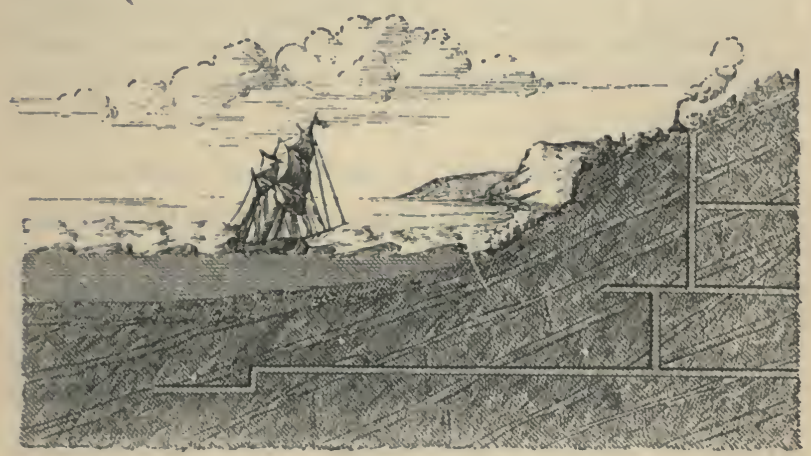

Fig. 57. - Section of a Tin Mine in Cornwall.

miner that this catastrophe takes place under the sea; the danger is not greater than if it happened in the middle of a continent. Before being drowned, he would be burnt or crushexl. Let us reserve our compassion for the poor sailor, who congratulates himself upon having reached an hospitable coast, and suddenly secs his ressel scattered to the winds and waves by the violence of a submarine explosion. 
CHANGES IN PROGRESS AT THE BOTTOMS OF SEAS -THEIR UNIVERSALITY.

1. Extent of the movements of the Terrestrial Crust-Nature incessantly at work-The gradual Cooling of the Earth a cause of its present form, owing to the crumpling and breaking of its Crust.

Everything material is mutable: continuity of change is the great law of nature. From the subtlest gas which escapes our visual observation, to the solid rock, all is subject to movement and transformation. The smallest atom and the mightiest solar system alike obey the laws of gravitation, and move on in cycles of endless progression. The modifications which everything, small and great, in the physical world is undergoing may be more or less apparent, more or less rapid; but whether it be or be not demonstrable to the sense, it takes place all the same, so that we may truly say that all matter, however apparently dead, pulsates with life.

Animals and plants are born, grow, and die. The elements which concur towards their formation and development are incessantly renewed. Having accom- 
plished their part in the organisation to which they had accrued, they are rejected, and their place taken by others. At a given moment they are, so to say, shunted off the track they had followed, and moved on a line to contract new alliances. To the being with whose existence they were identified succeeds another, totally different; instead of the concentration of force, there reigns for awhile anarchy; and anarchy is followed by the rise of fresh organisations, destined in their turn to disappear. There is no organised being that is immutable, any more than a simple atom that is so.

In like manner we learn from history that whole peoples, or national individualities, are born, grow, and die, like individual men, to be succeeded by others. Nay, even the species is no exception to tho law of everlasting change.

But at least, you will say, the solid rock is allowed to repose in quiet, and enjoy the privilege of immutability? No; its surface is exposed to the action of all manner of exterior influences, and eve every variation of temperature profoundly affects that apparently unchangeable mass. 'The truth is, our view of things is a very limited one. The infinitely great escapes us as well as the infinitely little. Even a wheel moving with great rapidity seems as if it did not move. Again, an extremely 
slow movement of the same wheel would not he ubserved.

The air is composed of a great number of elements. Oxygen and nitrogen form the greater part of its composition. The vapour of water, carbonic acid gas, and every kind of emanation from the earth's surface, add themselves to the two first-named gases. Oxygen is absorbed by animals, and replaced by carbonic acid. The converse takes place in vegetation, and a like exchange of gases occurs in combustion.

The vapour of water, raised by the action of the winds from the vast oceanic reservoirs, floats above us in the form of clouds, and is distributed over the surface of the earth in beneficent showers. But again the water finds its way back by means of rivers and floods to its original point of departure, to be again converted into vapour and recommence the cycle of its transformations.

There is a compensating or balancing process continually going on among the numerous causes of change, which renders the composition of the air sensibly constant, and makes its every movement tend to uniformity.

The clond which obscures the summit of a mountain marks the locality of a very rapid movement of the air. This motion is caused by the contact of a hot and moist air with one much colder. But the wind bears 
the cloud away, and it dissolves again, or vanishes when the air is dry. The apparent immobility of a cloud on the top of a mountain is caused by its being constantly re-formed. Its variations are really incessant and rapid. They pass unobserved by us, and thus, for a long period together, mountain-clouds app ar as if they had settled down immutable. Very slow changes, as we have remarked above, present the appearance of unchangeableness, no less than very rapid ones.

The vault of heaven is thickly besprent with stars, the greater number of which we call " fixed," while a few, called "planets," constantly change their places. 'The fixed stars, while preserving the same relative position unchanged, seem, as a whole, to make a daily revolution round a point marked by the polar star, and the latter, or centre of rotation, does not at first sight appear to shift its position. A long and careful study of the heavens, however, has shown that this is not the case. The apparent revolution of the whole concave of stars is accounted for by the fact that the earth moves on its axis, as well as describes an orbit round the sun. But the stars are at such an enormous distance from us that the axis of our globe remains, practically, parallel to itself luring the whole period of the earth's annual revolution, so that, at any given period of the year, the 
stars are seen in the same places as if the centre of the earth were a fixed position-that is to say, as if it always pointed to the same spot in the heavens. This constant parallelism of the earth's axis is, however, only apparent. In reality, it shifts to the extent (taking the extreme limit) of $4^{\circ}$, its revolution describing a cone in about 20,000 years.

If the stars are thus shifted from their apparently fixed position, their relative situation is at least constant, you will say? Careful observation, extended over many years, has shown the contrary. The whole solar system is moving, as if it were one compact and independent organisation, through space. Astronomers have demonstrated that it is approaching the constellation Hercules, but it would require ages of observation to detect any variation in the relative positions of the fixed stars. Such observation would demonstrate by an extraordinary effect of perspective, which it is no part of our present business to explain, that their distance from Hercules is increasing.

Every day the sun rises above the horizon, and sets at the opposite extremity of the heavens; so the lieat of the day succeeds constantly the cold of the night. Year after year the ice is melted by the soft breath of the spring; year after year summer ripens the fruits of the earth. Year after year 
autumn, with its heats and tempests, despoils the trees of their beautiful verdure; then, with the same regularity of succession, winter hangs her snowy garlands on the branches, and strikes with sudden paralysis the mountain torrent. The same succession of phenomena appears to be continually reproduced, with such modifications as would suggest a capricious and ill-regulated will. Notwithstanding that apparent regularity, within certain limits, the climate of the earth is undergoing a slow but constant variation. 'The débris of every kind found in the earth's crust affords demonstrative proof that the distribution of temperature on the surface of the globe has been very different at remote periods from what it is at present. 'The surface, beyond doubt, has been subject to numerous vicissitudes; but at least, you will say, the centre of the earth has remained unchangeably the same.

'This, however, cannot 'be the case; for, as the earth has grown gradually cooler, its crust has increased in thickness and solidity. The contraction towards the centre has been the cause of breakages and crumplings in the earth's crust, and, consequently, of the upheaval of mountains and continents, the sinking of the surface to form valleys, and, generally speaking, of such variations of the terrestrial land. scape as could only be produced through a long 
succession of ages. The human race has not existed for a sufficiently long period to witness the grander catastrophes or changes of what, nevertheless, there are palpable traces remaining to attest the reality.

We are the living witnesses, however, of changes whose average rapidity permits our senses to follow the phenomena, while our memory or our records enables us to compare with ease the different phases through which they pass. We observe that the sea changes its level day after day, as if it oscillated around a fixed point. We are witnesses to the siltingup of ports by the action of marine currents; to the ravages of the sea when it hurls its waves against a rocky coast; and to the growth of the polypier, which opposes an invincible rampart of stone against the assaults of the ocean, and builds up islands from the very bosom of the waters. We see the mountains crumble down under the action of atmospheric agencies; the debris of continents washed down by rivers into the sea, to fill up its abysses; the floating icechariots scattering the spoil of arctic lands over every part of their route; marine currents drawing in their train whatever they encounter, and accumulating upon their borders immense deposits of vegetable and animal remains, as well as of sand and mud. We see the foraminiferæ, those pigmies of creation, 
obstinately, and with immense labour, striving to build up every possible obstacle to navigation; while volcanoes, like malignant demons, destroy the existing basin of the ocean, or at least are incessantly active in modifying its level, or filling up its hollows with ashes and cinders. With our own eyes we are witnesses of these and innumerable other agencies of change; and, knowing the vastness of their consequences, we judge, in regard to past effects, what causes have been in action from the results they have produced.

For this reason, the exploration of the bottom of the sea is an excellent preparation to the study of the past history of our planet, and of its future possibilities. The sea itself would not exist except for the fact that the earth was originally a fiery mass, the surface of which has become solidified, and in the process of cooling has allowed the aqueous vapours to condense. Originally extended with an even surface over the whole globe, the sea served everywhere as the menstruum of the first solid precipitations. Thenceforth the crust of the earth grew in solidity and depth, both from the exterior and the interior-on the one side by sedimentation, on the other by solidification.

The cooling process continued. The crust, too 
large for the kernel which it everywhere enveloped, caved in, and thus the first heaving-up of mountainous masses marked the end of a geologic period. Lands rose above the waters, and marine deposits no longer covered the entire globe. The constancy of the ocean temperature, owing to the near neighbourhood of igneous matters, rendered very feeble, or altogether prevented, the formation of marine currents. As the equilibrium gradually ceased to exist in the liquid mass, owing to the constant growth and the changes that were taking place in the earth's crust, ocean-currents came into being.

The atmosphere was, in its turn, modified by continual precipitations and despoiled of its vapour of water, which went to elevate the level of the seas. This operation again brought into existence atmospheric currents.

The crust of the earth still continuing to cool, fresh collapses would take place, and fresh wrinklings or foldings of the solid envelope already formed. New mountains arose from the bosom of the waters, new rendings of the soil gave free passage to the igneous matters in the interior, and hence the great extent to which volcanic matter is found spread over the surface. By this time living creatures had appeared, which at first were remarkable for the simplicity of their structure and for the capability of 
the same species to dwell, at the same time, on any part of the earth. The currents of the atmosphere and the ocean were more and more decidedly and definitively established.

The extent of dry land was continually increased by fresh elevations above the waters. Rivers and lakes were formed; in addition to the hitherto exclusively marine deposits were those of the fresh waters and salt pools. Plants growing in marshes or on dry lands extended their species over new continents.

As time went on, the inequality of temperature at different points of the globe augmented ; the existing mountains increased in height; new ones were heaved up; the fauna and the flora became more localised, and the marine and atmospheric currents approached insensibly to the condition in which we find them.

2. The Shore-Its apparent fixity-Traces of the presence of the Oeean almost universal.

Have we yet reached fixed conditions, so far as regards the earth's surface? Can we be certain that some fresh revolution of the globe will not destroy the edifices of which we are so proud, and wrap in a watery shroud the accumulated fruits of civilisation? If we have indulgred in any illusion, it is only neces- 
sary to study with care the phenomena by which we are surrounded to dispel it for ever.

Continual change is going on in the basins of seas. These changes make, generally speaking, but slow progress, and are therefore difficult to follow; but little by little they assume a character of the greatest importance. Sometimes, however, they are sudden, and accompanied by phenomena so terrible as to strike mankind with horror, and apparently to disturb the harmony of the universe.

How shall we demonstrate the truth of our statement, that the bed of the Ocean is constantly changing? What we observe is that the sea rushes furiously against the shore, and throws its foam over the highest rocks. As the waves roll in, it would almost seem as if nothing could oppose a barrier to them: suddenly they are arrested, and the dreaded power expends itself by diffusion, as it were, in an inoffensive sheet of water. But another wave follows the first. A third presses on, and almost overleaps the former two. Nevertheless each succeeding column of the invading army is vanquished at the same point; in a word, the sea has encountered its shore.

Thus, day after day, the ocean seems to hurl defiance against the earth; and if it retires, it is to renew the assault against the barriers which it seems resolved to break through, with redoubled strength. 
Twice every day it adrances, and covers with its waters the vast extent of its coasts; twice it retires, abandoning to men some of its spoils and treasures. Restrained by a powerful though invisible hand, it apparently yields to the obstacle which opposes its advance. Its movement is so regular that we can determine, for every point of our coasts, the exact times of high and low water.

Thus regarded, the shore of the ocean would appear to be the very type of unchangeableness. 'The sea cannot pass it; in our confidence we cultivate lands, build cities, construct ports and harbours, and throw out piers, as if we dared the sea to do its worst. If we would know how puny our best efforts are, let us note the fact that marine shells, the fossil remains of fish, and other evidences of the presence of the ocean, are found on the highest mountains. 'This débris of former ages has been converted into stone, and now exists in gigantic masses. It is impossible to say how many ages may have elapsed since they were living beings : history and human tradition take no account of them.

Are we to imagine that those remote agres were visited by the most frightful of all eatastrophes, and that we, more privileged, are exempt from similar changes and their attendant dangers? No; the Supreme Intelligence which governs the universo 
has regulated the working of its stupendous mechanism. Everything occurs at the regulated time. Nothing is left to chance. The sea has once covered the whole earth. Geology affords the data by which we may determine its limits at successive epochs. But it is not necessary even to revert to remote geological periods in order to be convinced of the fact that land and sea have frequently changed their relative level.

3. Progressive cnlargement of the Straits of Gibraltar during the Historic Period-Columns of the ancient Temple of Hercules submerged-Descriptions left by Avienus, Pliny, and Pomponius-Mellaria, Carteia, and Belon submerged-Other examples of Cities and Islands covered by the Waters, and of Mountains violently separated from Continents.

The Straits of Gibraltar is a conquest of the ocean. Dureau de la Malle quotes the measurements of old geographers, and they tend to show that it has been continually enlarged even down to our own times.

Avienus quotes a measurement on the authority of Dæmon d'Amphipolis. It is nearly three miles, or more accurately 4694 English yards. He cites a subsequent measurement of nearly four miles, or 6000 yards, made by the Athenian Euctemon.

Scymnus of Chio, in the year 143 B.c., found it measured nearly 24,000 yards, or about thirteen miles 
on the side of the Atlantic, while at the presut time it is double that distance between Spartel and Trafalgar.

Turanius Gracilis, who was born on the shores of the strait 100 years B.C., gives the willth from MelJaria, in Spain, to Cape Blanco, on the African side, as abnut fou -und-a-half miles, or, more accurately, 7800 yards.

Strato estimates the greatest breadth at nearly seven miles, or about 12,000 yards.

Pliny, who had been quæstor in Spain, and had visited the strait, gives about seven-and-a-half miles for the narrowest part, and about ten miles for the widest.

Bishop Victor, about A.D. 500, found the distance about twelve miles; the Spanish measurement at present is fourteen miles.

These various estimates are good evidence that the strait has been gratually enlarged from remote times to the present. Besides this, Avienus relates that between Africa and Europe there were two wooded isles, on which were built a temple and altars in honour of Hercules. These were called the Pillars of Hercules. The same author mentions that the Carthaginians were obliged to build flat-bottomed vessels to sail over the shallow water. Finally, he says, we know that Hannibal reports that there was a bottom- 
less and boundless sea farther to the west-a proof that what he says about the Straits of Hercules may be regarded as trustworthy.

Pliny, who visited the straits, speaks of a low-lying island, covered with wild olives, situate in mid channel, upon which was built the Temple of Hercules. Pomponius Mela, a Spaniard, to whom these parts
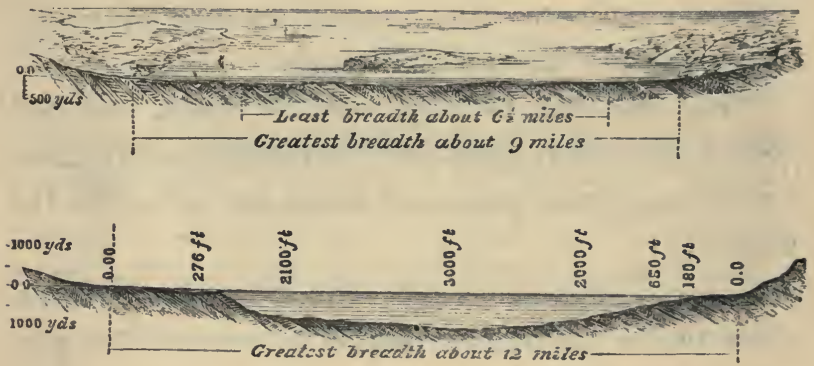

Fig. 58.-Straits of Gibraltar.

1. View and Section in the time of Pliny.

2. Section of the existing Charts.

were familiar, pictures the strait as a channel broken by a number of small islands without names. In our day the largest ships sail freely over these waters.

In 1748 , on the occasion of a very low tide, the remains of the famous Temple of Hercules were discovered in the oceanic part of the strait, and some souvenirs of it were obtained for preservation.

Jean Conduit, as rolated by Signor Ignacio Lopez de 
Ayla,in his "Ilistory of Gibraltar," assures us that the sea covers the greater part of the land on which stood the ancient city of Mellaria. Even in the Bay of Gibraltar the sea has engulfed a part of Carteia, $o l^{*}$ Algesiras. Three leagues to the west of 'Tarifa, the city of Belon occupied the shore of the strait. It is now engulfed, and we fin! traces of its existence leneath the waves.

Colonel James, in his "History of the Straits of Hercules," mentions that during an earthquak', some ages ago, the Isle of Cales disappeared, together with the small islands opposite the city of Bactes, near Turifa, and a rock named La Perle, which was once an island, and is now covered with more than twelve feet of water at low-tirle. The same author speaks of violent shoeks of earthquake, which, in the year 246 B.C., overthrew the last remaining part of the Isle of Cadiz, and left it completely covered bv the sea.

The earthquake of 1755 , which destroyed the city of Lisbon, and was felt far and wide, was not, says Colonel James, to be compared for the violence of its effects with that which engulfed Cales, which was of many leagues in extent. Nevertheless, it was plainly felt at Gibraltar, where Colonel James himself was an observer of the phenomenon.

() $n$ the morning of the 1st of Norember, 17j̄a, a 
shock was felt which lastel half a minute. It commenced by a trembling of the earth, tlien a violent shock succeeded, which was followed by a trembling similar to that with which the eartiquake commenced, and which gradially diminished. The sea rose more than three yards above its ordinary level, and then sank, leaving dry upon the shore many fish. and all that it had at first engulfed.

We may all to the list of cities that have been lost those of Hélicé and Bura, in Achaia, which were submerged in the year 3 lis B.c. 'T'he grenter part of Lycadia was also covered by the waters.

Strabo, in his Egyptian voyage, relates that he saw Mount Casius, which had been surldenly separated from the continent and become an island, which it was necessary to sail round to reach Phœnicia.

Sorca, one of the Moluccas, was swallowed up by the sea during an earthquake in 1693.

At Java a mountain, three leagues in circumference, disappeared sudilenly in 1772 .

It is on record that a space of about sixty learnes, in the province of Chan-tsy, in China, was completely c overed with water in a few days, in 1566 .

St. Lawrence once joined the American continent, i ut is now separated from it by an arm of the sea, some hundreds of yards broad.

One of the most disastrous eruptions uf the scal on 
record is that which, in 1446 , submerged more than two hundred cities of Friesland and Zealand. For a long time after this catastrophe, the summits of the

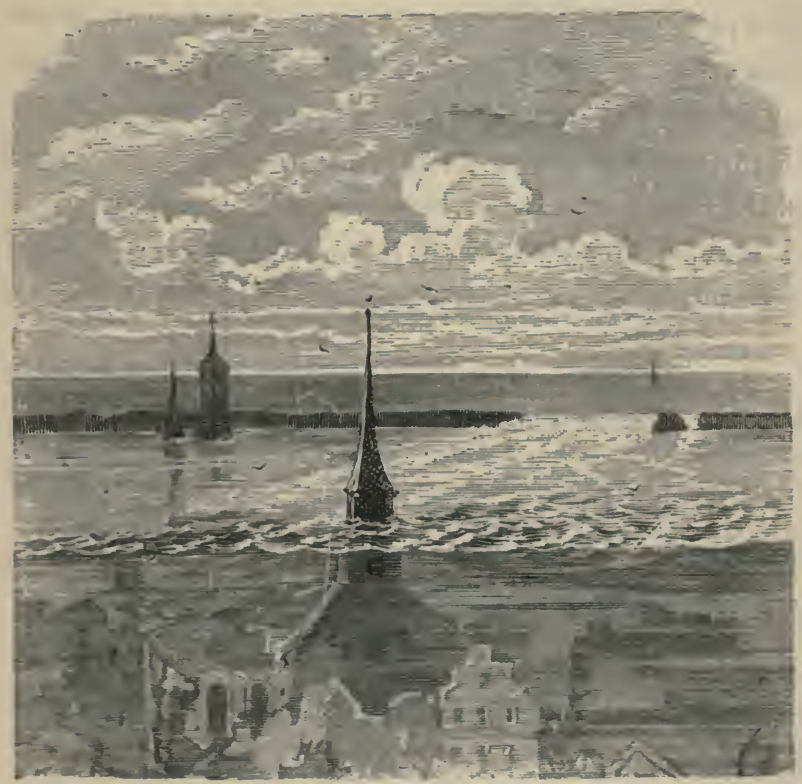

Fig. 59.-Irruption of the Sea in Zealand.

towns and the points of the steeples coull be scen standing above the surface of the sea.

We might multiply these examples of the fact that the bottom of the sea is continually changing. Here 
cities, nay entire continents, are covered by the waters: there, on the other hand, the land lias been known to rise, as in the case of the island of Julia, and in that of the Azores, and the Archipelago of Santorin. The port of Aigues Mortes has now three leagues of shore. The ruined Temple of Serapis, at Pozzuoli, was for a long time engulfed; it is now uncovered again. In the north of Sweden the sea appears to be retiring, whilst it slowly invades the south of that country, and at no very distant period it was the cause of great destruction by its inroads in Pomerania.

4. The Quantity of Water which covers the Earth is sensibly constant-An Elevation in one point is balanced by a corre. sponding Subsidence in another-Aristotle's opinion about the Greek tradition of the Deluge-The Earth will becomo dryer and colder.

If the sea retires from a given place, another becomes submerged. We are, therefore, led to conclude that the water area varies but little over the whole of the earth's surlace, but that the bed in which it rests is ceaselessly modified.

Such, moreover, was Aristotle's opinion. He believed that the apparent changes in the level of the sea in any given spot could not be explained by the supposition that the seas were drying up, as certain philosophers of his time had imagined. In the 
words of this illustrious savan: "Only those of narrow views and small experience attribute these partial changes to an overthrowing of the whole globe. When, in support of their views, they bring forward the drying-up of seas, and the existence of dry land where it furmerly was not, they give authentic facts, from which, however, they deduce false conclusions. It is true that certain spots heretofore covered with water now form a portion of the continent, but the contrary is also the case, and any one who studiously examines the facts would find that the sea had invarled and submerged several parts. Such appears to be the explanation of Deucalion's flood, the ravages of which were more especially felt in Greece, and which among other provinces was most terribly felt in ancient Helas, a country extending from Dolona to the Achelöus. This river then changed its course several times. The province was at that time iuhabited by the Selles, and by the people named Greeks, now called Hellenes."

Certain coasts of the same sea will, in the same time, show but little variation. The Strait of Messina, more especially on the Sicilian side, receives quantities of sand; but it lias relatively suffererl such slight changes, that the same race have inhabited it since the time of Homer. In reading the descriptions given of this place by Homer, Polybius, 
and Spallanzani, it is surprising to find that authors living in times so far apart give similar details respecting the inhabitants in this arm of the sea.* Now we have seen that marine animals sometime: emigrate, and leave their haunts to other species, if the depth changes notably. Swordfish are now still caught in the inanner described by Polybius.

Sometimes the movements of the terrestrial crust are limited to a very small range of country-sometimes they embrace a very large extent. They are nearly always compensated by inverse movements, produced at more or less distant points. 'The gra lual

* Polybius wrote, two thousand years ago: "The swordfish, seadogs, and other cetaceous animals, become singularly fat every year by living on the tuuny-fish, which visit the coast of Italy in shouls, and which their enemies watch for in the straits. In fishing two men are attached to each boat-one sculling, and the other standing at the prow armed with a spear. The various boats have a common scout, in an elevated situation, who signalises the approach of the swordfish, for the fish swims with haif his body out of the water. When it approaches the boat the spearman strikes it with his spear, the head of whích carries a barb, loosely fixed, so that it can be easily detached when the spearman withdraws the handle. To the iron head of the lance is fastened a long cord, which is let out to the wounded fish, until by his continued struggles to escape he shall have lost all his strength. Then they hanl it ashore, or, if not, take it on board their boat. If the spear-handle fall into the sea, it is not necessarily lost; it is made of oak and spruce, in such a manner that the oak sinking on account of its grester weight permits the spruce to project above the surface of the water, so that the fisherman may easily see and regain it. Sometimes it happens that the rower is wounded, the swordfish being armed with a lung swold, and being as furious and impetuous as a boar." 
cooling of our planet causes the thin crust already forme.], by unequal contraction, to pucker up. The sea occupies the cavities-the prominences alone appear above the waters.

Water tends to combine more and more with the rocks. A time will probably come when the earth will be too cold for water to exist in the liquid state. It is to be understood, in fact, that the quantity of water which bathes our planet continually diminishes; but this diminution is so slow, that thousands uf years are not sufficient to make it evident. 
SUDDEN MOVEMKNTS OF THE SUBMARINE SOIL.

1. Earthquakes modify the Bed of the Ocean-Submarine Volcanoes.

TIIIE bottom of the sea, as well as the surface on which we live, is subject to modifications by the action of earthquakes. They are, generally, accompanied by submarine volcanoes, which also alter the sea-be l, and cause a displacement of the waters. It is observable, in fact, that volcanoes never display their whole energy except in the neighbourhood of seas or large sheets of water. The existence of submarine volcanoes need not then excite astonishment; it is probable, indeed, that their number is very great, and it is reasonable to attribute to the action of submarine eruptions of which we have no knowledge, the seismical phenomena that have been accompanied by no visible volcanic disturbances.

At the commencement of its activity, submarine volcanic action is sometimes signalised by a peculiar agiation of the sea, where the depth is at 
all considerable. If the depth be slight, or the activity of the volcano very great, the water bubbles; a column of smoke rises above the lerel of the sea ; flames, scorix, or incandescent stones demonstrate the presence of a volcano. The sea changes colour to a greater or less extent, and becomes warm. Ships receive a shock as if they had struck a rock; indeed, in some cases the concussion is so violent that ressels have lost their masts.

Volcanic products of every kind, however, accumulate at the bottom of the sea, covering every

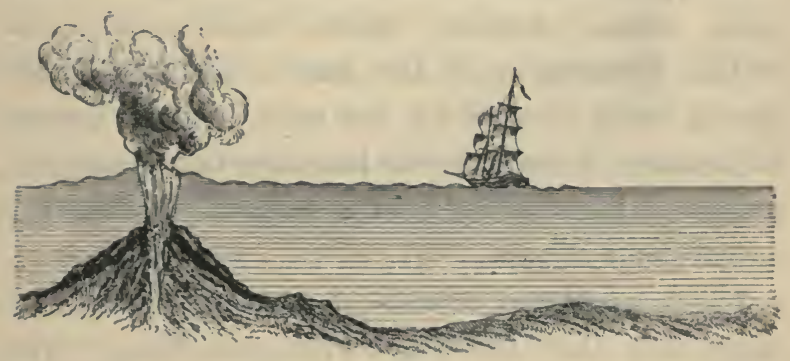

Fig. 60.-Eruption of a Submarine Volcano.

living thing; streams of lava, masses of scoriæ, and rocks, contribute to an elevation of the soil which must eventually raise it to the light of day. Such is often the origin of volcanic islands.

Submarine earthquakes disturb the sea throughout its whole depth, causing the terrible waves of 
which we have spoken in a previous chapter. The facts we are about to relate will exhibit the great influence exerted by subterranean fires over the submarine regions of the whole globe.

2. Greek Archipelago - Delos and Rhodes upheaved from the Bottom of the Sea-Successive additions to the Archipelago of Santorin.

The existence of submarine volcanoes has long been known. Several are to be found in. Greece. The islands which have appeared from time to time, as if by.enchantment, have owed their birth to volcanic causes. Ancient writers make mention of certain phenomena of this kind; but their statements, being founded for the most part on inexact information, or on more or less uncertain traditions, can be of little utility from a scientific or even historical point of view.

"The celebrated islands of Delos and Rhodes," says Pliny (Liv. II. chaps. xviii. and xix.), "have, from all accounts, risen from the waters: moreover, smaller ones have been seen to appear-such as Anapte, beyond Melos; Nea, or Nova Insula, between Lemnos and the Hellespont; Alone, between Lesbos and Theos; Thera and Therasia, amongst the Cyclades, in the fourth year of the 135th Olympiad; Hiera, or Antomate, situated between the two 
preceding, and formed 130 years subsequently. In our time, 110 years later than the above, during the consulate of M. Julius Silanıs and L. Balbus (yea: 19 A.D.) appeared Thia."

Many other ancient authors-among the rest Justin, Cassiodorus, Dion Cassius, Plutarch, Seneca, and Strabo-give very circumstantial details of the successive birth and growth of some of these islands by their elevation out of the sea. But the origin of some of them is surrounded with purely fabulous circumstances, and we are obliged to reject nearly all the ancient narratives as being but little worthy of belief. Volcanic phenomena were not seriously studied, or even carefully olserved, until modern times.

One of the most celebrated islands of the Grecian Archipelago is Thera, subsequently named SanteIrene, and later, Santorin.* Half a league from this island now exists Apronysi, the ancient Therasia. It appeared for the first time in 236 B.c. (the fourth year of the 135th Olympiad, according to Pliny, cited above). Antomate appeared 130 years after (106 B.c.), and was named Hiera in consequence of the worship

* Santorin is an immense crateriform mountain, some thirty-six miles in circumference. It may be accurately described as a furnace of incessant volcanie activity, some part of it being almost constantly in eruption.-Tr. 
of Vul'an there established. Thia (4 B.c.) rose at the distance of about 300 yards from Hiera. The details given by the ancient geographers, therefore, agree with each other.

Violent eruptions of cinders, rocks, and lava, in a state of ignition, filled the arm of the sea which separated Thia from Hiera in the year 726 of our era.

Similar phenomena occurred in 1427, as is attested by a marble monument erected in Santorin, near Fort Scauro. A new island, designated NeaKameni (New Burnt-island), appeared in 1570, at the termination of a sixth eruption. Hiera was then called Palœ-Kameni, which signifies Old Burntisland.

We owe to Father Kircher the details of an eruption which, in 1650, threw these coasts into trouble during a whole year. It was accompanied by showers of cinders and whirlwinds of flame, which were seen to issue from the sea. The quantity of cinders thrown out was so considerable, that Smyrna and Constantinople were much inconvenienced.

A new island was thrown up in 1707. Mons. J. Girardin describes this phenomenon in the following words: "On the 23rd of May, 1707, at sunrise, a floating rock was seen at sea about a league from the shore of Santorin. Some sailors took it for a ship 
about to break "u, and approached it with a view to pillage. Arrived near, and seeing what it was, they had the courage to descend; they brought back some pumice-stone and a few oysters which were attached to it. The rock was probably a large mass of pumice, that the agitation of the earth, which occurred a little time previously, had detached from the bottom of the sea. After a few days it became fixed, and thus formed a little island, which augmented in size from day to day. On the 14th of June it was some 800 yards in circumference, and about twenty-four feet in height; in shape it was roundish, and formed of a white light earth. At this period the sea began to be disturbed, and the heat near the island was so great as to prevent access to it; a strong odour of sulphur also spread around. On the 16 th of July there appeared in close proximity to it seventeen or eighteen black rocks; on the 18th, a dense smoke was emitted by it for the first time, and subterranean rumblings were heard. On the 19th, fire began to be visible, and its intensity gradually augmented. At night-time the island had the appearance of a number of furnaces vomiting flames. Its volume increased, and the fumes became insupportable at Santorin. The sea was now violently agitated, and dead fish were thrown on the shore; the subterranean. noises resembled discharges of 
artillery; the fire made new openings, whence issued showers of ignited cinders and stones, which sometimes fell at a distance of two leagues. This state of things lasted a whole year. In 1767, a new eruption took place between Nea-Kameni and Palœ-Kameni; it recommenced in the month of June, and after working ten or twelve days, a new island rose up in the neighbourhood of Nea-Kameni. J)uring four months, a series of terrible phenomena occurred; considerable portions of the island were swallowed up, but others were formed; at last a second island appeared, and it united with the first in June. It was named the Black Island, on account of the colour of its soil. The subterranean disturbance continued until the end of the following year; and on the 15th of April, there occurred an eruption of large ignited stones, which fell two miles off."

The eruptious and upheavings from the bottom of the sea continued long after. The Academie des Sciences sent M. Fouqué to study on the spot the manner in which this remarkable archipelago became developed. M. Fouqué perfectly distinguished the two processes simultaneously working towards the production of new lands-the raising of the ground, and the increase of the raised spots by the deposit of lava, scoria, and rocks, which were cast out from the boiling cavern. The bottom of the sea is, as we have seen, ger:erally 
rolder than the surface, If, therefore, rocks situated at a great depth are brought rapilly to the surface, they will not have time to acquire warmth in rising, and will therefore cool the surrounding waters to a certain distance. 'The lava and stones thrown ont by the volcano will, on the contrary, heat the water sometimes almost to boiling.

The elevation of the island of Julia, to the west of Sicily, was accompanied by phenomena similar to the above.

3. The Azores-Appearance and Disappearance of Islands subsequent to Earthquakes--'The epl:emeral Island Sabrina.

The Azores are entirely volcanic, and we there find the same remarkable phenomena oceurring that we have alrearly noticed in the Grecian Arrhipelagro.

Evidence of the existence of a submarine volcano, near St. Michatl, was given by four eruptions in less than 200 years. One of them began on the 11th of June, 1638, during an earthquake. Flames an I smoke were thrown out by the agitated sea near St. Michael; earth and rocks were projected to a great height, and, again falling into the sea, at last accumulaterl sufficiently to form an island ten kilometres in extent, and nearly 400 feet high. Like Julia, the island soon disappeared.

Another earthquake occurred suddenly on the B1st 
of December, 1719, and an island was formed between Terceira and St. Michael. At first it was of sufficient elevation to be seen seven or eight leagues out at sea;

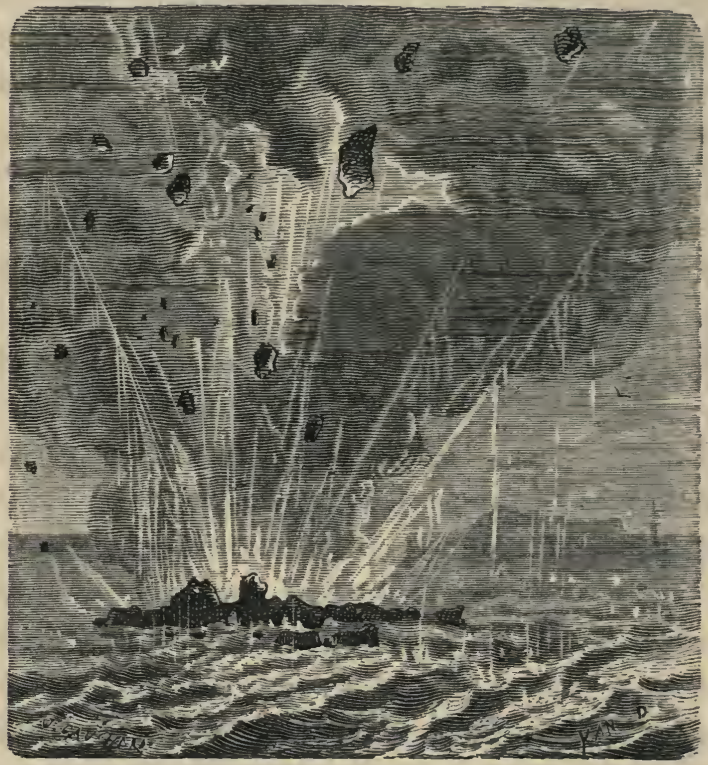

Fig. 61.-Submarine Eruption at the Azores.

it vomited incessantly a thick column of smoke, cinders, and pumice; a stream of molten lava flowed down its sides, and the sea became very hot in its neighbourhood. The height of the island diminished rapidly; after existing two years, in 1722 it had 
: unk to the level of the sea. It disappeared on the 17 th of Novernber, 1623.

Violent earthquakes disturbed the neighbourhood of St. Michael during the months of July and August, 1810. Shortly after (January 31st, 1811) the earth split on the eastern side of the island, near the village of Ginetas, a league and a half from the seashore. While the sea boiled violently, an enormous quantity of water and smoke, mixed with earth and einders, was thrown into the air. Stones were thrown to a height of 2000 feet. The eruption lasted eight days; a bank of pumice was then visible, against which the waves dashed on a spot where the water was previously not much less than 500 feet deep.

An island one or two kilometres in circumference, and about 300 feet in height, was the result of a new submarine eruption on the 15th of June in the same year. Captain Tillard, commanding the Sabrina. visited and touk possession of it in the name of the English Government. He gave it the name of his vessel. Little by little the island sank, and towards the end of February, 1822, a little vapour, floating over the surface of the sea, was the only remaining trace of its existence.

Porto de Ithéo, a vast hollow crater in which ships found a resting-place, as well as the island of Corvo, are of similar origin. 
During a grat earthquake which, in 1757, de stroyed one-seventh (1500 persons) of the population of the island of St. George, eighteen islets sudrenly appeared about 600 yards from the shore. 'i'heir fate was similar to that of Sabrina.

4. Submarine Volcano in the Midule of the Atlantic.

One of the most remarkable of submarine volcanoes exists in the mildle of the Atlantic Ocean. M. Daussy had already pointed out a region, situated about ' $24^{\circ} 42^{\prime} \mathrm{W}$. longitude and $0^{\circ} 50^{\prime} \mathrm{S}$. latitude, as interesting on account of volcanic phenomena. We reproduce a list given by M. Vézian of incidents observed on this spot, since the midille of the last century, by a large number of sailors :-

1747. The slip Prince, b und for tle Indies; two shocks, as though the vessel had touch d giound.

1754. The ship Sithouette; extraordinary shock.

1758. Le Fidèle; shock.

1761. Le Vaillant; an island of sand observed.

1771. The frigate Pacifique; very violent shock, sea much agitated.

1806. M. de Krusenstern saw a volume of smoke rising, twice repeated, to a gre at height.

1816. 'The 'Triton; a rock tiree miles long and one mile wide, 26 fathoms of water; bottom, brown sand.

1831. L'Aigle; 'a'm sea, shock, rumbling sound bene.th the water.

1832. La Seine; shock.

1†35̃. I a Couronne; sclaped tie bottom with her keel; sounded afterward, 35 fathoms. 
1836. Le Philanthrope; shocks which lasted three minutes, and which were also felt two mile's off by another vessel

1836. Sume voleanic cinders, collected near this point whilst the earth was in violent agitation, were forwarded to Calcuttis.

1856. Regina Coeli; rumbling sound as of a distant storm; afterwards severe shocks, accompanicd by a noise similar to that produced by striking several sheets of metal togrther. The helmsman was incapablo of managing the tiller, which was dragged from J,is l.ands.

1856. On the eame day and at the same hour-i.e., on the 30th of December, at 4 o'clock in the morn: $n_{g}$-the ship Gudavery rccived a severe shuck at a slight distance from the Regina Culi.

18ti1. February 20. Submarine earthquake felt on bonril the Félicie, wl ic, lasted a minute, and was preceded by a noise coming from the westward.

5. Submarine Eruptions near Kantschatka-Iceland-Ignited Sea ; appearance of an Islind near lieikianess-Rise of a Fiery Island from the Ocean, near the Aleutian Isles.

Occurrences similar to the above have often been ubserved near Kamtschatka, and in the latitudes of Russian America. For example, an eruption occurred on the 10th of May, 1814, when an island rose above the water, vomiting bitumen through many tissures.

Captain Kotzebue was eyewitness to the birth of sn island near Ounimack, in the Aleutian Archipelago. An account of the circumstances will be found in the narrative of his voyage.

On the 7th of May, 1796, M. Krinckhoff, agent of the Russian American Company, was at the northwest point of Ouninark ; a tempest, which blew from 
the north-west quarter, prevented him from seeing anything out at sea. On the 8 th, the weather cleared, when he observed, at some miles from the shore, a column of smoke or mist rising from the sea, and as evening approached he saw something black upheaved above the smoke. During the night fire

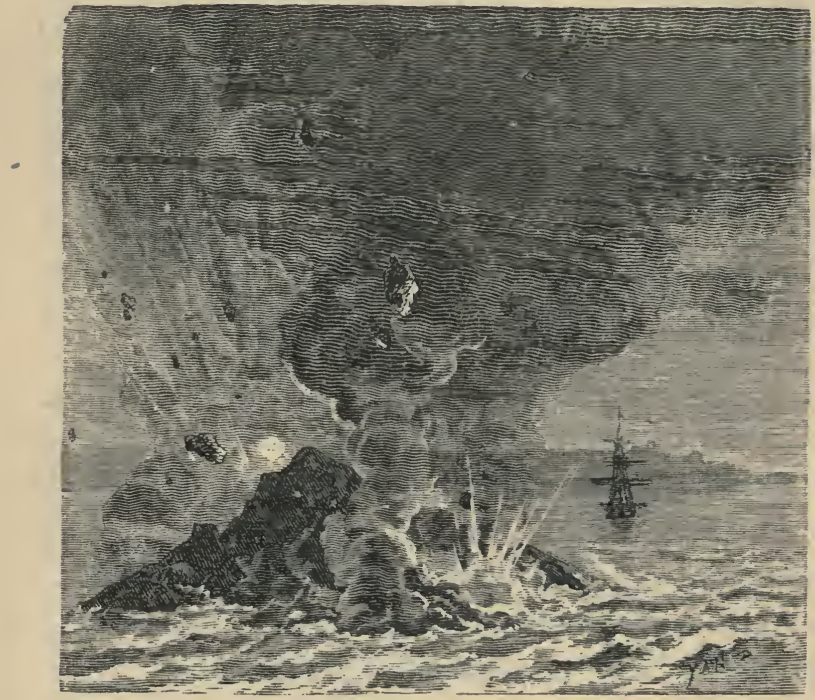

Fig. 62.- Kise of a new Island near Ounimack.

was emitted at the same plare, and with such intensity, that at a distance of ten miles objects were perfectly distinguishable. Then a trembling of the earth, accompanied by a frightful noise, which was echoed 
from the mountains of the south, shook the entire soil. The nascent island belched forth stones, which fell even upon Ounimack. The earthquake ceased at sunrise, the fire diminished, and the new island appeared plainly visible, conical in shape, and of a black colour.

A month later, M. Krinckhoff saw it again. The island was higher than before, and during all this time it had not ceased to vomit fire. Afterwards it appeared to increase in circumference and lieight, but the fire continued to diminish. Generally it emitted only vapour and smoke, and at the end of four years this phenomenon ceased also. When, abont eight years subsequently, the island was visited by a company of trappers, the surrounding water was found to be of a very high temperature, ant the soil so hot in many places that it was impossible to walk on it. Its circumference, which had gone on augmenting, was estimated at about two-and-a-half miles, and its height at about 350 feet. 'The bottom of the sea was strewn with stones even to a distance of three miles. The hottest part of the soil was from about the middle of the height to the summit, and the vapour which ascended from the crater was found to be of an agreeable odour.

Iceland is a very furnace of volcanic activity, and we observe in its neighbourhood phenomena of eleva- 
tion analagous to the instances we have already cited Mackenzie relates that, in the year 1780 , he observed on the western coast of the island, at the distance of ten leagues from Reïkianess, flames rising from the sea during many months. Afterwards a little island made its appearance. For some time this island vomited flames and stones, and then disappeared again. Immediately afterwards the Skaptaa Iokull, a neighbouring volcano, broke out in eruption.

6. The Buttom of the Sea feels the counterblow of terrestrial Volcanic Phenomena.

Terrestrial volcanoes and earthquakes are nearly always re-echoed, so to speak, from the bottom of the sea. . Ships experience a shock as if they had passed over a centre of volcanic activity.

Cracatoa, an island in the Indian Ocean, was destroyed in 1680 by an earthquake. Vessels at sua felt the shock.

Gounung-Api, or Gounapi, a volcano in the $\mathrm{Mo}$ lueca group of islands, burst into eruption on the $22 \mathrm{nd}$ of November, 1694. Its summit vomite I flames with a great noise. 'The bottom of the sea was, at the same time, heaved up to the level of the soil of the island, and flames ascended from the waters.

In $1 £ 20$, in a bay situated to the west of Gounapi, 
and where at other times sixty fathoms were sounded, a promontory was formed, which increased in extent until it filled up the bay. It is composed of gigantic blocks of basult highly calcinerl. The phenomenon was attended with so little noise that the inhabitants

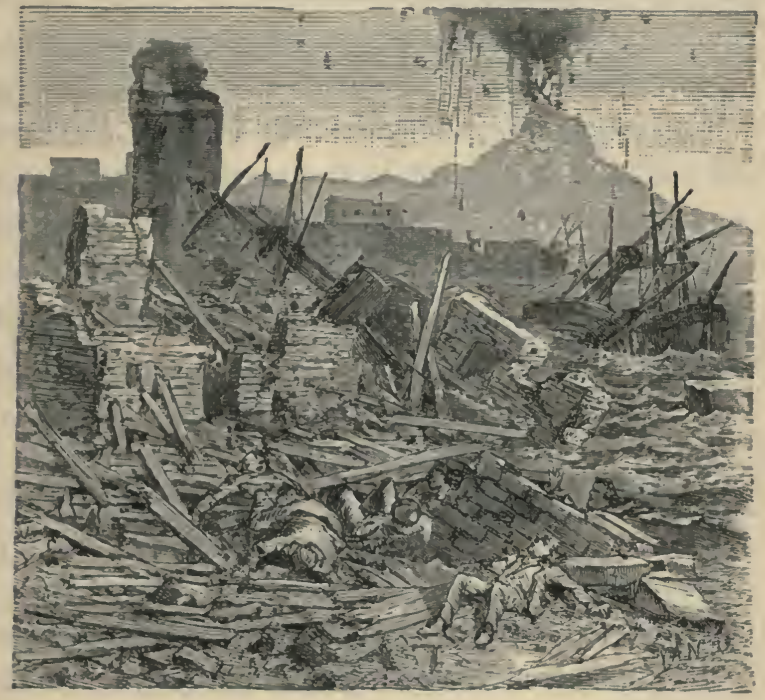

Fig. 63.-Eruption of Tomboro in $\mathbf{1 8 2 1}$.

of the Banda (or Nutmeg) Islands were unaware of th: occurrence until it was perfectly acenmplished. Thu: upheaval was slow, accompanied by an extraordinary rise of temperature in the water, which buiblen "p in the $l$ ay. 
In the island of Bima, or Sumbawa, there is a very active volcano, named the 'Tomboro. In 1821 such a movement of the sea occurred here, that the island " as partly submerged, and vessels at anchor in the port were thrown to a great distance on the shore. Many were landed even on the ronfs of the houses. Tomboro itself remained calm during the time, but a volcanic mountain to the north-east of it threw up stones and cinders in the midst of a torrent of vapours. The earthquake was felt in the neighbouring isles, at Celebes, and even at Macassar, where the same devastation occurred as at Bima. These two places are nevertheless separated by an arm of the sea 100 leagues broad.

7. Products of Submarine Volcunoes-How they differ from the products of Subaërial Volcanoes.

A very close analogy has been observed between the products of all the volcanoes on the earth's surface. Submarine volcanoes are no exception to the general rule. One and the same cause produces all these phenomena. The nature of the medium into which they eject their gas and igneous matter can alone vecusion any difference in the character of the eruption.

Submarine lava-streams may be expersted to cover 
a great extent of the ocean-bed, according to the opinion of Mr. Poulett Scrope, who has expressed himself to the following effect in his work on "Geology and the Extinct Volcanoes of Central France." "We ought to observe," he says, "that lava-streams at the bottom of the sea must have a greater breadth, compared with their thickness, than those which are cooled under atmospheric pressure, and that this lateral extension is proportioned to the depth of the water."

It ought also to be observed that lava-streams which have cooled at great depths under the water present little scoriæ. 'This, in fact, has been observed in the old volcanic rocks of submarine origin. This, however, may be caused by the influence of oceancurrents, or other movements of the water."

Some knowledge of the peculiar action of submarine volcanoes might' be acquired by investigating their products, which may be brought to light by the subsequent elevation of the ocean-bed above the level of the sea. Examples of this are frequent in the coral isles of the Pacific. The basaltic columns of the south and north coasts of Ireland, of the Faroe Isles, of the north-east of 'I'eneriffe, and numerous other localities, tend to demonstrate that the phenomena displayed by lava, when it is ejected beneath the sea, are very nearly similar to what occurs on the solid earth. The principal differences seem to be: 
1. That the lava cools more uniformly, and extends surther upon a plane surface.

2. That a submarine volcano ejects a less quantity of 'onglomerate, or of fragmentary matter, than a subaërial one, or that its igneous product extends further, and stratifies in thinner sheets of contemporary lava, than is the case with that of other volcanoes.

If these opinions be correct, the regions where we find immense formations, sometimes slightly inclined, of traprock and basalt, to which some countries are indebted for their picturesque aspect, have been at some distant period submerged, and exposed to the action of a submarine volcano, which has covered them with its products.

In such cases, when the volcano is in repose, it is obvious that submarine deposits of every kind -including animals and plants, if the depth be not too great-will be found supcrimposed upon the lava. Accordingly, when the ocean-bed is upheaved to the light of lay, we find a sheet of basalt between two beds formed of the débris of marine animals.

In Iceland we find subaërial volcanoes side by side with others of submarine origin, the latter having been upheaved to the light of day long after their activity had ceased. The first are the Jokuls, 
high mountains which abound in the island. 'The nurth and south of Iceland present an aspect thoroughly characteristic of these facts. IVe there find immense plateaux, whose submarine origin is plainly indicated by alternate beds of basalt and basaltic conglomerate.

The Isle of France (Mauritius) has all the characters of a submarine volcanic formation, which has been elevated en masse subsequently to the cessation of the eruptions. Bourbon, the near neighbour of Mauritius, presents, on the contrary, the appearance of the ordinary volcano, formed by the repeater coolings of lava-streams flowing from two or three sources constantly above the level of the sea, and one of which is in incessant activity.

Allowing, however, that the remarks of Mr. Poulett Siro are well-founder, it must be owned that they are subject to numerous exceptions. The remarkahle investigations of M. S inte-Claire Deville have, in fact, demonstrated that the nature of volcanic products viries ar ording to the length of time that the volcano has been in activity. It would lead us too far from our special subject to discuss this interesting question, but we may indicate in a very few words one of the many results obtained by M. Deville. A volcano seems to have its period of youth an' its periol of old age. During the first period, lavis are 
ejected; during the second, basalts. If a volcano which vomits lava is in repose, we may always expect a new eruption. When, however, the lava is succeeded by basalt, we may be equally sure the volcano is on the eve of extinction. We must, therefore, be careful not to pronounce too absolutely as to the marine origin of volcanic products from their nature and aspect.

8. Bottom of the Sea brought to light in consequence of the Eruptiou of Submarine Volcanoes.

If a mountain belching fire is lifted above the level of the sea by the action of some subterrarean fire, it carries with it the marine formations to which it had served as a support. The same expansive force acting upon a larger scale, and not limiting its effects to the elevation of the mountain, will raise to the light of day a more extende I region of the submarine world, with all the layers of débris, sometimes of very ancient formation, which cover it.

This is what we observe to have happened in Mauritius and two neighbouring islands. The configuration of the northern part of Mauritius is that of a level plane, formed of a recent calcareous rock, composed of polypi analogous to the coral. It covers the volcanic rocks which elsewhere form the summits of the island. The superposition of madrepores and 
corals upon volcanic products, is an evident proof that their formation was subsequent to the emission of the lava upon which they had planted themselves when it was sufficiently cool. But polyps live under water. The lava therefore, in this instance, must have been of submarine origin; the ocean-bed thus formed was long afterwards upheaved to the light of day.

By far the greater part of the surface of a group of islands situated a little to the east of Java, is composed of beds of coral, in all respects similar to those which are still in formation, and which constitute the well-known dangerous reefs of the Pacific. It is obvious that, in this instance also, the coral polypi had taken up their abode on the cooled lava, anıl that the whole mass was afterwards elevated alove the ocean, as in the case of Mauritius.

In the island of Pulo Nyas, to the westward of Sumatra, beds of coral, similar to those of the neighhouring seas, have been raised to a height of many hundreds of yards.

In the earthquake which, in 1820, destroyed a part of Acapulco (as described in a previous chapter). the level of the sea remained during two hours about 30 feet below its ordinary level, in consequence of the land having been raised to that extent. On the other hand, we remark a permanent 
elevation of the shore at Chili, to the extent of two or three yards, in consequence of an earthquake which destroyed Taluano in the Bay of Conception.

It would be possible to multiply, very greatly, examples of these upheavals of the submarine soil. W'e have only to recall the frequent formation of new islands, alluded to in a previous chapter.

The sudden changes which actually take place in the basins of seas are, in most instances, easy to verify. Often they are the cause of terrible catastrophes, which affect whole populations, and leave an indelible impression on the memories of those "ho witnessed or suffered ly them. 
(:RADUAL CHANGES OF THE BOTTOM OF THE SEA.

1. How the gradual change of the Sea-bottom can b. demonstrated -Modifications which the Map of Hurope would suffer hy a gradual sulsidence of Thirty Fet in a century-Paris sulimerged-Europe as it would be were the Level of the Se:t raiserl 500 feet-Toulouse and Vienna as Scaports.

WE have studied the more sudien shocks to which the earth's crust may be subjected. Incessant movements of a more gradual kind, which to be demonstrated must be studied during several generations, also influence it, embracing vast regions, and influencing equally the bottom of the sea and the highest mountains. Under the influence of such slow, almost insensible, changes of the earth's crustcountries, at one time flourishing, have disappeared, and others have risen in their stead.

So long as our study is confined to the sea, or to the interior of continents, we may look in vain for evidence of such changes; but if we visit the shores, we may find abundant proof that the ocean is either gradually retreating from, or slowly gaining on, the land. If the sea be apparently retreating, it is a 
proof that the land, at that particular spot, is rising. If the sea be gaining on the land, we may be assured that the soil is sinking.

On any coast terminated abruptly by a high cliff, we may perceive above highwater-mark an easily distinguishable line. The waves disintegrate the rocks. They are aided in their work by animals, of which we have spoken on a previous page. The pholades and other stone-borers are impelled by their instincts to select for their abode the line of demarcation between the two elements, where the air and water may be said to strive in perpetual conflict. 'These boring animals cunnot remain continually submerged, but the presence of water is indispensable to their existence. The cliffs against which the waves dash are better suited to their existence than any other situation. Wherever we find that these animals have established their abode, there must have been at one time the seashore. If the sea gains on the land, the colonies of pholades advance higher with the waves; if the sea retires before a rising continent, the pholades follow in its retreat.

Where the waves die away on a beach only slightly inclined, a coast-line is formed of rounded pebbles and rubbish, across which the waves only pass during great storms. This line defines the 
boundaries of the ocean. If the land be rising, this coast-line will appear to recede from the water, while a fresh one will be continually in course of formation by the retiring ocean.

The encroachment or retreat of the sea, easily proved in such a case, is much less obvious on a rocky or very steep coast. Where the ground is nearly horizontal, a slight rise in the level of the sea will cause the inundation of a great extent of country. The encroachment of the sea on an abrupt coast is, ou the contrary, insensible; and a number of observations, often repeated at considerable intervals, is necessary to obtain a definite idea of the phenomena.

If to this difficulty in making observations we add the complication caused by the ebb-and-flow of the tide, we may easily comprehend why so many years have been necessary to demonstrate anil accurately to measure the sinking of the land on the coast of Sweden.

When the earth is thrown up around us with a great noise, when crevices are produced in an instant, and the solid ground trembles and quakes beneath our feet, we can have no difficulty in remarking the facts. But although, after an earthquake or other perturbation of that nature, the country remains either raised or lowered several yards, the inhabi- 
tants of the interior of a continent would not be in the least aware of it, nor would they be more sensible of a slow and continuous rise or fall in the level. The seaside inhabitants would, however, recognise it by the obvious change in the level of the sea - the measure of its apparent rise or fall being equal to the actual rise or fall of the soil.

If Europe, sinking uniformly, laid itself open to the invasion of the sea, what would not be the modification of its map after a comparatively short time? Suppose the whole continent to sink at the rate of some ten yards in a century: at the end of fifty centuries, or 5000 years, the level of the sea would have risen some 500 yards - a result which would cause many rich plains and opulent cities to be engulfed. Paris, with her lofty monuments and her hills, would have disappeared long since ; a forest of marine plants would have covered this beautiful city, and marine animals would have disported themselves in her streets. The sands and other deposits with which the sea covers its bed, as with a vast curtain, would soon cover up the present scene of such advanced civilisation. Paris would disappear beneath the sea, as Nineveh beneath the sands of the desert.

But the change in the level of the sea need not be so great for the map of Europe to become 


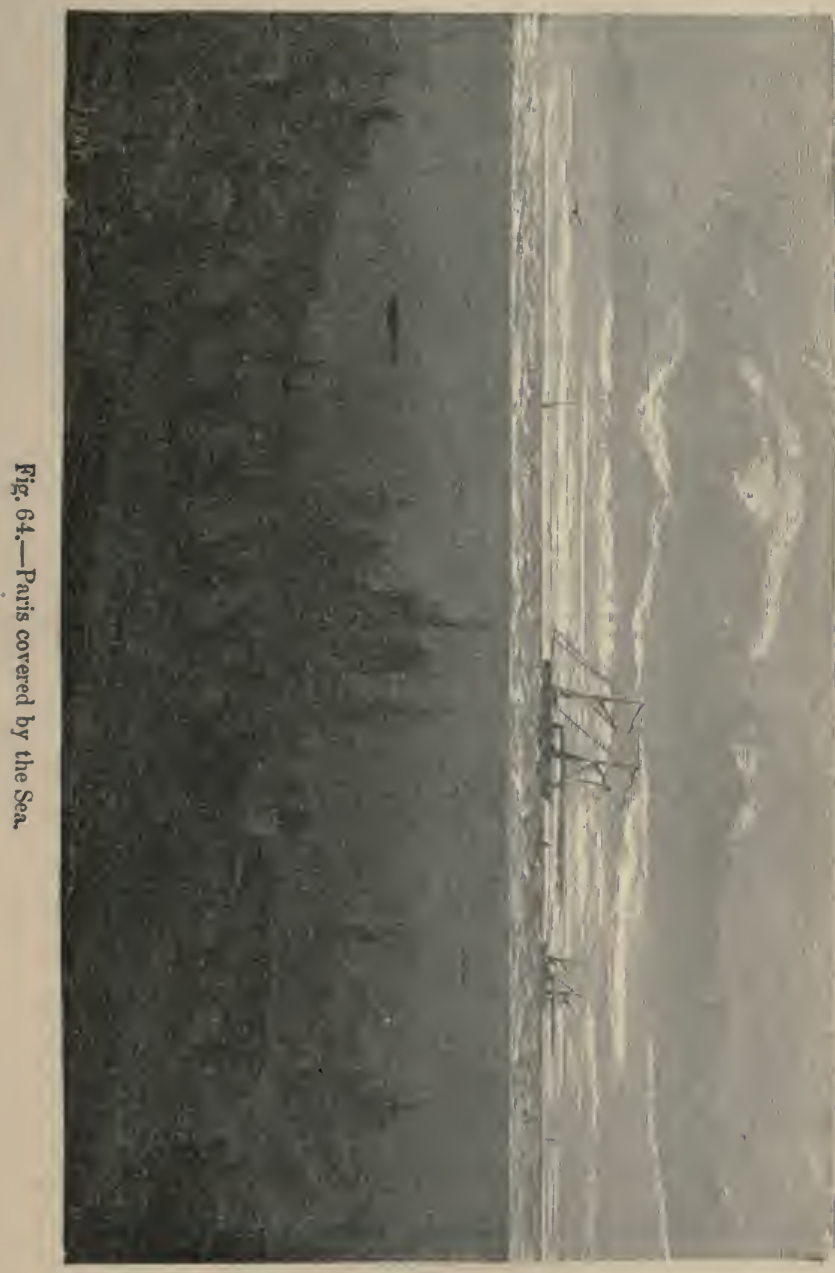



unrecognisable. The map at the commencement of this chapter represents the appearance which would be presented by Europe, supposing the level of the sea were to rise some 500 feet. Its land-connection with the Asiatic continent would then be broken; it would become an archipelago traversed by large arms of the sea. 'The valleys of the Vistula and the Dnieper would become vast sheets of water. An immense gulf would flow up the ancient valley of the Danube; a narrow channel would separate it from an interior sea corresponding to a large part of Hungary. Denmark, the low-lying plains of Germany and of the Netherlands, would be replaced by the ocean. England and France would be very much cut up. In the latter would be found three large gulfs, corresponding to the present courses of the Seine, the Loire, and the Garonne; fishing-boats would anchor over Bordeaux and Orleans, and make land at Toulouse. A narrow isthmus would unite France with Spain in the neighbourhood of Castelnaudary, and the rich wine-growing countries of central France would become transformed into submarine prairies.

The plain of the Po and the valley of the Ebro would make way for deep gulfs ; though, in general, the northern shores of the Mediterranean would suffer but little change. This would not be the case with the low plains which constitute Egypt and Cyre- 
naica. They would become one vast sea, bounded by the mountains of Algeria, Morocco, and Abyssinia.

The climate of this part of the world would in consequence be much changed. Immense sheets of water would cover the saline steppes of Russia; they would extend into Turkestan, as far as the Siberian mountains and the table-land of Gobi ; to the south they would invade the larger part of the African desert. The remains of Europe would have a very humid climate, for whilst at present the western winds alone bring us wet, all the winds would then be of oceanic origin.

We can hardly go further into the discussion of the modifications which would result from such an altered state of things; our only business is to point to the important part which the conquest of the sea plays in the general economy of nature.

2. Ancient limits of the Black Sea-Drying-up of the Russian Steppes.

Such changes do not entirely belong to fiction. The works of Tournefort, Chandler, and Tott, those of Count Potocki, of Prince Gallitzin, and of Pallas, unite with those of the ancients to prove that the northern coasts of the Black Sea have changed very much; and that between this sea, the Caspian, and Lake Aral, traces are to be everywhere found of the 
former presence of the sea. Pallas (vol. x.) thinks that the salt lakes of the steppes of Russia and Tartary are ancient gulfs, the mouths of which have been choked up with sand, and which have subsequently been considerably reduced by evaporation.

Originally, says Dureau de la Malle, the Mediterranean was a lake of small extent, fed by the Nile, the Rhone, the Po, and many other less considerable rivers. 'The ocean, making an irruption into it, inundated a part of the low sandy coasts of Spain, of Barbary, and the plains of Provence and Languedoc, and of course flooded the coasts of Egypt and Asia Minor, where it has penetrated to the foot of the mountains and hills.

After that period the Mediterranean, losing much more by evaporation than it gained from its rivers and the Straits of Gibraltar, then very narrow, gradually contracted. But it was entarged again, when, owing to the rolcanic eruption of the Cyanei Scopuli, the channel of the Bosphorus, and the plains in its neighbourhood, had opened a passage to the Euxine, the Caspian, and the Lake of Aral, and they were united in one sea, at least as large as the present Mediterranean. All the low plains of recent formation were corered with water afresh; but the sea again retired until an equilibrium was established, and it lost by evaporation what it 
gained by the influx of water. It has since preserved nearly its present form, the only material changes being on the low-lying coasts and about the mouths of the great rivers.

3. Movements of the Earth in the Northern Hemisphere-Subsidence in the North of Europe and of America-Elevation of the Polar Regions-Sinking of the Coast of Sweden.

Certain portions of the earth's surface sink; others rise, apparently perhaps without obeying any general law, but not really so. Everything goes to prove that in our hemisphere the continental mass is being elevated. A concave bend may be traced from the south of the Baltic to the Atlantic, passing by Denmark, the North Sea, and the Low Countries. Prolonged through the Channel, it is probably continued under the ocean, where, however, we cannot follow it ; but it is demonstrable again to the north-east of North America, and at Greenland. On the inner side of this bend, which marks a zone of subsidence, the bed of the former ocean is in process of elevation.

The line of subsidence cannot be followed to the east beyond the Baltic, for reasons we have already mentioned; but it certainly should not stop where we can no longer demonstrate the phenomena. In the neighbourhood of Sweden, where the oscillating 
motion of the soil is from east to west, the appearance of the phenomenon is that of a seesaw movement: the nurth rises and the south subsides.

New islands have appeared in the Gulfs of Bothnia and Finland : if this should continue for two thousand years, the Gulf of 'T'ornea will become a lake, like those which occupy the depressions in the granite all over Finland; and eighteen hundred years later, Stockholm will be united to this provinee by the Isles of Aland, transformod into an isthmus.

Sir Roderick Murchison first noticed, in 1845, the existence of a line, around which the surface of Scandinavia appeared to turn; but the honour of first demonstrating the movements of the land in Sweden belongs to the Swedish naturalist, Celsius, who lived at the commencement of the last century. He published his opinion that the level of the Baltic and of the North Sen gradually fell; and the result of a large number of observations was to settle the amount of this subsidence at about one yard in a century. The rocks on the borders of the Baltic and the ocean, which had formerly been the hidden cause of much disaster to vessels, showed in his time above the level of the water. The fact that terra firma gained continually on the waters of the Gulf of Bothnia, was proved by the existence of many ancient

" See "Les Oscillations de l'écorce terrestre," by M. Hébert. 
ports at a distance from the coast, by the abandonment of fisheries dried up or converterl into shallows, and the conversion of islands into continuous land.

The facts stated by Celsins were exact, but his explanations were erroneous. In 1802, Playfair assigned their true cause by attributing the observed changes to the movement of the land.

His opinion was confirmed, in 1807, by Leopold de Buch, who discovered, when he was travelling in Scandinavia, the gradual elevation of the whole country between Frederickshall (Norway) and St. Petersburg. He thought, without being certain, that Sweden rose more than Norway, and that the effects were more rapid in the north than in the south.

At the commencement of the eighteenth century, lines had been cut in the rocks to indicate the ordinary level of the sea in calm weather. These data were examined, in 1820 and 1821 , by the officers charger with the pilotage, and new lines were cut. During this interval of time the level of the Baltic had sunk, but not everywhere equally during equal times.

Nilson declared, in 1837, that Scania, the most southern province of Sweden, seemed to have sunk during several centuries. This Swedish savan at the same time cited a number of facts in support of his novel statement. A large stone near Talbourg, the 
distance of which from the sea had been measured by Linnæus, in 1749 , was more than 30 yards nearer the shore in 1837. Certain maritime towns were being constantly invaded by the sea, the level of some of the streets being below that of the lowest tides.

An entire province, heretofore called Witlanda, and situated between Pillau, Brandenburg, and Bolga, at the period when the Teutonic Order flourished, is now completely submerged. Moreover, the soil of Denmark, of Norway, and of Sweden contains deposits of shell entirely similar to those which are formed at the bottom of the neighbouring seas. The soil of Scania contains none. Therefore, at no very rernote period, Denmark, and certain parts of Norway and Sweden, were submerged; but not so Scania. The first-named countries are now, on the contrary, raised above the waters, and man establishes himself in them; Scania sinks, and Witlanda has already disappeared.

Such are the observations which have enabled the celebrated geologist, Sir Roderick Murchison, to conclude, in a general manner, that the actual motion of the Swedish soil, and of the bed of the Baltic, resembles that of a seesaw, the fixed line or axis of which would pass to the north of Scania. The south falls, the north rises. 
1. Elevation of Spitzbergen-Sinking of the Western Coast, and Elezation of the Eastern Coast of Greenland-Gradual Submer. sion of the Forests of Labrador und of Nova Scotia--Roman Constructions engulfed in the Low Countries-Origin of the Zuyder Zee-Failure of the Dutch Sta-dams-The Valley of the Somme and the Coasts of Normandy follow the movement of subsidence of the Low Countries.

Spitzbergen is going through a phase of elevation. Ancient coasts are now about 50 feet above the level of the sea. Siberia follows the same movement. Timbers floated and thrown on to the coast by the waves, are now in the interior, at a distance of 40 or 50 kilometres from the shore. An ancient island, still separated from the continent in 1760, was connected with the mainland in 1820 .

The line of subsidence, of which we have spoken above, passes to the south of the British Isles, the northern portion of which (Scotland) has been elevated some 25 feet since the Roman period. It commences to the north-west, between Greenland and Iceland. The ruins of ancient monuments may still be seen beneath the water. A Danish naturalist, Dr. Singel, has proved that during the last four centuries, the sea has encroached on the land over a length of more than 900 kilometres from north to south - a circumstance which had made it necessary to remove, repeatedly, some factories 
which had been.established on the shore, and subsequently invaded by the water.

The submerged forests in Fundy Bay, Nova Scotia, the subsidences at other points on the coasts of Labrador and Upper Canada, show that Davis Straits and the north-east of America are in the same line of motion as Greenland.

Several very flourishing Danish missions existed in Greesland in the ninth century, as is proved by papal bulls. These coasts, now unapproachable on account of the ice, which entirely shuts them in, possessel at that time an active and industrious population. Two towns, one cathedral, eleven churches, and three or four monasteries, show the prosperity of these colonies in the middle ages. The channel which separated Greenland from Iceland was frozen over during the winter, but each year the passage had been free in the warm season, and a Danish fleet carried supplies to the colonists, in exchange for the products of the chase and the fisheries.

In 1408 the ice did not break up. Subsequentiy, communication being interrupted, and the colonists separated from the mother-country, they were either massacred by the Esquimaux, or perished of cold and hunger. 'These coasts have since become still colder, and glaciers have covered the ruins of the 
Danish settlements. The cause of this cooling is, very probably, a general elevation of the whole eastern coast, whilst the western coast has subsided. The elevation has had a doublo effect: it has 'iminished the temperature while increasing the altitude of the country; it has compelled the warm waters of the Gulf Stream to flow more to the east-a result which has contributed enormously to diminish the temperature of the country. We shall not be astonished at this, if we consider the enormous influence exercised on climate by marine currents.

The Netherlands, as M. Elie de Beaumont has shown, are subsiding gradually. Roman constructions may there be seen surrounded by water, having long since been passed by the coast-line. Peat-beds, at one time important, have been buried beneath the sea during the historic period. As the oceanic waters, filtering through a porous soil, continued to rise, the Lakes of Haarlem were gradually enlarged, until at the end of the seventeenth century they united to form an inland sea.

It is all in vain that men have attempted to raise powerful dams against the encroachment of the sea. The dams sink slowly with the soil on which they rest, and there is no doubt that, in a more or less distant future, the barrier which they oppose will be insufficient to protect the low-lying plains of Holland. 
The valley of the Somme and the coasts of Normandy are also gradually sinking. Already the turfpits of the valley of the Somme are below the level of the sea. Submerged forests, whose disappearance beneath the waters is proved by positive documentury evidence, exist off the coasts of Normandy. The same may be said of the opposite English coasts. The whole of the Channel is sinking. The Straits of Dover, which would lecome dry land by a slight elevation of the soil, are therefore but little likely to serve as a means of communication between France and the British Isles. There are two reasons to convince us that it must enlarge: first, in consequence of the action of the sea on its shores; and, secondly, on account of the subsidence of the surrounding countries.

5. Two extensive Zones of Subsidence in the Southern Hemisphere - They are separated by a Zone of Elevation-The Fiji Islands have been sinking during 300,000 years.

Two vast regions are subsiding in the southern hemisphere. One of them comprehends the numerous ocennic archipelagos-the Bass Islands, the Society Isles, the Carolinas, Gilbert's Archipelago, Marshall's Archipelago, and others. Its length is more than 8000 miles, and its mean breadth 
more than 1200 miles. Each year has furnished, and still furnishes, proofs of the disappearance or diminished size of islands in this immense zone.

It has been seen in a preceding chapter how the incessant labours of the coral insects compensate for the sinking of the soil, and how the rapidity of the growth of the coral reefs furnishes a measure of the rate of subsidence. The size of the reefs also indicates the epochs since which the movement of the soil has continued. The annual growth in height of the polypiers is $0^{\mathrm{m} \cdot 003}$. Now certain reefs are several hundred yards in depth. Those of the Fiji Islands, for example, are about 1000 yards, those of the Gambier Islands about 400, and those of Tahiti about 80 yards. If the growth of those reefs has always been at the same rate, 300,000 years have been necessary for the production of the reefs of the Fiji Islands.

The coral insects grow only near the surface of the water: they have therefore sunk 1000 yards at the Fiji Islands since they first commenced their work, and that has been during a period of 300,000 years.

The second region of subsidence comprehends New Caledonia, Australia, and the basin of the Indian Ocean, including the atolls* of the Chagos Bank and

* An atoll is a circular wall or reef of coral enclosing the sea, within which it resembles a small lake.-Tr. 
the Maldives. The polypiers there play a very important part.

Between these two zones there extends a vast zone of elevation. It is formed by a semicircle of volcanic islands: New Zealand, the Kermandec Islands, the Friendly Islands, New Hebrides, the Solomon Islands, and New Guinea. This volcanic line bifurcates. One of the branches passes by the Philippines, Formosa, and Kamtschatka. Its direction is therefore first east and afterwards south-east. It passes the Sandwich Islands, and runs parallel with the western side of the Andes for about 2500 miles. The other branch, tending westward, passes Timor, Java, and Sumatra. The rising is very evident on the coral banks of Mauritius, the Isles of Réunion, Madagascar, the Seychelles, and the Red Sea, \&c., which serve as a point of junction between the oceanic and continental zones of elevation.

We have already explained by what means these variations are discovered; they are slow but continual. We are still far from being acquainted with the laws which regulate them, but it is a great honour for our century to have clearly demonstrated their existence. We may from this moment say, with M. Hébert: "In spite of its apparent immobility, the whole surface of the earth is continually undergoing a balancing action 
which is at present of such a character that the great continental zones are rising, whilst the great oceanic basins sink. . . . The varied surface of the earth is simply due to a series of movements, which have taken an incalculable time to produce existing results. . . . Let us carefully remember that our measures, adapted to our own comprehension and to the length of our existence, are borrowed from the dimensions and motions of this point in the universe which forms our habitation, and can never be regarded, whether as respects space or time, as in any sense proportionate to the dimensions and the duration of the works of the Creator !" 
AC'TION OF RIVERS AND CURRENTS ON 'I'HE BOT'T'M OH THE SEA.

1. Choking of Ports with Sand-Deltas, and the action of the Tide upon them-The formation of Deltas may be either favoured or retarded by Marine Currents according to circumstancesDeltas formed in Shallow Seas-Rapid growth of the Delta of the Po clue to the Clearing of the south side of the Alps, and to the Damming-in of the Shores of the River.

Trie movements of the submarine soil are among the most active causes of variation in the distribution of land and sea on our globe; but they are far from being the only causes of this phenomenon. The rush of the waters is continually causing disintegration of the soil where the current is rapid, and the whole of the matter thus carried in suspension is deposited when the waters attain a position of rest in parts of the ocein where these currents cease to act. This is why ports choke up, unless a strong current of water can be made to flow through them. The sand is deposited most rapidly when the entrance to the port fullows the direction of a current parallel with 
the coast. A dam constructed at a given distance, and turning the current towards the offing, diminishes the accumulation of the sand.

In consequence of the same action, sandy or muddy deposits are produced at the mouths of rivers, in part embarrassing tho issue of the waters, and sometimes becoming sufficiently important to constitute islands extending to a greater or less distance into the sea, and called "deltas."

We have already seen that rivers carry a large amount of rubbish of all kinds into the sea. Rocks of any size do not travel far beyond the mountains from which they are torn; coarse gravel goes a little farther, but does not always reach the sea. In the case of the Ganges, it is found 400 miles from the mouth; whilst in that of the Po, it is not discoverable beyond Piacenza. Bodies carried in suspension go farther in proportion to their lightness.

Mud and sand, therefore, form essentially the base of the delta. Fresh-water or land shells, the remains of salt-water animals, and more rarely marine shells, help to increase these deposits.

Remains of animals of large size are also found in such situations, whether they have been carried there by the river-current, or whether the delta has served them for a habitation. The delta of the Ganges is inhabited by tigers and alligators; all the human 
bodies thrown into the river, in accordance with Hindoo custom, are stranded there. The delta of the Mississippi serves as a retreat for numerous alligators. The deltas of the Nile, the Rhone, and the Rhine are covered with flourishing cities, while venerable forests occupy the immense islands which obstruct the mouths of the larger rivers of South America. The form of a delta is triangular. The point where the river first divides is the apex of the delta. The base is the portion of coast-line comprised between the mouths of the two inferior branches. Sometimes two rivers flow into the sea at points near each other, when their deltas may be more or less confounded; in such cases the regularity of an ordinary delta must not be expected. The two deltas combined form a network, more or less irregular, of islands and canals. The Po and the Adige, the Rhine and the Meuse, the Ganges and the Brahmaputra, are examples in point.

Many causes influence the collection of such débris at the mouth of a river. They have been examined with minute care in the work of M. Alexandre Vézian, ${ }^{*}$ to whom we are indebted for details.

The more extended the bed of a river is, the more materials it is enabled to collect, and consequently the more rapid is the formation of its delta. 'The

* Prodrome de Géologie. 
two largest deltas are those of the Ganges and Mississippi.

The tides tend to hinder the formation of deltas. They cause the waters of the river to be driven back daily with considerable agitation. The bed of the river is disturbed and broken up, and the great rapidity of the current of the falling tide augments such disturbance. The Thames, the Tagus, the St. Lawrence, and the Amazon are thus influenced. If, however, the current of the river be sufficiently strong to overcome that of the sea, the delta is formed, as in the case of the Ganges.

An inland sea offers the most favourable conditions for the establishment of a delta. The Mississippi, the mouth of which is at the head of a gulf, is subject to conditions intermediate between these two extremes.

A current, parallel with the coast, hinders the formation of a delta. It seizes the materials as they are deposited by the river, and sometimes carries them to a great distance, to a spot more calm. 'This has happened in the instance of the Amazon. The current of this immense river is recognisable a hundred leagues from its mouth. The sediment which it carries in suspension is considerable; but the great equatorial current, which flows from east-south-east to west-north-west alnng the shores of South 
America, carries the river-mud along with it as far as Guiana, where, far from its parent river, it forms deposits which are quite analogrous to those of a delta. These deposits become gradually transformed into dry land, and they may be considered as the delta of the river, carried, bit by bit, to a point westward of its proper destination.

How does man himself proceed to work, when he wishes to recover a few feet of land from the sea? He deposits offshore rocks, stones, and whatever else can be used to fill up the deep. 'The river at its mouth carries with it light sand and mud. At the time of its rising, immense rafts or floating islands of forest timbers encumber its bed, and, becoming entangled in its numerous curves, stop and form true dams. The river flows round them, and an island is formed. Farther on, similar islands are built up near the sea, where the deposits are continued in a shelving form, the base of which gains daily; every hour, every minute, brings fresh materials. Nature's work never comes to a standstill.

It is evident that the more shallow a sea is, the more rapidly will it fill up, and the more rapidly will the delta be formed. 'The great depth of the Bay of Bengal contributes to retain the formation of the delta of the Ganges. It may be clearly seen on a map of this relta, that the two principal exterior 
branches fill on either side the ocean depths-building up two immense slopes, separated by a narrow ravine. Ultimately the two banks will become connected, the deep water between them being gradually filled up.

The rapid formation of the delta of the $\mathrm{Po}$, and the slight depth of the Adriatic, into which sea this river pours its waters, are well-known facts. But other causes have contributed very considerably to this effect; these are the embankment of the rivers and the clearing of the forests.

The clearing of the soil and the destruction of forests tend to augment the quantity of water which, in the rainy seasons, flows down into the rivercourses. Thus man himself helps to increase the quantity of material that streams and rivers carry into the sea.

Embankments produce similar effects by augmenting the rapidity of the current, which, in times of flood, carries sediment much farther than when allowed to spread at its pleasure over vast plains, where it deposits great quantities of mud.

The embankments of the Nile, of the $\mathrm{Po}$, and of the Mississippi, show how the growth of a delta may be accelerated by narrowing the channel of the river.

The great labour of embanking the Po, and effect- 
ing the clearings on the southern side of the Alps, was performed between the thirteenth and the seventeenth centuries. Since, then, the mouth of the river has advanced with great rapidity into the bosom of the Adriatic. The embankment has not only increased the amount of materials carried by the Po towards the sea, but is continually raising the bed of the river, which is actually above the level of the houses of Ferrara.

Similar causes have produced similar effects in the case of the Mississippi, since human industry has taken possession of the vast region through which this river and its tributaries flow.

2. Egypt, according to Herodotus, a present from the Nile.

The Egyptians, more intelligent than ourselves, take the greatest pains to store up the waters of the Nile, by means of dams, at each period of flood. They receive them in canals, so as to distribute them more completely over the soil. By this means they also diminish the force of the current, and generally succeed in mitigating the otherwise disastrous effects of the inundation. The mud, which would under other circumstances be carried to the sea, is deposited on its way, and fertilises the soil; the materials which would form the delta are spread over the 
whole extent of the river's basin. The delta of the Nile, therefore, increases less rapidly than those of the Mississippi and of the Po, and this in spite of the relative smallness of the basin of the last-mentioned river.

The ancient Egyptians knew the importance of the alluvial matter carried in suspension by rivers. Herodotus (Book II. chap. x.) cites the opinion of the Egyptian priests, according to whom Lower Egypt is a present from the Nile, which has filled, by the deposition of its mud, an arm of the sea enclosed between Libya and the Arabian mountains. He adds, that if the lead be thrown at the distance of a day's journey from the sea it will come up well covered with mud from a depth of eleven fathoms. Herodotus bases his opinion on the fact that the superficial soil of this country is a blackish mud from Ethiopia, which contrasts with the sand and gravel, the ordinary soil of these countries.

The Egyptian priests also remarked, in Hero. dotus' time, that under $M$ ris, 900 years before, if the Nile in its annual overflow rose eight bits, it watered the whole of the plain below Memphis, and that it then producel the same effect only when it rose fifteen or sixteen cubits.

Aristotle speaks of the variation of the seas in his "Treatise on Meteors." "Egypt," he says, "fur- 
nishes an example of a country becoming drier and drier ; it is entirely formed of the depositions from the Nile." According to him, the Canopus, or western branch, is the only natural one; the others appear to have been dug by man to facilitate drainage.

Plutarch ("Isis and Osiris") says that in ancient times the valley of the Nile was covered by the sea, as is proved by the shells met with in the neighbouring desert, and the saltness of the wells dug there. Arabian authors of the middle ages express the same opinion.

It is very curious to remark, that ancient observers had already sufficiently studied this question to recognise the slow but continuous elevation of the bed of the river, and the deposition of its suspended matter in the sea, so as to constitute a delta. From this elevation of the bed it results, that near their mouths, in very flat regions, the rivers often flow at a level higher than that of the surrounding plain, so that at each flood the waters sprearl over the surruunding country, and cannot re-enter their bed but from lakes.

Often, as if uncertain of their course, the waters divide into several branches to reunite farther on. 'The slightest inequality in the soil forms an insurme ntable obstacle to their progress. The waters 
seem wearied, as of a long journey-then appear to leave with regret the land which they have fertilised; they follow a thousand capricious courses, separating only to come together again; they heap up sand and mud, as if to reproduce at the last moment the mountains which they have destroyed in their force. But, alas! they have no longer that power which the suddenness of their descent had before conferred on them, and they still labour to diminish it after it has already become almost insensible. It is thus also that the greatest efforts of man may only serve to paralyse his powers, when he works without the enlightenment of real knowledge!

3. Description of the Delta of the Mississippi-A Village at Anchor -Ships lost in the Sand and Mud of the River.

The Mississippi is elevated nearly twelve feet above the plain about a mile and a half from its banks. The main stream therefore has acquired a tendency to send its ramifications right and left, which soon become the subject of similar phenomena.

The continual deposition of soil along the banks of the river raises its bed above that of the neigh bouring plains, and it therefore runs along the summit of a low hill. If the waters overflow, they spread on both sides of the hill, and are never able 
to return to the channel which they have abandoned. They travel gradually towards the sea in innumerable tortuous canals, named bayous, which occasionally swell out to form ponds or small lakes. Like the principil stream, the bayous also undergo a process of gradual elevation of their beds. A second series of bayous branch out from the first, and a third from these; the elevation of these bayous above the plain becomes less as the distance from the main stream increases. The entire region presents an appearance opposite to that ordinarily met with. The watercourses occupy the crests of low hills, and their importance is the greater as the height of these hills increases. Irrigation becomes a very simple matter in such a country.

The Mississippi extends very far into the sea. It runs out between two banks of slight elevation, which it continually lengthens. First, it converts he more or less deep sea into shallows, which soon become covered with a forest of aquatic plants and reeds. A thick layer of inud is deposited at every flood, which buries the stalks of the plants, and elevates the bottom of the sea in such a manner as to form a species of submarine delta. This deposit is increased from year to year.

Immense rafts of forest timber, carried to the sea and again rliven back by the waves, become covered 
with earth, forming floating islands; and being stranded on the banks described above, the growth of the latter is much facilitated.

In the popular "Tour du Monde," published under the direction of "Mons. E. Charton, an interesting account is given, by Mons. E. Reclus, of a voyage on the Mississippi as far as New Orleans. He describes all the phases of the phenomena of deltas, shows the fresh-water separated from the ocean by a moveable line of demarcation of sandy mud, forming low islands and marshes, and ultimately dry land.

"All night," he says, "our vessel dragged over a bottom of nauseous mud; but, far from complaining, I congratulated myself on the opportunity of witnessing what I had travelled 2000 leagues to see. What can be more interesting, from a geological point of view, than this vast stretch of alluvial soil in a semiliquid state! Produced by the slow corrosion of flowing waters during many ages from the mountain-chains of North America, this sand and clay form in the Gulf of Mexico a thick bed of from 200 to 300 yards in depth, which sooner or later, by subsidence and the influence of tropical heat, will become transformed into vast strata of rock, and will serve as a base for fertile and populous regions. In their work of creation these suspended particles are sifted by the sea into deposits of various sizes, and 
are thus heaped up into islands or new shores; or perhaps, carried away by the current of Florida, are deposited a thousand leagues farther off, on the Banks of Newfoundland.

"Towards daybreak the captain thought of a means of getting off the mud-bank, and sent one of our boats to the mouth of the river to find a pilot. Some miles ahead a long thin black line seemed to jut out into the sea, like an immense mole; beyond this dark line the river was distinguishable like a broad silver ribbon; farther, another black line, parallel to the first, was visible; and still beyond this might be seen the blue sea-waters stretehing to the horizon. The Mississippi appeured to us like a canal curried right out into the sea between two long jetties, and the forty or fifty sail, just apparent against the sky, rendered the resemblance still more remarkable: such a spectacle will one day be presented, on a sinaller scale, by the Suez Canal projecting into the waters of the Mediterranean.

"When we approached the mouth of the river the tug slackened speed, for caution was necessary in entering the buoyed channels which lead to the entrance of the river: these passes are very dangerous because the currents, both of river and tide, cause the depth to vary. Ordinarily, the islands formed by the subsidence of the suspended matter 
grow insensibly; but, during tempests, the submarine configuration of the mouth changes completely, and it is unsafe for ships to attempt an entrance until numerous soundings have been made. In spite of his native audacity, even our American pilot felt it necessary to cast the lead repeatedly.

"At last we entered the course of the river itself, and joyfully felt the rush of the current against the sides of the vessel. Nevertheless, although sailing up the Mississippi, we could not see the banks of this wonderful river-it appeared to us like a river flowing in the middle of the sea. The only indication of the submarine banks which had been built up between the salt and fresh water, was an occasional muddiness just above the more elevated portions of the banks, or perhaps here and there the bank itself was visible in dim outline. As we ascended the river, the outlines became more connected; what had previously appeared as disconnected or accidental elevations in the submarine soil now acquired the appearance of a continuous line of demarcation, and speedily assumed a more solid and definite appearance, until ultimately it rose, a solid bank, above the level of the surrounding water. At this point also the bar, or alluvial dam formed across the river, attains its greatest elevation.

"So far the water ploughed by our keel, and left 
bubbling in our wake, has been the undercurrent of blue sea-water which flows beneath the yellow water of the river, and in the reverse direction; but no sooner have we touched the bar, and felt the ship's progress impeded by the resistance of the mud, than the colour of the water in our wake changes to a dirty yellow, and the already inuddy current is rendered sensibly thicker by the disturbance of the mud at the bottom. The helmsman now requires a firm liand and a sharp eye, for the bar is nearly a mile long, and the slightest deviation to the right or left may entangle the vessel irretrievably in the mud. If the keel once stick, its peculiar motion raises the mud, the light particles of which are carried in a state of suspension in the current, whilst the heavier settles around the hull; the slow motion of the ship soon allowing it to collect in sufficient quantity so as entirely to stop the vessel, and enclose it as in a wall of rock. We passed a few yards from a magnificent three-masted vessel which had been thus beleaguered, and in the attempts to disengage which fruitless efforts had been spent. Enormous banks of sand had already collected around it, and now appeared like great masses of floating cork.

"The village of Pilotsville, the wooden huts of which were visible on the left shore, is generally known by the name of Balize. 'This name really belongs to 
another village founded by French colonists on the shore of the south-east channel ; but since the southwest channel has become the principal entrance to the Mississippi, the pilots have at one and the same time carried their industry and the name to this miserable town. Certainly few places on the earth have a more wretched appearance; the narrow slip of earth on which the houses stand is at once the shore of the river and of the sea. The waves of the one and the floods of the other cover it in turn, and mingle together in a labyrinth of slimy and offensive ditches: wherever a little solid earth permits the plants to take hold, there will be found an impenetrable jungle of wild sugarcane and rushes. The wooden cabins are constructed with extreme lightness, so that they may not sink in the soft soil, and to keep them as dry as possible they are perched on the top of piles like stilts. Moreorer, in heavy gales, when the waves rush over the bank into the river one after another, the houses of Balize might easily be swept away if they were not anchored like ships; sometimes, indeed, the village does drag its anchor. The miasma which encircles the town of Balize is the everlasting source of fever and death, and yet four hundred Americans courageously face these dangers, and draw what profit they can from the strcecour afforded to ressels in distress. 
"A light wind blew from the south, and our axptain wished to profit by it and sail up the river. Unhappily, the river winds in the most distressing manner, and the sailors were obliged to tack about continually, to furl and unfurl only to furl again. They could scarcely use their hands for fatigue when the ship considerately stuck in the soft mud of the bank. Towards evening a tug came and pulled us out of our ridiculous position. Thanks to this yowerful aid, we arrived in less than an hour at the point where the river divides into several distinct channels. In the last hundred miles of its course the Mississippi seemed to me like a gigantic arm stretching out into the sea, with its fingers spread out on the surface of the water. 'To the west extends the Gult of Barataria; to the east is another gulf, known as Lake Borgue; to the south, between each of its channels, a little marine gulf also flows, so that the whole land-surface consists of narrow strips of coastline, ceaselessly demolished by the waves, ceaselessly renewed by deposition from the river. In some places the bank is so little elevated above the sealevel that the waves almost flow over into the Mississippi; and if the roots of the rushes did not bind the soil together with their tenacious hold, the beach would soon break down, and a new channel be made for the 'Father of Yellow Waters.' 
"The only vegetation on these narrow humid coasis is that of the wild sugarcane; trees cannot as yet find any hold for their roots. The first tree to be found is a poor stunted willow, which has managed to drag out a miserable existence on the first sufficiently elevated mound of earth to be foundnamely, one situated about twenty-four miles from the mouth of the river. A few hundred yards farther up, a little group of two or three moro healthy-looking willows have managed to plant themselves; still farther, the clusters of willows become more frequent: at last they grow in continuous clumps, and, intermingling their foliage, form a curtain of pale-green, which hides the sea from the traveller, and gives a more continental appearance to the country."*

4. Rapid growth of the Deltas of the Po and of the MississippiDelta of the Nile eularged by Seven Miles during the Historic Period-The Rhone.

Dry land is being continuously extended seaward at mouths of rivers which have formed deltas. As the older channels get gradually choked up, a tinie comes when only one remains, which divides again into several branches nearer the sea. At the same

- Extracted from "A Voyage to New Orleans," by MI. Reclus. 
time new deposits are built up against the assaults of the waves, as we have seen to be the case with the Mississippi. It results that the delta of former times is no longer that of to-day, and that the navigable channels are always in course of change.

'The channels of the Nile do not extend more than about four yards in a year. 'This is partly owing to the system of canals established by the Egyptian priests, partly to the current which flows along the coast, and which carries a large part of the suspended matter towards the east, and oceasionally breaks down its banks.

In the time of Augustus the sea washed against the walls of Adria (a city near the mouth of the Po); the shore is now eight leagues distant, in consequence of the growth of the delta of the Po. The increase from the twelfth to the sixteenth century was at the rate of about twenty-seven yards annually; it has augmented since then, and is now at the rate of about seventy-five yards.

'The delta of the Rhone advances, perhaps, fiftyfive yards each year, and that of the Mississippi about 380 yards. The immense delta of the Ganges, situated at the head of a gulf, must grow rapidly; but, as the spot is very unhealthy, it has never been inhabited, and there are no data which would enable us to form a ju'grment on the subject. 
'The outward growth of the heads of deltas is proved by many facts, but none are so striking as those which concern the delta of the Nile. At one time this river flowed into the sea through seren branches, of which there were three principal ones. Of these branches two only now remain-those of Rosetta and Damietta. The exterior branches (the Canopus and the Pelusiac) are filled up, and the head of the delta, which was at one time under the parallel of Heliopolis, is now about seven miles nearer the sea.

In all deltas the relative importance of the various branches of the river is constantly changing. In the time of the Etruscans the course of the Po was the Po-di-Primaro, but now the principal branch is farther north.

The head of the delta of the Rhone is at Arles. The western branch, now called the Little Rhone, was at one time the more important. It was itself successor to a still more western branch, now dried up. The principal course, at the present time, divides into several branches before falling into the sea; one of these will, in course of time, alone remain, as the others will gradually be filled up. 
5. Littoral aceumulations-Coast-line-Marine Iagoons nnd Ponls-I agoons moved inland by the etleets of the Dunes in GasconyVillages buried lieneith the Dunes near St. Pol-de-Léon in Brittany, and also in Guscony-Bordeaux menaced.

The elevation of a shore by the addition of fresh soil is effected by the sea-waves as well as by rivers. Every coast exhibits, within the limits occupied by the sea, a quantity of loose sand and rounded pebbles. The less rapid the current is at the bottom of the sea, the slower is the accumulation, which, however, attains great importance on low coasts, giving rise to dunes, bars, and a number of other phenomena, which we shall indicate in a few words.

We have seen that the mass of loose stones, \&c. thrown up by the sea at its borders, is continuous along every coast, and that it marks what is called the coast-line. When formed of fine sand, and the soil is not clayey, the action of the wind, in conjunction with the waves, causes the production of those hills of sand called dunes.

Lagoons often accompany the coast-line if the shore be clayey, and if the country be sufficiently flat to allow the water to remain in any slight inequality of the soil, or to flow very slowly towards the sea.

Bars and other phenomena, the study of which would carry us beyourl our subject, in conjunction 
with the coast-line, the dunes, and the lagoons, constitute the littoral apparatus. "l'hey combine to form a very decisive line of demarcation between the region of storms and agitation outside the sea, and the abode of peace within the land."

The coast-line, in some cases, may become a barrier which completely separates the waters of a gulf from those of the sea. But even when the coast presents no hollow for the collection of the water, salt lakes or lagoons may be formed if a line of rocks, visible or not above water, should exist at a certain distance from the shore, and form a bar to the sand or other stuff that may be washed up by the sea. The lagoon may retain one or two communications with the sea, in the shape of channels, or it may become completely enclosed.

Marine ponds are deep lagoons; they are numerous on the coast of France. 'That of 'Thau, near Cette, is one of the most remarkable. If a lagroon entirely separated from the sea does not receive any stream of water, it dries gradually, and increases in saltness. When it receives a river, its saltness diminishes. In any case, the creatures which it feeds are modified according to the changes in the composition of the water. Thus, the lagoons of Finland are inhabited by freshwater animals, and also by a kind of shrimp

* Flie de Beaumont, Leşons de Géologie Pratique. 
which is able to live in water less salt than that of the ocean.

'The encroachments of the sea on dry land are not confined to inundations; it sometimes bores beneath the sand, which it throws up from its bosom. The dunes (so called from the Celtic word dun, which signifies an elevated spot), or sandhills, are formed on the seashore, as in the African desert, by the action of the wind on the loose sand. They present a gentle inclination towards the sea, whilst on the land-side they are terminated by an abrupt declivity. Their height is generally from 15 to 20 yards, but in rare instances they attain a height of 80 yards, which may be considered the extreme limit.

For the rapid formation of dune; it is necessary that the sea should leave a large space bare, which subsequently it will cover with its waters and the sand it carries with it. 'These conditions are best fulfilled on those coasts where the daily ebb-and-flow of the tirle leaves a large extent of sand exposed to the drying action of the sun and wind. Another condition on which the increase of the dunes depends, is that the sea-winds blow more frequently than those from the land-otherwise the work of one day will be undone by that of another.

The formation of dunes is sufficiently simple. Tho wind from the sea blowing over the sandy waste, 
causes an inclined plane to be formea, up which the particles of sand are afterwards driven, and having attained the summit, fall down the declivity, which they continually enlarge. At the base another sund-

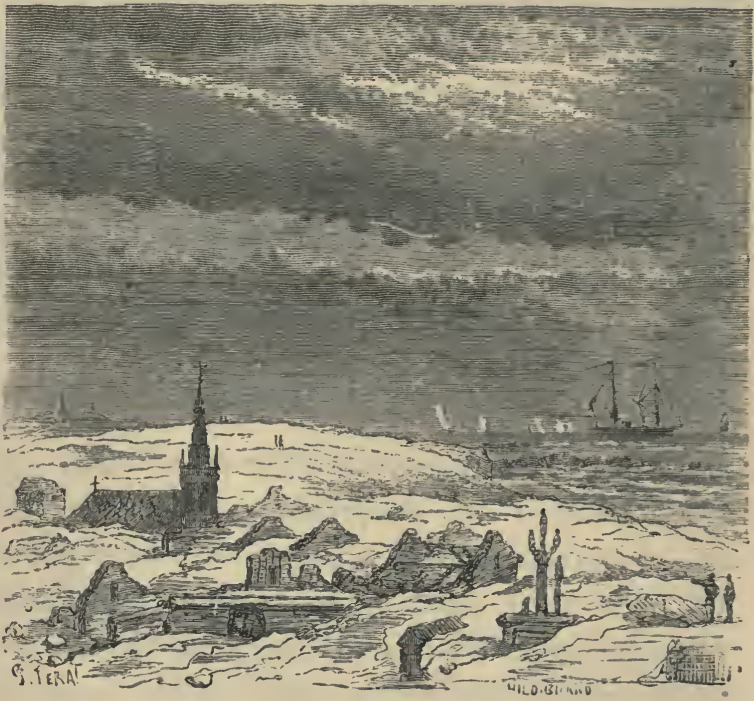

Fig. 65.-A Village buried under sand Dunes.

hill commences its inclined plane, and the same action of the wind effects a similar transference of the sand to a third hill. The materials of each dune are thus driven from one drift to another; so that they are continually being destroyed, and as con- 
tinually re-formed, at a greater distance from the sea. As the sand is carried farther inland by this process, it makes way for new supplies from the inexhaustible stores of the ocean.

These waves of sand, invading the land by the impulse of the wind, have, like the sea-waves, an unequal motion, according to the configuration of the ground. Everything must alike yield to their constantly advancing forces: cultivated land, forests, houses, villages, and towns disappear beneath them; even pools of water retire before them, as in Gascony, where, under the influence of the dunes, numerous saltwater pools are pushed farther inland, and their level constantly raised.

As the Mediterranean is almost tideless, the dunes are formed there with much less facility than on the oceanic coasts. On the latter examples may be cited of villages being buried like caravans in the desert.

At a spot near St. Pol-de-Léon, in Brittany, where a village stood in 1666, a few sand-hillocks, with a few chimneys and steeples to indicate the original site of the village, alone remained fifty years after: the dunes had advanced at the rate of about 580 yards every year. 'The dunes of Gascony, however, do not grow with this frightful rapidity, their progress not exceeding some 25 yards annually. If the progress should remain constant, at this rate they 
will reach Bordeaux in 2000 years. Several Gascon villages, the names of which are transmitted by documents of the middle ages, have completely disappeared.

The coasts of the Netherlands, La Vendée, Patagonia, and more especially of the Sahara, are among the more important fields of this phenomenon.

\section{Floating Icebergs-Polar Winters.}

As we have already explained, floating icebergs deposit a vast quantity of earthy material at the bottom of the sea. They are, in fact, one of the most powerful agents of transport. As we approach the poles, floating masses of ice are met with. They become larger and more numerous as we advance, and at a high altitude a continuous field of ice stretches before the view, and, no doubt, joins a continent which is also frozen.

Great danger is incurred in an nttempt to penetrate these regions. Ships are in constant danger of being crushed between the immense masses of floating ice, some of which rise to a height of 40) yards above the level of the sea, which corresponds to a submerged thickness of 280 yards. As they advance they gradually melt, and distribute on their 
route the materials which they have transported from the arctic continents, or from the beds of the polar seas.

If the sailor succeod in pasing the zone where these immense masses of ive float, he may expect

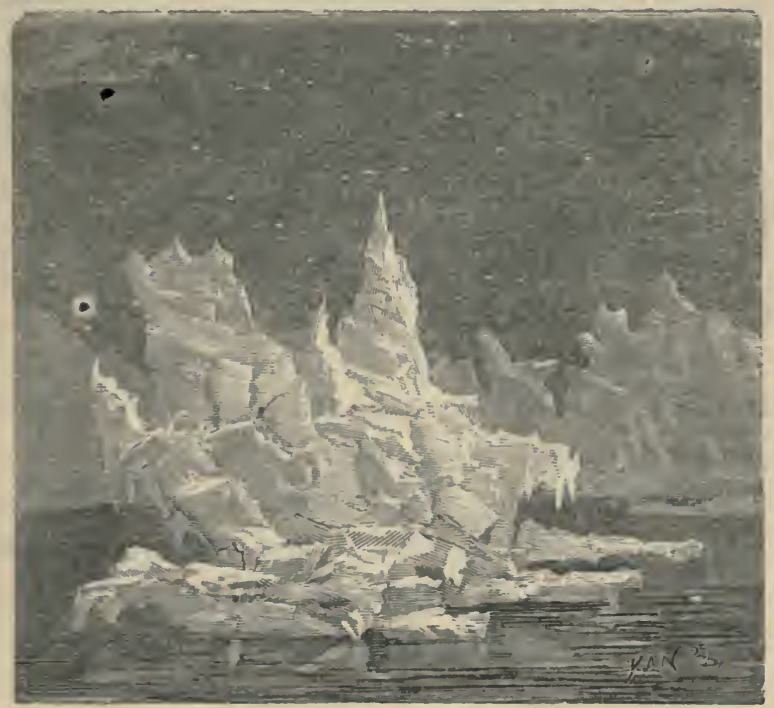

Fig. 66.-Floating Glaciers.

every instant to see the sea freeze up around his vessel and keep him prisoner for entire months, in a region where he may perish of hunger, should he escape the thousand-and-one more immediate dangers which threaten him. 
The celebrated arctic explorers, Captain John Davis, Sir Edward Parry, Sir John Ross, Sir John Irauklin, Captain (now Sir Robert) M'Clure, Dr. Kane, Captain (now Sir Leopold) $M^{\circ}$ Clintock, and others, in their search for the north-west passage, have only too clearly demonstrated the dangers of any attempt to penetrate these regions. Nor ought we to omit the name of the intrepid and learned De Blosseville. Sent on an exploring expedition to the coasts of Greenland in the Lilloise, he ald his companions must have perished miserably in those inhospitable regions, for not a trace has since been discovered of them.

The ice-bound ship is in an unsafe position, but its release may be attended with even more danger than its captivity. Sir Leopold M'Clintock, who suc. ceeded in discovering a few remains of Franklin's expedition, says: "On the 18th of August we had arrived in the mid-channel of Melville's Bay, in Lancaster Straits, when, being unexpectedly encircled by an immense accumulation of drift-ice, we found ourselves compelled to pass the winter in the midst of one of those vast fields of ice of which I had often heard during my career as a sailor. In the course of the winter the force of the water often opened long crevices or channels in the solid vault of ice which covered it, and these solutions of continuity 
were producel with such violence, that often masses of ice were thrown up, as by the effect of a mine, several feet in the air, and formed banks on either side of the crevice from which they had been projectel. During our captivity we were able to capture in these channels of open water about 70 scacows, which furnished us with food for our dogs and oil for our lamps.

"We did not regain our liberty until the 25th of April, in latitude $60^{\circ} 30^{\prime}$, and under circumstances which will long be remembered by those who shared in the expedition. A violent tempest arose in the south-east ; the ocean, stirred from its depths, broke up its icy crust, and hurled into chaotic disorder the broken masses of the icefield, threatening a score of times the little Fox with total destruction. Our salvation in these critical circumstances was due in the first place to Providence, and secondarily to the excellence of our screw and the form of our stem."

It thus appears that M'Clintock's ship had drifted with the ice from the 75 th to the 63rd degree of latitude-that is to say, a distance of about 300 leagues from its starting-point. A violent spring storm broke up this mass of ice, which then drifted in dangerous confusion towards Newfoundland, where it would meet with the warm waters of the Gulf Stream, and gradually disappear in the ocean. 
INFLUENCE OF LIFE ON VARIATIONS IN THE BED OF THE OCEAN.

\section{Formation of Coral Reefs; limit to their growth-Conditions favourable to their development.}

Animal and vegetable life influences to a great extent the various changes at the bottom of the sea. We have already seen that animals of the smallest size build the most important submarine constructions, but that every other kind of existence has also a hand in this continual transformation or modification of the submarine world.

The tropical seas especially swarm with an immense variety of living beings. But as in other seas, so here in warmer waters, the shores are more inhabited than the deeps, and at a little distance from the surface life ceases to exist.

We will attempt to describe briefly one of the most interesting and wonderful of marine phenomena, that of the construction of coral reefs, which attain such important dimensions in the Pacific Ocean, the Indian Ocean, and the West Indian seas. 
Polypiers continue to grow until they hare reached the surface of the water. The construction of coral may be likened to a forest; intervals are left comparable to those between the branches of a tree and the trees of the forest. Animal remains-partly derived from the decay of some parts of the coral, partly consisting of the débris of molluses and fish-fill up the gaps, and, in the manner of a chemical cement, serve to bind the whole into a compact mass.

The coral insects absorb, particle by particle, the carbonate of lime from the water, and they deposit it afterwards. The carbonate sometimes appears in a muddy form, and, hardening by exposure to air, appears very similar to ehalk. This phenomenon is very remarkable in the Bermudas, where it has been studied by the naturalist Nelson: "After having observed the decomposition of shells and polypiers from the less calcareous to the clumps of meandrinæ and astrex, not only in situ, but in the masses which had been detached by means of the diving-bell for the works of the arsenal, I do not hesitate to affirm a common origin for the chalk of the Bermudas and the banks of stone, more or less solid, which constitute the islands themselves - only that the latter result from the accumulation of fragments mechanically broken, whereas the rock or chalky paste is due to the destruction, owing to prolonged submersion, of the mem- 
branous tissue which penetrates the whole mass, and which is then separated from the calcareous matter contained in its meshes. The former, by its precipitation, forms that soft whitish substance, analogous to chalk, which is found in the bottoms of creeks and gulfs mixed with shelly sands, the debris of polypiers, well-preserved shells, and consilerable masses of meandrinæ and astreæ."

The coral insects love warm water and constant agitation. 'This last circumstance gives a very characteristic appearance to the calcareous deposits which accompany them. Crystals of carbonate of lime are deposited in the liquid mass, and become centres aromnd which new molecules of the same matter group themselies. The constant agitation of the water gives a rotatory motion to the little solid nuclei already formed, whilst continued deposition goes on in such a manner as to give them a spherical form. The rock thus acquires a peculiar texture, called oolitic.

Lastly, we may observe that coral does not flourish except in limpid water and on a rocky bottom. 
2. Life and Inanimate Nature-Coral Inseets die in th" calm of Deen Waters-Explanation of the formation of the De: p liec fs of the Pacific Ocen-Coast Reefs-Broken Reefs-Barier Reefs of Anstrulia-How the Coral Reef becomes an Islnnd.

Darwin observes, in his beautiful work on the formation of Coral lieefs, that when the ocean hurls its waves against the shores of the Pacific Islands, they find in it an invincible enemy. Never. theless, its force is sometimes withstood by obstacles apparently very feeble. It never seems to repose. Its mighty billows, raised by the trade-winds, roll incessantly against the shores. The turbulence of the water lashed into foaming breakers is much greater on the shores of these islands than in our temperate regions; and no one could observe them without feeling convinced that rocks even of granite or quartz must eventually yield to forces so considerable, and be utterly demolished. These little isles of coral, however, so low, so insignificant, resist successfully the assault made upon them, thanks to the intervention of another force, in some sort opposed to the first, which takes part in the struggle. The organic forces detach, particle by particle, from the foaming breakers the carbonate of lime, which they afterwards reunite in a symmetrical form. Myriads of architects are employed in this work night and 
day, and we see their soft gelatinous bodies, aided by the law of vitality, quell the brute power of the waves, against which neither the industry of man nor the inanimate forces of nature would be able to struggle with success.

Life, apparently weak and mean, but in reality active and full of resources, issues victorious from an incessant struggle, in which inert matter threatens momentarily the destruction of the frail enemy whose strength she continually feeds. Coral insects prefer a current of water. It carries away from them the matters rejected or secreted by their bodies; and become innutritious, or even as dangerous to them as poisons. The calm reigning in deep water is death to these minute animals.

T'he coral polypi live near the surface : according to Darwin and Dana, they never build at a depth exceeding forty yards, whilst other species live at much greater depths, even reaching to 400 yards. How, then, can we explain the great depth to which some of the larger coral banks, like those of the Fiji Islan?s, descend? Darwin has discovered a simple explanation of this fact. Founded on numerous observations, it entirely accorls with what geology teaches us respecting the crust of the globe.

Since the coral insect does not live out of the water. the growth of the reef cannot go on above its surface. 
Here the sea itself assists in raising the elevation of one part of the reef by disintegrating or breaking up others. When the reef is of sucl a height, says Chamisso, ${ }^{*}$ that it is left almost dry at low-tide, the coral insects abandon their work. Above this line a continuous stony stratum may be observed, com posed of the shells of molluses, of echinoidre with their points broken, and of fragments of coral cemented together by a calcareous sand produced by the pulverisation of the shells. 'The heat of the sun often penetrates this mass when it is dry, and causes cracks in different directions; then the waves have sufficient power to break off masses of coral, sometimes six feet long, and four or five feet in thickness, and to throw them up on the reef's, whereby the crust is so elevated that high-tide only covers it at certain seasons of the year. The calcareous surface does not, however, suffer any subsequent disturbance, but offers a soil to the seeds of trees and plants brought by the waves, upon which the vegetables grow with sufticient rapidity to form very soon a covering for its dazzling white surface. Even before the trees become sufficiently bushy to form a wood, the seabirds luild their nests on the once bare reef; and land-birds, lost in the ocean waste, fly to it as a place of refuge; and still later, long after the coral

* Expedition of Kotzebue. 
insects have finished their work, man appears, and builds his hut on the now fertile soil.

The coral insects, unable to live in fresh-water, are interrupted in their work wherever a river pours its tribute into the sea. 'The reefs are also subject to very sudden breaks at a short distance from the sea, if the bottom be a very steep incline; such are the coast reefs, or broken reefs, so called on account of their situation and of their frequent breaks.

Sometimes a channel of considerable width, and of more or less depth, separates the reef from the coast. It is then called "a barrier reef." Some of these are of very great extent. One, on the coast of New Caledonia, is 100 leagues long; another follows the eastern coast of Australia for a distance of 400 leagues, almost without interruption. The channel which separates this reef from the mainland is from 60 to 100 feet in depth, and its width yaries between 15 and 50 leagues.

Coral reefs are circular when the coast opposite to which they are built is that of a small island. If, instead of an island, there is a shallow, such as would be produced by the summit of a submarine mountain, the reef becomes converted into an island, in the form of a ring, in the midst of which is a lagoon, generally communicating with the ocean, although occasionally it is quite enclosed. Sometimes the lagoon fills up, and 
the island takes the form of a circular plateau. In either case such an island is called an atoll.

The recurrence of this phenomenon is too frequent, more especially in the Pacific Ocean-its cause has been too long a hard nut for the savans-for us to pass it by without saying a few words in respect to it.

The shape of these islan's led to the belief, that the coral insects had built their reefs on the edges of submarine craters. The general resemblance between them and certain volcanic islands had struck the first observers. Such islands (as Barren Island and others) presented a circular belt of mountains, interrupted in one spot by a canal forming a communication between the sea and the interior lake. 'The mountains are the sides of a crater, the bottom of which has been filled up with the invading waters of the ocean. 'The same general character is at first evident in the appearance of an atoll. But how can the size of craters which correspond to atolls be explained?-eleven leagues in diameter, such as that of Bow Island, or of double the diameter, as in several of the Maldive Islands? Again, how is it possible to admit that the Pacific Ocean is studded with so many volcunoes, all of which attain about the same height of 40 yards? Lastly, how can the theory of submarine volcanoes be applied to the formation of 
barrier reef's, of which atolls are evidently only a particular instance?

We have already explained that the bottom of the sea is undergoing a constant though very slow variation. It rises in some points to sink at others; and this movement, which requires centuries to make itself evident, is the most energetic agent of the modifications occurring on the surface of our planet. Darwin has very ingeniously applied the knowledge of this general fact to the explanation of atolls. We give his theory in a few words, as follows:

The coral insects do not live beyond a depth of forty yards. They are therefore confined to the shallows, or to the neighbourhood of coasts. On the other hand, the close proximity of land troubles them for various reasons, among which may be mentioned the outflow of the soft waters of rivers, and the agitation which causes mud, \&c. to be held in suspension. They therefore remain at a certain distance from the shores. Sooner or later the waves break up a portion of the coral barriers, and wash the fragments over the reef into the clear channel which it thus tencls to fill. When the reef reaches the surface of the water the existence of its artificer's becomes impossible. But if the soil be slowly sinking, there must always remain sufficient water above the colony to permit of its continued growth. 
Take the instance of an island slowly sinking. The coral forms at first a continuous reef around the cuast; as the level sinks, the coral grows upward. The island diminishes at the same time in size, and leaves a channel between it and the reefs, which then continue their growth. A time would at length come when a coral reef, in the form of a ring, would be visible surrounding a lagoon, in the middle of which would be seen the remains of the primitive island. At last, when the island shall have completely disappeared, the coral ring-thanks to the persistent eftorts of the coral insect-will remain; it will surround a lake of less depth in the centre than at the sides. Later, the earth continuing to sink, the depth of the middle of the lake will continue to increase, whilst the edges will be slowly filled up with the débris arising from the disintegration of a portion of the coral reef. 'The lake will have become like any other-the atoll will be complete; it will itself perhaps finally disappear, or increase in size, if the morement of the earth's crust should change its direction.

The same theory evidently explains the forma tion of coast reef's and barrier reet's, since these are nothing more than the elements of the atoll built in a peculiar situation relative to the land. 
3. Slowness of the growth of Coral Reefs-Florida Kieys-Destruetion of Coral Islands during a tempest in January 1s65-Regions in which Coral Reefs are found.

Although it is certain that the growth of coral reefs is very slow, yet we have no very precise observations on this point. Dana estimates the growth of the madreporic polypier at the rate of $\left(0^{\mathrm{m}} \cdot 41\right)$ more than a foot, annually.

According to an observation by Hunt in West Key, Florida, in 1857, a meandrina increased six inches in radius in eleven years. According to the observations of the same naturalist, an occulina grew rather faster.

Some large specimens of meandrinæ, observed by Ehrenberg in the Red Sea, would thus appear to be thousands of years old, and must at least have been contemporaneons with Moses. But Ehrenberg's estimate of size was perhaps a little exaggerated.

The growth of a reef is much slower than that of the coral which composes it. The sea incessantly effects its partial destruction. Sometimes, indeed, the violence of the waves uproots it completely. Such a case occurred in the Palmerston Islands in January 1865, as described by Captain Dunn, of the English brig Annie Laurie, in an account to the 
United States' consul at Tahiti.* 'This sailor had encountered a terrible hurricane in south latitude $19^{\circ} 20^{\prime}$, west longitude $162^{\circ}$. "I found," says he, "the islands of this group in a deplorable state. The Palmerston group originally numbered seven islands - six only now remain; the north-easterly one, and a part of the coral reef, having entirely disappeared."

Coral reefs and islands are only developed in tropical seas. They are, however, exceptionally found in the Bermudas, in latitude $33^{\circ} \mathrm{N}$, a circumstance due to the warmth of the waters of the Gulf Stream which flows by these islands. They are not met with on the western coasts of Africa and America, in consequence of the diminution in the temperature of these parts, occasioned by the cold marine currents from the poles.

In no part are the coral reefs so extensive as on the coasts of New Caledonia and Australia. In fict, these seas have in conseqnence been designated the Coral Seas.

The atolls of Tahiti and of the Bass Islands are surrounded by sea at a mean temperature of $77^{\circ}$ Fahr. Near Peru and Chili the mean tempera-

* Extract from a letter by Mr. Withing, Commodore in the Americ in Nary, inserted in the Bulletin Internutional de l Observatoire Imperiul de l'aris. 
ture of the sea is $60^{\circ}$ Fiahr. A difference of temperature, amounting to $17^{\circ} \mathrm{Fahr}$., therefore arrests the growth of the coral reefs.

The Persian Gulf, the Red Sea, and that part of the Indian Ocean comprised between $\Lambda$ frica and Sumatra, are also very rich in coral. We must, however, remark that these seas have the highest temperature of any on the globe.

For the same reason coral flourishes in the seas of the West Indies, and on the eastern coast of Florida. The researches of Agassiz show that the entire peninsula of Florida is formed of rocks belonging to the present epoch, and that these rocks are principally composed of coral reefs and marine shells. The southern and western coasts of Florida are surrounded by an immense number of islands, separated one from another by very narrow channels. These islands are in many instances connected at low-tide, or even sometimes only separated from dry land by flat marshes.

These islands, designated "Keys," form concentric lines fronting the continental shore, from which they do not extend a great distance, the most remote being ten leagues off. They rise little more than from six to twelve feet above the level of the sea; and, like the land itself, are composed of coral, both in masses and in sand thrown up by the sea, the 
whole cementid together by the infiltration of carbonate of lime.

A coral reef, still inhabited by the animals, runs parallel with the Keys, following the same curves, and at a listance varying from 2000 to 6000 yards. Between the reef and the Keys there is a navigable channel (six or seven fathoms in depth), which commmicates with the open sea by a number of channels traversing the coral reef.

Generally speaking, the banks of coral forming the reef do not reach to the surface of the sea except at particular points, where the accumulation of broken coral, \&c. has initiated the formation of little keys.

The Gulf Stream flows beyond the reef of living coral.

4. Alga-Submarine Forests and Prairies-Floating Seawerd of the Sargossa Seas-Extension of the Coasts by the Iihizophora Mangle.

Marine regetation, like marine animals, leaves its debris to accumulate at the bottom of the sea; but, as we have before explained, their range is much more limited than that of the animals, as they are principally confined to the shallow parts of the sea and to the neighbourhood of coasts. Their pro- 
digious growth results in the formation of submarino prairies, which serve as a retreat for thousands of animals.

The tangled roots of the algæ serve to bind together and strengthen the loose bottom of the sea, and in some cases near the coast favour the extension of the land into the sea-thus themselves assisting to diminish the extent of the domain they inhabit.

In the middle of oceans, more particularly in the Atlantic, enormous quantities of seaweed are met with, which have no hold on the bottom of the sea, in these parts of great depth. The quantities of these plants are so enormous, that the first sailors who met with them mistook the appearance they presented for dry land, and were terrified to find their vessels becoming more and more entangled in the weeds which thus hindered their progress. It is now known that these immense accumulations of seaweed are due to a species of circular current in the vast basin of the sea, towards the centre of which all the loose floating débris detached from the coasts tends to converge.

A tree, the Rhizophora mangle (mangrove), has a remarkable influence on the extension of the coasts of Guiana, uniting its action with that of the equatorial current, which, as we have already seen, transports the delta of the Amazon, fragment by 
fragment. This exemplifies the varicty of Nature's means for producing the same result.

The mangrove grows abundantly on low coasts and in lagoons. Its penlant branches ultimately form its roots. At first they swing in the air, of which they retain the moisture like the finest sponge. When they reach the soil they continue to grow and increase in size, penetrating the mud like ordinary rcots. 'They resemble so many columns intended to support the gigantic branches of the mangrove. Each branch thus curiously rooted becomes a new trunk, which will ultimately transmit sap and strength like the parent stem. 'The roots going ont from the new trunk give more solidity to the marshy ground, and enable the natives to penetrate the forests formed of this tree. The mangroves take possession of all the shallows as they are formed. The mud, and all kinds of floating bodies, are arrested by their roots as by a fine net. 'The algæ consolidate the newly-formed land at the seaside, and the accumulation of sediment elevates it on the land-side. 'The soil in this part soon becomes too dry to continue to support the mangroves. The cocoanut and other trees replace them, and by their presence complete the conques: of the ecintinent over the ocenn. 
INSIGNIFICANCE OF MAN COMPARED WITH THE OCEAN.

The reader has now been introduced to a little museum of submarine wonders, by a guide who has sometimes perhaps trespassed on his patience, but who has aimer, at least, to be instructive without being dull. A general idea of the form of the oceanbed, and of some of the mysteries concealed in the abyss of waters, has, we may. hope, been clearly given. Aided by the apparatus of the diver, we have been able to enjoy a few moments of submarine life, and to advance some steps in the more frequented valleys of the ocean landscape. Is the author to blame if he cannot find the means for extending these excursions still further-if he cannot defy the very laws of nature-set at naught the pressure of 800 atmospheres, under which are hardening the marvellous stratifications upon which our descendants will live and flourish - see without light, and surpass in agility and force the monsters who would make us their prey? While we are anxious that these lacuna in our knowledge of the sea should be filled 
up, it is only prudent not to be too venturesome in an element for which we are not adapted.

Standing on the shore, we look with wonder on that eable fixed to the rocks, and slowly unrolling from a chain carried by a ship steaming seaward. It would almost look as if the hardy seaman had shrunk from trusting himself to a desert without a landmark, and had contrived this means of preserving his communication with the shore. But we know well enough that he has no need of that thread to guide him safely over the vast labyrinth of waters. That cable means something quite different. If we choose to examine the shore-end, we shall find that a few copper wires carefully enveloped in gutta-percha occupy the centre. Around this nueleus is a firmly-twisted cord of iron. The heart of the cable is thus protected so that nothing may interrupt the track destined for the transmission of thought. When resting on the bottom of the ocean, this simple apparatus shall serve as the medium of communication between one human being and another who wish to converse together though thousands of miles apart.

While a just pride may be felt in the audacity and good fortune which has enabled man to make a pathway for thought over the bottom of the abyss, there is yet much in this very achievement to make 
us sensible of our littleness. After all, though we can make signals through the cable, and see how they work at the two extremities, what do we know of the whole chain of communication, or of the power which we have so audaciously forced into our service? We are ignorant of a thousand mysteries in the route, and the work of the ocean goes on with small respect for the noble destination of the electric submarine conductor of thought. Sponges, algæ, polypiers, anatiferæ, and serpulariæ freely make use of it as their abode-feeling no disquiet, whatever secrets of human grief, or joy, or ambition traverse their support. A rupture occurs, however, and they who laid the cable fish it up again, at the same time lifting out of their element the imprudent adventurers who had fastened upon the rope. He studies them, and consoles himself for his ignorance, as the hare laughed at the fright which the frog caused him. The multitude of animals which cover the cable serve not only to hide it from view, but to increase its volume three or fourfold. That represented in the engraving has certainly not been very long under the water. The animals and plants, at first taken by surprise, have to get accustomed to its presence before they weave around it its oceanic vestment.

When the cable is laid at the depth of some 
thousands of yards, the operation for its recovery is extremely delicate and laborious. Any agitation of the ship might injure it; its weight, added to that of the animals and plants which have made it their home, would often be sufficient to make it break, and in such a case the broken end falls back into the ocean.

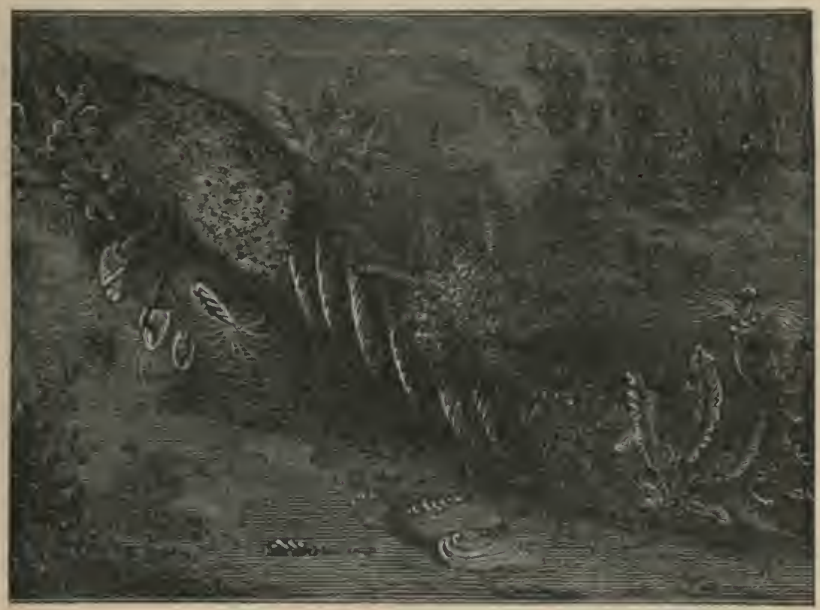

Fig. 67.-Telegraphic Cable at the Bottom of the Ocean.

Unce more settled at the bottom, it serves, as before, for the support of the living beings who clothed it with their strange forms after having for an instant, by its fall, disturbed the calm repose of the submarine solitudes. It some remote period, when the 
work of ages shall have raised the bottom of the sea above the waters, and the mountains, which now form the grandest features of the earth's surface, shall have sunk beneath the waves, the successors of the present race of mankind will look with astonishment on this new species of fossil, the relic of a forgotten civilisation, buried out of sight in the same way as the vestiges of the past which we ourselves are so interested in studying.

Shipwrecks, too, with the débris of their various freights, will lend their irrefragable testimony to the former existence of man, and increase the perplexity of the geologists of the future. Still more, in the midst of the most sharply-defined marine deposits, the observer will discover the remains of our vanishing race. He will see artificial tunnels pierced through the most varied strata ; and in these, at least, he will find evidence of our present labours to reward his researches. If hereafter, not contented with piercing the mountains to avoid the labour of ascent and descent, we drive our roads beneath the seas themselves, what would come to pass? Above our secure highway, storms and cyclones would pass harmlessly; we should hear, perhaps, their fearful music, and be deafened by the roar of the waves, or the rush of the locomotive with its ugly train of carriages; but we should speed with the swiftness of the wind from one 
ocean shore to another, and defy the caprices of the winds and waves.

But the geologists and engineers of former ages need not despair. We are yet very far from the accomplishment of these marvels. For a long time to come the monsters of the deep will make sport of our telegraphic cables ere they fly before the breath of the locomotive, and the discordant noises of the submarine tunnel.

In the meantime, as a foreshadowing of what may be anticipated for the distant future, the Thames has been securely tunneled, and there is much talk of plans for cheating the storms of the English Channel by driving a road beneath it from Dover to Calais. It may be thought there is too much bravado in the project, but the Channel is little more than a stream compared with some of the American rivers, and the depth of the water in several points is not more than from 20 to 25 feet. Even were this design accomplished, we should be far indeed from attacking the ocean itself.

Until, as the skill of our engineers progresses, we lose all dread of anything crushing in our tunnels, the sea will demand innumerable victims, and swallow up many a rich argosy. It would be interesting to make an approximative estimate of our gains and losses by the ocean, so as to ascertain on 
which side the balance of the account lies. But a mere enumeration of the oceanic imposts would be tedious, while a history of our gains, of the various means by which man compels the ocean to pay him tribute in return, would be too large a subject for the scope of this little book.

Let us rather turn from a subject so full of painful memories to contemplate man in contrast with the grandeur of creation. The thin pellicle of the earth's crust, which we laboriously scratch here and there in the accomplishment of our great designs, hardly counts for anything in the harmony of the universe, even as a whole; its modifications by our labours are of small account indeed, whether regarded for their grandeur or their durability. If the intelligence of man has placed him at the head of the creation, the feeble influence that he can exercise over Nature ought to humble his pride. All that he can accomplish by physical labour is almost imperceptible by the side of the work effected by the microscopic infusoriæ; man, the giant, is dwarfed in results by the almost invisible atom! 



RETURN TO the circulation desk of any

University of California Library

or to the

NORTHERN REGIONAL LIBRARY FACILITY

Bldg. 400, Richmond Field Station

University of California

Richmond, CA 94804-4698

ALL BOOKS MAY BE RECALLED AFTER 7 DAYS

- 2-month loans may be renewed by calling (510) 642-6753

-1-year loans may be recharged by bringing books to NRLF

- Renewals and recharges may be made 4 days prior to due date

\section{DUE AS STAMPED BELOW}

\section{SENT ON ILL}

AUG 17 7IIN5

U.C. BERKELEY 

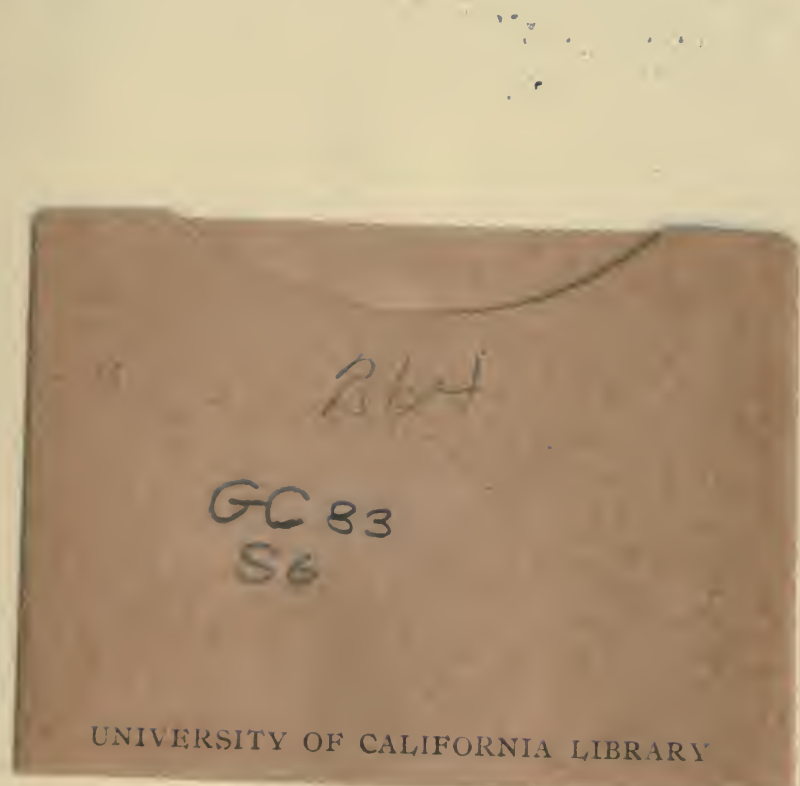


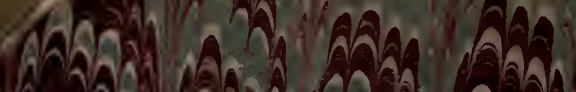

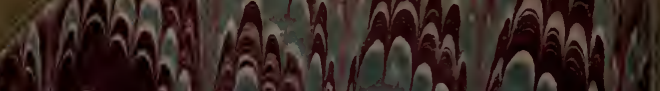

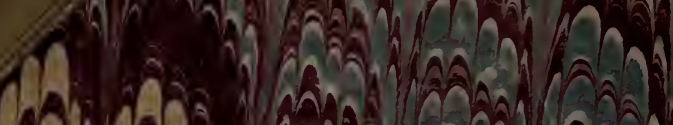

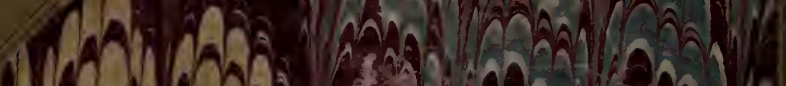

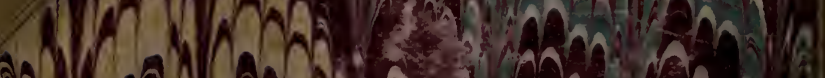

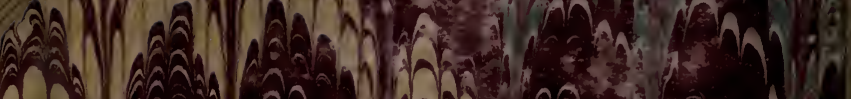

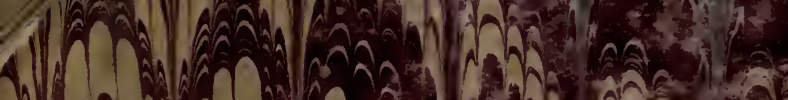

A)

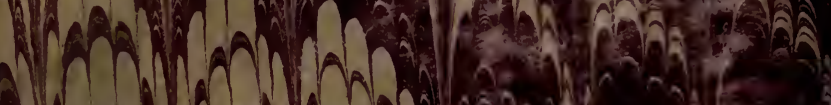
Hanan a)

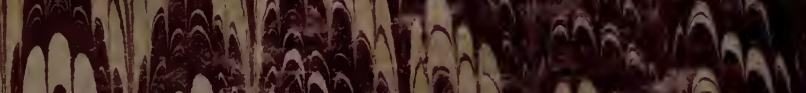

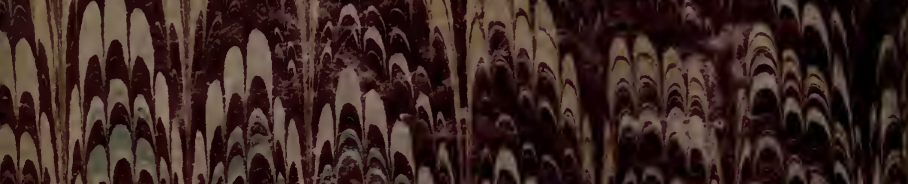

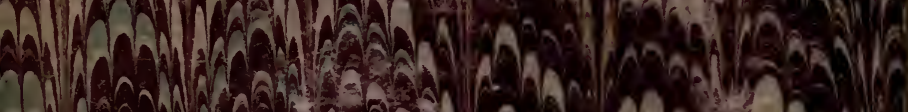
(1) Ân (6)

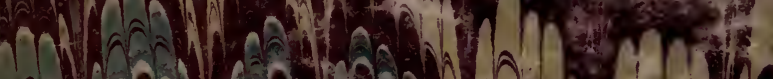
hand

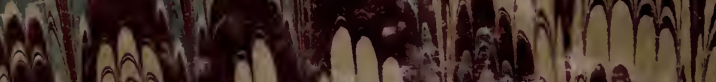
âA An 